\title{
CRITICAL TRANSITIONS
}

\section{WRITING AND THE QUESTION OF TRANSFER}

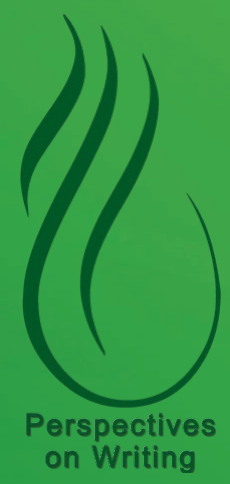

Edited by Chris M. Anson and Jessie L. Moore 



\section{CRITICAL TRANSITIONS: WRITING AND THE QUESTION OF TRANSFER}




\section{PERSPECTIVES ON WRITING}

Series Editors, Susan H. McLeod and Rich Rice

The Perspectives on Writing series addresses writing studies in a broad sense. Consistent with the wide ranging approaches characteristic of teaching and scholarship in writing across the curriculum, the series presents works that take divergent perspectives on working as a writer, teaching writing, administering writing programs, and studying writing in its various forms.

The WAC Clearinghouse, Colorado State University Open Press, and University Press of Colorado are collaborating so that these books will be widely available through free digital distribution and low-cost print editions. The publishers and the Series editors are committed to the principle that knowledge should freely circulate. We see the opportunities that new technologies have for further democratizing knowledge. And we see that to share the power of writing is to share the means for all to articulate their needs, interest, and learning into the great experiment of literacy.

\section{Recent Books in the Series}

Joanne Addison and Sharon James McGee, Writing and School Reform: Writing Instruction in the Age of Common Core and Standardized Testing (2017)

Lisa Emerson, The Forgotten Tribe: Scientists as Writers (2017)

Jacob S. Blumner and Pamela B. Childers, WAC Partnerships Between Secondary and Postsecondary Institutions (2015)

Nathan Shepley, Placing the History of College Writing: Stories from the Incomplete Archive (2015)

Asao B. Inoue, Antiracist Writing Assessment Ecologies: An Approach to Teaching and Assessing Writing for a Socially Just Future (2015)

Theresa Lillis, Kathy Harrington, Mary R. Lea, and Sally Mitchell (Eds.), Working with Academic Literacies: Case Studies Towards Transformative Practice (2015)

Beth L. Hewett and Kevin Eric DePew (Eds.), Foundational Practices of Online Writing Instruction (2015)

Christy I. Wenger, Yoga Minds, Writing Bodies: Contemplative Writing Pedagogy (2015)

Sarah Allen, Beyond Argument: Essaying as a Practice of (Ex)Change (2015)

Steven J. Corbett, Beyond Dichotomy: Synergizing Writing Center and Classroom Pedagogies (2015)

Tara Roeder and Roseanne Gatto (Eds.), Critical Expressivism: Theory and Practice in the Composition Classroom (2014) 


\section{CRITICAL TRANSITIONS: WRITING AND THE QUESTION OF TRANSFER}

Edited by Chris M. Anson and Jessie L. Moore

The WAC Clearinghouse

wac.colostate.edu

Fort Collins, Colorado

University Press of Colorado

upcolorado.com

Boulder, Colorado 
The WAC Clearinghouse, Fort Collins, Colorado 80523

University Press of Colorado, Boulder, Colorado 80303

(C) 2016 by Chris M. Anson and Jessie L. Moore. This work is licensed under a Creative Commons Attribution-NonCommercial-NoDerivatives 4.0 International.

ISBN 978-1-64215-079-7 (pdf) | 978-1-64215-090-3 (epub) | 978-1-60732-647-2 (pbk.)

DOI 10.37514/PER-B.2016.0797

Produced in the United States of America

Library of Congress Cataloging-in-Publication Data

Names: Anson, Chris M., 1954- editor. | Moore, Jessie L., editor.

Title: Critical transitions : writing and the question of transfer / edited by Chris M. Anson and Jessie L. Moore.

Other titles: Perspectives on writing (Fort Collins, Colo.)

Description: Fort Collins, Colorado : The WAC Clearinghouse ; Boulder, Colorado : University Press of Colorado, [2016] | Series: Perspectives on writing | Includes bibliographical references. Identifiers: LCCN 2016045185 | ISBN 978-1-64215-079-7 (pdf) | ISBN 978-1-64215-090-3 (epub) | ISBN 978-1-60732-647-2 (pbk.)

Subjects: LCSH: English language—Rhetoric—Study and teaching (Higher) | Report writingStudy and teaching (Higher)

Classification: LCC PE1404 .C7494 2016 | DDC 808/.0420711—dc23

LC record available at https://lccn.loc.gov/2016045185

Copyeditor: Don Donahue

Designer: Mike Palmquist

Series Editors: Susan H. McLeod and Rich Rice

The WAC Clearinghouse supports teachers of writing across the disciplines. Hosted by Colorado State University, and supported by the Colorado State University Open Press, it brings together scholarly journals and book series as well as resources for teachers who use writing in their courses. This book is available in digital formats for free download at wac.colostate.edu.

Founded in 1965, the University Press of Colorado is a nonprofit cooperative publishing enterprise supported, in part, by Adams State University, Colorado State University, Fort Lewis College, Metropolitan State University of Denver, Regis University, University of Colorado, University of Northern Colorado, Utah State University, and Western State Colorado University. For more information, visit upcolorado.com. 


\section{CONTENTS}

Introduction. . . . . . . . . . . . . . . . . . . . .

Jessie L. Moore and Chris M. Anson

Part i. Understanding Writers' Transitions

Chapter 1. Assembling Knowledge: The Role of Threshold Concepts

in Facilitating Transfer .......................... 17

Linda Adler-Kassner, Irene Clark, Liane Robertson,

Kara Taczak, and Kathleen Blake Yancey

Chapter 2. Attending to the Subject in Writing Transfer and Adaptation .. 49

Stuart Blythe

Chapter 3. Building a Conceptual Topography of the Transfer Terrain . . . . 69

Donna Qualley

Chapter 4. Writing and Global Transfer Narratives: Situating the

Knowledge Transformation Conversation. . . . . . . . . . . . . . 107

Christiane Donahue

Part 2. Supporting Writers' Transfers at Critical Transitions

Chapter 5. Minding the Gap: Writing-Related Learning In/Across/With

Multiple Activity Systems. . . . . . . . . . . . . . . . . . . . . . . . 139

Regina A. McManigell Grijalva

Chapter 6. Double Binds and Consequential Transitions: Considering

Matters of Identity During Moments of Rhetorical Challenge . . . . . . . 161

Elizabeth Wardle and Nicolette Mercer Clement

Chapter 7. Dynamic Transfer in First-Year Writing and "Writing in the Disciplines" Settings. . . . . . . . . . . . . . . . . . . . . . . 181

Hogan Hayes, Dana R. Ferris, and Carl Whithaus

Chapter 8. Cultivating Constructive Metacognition: A New Taxonomy for Writing Studies . . . . . . . . . . . . . . . . . . . . . . . . 215

Gwen Gorzelsky, Dana Lynn Driscoll, Joe Paszek, Ed Jones, and Carol Hayes 
Chapter 9. Students' Perceptions of the Transfer of Rhetorical Knowledge between Digital Self-Sponsored Writing and Academic Writing: The Importance of Authentic Contexts and Reflection . . . . . . . . . . . . . 247 Paula Rosinski

Chapter 10. Liminal Space as a Generative Site of Struggle: Writing Transfer and L2 Students.

Gita DasBender

Chapter 11. Negotiating Multiple Identities in Second- or ForeignLanguage Writing in Higher Education

Stacey M. Cozart, Tine Wirenfeldt Jensen,

Gitte Wichmann-Hansen, Ketevan Kupatadze, and Scott Chien-Hsiung Chiu ${ }^{1}$

Afterword

Chris M. Anson and Jessie L. Moore

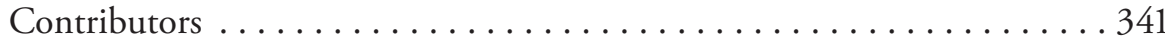

Appendix A: The Elon Statement on Writing Transfer ............. 347

Appendix B: The Video Journals Assignment . . . . . . . . . . . . . . . 359

Appendix C: OCU English Department Composition Outcomes

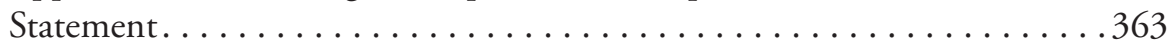

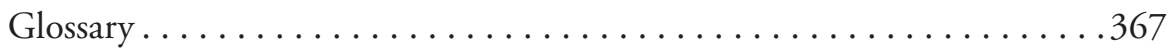




\section{CRITICAL TRANSITIONS: WRITING AND THE QUESTION OF TRANSFER}





\section{INTRODUCTION}

\section{Jessie L. Moore and Chris M. Anson}

Most US colleges and universities require students to complete a first-year writing course (or even two), with the premise that students will apply what they learn there to their writing across the university and beyond. Around the globe, employers assume that applicants bring knowledge about writing for the specific workforce they are entering, having gained that knowledge in secondary and post-secondary studies. In other words, underlying our educational systems is an assumption that students will transfer knowledge-specifically writing knowledge-across critical transitions (e.g., course to course, school to workplace, etc.). Until recently, though, those assumptions were largely untested. A handful of studies (e.g., Anson \& Forsberg, 1990; Beaufort, 2007; Bergman \& Zepernick, 2007; Clark \& Hernandez, 2011; Driscoll, 2011; McCarthy, 1987; Nelms \& Dively, 2007; Wardle, 2007) followed localized groups of students navigating writing across specific critical transitions or examined faculty expectations for students' transfer of writing knowledge. Writing Program Administration, the journal of the Council of Writing Program Administrators, featured three articles on "concepts of knowledge transference" in 2007, signaling a growing interest in the topic (Pettipiece, Ray \& Macauley, 2007, p. 9).

Building on this increased attention to writing transfer, Elon University sponsored a multi-institutional research seminar on Critical Transitions: Writing and the Question of Transfer from 2011 to 2013. As part of the seminar, 45 writing researchers from 28 institutions and five countries participated in multi-institutional research cohorts focused on extending the field's knowledge about writing transfer. The seminar fostered discussions and research about recognizing, identifying enabling practices for, and developing working principles about writing transfer. Seminar participants contributed to the 2012 special issue of Composition Forum (edited by seminar participant Elizabeth Wardle), developed the Elon Statement on Writing Transfer (excerpted below and included in full in Appendix A), and hosted the Critical Transitions: Writing and the Question of Transfer Conference in June 2013. An additional outcome of the seminar's collective inquiry is this collection.

Like much of the discipline's transfer research, the studies that follow draw on learning and transfer theories that examine intersections among the nature of knowledge, learners and learners' processes, and the contexts or situations in which transfer of learning might occur (see Figure 1). Focused on the intersection 


\section{What does the concept/idea emphasize?}

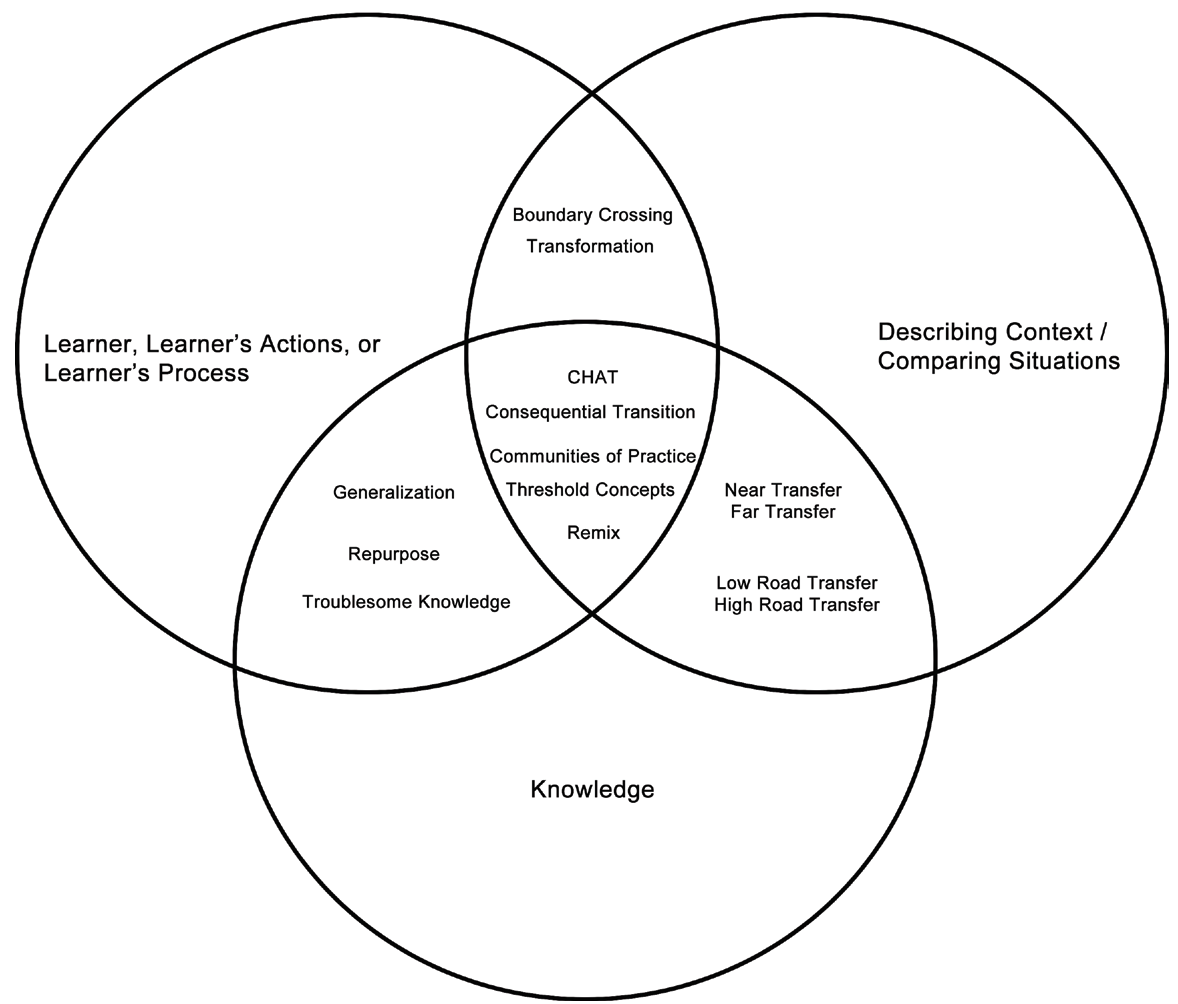

Figure 1. What the learning and transfer theories emphasize.

of knowledge and context, for instance, David Perkins and Gavriel Salomon introduced two complementary sets of terms that now permeate many writing transfer studies: near and far transfer, and high road and low road transfer. Perkins and Salomon write that "near transfer occurs when knowledge or skill is used in situations very like the initial context of learning" while "far transfer occurs when people make connections to contexts that intuitively seem vastly different from the context of learning" (1992, p. 202; see also Salomon \& Perkins, 1989). Focusing on the mechanisms that facilitate transfer of learning even when the contexts "seem vastly different," Perkins and Salomon introduced the low road transfer model to describe similarities between a new context and prior situations triggering extensively practiced, or nearly automatic, skills. In contrast, high road transfer requires deliberate, mindful abstraction of principles to apply them in new situations (Perkins \& Salomon, 1988, 1992; Salomon \& Perkins, 1989). 
Building on activity systems theory, Terttu Tuomi-Gröhn and Yrjo Engeström offer the concept of boundary-crossing, pointing to an intersection between the learner and context. Tuomi-Gröhn and Engeström explain that boundary-crossing "involves encountering difference, entering into territory in which we are unfamiliar and, to some significant extent therefore, unqualified. In the face of such obstacles, boundary-crossing seems to require significant cognitive retooling" (2003, p. 4). Boundary-crossers employ "boundary objects," tools that develop at the intersection of communities/activity systems to facilitate interaction between and across systems. Paula Rosinski (Chapter 9) picks up this concept as she explores how students' self-sponsored digital writing influences their rhetorical choices in academic writing.

Working at the intersection of knowledge and learner, King Beach examines generalization as knowledge propagation, suggesting that generalization is informed by social organization and acknowledges change by both the individual and the organization. Beach's learning theory moves to the intersection of context, learner, and knowledge with Beach's exploration of consequential transitions. Beach explains transition as "the concept we use to understand how knowledge is generalized, or propagated, across social space and time. A transition is consequential when it is consciously reflected on, struggled with, and shifts the individual's sense of self or social position. Thus consequential transitions link identity with knowledge propagation" (Beach, 2003, p. 42). In this volume, Donna Qualley (Chapter 3) examines graduate teaching instructors' consequential transitions as they learn to become teachers of writing. Elizabeth Wardle and Nicolette Mercer Clement (Chapter 6) also illustrate the notion of consequential transitions and consider how Nicolette navigated the double bind presented during her own consequential transition from a college composition course to subsequent writing situations across the university.

Like the theory of consequential transitions, communities of practice and threshold concepts also theorize practices at the intersection of learner, context, and knowledge. Etienne Wenger's and his colleagues' development of communities of practice theory offers writing studies scholars a way to examine the shared values, goals, and interests within communities (see, for instance, Wenger, McDermott \& Snyder, 2002). As novices work to advance their expertise within a community of practice, they learn from others in the community-and part of that identity development involves learning how to learn within the community. Community membership is fluid, though, so new members with different levels of expertise may enter the community while members looking for new challenges or seeking to meet different goals may move out. Christiane Donahue (Chapter 4) invokes communities of practice not only as a way to understand students' knowledge transformation but also as a reminder that international scholars are 
contributing to the community of practice developing around writing transfer research - and bringing alternate terms and theories to the conversation.

Also at the epicenter of learner, context, and knowledge, Jan (Erik) Meyer and Ray Land introduced the theory of threshold concepts, which informs several of the writing transfer studies in this collection and elsewhere. Building on David Perkins' notion of troublesome knowledge, Meyer and Land (2006a) challenge educators to identify concepts central to epistemological participation in disciplines. Threshold concepts are transformative, troublesome, and irreversible; they may challenge a learner's prior knowledge, but once a learner grasps a threshold concept, the concept changes the learner's understanding of the discipline in ways that are likely irreversible. Threshold concepts are discursive. They also may be bounded by situational or disciplinary cues, and they may be integrative, enabling a learner to bring together previously disparate knowledge. Finally, threshold concepts involve liminality; learners may hover in a threshold zone before fully grasping the concept and moving beyond the "conceptual gateway” (Meyer \& Land, 2006a, 2006b). Linda Adler-Kassner, Irene Clark, Liane Robertson, Kara Taczak, and Kathleen Blake Yancey (Chapter 1) explore threshold concepts as a framework for designing for and understanding transfer of writing knowledge across contexts, and Gita DasBender (Chapter 10) uses threshold concepts theory to examine the liminal space second language writer's occupy as they attempt to transfer between their first language and second language.

Additional learning and transfer theories (e.g., James Paul Gee's concepts of learning and acquisition, Urie Bronfenbrenner's Bioecological Model of Human Development, Pierre Bourdieu's notion of habitus, etc.) are introduced in the Elon Statement on Writing Transfer and within the individual chapters. Although each theory shifts the perspective for analysis slightly, they collectively enable the discipline to develop a richer understanding of writing transfer, as each theory adds a new overlay to our understanding of the rhetorical situations and activity systems in which writers compose, the writing knowledge required for those situations and their varied audiences and purposes, and the activities of the learners trying to repurpose and transform writing knowledge in order to communicate successfully within and across contextual boundaries.

\section{THE ELON STATEMENT ON WRITING TRANSFER-EXCERPT}

These transfer and learning theories inform the Elon Statement on Writing Transfer, excerpted here, and the chapters in this collection. ERS participants brainstormed extensive lists of principles and enabling practices about writing trans- 
fer, examined which were supported by existing and in-progress research, and then indicated their degree of confidence in each working principle. As a collaboratively authored document, the Elon Statement focuses on working principles and enabling practices that the seminar participants collectively have highconfidence in based on findings from the research seminar's multi-institutional inquiry projects and the field's prior transfer scholarship. Additional principles in which participants had moderate- to high-confidence but that would benefit from additional research are identified in the Elon Statement as working principles in development. The chapters in this collection provide evidence for and examples of the working principles, enabling practices, and principles in development described in the statement.

\section{Working Principles about Writing Transfer}

Drawing on their own research and that of others, ERS participants have identified a number of principles in which they have high confidence- that is, principles that emerge out of empirical studies focusing on writing transfer. These principles extend from the idea that transfer does occur, contrary to suggestions reflected in some prior research. Writers consistently draw on prior knowledge in order to navigate within and among various contexts for writing and learning. Sometimes the rhetorical challenge requires bringing what we know to conscious attention in order to think about similarities and differences between what we know and have done and what we must do now. Sometimes we must reflect, repurpose, and generalize what we bring to bear. Sometimes we must do even more than repurpose and must engage in consequential transitions (Beach, 2003; see above). And usually, even while we are bringing existing knowledge and experience to bear on the new situation, we must learn anew as part of the process of understanding, adaptation, and enculturation.

Nevertheless, while we know that writing transfer both occurs and is necessary for successful writing, prior research highlights the challenges of teaching to facilitate transfer. Students typically do not expect to be able to apply what they are learning in traditional first-year writing courses to other contexts (e.g., Bergmann \& Zepernick, 2007; Driscoll, 2011), and when they do try to transfer new skills and knowledge from one academic setting to another, they often encounter roadblocks (e.g., Nelms \& Dively, 2007; Nowacek, 2011). Furthermore, some curricular designs unintentionally impede transfer (e.g., Wardle, 2009).

As teachers, then, we must consider what sorts of rhetorical challenges students encounter in our classes and contexts beyond and how to best help students navigate those challenges. Research suggests that there are things that teachers can do to afford learning in these moments of challenge. In other words, it is 
possible to "teach for transfer" (as Perkins and Salomon put it), and the discipline is learning more about what writing transfer entails:

- Writing transfer is the phenomenon in which new and unfamiliar writing tasks are approached through the application, remixing, or integration of previous knowledge, skills, strategies, and dispositions. (See, for instance, the chapters by Adler-Kassner, Clark, Robertson, Taczak \& Yancey; Qualley; and Wardle \& Mercer Clement.)

- Any social context provides affordances and constraints that impact use of prior knowledge, skills, strategies, and dispositions, and writing transfer successes and challenges cannot be understood outside of learners' social-cultural spaces. (See, for instance, the chapters by Blythe; Hayes, Ferris \& Whithaus; and Wardle \& Mercer Clement)

- Prior knowledge is a complex construct that can benefit or hinder writing transfer. Yet understanding and exploring that complexity is central to investigating transfer. (See the chapters by Adler-Kassner et al., Qualley, and DasBender.)

- Individual dispositions and individual identity play key roles in transfer. (See, for instance, the chapter by Gorzelsky, Driscoll, Paszek, Jones \& Hayes.)

- Individuals may engage in both routinized and transformative (adaptive, integrated, repurposed, expansive) forms of transfer when they draw on or utilize prior knowledge and learning, whether crossing concurrent contexts or sequential contexts. (See, for instance, the chapter by Qualley.)

- Successful writing transfer occurs when a writer can transform rhetorical knowledge and rhetorical awareness into performance. Students facing a new and difficult rhetorical task draw on previous knowledge and strategies, and when they do that, they must transform or repurpose that prior knowledge, if only slightly. (See, for instance, the chapters by Blythe, Qualley, and Rosinski.)

- Students' meta-awareness often plays a key role in transfer, and reflective writing promotes preparation for transfer and transfer-focused thinking. (See the chapters by Adler-Kassner et al. and Gorzelsky et al.)

- The importance of meta-cognition of available identities, situational awareness, audience awareness, etc., become even more critical in writing transfer between languages because of the need to negotiate language-based differences and to develop awareness about the ways language operates in written communication in each language. (See the chapters by DasBender and Cozart et al.) 


\section{Enabling Practices}

Practices that promote writing transfer-and which are explored in multiple chapters in this collection and in research seminar participants' other recent publications (e.g., Writing across Contexts: Transfer, Composition, and Sites of Writing by Yancey, Robertson, and Taczak, 2014)—include:

- Constructing writing curricula and classes that focus on study of and practice with concepts that enable students to analyze expectations for writing and learning within specific contexts. These include rhetorically-based concepts (such as genre, purpose, and audience);

- Asking students to engage in activities that foster the development of metacognitive awareness, including asking good questions about writing situations and developing heuristics for analyzing unfamiliar writing situations; and

- Explicitly modeling transfer-focused thinking and the application of metacognitive awareness as a conscious and explicit part of a process of learning.

ERS participants have investigated both "Teaching for Transfer" and "Writing about Writing" curricula in multi-institutional studies. Because these types of curricular approaches forefront rhetorical knowledge, terms, and concepts that students will need to apply in future contexts, they equip students with tools and strategies for successful boundary crossing. These approaches typically also build in reiterative opportunities for developing metacognitive awareness. Although these curricula often are implemented in first-year writing contexts, courses university-wide can include reflection activities about both generalizable and discipline-specific writing strategies.

\section{Recognizing and Studying Transfer: Sites and Methods}

Cross-institutional, cross-disciplinary, and cross-cultural collaboration enriches the discussion about writing transfer and allows new perspectives to become visible. Even if multi-institutional research is not feasible for a specific writing transfer study, scholars should pursue both new and replication studies in varied contexts and routinely revisit how new inquiries intersect with prior and concurrent studies (across global contexts, as Donahue's chapter emphasizes).

Both in case studies of individuals or contexts and in larger data samples, writing transfer studies use a variety of qualitative and quantitative methods to identify evidence of and measure transfer, including surveys, focus groups, interviews, classroom observations, text analysis, discourse analysis, 
composing-aloud and think-aloud protocols, group discussion logs, and analysis of students' course work and faculty comments. While students often are the primary participants in transfer studies, researchers also interact with and collect data from teachers and community partners, and new studies are beginning to investigate transfer in experienced writers (e.g., Anson, 2016; see also Smart, 2000). Most transfer studies are short-term (one or two terms), but additional longitudinal studies and studies that examine both writers' academic and non-academic activity systems could extend the field's understanding of writing transfer.

ERS studies and other contemporary work in writing transfer reiterate the value of using mixed methods across multiple contexts to achieve a "scalable" understanding of writing transfer-enabling teacher-scholars both to focus in detail on specific communities of practice and activity systems and to "zoom out" to examine working principles of writing transfer that apply across multiple contexts. For this reason, both short-term and longitudinal studies will enrich disciplinary understandings of transfer, particularly as scholars examine learners' development as writers, not merely their transitions from one context to another. Adding student voices as participants, or even as co-inquirers (as in Wardle and Mercer Clement's chapter), facilitates this more holistic examination of learners' development, boundary-crossing, remixing, and integration.

\section{Working Principles in DeVelopment}

In addition to the high-confidence working principles discussed above, ERS participants identified a number of working principles that remain in development. ERS participants have moderate to high confidence in these in-development principles, but they merit further research.

- With explicit rhetorical education, students are more likely to transform rhetorical awareness into performance.

- Helping students develop strategies and tools to think about how writing functions in communities can potentially prepare them to draw effectively on prior knowledge when they encounter writing in new settings, whether writing for a major, writing in a workplace, or writing for extracurricular activities.

- Some dispositions seem to better afford engaged rhetorical problemsolving. We are only starting to explore what such dispositions might be, so pedagogy that promotes transfer needs to be attentive to dispositions research. 
- Some physical and digital space designs afford learning and transfer better than others.

- The transfer of rhetorical knowledge and strategies between selfsponsored and academic writing can be encouraged by designing academic writing opportunities with authentic audiences and purposes and by asking students to engage in meta-cognition.

\section{THE ELON RESEARCH SEMINAR STUDIES}

In this collection, the authors-all Elon Research Seminar participants-build on prior learning and transfer theories to ask what writing knowledge should transfer (Adler-Kassner et al., Chapter 1), how we might recognize that transfer (Blythe, Chapter 2; Qualley, Chapter 3), and what the significance is-from a global perspective - of understanding knowledge transformation related to writing (Donahue, Chapter 4). In part two of the collection, authors examine strategies for supporting writers' transfer at key critical transitions, including transitions from high-school to college (McManigell Grijalva, Chapter 5), from first-year writing to writing in the major and in the disciplines (Hayes et al., Chapter 7; Gorzelsky et al., Chapter 8; Wardle and Mercer Clement, Chapter 6); between self-sponsored and academic writing (Rosinski, Chapter 9); and between languages (Cozart et al., Chapter 11; DasBender, Chapter 10). Finally, the collection concludes with an afterword offering next steps in studying and designing for writing transfer.

Two themes reappear throughout the collection. First, language matters, and the varied terms introduced in the Elon Statement on Writing Transfer and embedded in the learning and transfer theories underlying these studies all carry baggage. In this collection, as in the Elon Statement, we use "transfer" as an umbrella term, connecting writing transfer studies to the other multidisciplinary inquiries about transfer of learning. Nevertheless, the limitations of the term necessitate supplementing it with more descriptive language: generalization, transitions, transformations, boundary-crossing, remixing, and integration, among others. Defining the terms we use (see the Glossary at the end of this collection) and actively looking for studies that use alternate terms in similar ways remains imperative if writing studies is to have a true sense of the scope and work of writing transfer research. Furthermore, acknowledging — even embracing — the complex and varied existing vocabulary enables scholars to focus on understanding and designing for writing transfer, rather than getting bogged down in what we call it.

Second, faculty can teach for writing transfer. The studies in this collection demonstrate that the assumptions underlying US writing curricula and global 
hiring expectations can be substantiated if:

- Colleges and universities construct writing curricula that focus on the study and practice of writing knowledge, including rhetorically-based concepts,

- Faculty ask students to engage in and develop metacognitive practices about writing and writing situations, and

- Faculty explicitly model transfer-focused thinking.

The chapters that follow offer critical insights into identifying transferable writing knowledge, exploring writing transfer across contexts, and supporting students' application and repurposing of prior writing knowledge as they learn practices and dispositions that foster future writing transfer.

\section{REFERENCES}

Anson, C. M. (2016). The Pop Warner chronicles: A case study in contextual adaptation and the transfer of writing ability. College Composition and Communication, 67(4), 518-549.

Anson, C. M. \& Forsberg, L. L. (1990). Moving beyond the academic community: Transitional stages in professional writing. Written Communication, 7(2), 200-231.

Beach, K. (2003). Consequential transitions: A developmental view of knowledge propagation through social organizations. In T. Tuomi-Gröhn \& Y. Engeström (Eds.), Between school and work: New perspectives on transfer and boundary-crossing (pp. 39-61). Bingley, UK: Emerald Group Publishing.

Beaufort, A. (2007). College writing and beyond: A new framework for university writing instruction. Logan, UT: Utah State University Press.

Bergmann, L. S. \& Zepernick, J. (2007). Disciplinarity and transfer: Students' perceptions of learning to write. WPA: Writing Program Administration, 31(1-2), 124-149.

Clark, I. L. \& Hernandez, A. (2011). Genre awareness, academic argument, and transferability. The WAC Journal, 22. (2011). Retrieved from http://wac.colostate.edu /journal/vol22/clark.pdf.

Driscoll, D. L. (2011). Connected, disconnected, or uncertain: Student attitudes about future writing contexts and perceptions of transfer from first year writing to the disciplines. Across the Disciplines, 8(2). Retrieved from http://wac.colostate.edu/atd /articles/driscoll2011/index.cfm.

Meyer, J. H. F. \& Land, R. (2006a). Threshold concepts and troublesome knowledge: An introduction. In J. H. F. Meyer \& R. Land (Eds.), Overcoming barriers to student understanding: Threshold concepts and troublesome knowledge (pp. 3-18). London: Routledge.

Meyer, J. H. F. \& Land, R. (2006b). Threshold concepts and troublesome knowledge: Issues of liminality. In J. H. F. Meyer \& R. Land (Eds), Overcoming barriers to 
student understanding: Threshold concepts and troublesome knowledge (pp. 19-32). London: Routledge.

Nelms, G. \& Dively, R. L. (2007). Perceived roadblocks to transferring knowledge from first-year composition to writing-intensive major courses: A pilot study. WPA: Writing Program Administration, 31(1-2), 214-240.

Perkins, D. N. \& Salomon, G. (1988). Teaching for transfer. Educational Leadership, 46(1), 22-32.

Perkins, D. N. \& Salomon, G. (1989). Are cognitive skills context-bound? Educational Researcher, 18(1), 16-25.

Perkins, D. N. \& Salomon, G. (1992). The science and art of transfer. In A. L. Costa, J. Bellanca \& R. Forgarty (Eds.), If minds matter: A forward to the future. Volume 1 (pp. 201-209). Palatine, IL: Skylight Publishing.

Pettipiece, D., Ray, T. \& Macauley, W. J. (2007). Letter from the editors. WPA: Writing Program Administration, 31(1-2), 9-10.

Smart, G. (2000). Reinventing expertise: Experienced writers in the workplace encounter a new genre. In P. Dias \& A. Paré (Eds.), Transitions: Writing in academic and workplace settings (pp. 223-252). Cresskill, NJ: Hampton.

Tuomi-Gröhn, T. \& Engeström, Y. (2003). Conceptualizing transfer: From standard notions to developmental perspectives. In T. Tuomi-Gröhn \& Y. Engeström (Eds.), Between school and work: New perspectives on transfer and boundary-crossing (pp. 19-38). Bingley, UK: Emerald Group Publishing.

Wardle, E. (2007). Understanding "transfer" from FYC: Preliminary results from a longitudinal study. WPA: Writing Program Administration, 31(1-2), 65-85.

Wenger, E., McDermott, R. \& Snyder, W. M. (2002). Cultivating communities of practice: A guide to managing knowledge. Boston: Harvard Business School Press.

Yancey, K. B., Robertson, L. \& Taczak, K. (2014). Writing across contexts: Transfer, composition, and sites of writing. Logan, UT: Utah State University Press. 



\section{PART 1. \\ UNDERSTANDING WRITERS' \\ TRANSITIONS}





\title{
CHAPTER 1
}

\section{ASSEMBLING KNOWLEDGE: THE ROLE OF THRESHOLD CONCEPTS IN FACILITATING TRANSFER}

\author{
Linda Adler-Kassner, Irene Clark, Liane Robertson, \\ Kara Taczak, and Kathleen Blake Yancey
}

As the Elon Statement on Writing Transfer (2015; Appendix A) explains, recent research has examined a number of factors associated with how composers move knowledge, strategies, and/or ways of working among and between contexts. Across the range of terms used for research on transfer summarized in the statement, common threads emerge. Some studies have focused on prior knowledge, looking at the roles that understandings of activities within one context play in movement from one learning situation to the next (Perkins \& Salomon, 1992; Reiff \& Bawarshi, 2011; Robertson, Taczak \& Yancey, 2012). Others such as Moore (2012) have used the frame of knowledge propagation (Beach, 2003), looking at "change by both the individual and the organization" (Elon Statement, 2015, p. 2; Appendix A). Studies focused on situated learning have examined practices associated with expertise in specific contexts, and on the ways learners develop from novice to expert within those contexts (Lave \& Wenger, 1991; Tuomi-Gröhn \& Engeström, 2003). Others have looked at interactions of subject identities (including learners' perceptions of selves and of learning situations); the strategies or tools that learners bring to learning situations; and the objects/outcomes of learning situations - learners' knowledge of discourse communities, process, subject matter, and genre knowledge (Russell \& Yañez, 2002). This focus on contexts for learning, often examined through activity theory or other frames affiliated with the idea of situated learning, has also informed the preponderance of research on transfer that is more firmly grounded in writing studies. Within our field, studies have focused on examining and/or engaging students around their understandings of genre or with the idea of genres as they circulate within particular activity systems (Beaufort, 2007; Carroll, 2002; McCarthy, 1987; Wardle, 2009). Recently, researchers have also added to this study a more specific focus on the role of dispositions (Driscoll \& Wells, 2012; Robertson et al., 2012; Wardle, 2012).

This chapter focuses on an idea introduced recently to the growing body of literature on writing and transfer: threshold concepts. Researchers Meyer 
and Land (2006) define these as concepts critical for epistemological participation in disciplines. More than mere concepts, threshold concepts act as portals that learners pass through; in doing so, learners change their understandings of something. Threshold concepts are, then, transformative; they are often irreversible. Expanding Meyer and Land's original conceptualization to accommodate our focus on writing instruction in postsecondary institutions, we define threshold concepts as concepts critical for participation in communities of practice, the formally or informally defined sites where participants share common rituals, values, and stances (Johns, 2002; Wenger, 1998). Within communities of practice, participants also share beliefs around what ideas are most important-threshold concepts - and the ways in which these concepts shape members' perspectives. These ways of seeing through and seeing with (Kreber, 2010) are synonymous with Meyer and Land's (2005) idea of epistemological participation. As we define them here, threshold concepts seem especially salient given the ways that academic disciplines are constituted for postsecondary undergraduate education; for learners of writing, threshold concepts create a different lens through which they interpret writing within communities of practice, like disciplines. At the undergraduate level, regardless of specialization within a discipline, faculty within departments tend to share common beliefs about how questions might be asked and investigated, how evidence might be represented, what constitutes a common discourse, and so on. Beyond the level of undergraduate study and for faculty themselves, the characteristics associated with disciplines as communities of practice are even stronger, including common sets of rituals, rules, conventions (guiding spoken and written interactions), and ideologies that are reinforced by members of the community through practices such as peer review that are critical for advancement. Of course, as Lave and Wenger's research (separately and together) also affirms, communities of practice also exist outside of the academy (Lave \& Wenger, 1991; Wenger, 1998).

As intrinsic as threshold concepts are for epistemological participation in communities of practice, though, only recently have researchers (Adler-Kassner, Majewski \& Koshnick, 2012; Adler-Kassner \& Wardle, 2015; Gogan, 2013) begun to consider the potential for synthesizing these concepts as a framework for designing for and understanding transfer of learning across contexts. Doing so creates two propositions, both of which are essential for realizing the enabling practices described in the Elon Statement:

- In order to be successful, learners must develop abilities to recognize the boundaries around the communities of practice in which they participate and change their practices accordingly. In writing classes, these boundaries include "concepts that enable students to analyze 
expectations for writing and learning within specific contexts" (Elon Statement, 2015, p. 5). Recognizing the boundaries that distinguish one community of practice from another involves both identifying and enacting threshold concepts, as well as learning how to learn about those concepts (Wenger, 1998).

- The ability to identify threshold concepts within communities of practice is critical for learners to develop the metacognitive awareness described in the Elon Statement because with it, learners can (1) understand—and, perhaps, see through and with—concepts critical to the community; (2) identify the roles that these concepts play in delineating the community; and (3) differentiate boundaries between one community and the next.

Accordingly, because of the intrinsic role that threshold concepts play in forming and delineating communities of practice, a more explicit focus on these concepts reflects the enabling practices described in the Elon Statement and, as a result, might help writing teachers (and researchers) address a troubling issue that has emerged throughout research on writing transfer: "Students do not expect their writing in [first-year composition] FYC, or even classes in their majors, to transfer to other coursework or professional contexts" (Moore, 2012, "Research Outcomes," para. 1). This perception may be due, in part, to the tendency in some first-year writing courses (and curricula) to place writing processes at the focus of their courses (and to teach that focus through a variety of themes). In privileging process and instructor-selected themes, many writing courses seem to reflect the belief that a writing class can revolve around any content-because the role of content is merely to facilitate an often implicit focus on the development of habits of mind and strategies associated with writing process (e.g., brainstorming, drafting, revising, reflecting) that are presumed to be both generalizable and content-neutral (Downs \& Wardle, 2007; Robertson, 2011; Wardle 2007, 2009; Yancey, Robertson \& Taczak, 2014). Such an approach to writing, though, misrepresents the nature of writing and its role in both communities of practice and disciplines where writing practices are shaped by and reflective of specific communities. The more process-based universalist approach has failed to serve students well (Yancey et al., 2014). Students, of course, realize this, often early in their college careers when they discover that strategies they learn in English classes are not applicable, as near or far transfer, to other courses (Bergmann \& Zepernick, 2007).

In sum, working with - writing about, reading about, and using in practice-threshold concepts of writing is critical for students seeking to develop as writers both in writing classes and, because of writing studies' focus on the 
study of composed knowledge within specific contexts, within other courses. In this chapter, as a mechanism for thinking about a writing curriculum informed by threshold concepts, we define five threshold concepts of writing studies that are critical for cultivating students' abilities to assemble and reassemble knowledge-making practices within and across communities of practice. We illustrate the implications of integrating these threshold concepts into instruction by drawing on data from studies that each of us has conducted in conjunction with our participation in the 2011-2013 Elon University Research Seminar on Critical Transitions: Writing and the Question of Transfer, during which we worked as a cohort focusing on questions associated with transfer from writing courses to other general education courses. We conclude by considering the implications of our focus on threshold concepts and what we have learned through this research for writing instructors and, more broadly, for general education moving forward.

\section{THRESHOLD CONCEPT \#1: WRITING IS AN ACTIVITY AND A SUBJECT OF STUDY (LINDA ADLER-KASSNER)}

The idea that writing is an activity — an action in which writers engage for any number of purposes (to learn, to begin developing ideas for projects, to air grievances, to advocate for a cause, to share an experience or idea with others, and so on) - is commonly understood. Sometimes, this activity is linked to performance, demonstrating the achievement of something; sometimes, it is linked to myriad other purposes.

But at the same time that writing is an activity, it is also a subject of study. That is, it is possible to investigate writing as an activity and apply to it questions that provide insight both into individuals' encounters and experiences with writing and into the multiple roles that writing plays within specific communities of practice. These questions include ones such as: How is "good" writing (and its opposite, "bad" writing) defined in this community? What values and ideologies are reflected in those definitions? How have those definitions been constructed and reified over time? How is good writing assessed? What consequences or implications extend from definitions of good (and bad) writing, for whom, and why? How do individuals who produce this writing experience its production? How is writing used in this community of practice, and how do individuals and groups come to understand those uses? And why is it beneficial to individuals and groups to be able to understand and experience writing as a subject of study, not just to be able to practice it as an activity?

This idea, that writing is something that can be studied and that the study of writing can provide unique insights into communities of practice, is a threshold concept for learners at a variety of levels. For undergraduates entering college 
writing courses, it can be particularly troublesome (Meyer \& Land, 2003, 2005, 2006) — one of the key characteristics associated with learners' encounters with such concepts-because in many instances, their previous school experiences have focused on writing only as an activity, as something that one does in order to represent (or, occasionally, produce) knowledge, rather than as a subject of study.

Evidence of this focus on writing-as-activity (but not as subject of study) is ubiquitous, especially as teachers, parents, and even students reflect on the ways in which high-stakes testing has led teachers to necessarily focus on teaching to the test, especially in secondary English courses. A November 2013 guest post for the popular Living in Dialogue blog written by Joan Brunetta, a student at Williams College, captures the issues that extend from this approach. Brunetta wrote that as she moved through school, students perceived that learning was aligned with the score or grade that they earned on standardized exams. Brunetta devoted special attention to writing, which by high school, she said, was exclusively about the entirely predictable representation of ideas - the activity, in other words, of performance.

To do anything but constrain your ideas by the structure was very wrong. When we learned essay writing in high school, we were often handed a worksheet, already set up in five paragraphs, telling you exactly where to put the thesis, the topic sentences, and the "hook." In my freshman history class, I was told that each paragraph should have 5-9 sentences, regardless of the ideas presented in the paragraph. The ideas didn't matter-structure reigned supreme. (Brunetta, 2013, para. 13)

Brunetta's blog post highlights the way in which writing was and is taught as a rigid and highly constrained activity, limiting the opportunities that she and other students in her Cambridge, Massachusetts, high school might have to experience writing as a subject of study. Data collected as part of a listening tour organized by the Conference on College Composition and Communication (CCCC) also reflects this experience. As reported by their teachers, students enrolled in college first-year writing classes in fall 2013 said that their writing in high school was largely geared toward producing particular text types to fulfill the requirements of various kinds of tests (Conference on College Composition and Communication, 2013).

Students' experiences of writing as an activity, but not a subject of study, were also voiced by students enrolled in a first-year writing course where writing was a subject of study. As context, it is helpful to explain that these students were enrolled in a section of Writing 2, a general education writing course (taught by Linda Adler-Kassner). At the same time, they were also enrolled in History 17b, 
another general education course. In the Writing 2 course, assignments asked students to analyze writing in and from $17 \mathrm{~b}$ - both writing used in the course (such as primary sources, textbooks, assignments, and syllabi) and writing that they completed for the course- as a subject of study. Interviewed after the conclusion of both courses, the following excerpts from four students, which are typical of the range of responses from all students interviewed, point to the ways in which students' understandings of writing changed as a result of experiences in the class.

Initially, students said, they understood writing primarily as an activity constrained by particular limitations. "[In high school,] we were always taught very specific ways to write," said Jane. "We weren't allowed to use certain words. . . . We had really strict rules. And ways of writing." Coming out of high school, Jonathan reported that he expected Writing 2 to be "all grammar ... making my paper look great grammar-wise" because "all of my high school, middle school writing classes were ... about proper sentence structure, paragraph structure, all of that stuff" (see also Hillocks, 2002). As a result of their prior experiences, both Jane and Jonathan had particular ideas about what writing was: the production or representation of ideas in a specific and rigid form. Jonathan's description of his writing captures this expectation. "I always wrote in exactly the same way," he said. "It was intros . . . and at the bottom of my intros my thesis statement, and within the intro I would structure my paper and then start para 1, para 2, para 3, concluding para. I was very structured." Writing these structured essays, he reported, was a constant. "The [Advanced Placement] AP test and everything like that - that's exactly how I was taught to do it. ... It would just blend in with everyone else's paper."

In Writing 2, these writers began to work with the idea that writing is both a subject of study and an activity, the latter a process that can be used to develop ideas within multiple contexts. In addition, as they moved toward (and, in some instances, away from) the liminal boundary associated with threshold concepts, some began to understand the concept as transformative- that is, it changed the ways that they understand writing within and across contexts. Portions of Jonathan's interview, for instance, illustrate a learner at a less fully realized, but still developing, point along the liminal path toward full participation in threshold concepts. Jonathan said that before working with the concept that writing is a subject of study and an activity, "structure was a higher priority for me" when writing any paper. After studying writing explicitly as the content of Writing 2, Jonathan explained that he tries to "understand the question before I even start to write." Analyzing his writing for History 17b, he explained that he could look at that writing through a different lens, as well. He could see, he said, where he didn't do things in ways that were expected in the class or the assignment-and, importantly, "here's how I didn't quite accomplish what I was trying to do. ... I 
was trying this and I could see where I was going, but it didn't really work at all.” Of course, the range of contexts in which Jonathan and other students in these two courses were writing was relatively narrow: both were general education courses within the same institution. There are also similarities between threshold concepts in writing studies and in history (e.g., close attention to context and the nature of text as socially constructed [see Adler-Kassner et al., 2012]). Whether Jonathan's burgeoning engagement with the threshold concept that writing is a subject of study would transfer to more disparate writing contexts, such as between a writing class and a workplace setting, is hard to say.

Ramona's and Ellen's interviews provide examples of learners at more advanced points on the way toward participating in the threshold concept that writing is a subject of study and an activity. Ramona read aloud a paragraph from her final project in Writing 2, which asked students to create a genre for a specific audience that they selected to help that audience understand the relevance of a particular approach to the study of history. For the assignment, students needed to draw on the writing of Wineburg (2001), who has long examined the process of learning and meaning-making among expert and novice historians. Ramona's paragraph focused on her analysis of the importance of explicitly presenting history as a narrative, one that is generated through interpretation of primary sources but that is also necessarily inflected with the presence of the interpreter. In her assignment, she wrote, "If a story does not have a teller, it cannot be debated. History is about people. Humans are always going to have different opinions — and that's okay. It is necessary to present history with different perspectives." As she described her work the subsequent quarter in History 17c, a class focusing on American history from roughly World War I through the 1960s, Ramona said that she realized that the process of studying the stories of history helped her understand a threshold concept of that discipline, that history consists of meaningful and competing narratives (see Adler-Kassner et al., 2012; Adler-Kassner \& Majewski, 2015). "Reading . . and understanding how to think about [history]," she said, was critical. "It's all about understanding stories, and putting things together."

In her interview, Ellen said that she realized she could study the ways that the faculty member teaching History 17b, John Majewski, structured his lectures and use that as a lens through which to view the writing for that class. Going through her lecture notes, she said she saw "a trend of how Professor Majewski discusses things ... and then I started to notice . . . every lecture, he really outlines like it's an essay. He forms a thesis, he has an argument ... and he includes examples. And then I looked at my essay [for 17b] and ... how my essay compared with how he would structure a lecture [and] in my head I was thinking, 'Can I make a lecture out of my essay?'” Ellen's comment is a particularly 
notable example of a learner who seems to have stepped through the threshold associated with the concept that writing is a subject of study and an activity. She applied the threshold concept from one class, Writing 2, to her lecture notes from History $17 \mathrm{~b}$; she then took the analysis of those notes as a subject of study and applied those to the writing she was doing for that class.

As the Elon Statement explains, writing classes that "focus on study and practice with concepts that enable students to analyze expectations for writing and learning within specific contexts" (2015, p. 5; Appendix A) are a central enabling practice for facilitating transfer. The threshold concept that writing is an activity and a subject of study is critical for engaging in this kind of analysis. These excerpts, generated by undergraduates after only 10 weeks grappling with this concept, illustrate the ways in which the concept is troublesome and, to varying degrees, transformative. It is also worth noting that the threshold concept that writing is an activity and a subject of study can also be troublesome for learners at other levels. This could, for instance, be understood as a central principle underscoring the effort to work with faculty outside of writing classes to understand the expectations for writing in their disciplines (as communities of practice) not as natural or common sense, but as practices embedded in the values, ideologies, and practices of those disciplines. For students and faculty, then, working with the idea that writing is an activity and a subject of study can lead to a focus on understanding and/or making more explicit expectations for writing within specific contexts (see Adler-Kassner \& Majewski, 2015; Estrem, 2015; McGowan, 2014).

\section{THRESHOLD CONCEPT \#2: WRITING ALWAYS OCCURS IN CONTEXT, AND NO TWO CONTEXTS ARE EXACTLY ALIKE (LIANE ROBERTSON)}

The idea that writing occurs in context is not new and is not a threshold concept on its own. However, while writers may understand that writing occurs in context, they also benefit from understanding that writing is situational even within similar contexts. The idea that writers can learn to write for a recurring context-applying what they learned during the first time they write in a given context to the next-is mistaken. Writers must differentiate between an understanding that writing occurs in context and an analysis of each context in order to write well in that context.

The contexts for writing vary even when the task and audience seem similar. For example, a marketing executive may understand how to write a proposal for a project she wants to pitch to a client or superior, one that outlines the idea and includes possible conventions (a cost-benefit analysis, a budget, and any 
other rationale or potential issues that might accompany the endeavor being proposed). But the proposed idea is not the idea she previously pitched; the situation involving the client or superior is different (either involving different people or the same people who may have a revised perspective since the last proposal); the ability to allocate budget may have changed; or other intangible factors affecting the willingness to approve a proposal will be different than the last time the executive submitted a proposal. In this example, the marketing executive writer requires analysis of the situation for which the proposal is being prepared, and based upon that analysis, will write the proposal with a goal of securing approval for the proposed project. While there are conventions that guide the writing of any proposal, it is the context situating each proposal that most affects its development and its success as a written product for a specific purpose; that success is based on the writer's success in employing conventions appropriate for the context.

Russell's (1997) work in activity theory demonstrates (1) that writing occurs within contexts, particularly the activity system in which the writing is situated, and (2) that all writing is affected by the way in which the writer interprets or reacts to the activity system or situation in which the writing takes place. Grounding this idea in teaching, Russell asserts that classroom contexts can be made explicit by asking, "How can one analyze the macro-level social and political structures (forces) that affect the micro-level actions of students and teachers writing in classrooms, and vice versa?" (1997, p. 504). Russell contends that the connections between genres and activity systems are more easily made within professional or specialized contexts. In more general writing classes, though, there tend to be wider ranges of genres and foci evidenced across courses (as discussed in Threshold Concept \#4 below). For example, writing classes can revolve around one or more virtually limitless areas of content, or, alternatively, can revolve around genres that are perceived to be associated with disciplines (natural science, social science, humanities). Within any given writing course, then, there is the possibility that the range of genres or content available to students is broad and diffused. Additionally, the connections to writing in other disciplines might be framed by the instructor through one or more of a number of lenses: a similar content, a similar process, a similar genre. Not surprisingly, then, "composition students have particular difficulty seeing the connection between the writing and other social practices" (Russell, 1997, p. 536). Activity theory, though, provides learners the opportunity to study the expectations for and specific types/genres of writing used in a specific context and to practice with those, recognizing that context is a key factor in identifying sites for writing as a subject. Through such a focus, writers can examine and begin to participate in genre systems (Bazerman, 2002), which allows writers to consider how writing works across 
activity systems and how relationships between concepts develop. By exploring the interactions between systems, writers can analyze the writing within them, building on their prior knowledge with each analysis. This expands and deepens their understandings of the ways writing works and the writing approaches one might employ in various contexts, once that deeper understanding of the social systems involved is realized. By understanding writing as a subject of study, not just an activity (as suggested in Threshold Concept \#1), writers can develop and continuously revise a framework (Beaufort, 2007) of knowledge about writing, which allows them to repurpose appropriately between contexts (see also AdlerKassner \& Wardle, 2015).

Once writers understand how to decontextualize a writing situation-to evaluate and analyze a context, to identify the rhetorical choices performed in a writing situation, and to conceptualize their own rhetorical choices as writers in a new situation-they will understand the threshold concept that writing always occurs in context and that no two contexts are exactly alike. This notion of context, in the terminology of threshold concepts, is likely transformative for writers in that it changes their internal view of writing to something non-formulaic and only appropriate to a given context; is irreversible in that writers can never return to writing without considering context; is integrative in that it demonstrates relationships between genres, audiences, purposes, and contexts of writing that complicate writers' understanding of the writing product; and is bounded in that writers who now consider context in this new way must also consider context in other ways of communicating and receiving communication from others (Meyer \& Land, 2005). At the same time, this threshold concept can also constitute what Meyer and Land define as troublesome knowledge (Meyer \& Land, 2003, 2005 , 2006) or knowledge that proves problematic, because it requires a paradigmatic shift in previous thinking: It requires writers to understand that writing within contexts requires an interpretation of each context, rather than assuming that a model or formula for writing will lead to success in any context. This idea, especially, can be particularly alien for first-year students, who may be emerging from an environment in which they have been taught to write to a particular target such as a standardized test or one model of essay writing.

This troublesomeness was particularly evident in students interviewed in a qualitative research study (see Robertson, 2011; Yancey et al., 2014) reported in Writing Across Contexts: Transfer, Composition, and Sites of Writing (Yancey et al., 2014) that introduced the Teaching for Transfer (TFT) curricular model. ${ }^{2}$ The TFT curriculum was designed specifically to encourage transfer from first-year composition to other sites of writing through the study of rhetorical concepts about writing, the use of a systematic approach to reflection, and students' development of a "Theory of Writing" which frames their prior and developing 
knowledge about writing. The research study which featured the TFT curricular model, explored the success of first-year students at writing in various disciplinary contexts after having experienced three different types of FYC content: (1) an Expressivist design, (2) a course themed around media and culture, and (3) the Teaching for Transfer curriculum described above. By comparing these three types of content across the three courses and exploring the knowledge about writing that students transferred from each of the three different courses to new writing contexts, the study demonstrated that students can transfer knowledge, but also that sometimes (as was the case for subjects from the non-TFT sections in the study) only partial knowledge transfers, or that transfer occurs without mindfulness, or is situated within a context that a writer does not understand deeply enough to appropriately interpret and successfully write in. In contrast, students in the Teaching for Transfer section that explicitly focused on content associated with the threshold concept that "writing occurs in context and no two contexts are exactly alike" were able to develop the conceptual model that research has indicated is necessary for transfer to occur (e.g., Beaufort, 2007). Students who experienced writing courses located in an Expressivist approach or a cultural theme were unable to transfer concepts about writing, but merely retained strategies or processes of writing because the content of their FYC course had not allowed for the development of a conceptual framework or of greater knowledge of the context for writing necessary for successful transfer (Beaufort, 2007, p. 19).

In particular, two students from the Teaching for Transfer course developed a conceptual model of writing knowledge, as well as both the procedural and declarative knowledge that Michael Carter purports is necessary to develop expertise (1990, p. 273). Both students demonstrated transfer between the context of FYC in one semester to the contexts of writing they experienced in other courses in a second semester. More importantly, they also transferred a conceptual model of writing that included context at its core. As a result of the transfer curriculum, both were able to articulate their approaches to contexts they were experiencing and predict approaches to the contexts they expected to experience in the future. This research indicates (see Yancey et al., 2014) that their abilities to consider writing in this abstract way were cultivated by the content of their Teaching for Transfer FYC course, which had taught them to decontextualize a writing situation to determine the role of rhetorical concepts such as audience, genre, and context, which they were then able to re-conceptualize for new contexts, both real and imagined. One subject (known pseudonymously as Clay) observed that by the end of the Teaching for Transfer FYC course he understood how the concepts of writing learned in the course worked in various contexts: "I didn't just learn strategies in [the FYC course], I learned to think about how to 
write in any situation" (Robertson, 2011, p. 153) and he learned to analyze the effect of the writing he was doing for particular situations. In other words, Clay realized that his writing varied depending on the rhetorical situation and his own understanding of the context for which and in which he was writing. Evidence of Clay's ability to apply this analytical prowess was demonstrated when he was able to transfer from the context of FYC to the context of a meteorology course by mindfully abstracting the concepts of genre and audience. Specifically, he decontextualized these concepts so that he could re-conceptualize them for successful performance on an essay in the meteorology course. In doing so, he understood and acted upon the threshold concept that "writing always occurs in context and no two contexts are exactly alike," reimagining these concepts for success in other contexts for writing (Robertson, 2011, p. 154).

Another subject (known pseudonymously as Rick) experienced troublesome knowledge in attempting to understand the conceptual framework he was required to develop in order to transfer. However, in his initial failure to navigate contexts smoothly, he moved through the bottleneck of learning that Meyer and Land identify as preceding the transformation that shifts a learner's perspective (Meyer \& Land, 2006). Rick remained tied to the notion of writer's agency (as discussed in Threshold Concept \#3 below; see also Yancey, 1998) without fully understanding the concept of rhetorical situation and found himself failing at writing for a specific context - the lab report required in his chemistry class-because of his unwillingness to let go of agency. However, when Rick understood the audience (his instructor, classmates), the genre conventions of the lab report (as required by his instructor), and the purpose of the lab report (to convey observations of an experiment), he began to understand the context in which he was writing as requiring a different approach than others that called for his opinion or interpretation (Robertson, 2011, p. 139). Further, Rick's ability not only to follow the genre conventions for the lab report provided by the instructor, but also to understand that the context of the lab report involved writing for a specific situation, meant that he was able to reconsider his writing approach for other lab reports in his science classes. He reported that his grades began to improve.

In any writing course, but particularly in FYC courses where students are often very recently removed from the more formulaic experience of high school writing, the threshold concept that writing always occurs in context and no two contexts are exactly alike can help students develop the conceptual model of writing (as discussed in other sections of this chapter) they need to transfer writing knowledge and practice to new contexts. This transfer goes beyond simply matching abilities to context; successful writers repurpose their knowledge in ways appropriate to the specific context in which they are working, an approach critical for success in any context. 


\section{THRESHOLD CONCEPT \#3: REFLECTION IS CRITICAL FOR WRITERS' DEVELOPMENT (KARA TACZAK)}

To say that reflection is critical for writers' development is to suggest that reflection must be an integral part of the writing process, making it more than an after-the-fact activity, a practice in revision, or an act of self-assessment. Reflection thus needs to be a practice in which writers bridge cognition and metacognition as a way to tap into their prior knowledge and experience so they can begin to question and theorize their writing processes, practices, attitudes, and beliefs (Taczak, 2015). As a mode of inquiry, then, reflection prompts writers to recall, reframe, and relocate their writing knowledge and practices: This practice of reflection asks writers to look backward as a way to recall prior knowledge (which could include prior dispositions, attitudes, and understandings about writing), to look forward as a way to frame and reframe writing situations, and to look outward as a way to relocate knowledge in effective and meaningful ways in different contexts (Taczak, 2011; Yancey et al., 2014). Reflection then becomes a systematic and intentional part of writers' processes.

Systematic and intentional reflection prompts writers to transfer. For example, a writer might learn how to address an intended audience in a first-year writing course (whether an instructor, a peer, or another specific audience that has been identified for his or her writing) and later reframe and relocate that knowledge for a chemistry lab report in which the writer has identified another specific audience (e.g., a teaching assistant). In order to promote transfer like this, though, reflection must be learned as both process and product: as beforethe-fact activity, during-the-fact activity, and after-the-fact activity, as well as a way to access both cognition and metacognition. Reflection therefore must be taught in deliberate and intentional ways, so that writers become active, reflective writing practitioners of their own learning about effective rhetorical practices. Later, when they enter new writing situations, they can transfer what they have already learned and begin to analyze what they need to know about what is required to construct new rhetorically situated responses.

However, much like other threshold concepts, reflection can be troublesome. As a result, it also can be absent from writers' processes. Some reasons for this include the belief that reflection happens naturally (i.e., it is assumed and thus not practiced) or that reflection is difficult (i.e., writers, at that moment, are not capable of engaging in reflective practice). To respond to these issues and others, reflection needs to be taught as a deliberate, reiterative process that creates conditions where transfer can be encouraged. In "Transfer of Learning," Perkins and Salomon (1992) identify conditions that speak to the type of deliberate reflection required to respond to this type of troublesomeness: active 
self-monitoring and arousing mindfulness. Active self-monitoring focuses on the ability to monitor "thinking processes" while arousing mindfulness refers to "a generalized state of alertness to the activities one is engaged in and to one's surroundings ... mindfulness would foster both [explicit abstraction and active self-monitoring]" (Perkins \& Salomon, 1992, para. 19). These two conditions promote near and far transfer because they respond to situations "under what conditions transfer appears" (Perkins \& Salomon, 1992, para. 16).

Reflection as a mode of inquiry encourages both self-monitoring and arousing mindfulness because writers are routinely theorizing about what and how they are learning. Thus, reflection becomes a practice that enables writers to recall, reframe, and relocate their thinking, understanding, and processes about writing and link prior knowledge with new knowledge, as they develop as writers able to transfer knowledge and practices to new writing situations.

The role of reflection in transfer became especially apparent in a qualitative study examining a first-year writing course where the explicit goal was to teach for transfer (Robertson, 2011; Taczak, 2011; Yancey et al., 2014). (This qualitative study featured the Teaching for Transfer curriculum discussed in Threshold Concept \#2 above but focused on students' reflection and transfer). As outlined above, the Teaching for Transfer curriculum on which the study was based centered on key rhetorical terms, a reflective framework, and the students' development of a theory of writing. The last was a semester-long reflective process that asked students to theorize about writing. The reflective framework incorporated reflection at different, intentional points during the semester using three components: reflective theory, reflective assignments, and reflective activities.

From this year-long study, two findings attest to the importance of the threshold concept that reflection is critical in the development of writers so that they might achieve successful transfer. First, over half of the participants reported that reflection offered them a chance to look backward so that they could go forward as a way to continue to develop as writers. Renee, a first-year environmental law and English double major, noted that "writing 'good' can take multiple drafts, details, and supportive arguments, but writing excellent takes an author who knows themselves as good as their reflective assignments do." She continued,

You learn a lot from reflection because when you got back into the paper you see yourself-how you write and how you explain things—so it helps you improve on your writing making it more coherent, but it also shows who you are on the paper. (Taczak, 2011, p. 97)

This is similar to what Yancey (1998) argues about reflection when she explains that "we learn to understand ourselves through explaining ourselves to 
others. To do this, we rely on a reflection that involves a checking against, a confirming, and a balancing of self" (Yancey, 1998, p. 11). As Renee continued, "[reflection] does not necessarily teach authors anything new, but it gives great insight into themselves on how they think and react to the situations they write about." Similarly, Yancey explains, reflection "attempts to describe what is" (1998, p. 194) and encourages writers to "know their work, to like it, to critique it, to revise it, to start anew" (1998, p. 201) (see also Beaufort, 2007; Bransford, Pellegrino \& Donovan, 2000). Reflection, as defined by Renee and the other participants, provided a way for them to understand themselves as writers so that they could reframe and relocate knowledge and practices in new writing situations. All of the participants noted similar sentiments about reflection by the end of the study. Reflection was a practice that helped them think about who they were/are as writers, which promotes the kind of recalling, reframing, and relocating outlined in the beginning of this section: recalling prior knowledge and reframing the prior with the new knowledge as a way to approach the new writing context (Taczak, 2011; see also Yancey et al., 2014).

The second finding from the study is that engagement with the threshold concept that reflection is critical for writers' development (Taczak, 2015) has a direct link to transfer because of its close relationship to the development of students' theory of writing. This study, like the one outlined in Threshold Concept \#2 above, showed that students are able to develop a theory of writing based on prior and new knowledge that they use to frame and reframe writing situations both inside their composition course and outside the composition course. The theory of writing asks students, in a semester-long reflective process, to explore writing: their writing processes, their understanding of key terms they enact in their own writing, and their ability to create a knowledge-base of writing and its practices. Developing the theory of writing is also a reiterative, reflective process that helps writers synthesize the learning acquired in first-year composition and the writing required in other sites. As Renee summed up, "As you reflect more and more you develop your theory of writing more and more-[reflection and a theory of writing] are coherently intertwined. It's like as [a theory of writing] goes up [reflection] has to follow it ... without reflection I don't think you could get to the next level of writing." Renee's comments point to a specific connection between reflection and transfer. She noted that reflection and the theory of writing are intertwined; put more simply, through reflective assignments and activities, Renee and others developed their theory of writing.

In addition, the development of the theory of writing, especially one specific to each individual writer's writing practice, encourages writers to develop their identity as reflective writing practitioners. This allows writers to develop expectations of what they need to look for in different academic writing situations and 
how they can respond to them. As reflective writing practitioners and based on their theories of writing, writers begin to learn to recall and reframe knowledge and practices that could be helpful in approaching new writing situations: by recalling their theory of writing, writers are able to reframe new academic writing situations and thus consider where and how they might relocate-or transferknowledge about writing to other contexts after the composition course. Many students in the study also understood the importance of developing a theory of writing and were able to reflect back on this well after the course ended. For example, in an exit survey 15 weeks after she initially took the course, Julia stated that her theory of writing sought "to address a rhetorical situation in an organized manner and specific genre through logos, pathos, and ethos to achieve my purpose of writing." She concluded the exit survey by suggesting the importance of having a theory of writing:

Yes, I believe a theory of writing is very important to have to make your writing matter. It has to include specific [terms and concepts] and without these[,] the writing would not make sense. . . I have enacted my theory of writing in most of my papers I have written this past semester [from the semester following the Teaching for Transfer course]. I will continue to use my theory of writing because it includes some of the many [terms and concepts] I think about before writing. (Taczak, 2011, p. 195)

As the findings from this study suggest, when reflection is a significant part of a writer's process, successful transfer of knowledge and practices can occur, but for this transfer to happen, reflection must be fostered in meaningful and intentional ways within the classroom. Thus, through the development of a theory of writing - which is created and fostered through reflective activities and assignments-writers are able to recall, reframe, and relocate knowledge and practices about writing to new and different writing contexts.

\section{THRESHOLD CONCEPT \#4: GENRE AWARENESS CONTRIBUTES TO SUCCESSFUL TRANSFER (IRENE CLARK)}

The idea that the threshold concepts of writing discussed here facilitate learners' abilities to recognize boundaries between communities of practice, understand concepts within those communities, and begin to differentiate between the threshold concepts (and boundaries) of one community and the next suggests that threshold concepts constitute a type of knowledge (reflected in particular abilities) that will enable a novice to engage meaningfully in a particular 
discipline (Meyer, Land \& Baillie, 2010). However, in considering the role of threshold concepts in FYC, the concept of knowledge can sometimes become problematic. As suggested in Threshold Concept \#2, when the first-year writing course is grounded only in process, strategies, and skills, students are unable to conceptualize their knowledge about writing. Furthermore, the lack of specific content in a FYC course means it is not necessarily situated in or understood as introductory to any specific community of practice or any discipline. Instead, unlike introductory courses in biology or history, FYC has often been conceived of as a generalizable and content-neutral course (e.g., Bergmann \& Zepernick, 2007; Wardle, 2009). However, if one assumes that writing is something that can be studied, as we do here, then the idea that understanding genres of writing can help students transfer may be considered a threshold concept in that it enables students to recognize that all genres are shaped within their communities of practices - disciplines, professions, or communities—and that to be successful, writers must be aware of both the conventions of the genres and the roles that they play within those communities. As is emphasized in the Elon Statement, a significant element of transfer involves "a framework for continued inquiry and theory building" (2015, p. 1; Appendix A). As defined by Haskell, "Transfer isn't so much an instructional and Learning Technique as a way of thinking, perceiving, and processing information" (Haskell, p. 23, as cited in Elon Statement, 2015, p. 1). The Genre Awareness Project, conducted from 2012 to 2013 in a large, western, Hispanic-serving university, substantiates this connection between genre awareness and transfer, suggesting that genre awareness, which incorporates both a theoretical approach and an enabling practice, contributes to students' transfer of writing knowledge and practice.

Building on a 2010 pilot study (see Clark \& Hernandez, 2011), the Genre Awareness Project, involving students enrolled in four first-year writing classes, defined genre awareness as a metacognitive understanding of genre, especially the ways that genres are constituted (both in terms of their conventions and in terms of the roles that genres play within communities of practice, for particular audiences and purposes, and so on) that can help students make connections between the genre knowledge emphasized in FYC and the writing genres they encounter in other contexts. The underlying idea was that understanding a text in terms of its rhetorical and social purpose and gaining metacognitive insight into the concept of genre would provide students with a type of knowledge that will enable them to address new writing situations more effectively, wherever they might occur. Metacognition in the context of genre would not only provide students with a type of knowledge that would help them approach new genres more effectively, but also it would enable them to realize that they had this type of understanding. The rhetorical concept of genre informing this project 
was derived from the re-conceptualized rhetorical view of genre (Miller, 1984; see also Bawarshi \& Reiff, 2010; Bazerman, 2002; Clark \& Hernandez, 2011; Dean, 2008; Devitt, 1993; Nowacek, 2011) that defines genre not simply in terms of formal or structural characteristics but in terms of function. The curriculum presented was based on this concept of genre, with assignments and class discussions focusing on similarities and differences between various genres and the rhetorical decisions writers make when they compose in a particular genre. In addition, in order to focus entering students attention on the concept of genre, they were asked to recall the antecedent genres (Bawarshi, 2000) with which they were familiar-in particular, school genres such as the five-paragraph essay, books reports, research papers, and literary analyses-and to predict which of these genres they expected would be most useful for them in their college classes.

The usefulness of fostering genre awareness in FYC has been suggested in current scholarship concerned with genre study (See Bawarshi, 2000; Bawarshi \& Reiff, 2010; Devitt, 1993; Swales, 1990) and developed for this study through the Elon University Research Seminar on Critical Transitions: Writing and the Question of Transfer. The study began with surveys distributed at the beginning of the fall 2012 semester to 84 entering students. The surveys asked students to indicate (1) their familiarity with rhetorical terminology; (2) the genres that they predicted would be most useful for them in their college courses (from a list of genres provided); (3) their self-reported degree of writing anxiety; and (4) their self-reported evaluation of writing ability. Additional surveys were administered at the end of the fall 2012 and spring 2013 semesters and supplemented by interviews conducted with 10 students selected from four classes. The surveys conducted in the 2012-2013 academic year indicated that on a four-point scale of usefulness in approaching new writing tasks, all students rated rhetorical terms associated with analysis of genre within specific contexts as above a mean of 3.5. In addition, students selected four genres, from a list provided to them, that they predicted would be most useful for them in their college classes. "Academic argument," "personal narrative," "the research paper," and "the five-paragraph essay" were rated the most useful, with the five-paragraph essay receiving the highest score both at the beginning and end of the fall 2012 semester and at the end of the spring 2013 semester. This insistence on the usefulness of the five-paragraph essay confounded our expectations; however, as Hillocks' (2002) research indicates (and Linda Adler-Kassner's, cited above, echoes; see also Kathleen Blake Yancey's below, which focuses on several elements contributing to prior knowledge, including experiences, attitudes and beliefs), students likely had extensive experience writing five-paragraphs essays when they entered. Although all instructors in the project had attempted to discourage students from 
a dependence on what is generally regarded as a form-based, a-rhetorical genre, students noted its usefulness for taking timed essays, and, during interviews, several students indicated that they were quite aware of when the five-paragraph essay was likely to be useful and when it was not.

Interviews conducted at the end of fall 2012 and spring 2013 indicated that students did consider the concept of genre when they engaged in writing tasks in other classes and contexts. Student \#1 affirmed that he had found the fiveparagraph essay useful for exams and papers written quickly, "a standard," a paper written "to get the grade. You know, that's sort of the minimum, I guess the standard." He also claimed that many professors expect a five-paragraph essay, although he qualified that "outside of school, at work, I tend to write a lot of papers for financial research and not once have I ever done a five-paragraph essay." Student \#2 recalled a paper that he had written for an anthropology class, which he described as an interview project on the subject of kinship. When questioned about the extent to which that project was similar to and different from essays he had written in FYC, this student responded that it was different because he was not required to have a persuasive thesis:

When I think of a thesis, I think about a paper that has a message that I'm trying to get across, and the papers that I've done in that class weren't like that. But now that I am thinking about it, yeah, I would say that I did have a thesis, but I couldn't have an argument for or against someone's family structure. So it was a different kind of thesis.

This conversation suggests that this student is gaining an understanding that a thesis will vary according to disciplinary context, an insight that suggests a developing awareness of genre.

However, all students indicated in their survey responses that they had found the concept of genre useful in approaching writing tasks in other classes and contexts; several responses from student interviewees indicated a primary focus on structure or format that separated those features from the rhetorical elements incorporated in the concept of genre. In terms of how this perspective pertains to the idea of threshold concepts, this separation suggests that these students were in "a suspended state of partial understanding or 'stuck place' at which understanding approximates a kind of 'mimicry' or lack of authenticity" (Meyer, Land \& Baillie, 2010, p. x). At this point in their understanding, these students viewed all school writing in terms of format/structure without realizing that even in school writing, genres vary considerably in terms of situation or disciplinary context. For example, Student \#3, in discussing differences between the five-paragraph essay she had learned in high school and college-level writing, 
stated that in high school, "You write a thesis and then just list the main points that you're going to make, and then in college we use an argument that uses 'although' or something like that." Other differences Student \#3 noted included the length of college papers (five pages, not five paragraphs) and "a lot more elements that you put into your paper, like your works cited page and your MLA formatting." Overall, responses from interviewees indicated that although students were developing an awareness of substantive genre differences, many tended to focus on the formal features of a genre rather than on how formal features reflected disciplinary or rhetorical elements.

Nevertheless, awareness of even superficial similarities and differences constitutes a fledgling stage of genre awareness that ultimately can result in effective transfer. An example of how this process works is discussed in Villanueva's (1993) well-known literacy autobiography Bootstraps, which narrates the process undertaken by the protagonist as he moves from writing essays assigned in community college to those assigned in a four-year college. Concerned about the grade he had received on his first paper, Villanueva goes to the library "to look up what the Professor himself had published" and was able to see the pattern:

... an introduction that said something about what others had said, what he was going to be writing about, in what order, and what all this would prove, details about what he said he was going to be writing about, complete with quotes, mainly from the poetry. (Villanueva, 1993, p. 70)

As a result of his efforts, Villanueva's grades improve, and professorial analysis becomes "a standard practice: go to the library; see what the course's professor had published; try to discern a pattern in her writing; try to mimic the pattern" (Villanueva, 1993, p. 71).

In the context of how genre awareness may be considered a threshold concept, one might say that Villanueva's experience constitutes a well-articulated example of how a threshold concept works. At first, he simply replicated the genre of writing he had learned at community college. He then realized that his professor expected a different genre, and as he moved from a state of liminality, he eventually was able to understand and ultimately to produce the genre that was expected. Like the student interviewees, Villanueva learned to examine differences between genres, and his insights, at first superficial, eventually enabled him to apply or transfer previous knowledge into a new context. This learning sequence was addressed in some of the student interviews, which indicated that although some students had focused initially on formal elements, ultimately they were able to discern rhetorical distinctions in different writing tasks. Overall, both the survey responses and student interviews support the idea 
that students had begun to acquire a degree of metacognitive understanding in accordance with the idea that genre awareness may be considered a threshold concept in the field of writing studies.

\section{THRESHOLD CONCEPT \#5: PRIOR KNOWLEDGE, EXPERIENCE, ATTITUDES, AND BELIEFS SET THE STAGE FOR WRITING AND SHAPE NEW WRITING EXPERIENCES AND LEARNING (KATHLEEN BLAKE YANCEY)}

As suggested in the research reported in the National Research Council volume How People Learn (HPL) (Bransford et al., 2000), all "new learning involves transfer based on previous learning" (p. 53), though how the prior knowledge contextualizes new learning varies. Moreover, the prior includes a good deal more than knowledge: experience, attitudes, and beliefs - in addition to knowledge - constitute part of a larger construct of the prior. The threshold concept that prior knowledge, experience, attitudes, and beliefs set the stage for writing and shape new writing experiences and learning is thus important for two reasons: (1) it means that all writers are influenced by factors of prior knowledge that are typically tacit but often very powerful, and often in unhelpful ways; and (2) it means that in understanding prior knowledge, all writers can begin to perceive more generally why they (we) approach writing as they do, and more specifically, be more intentional in all writing situations. Likewise, this threshold concept is especially important for writing in college-which, as we have seen, involves thinking about writing as an object of study; about the role of context in writing; about reflective practice as a connector and facilitator of writing; and about genre awareness. This threshold concept, in complementary ways, calls into question the idea that writing is formulaic and unfixed, that once you know how to write in a specific genre, you can write in that genre anytime, and that you can also write in other genres anytime, an issue addressed in Threshold Concept \# 4, above.

According to How People Learn (Bransford et al., 2000) prior knowledge in the context of new learning functions in one of three ways, as we see within the context of college writing courses, especially first-year courses. In the most hospitable function, prior knowledge and the new learning provide a good fit: As suggested in Threshold Concept \#4, students entering college writing classrooms aware of genre, for example, bring a conceptual understanding of writing that college writing faculty can build on. However, prior knowledge can function in two other, less hospitable ways. In the first of these, students entering college bring with them knowledge or practices at odds with the FYC curriculum. We see this misfit between prior knowledge and new learning situations, for exam- 
ple, when students enter a FYC writing classroom with an unelaborated writing process - one absent of multiple drafts, peer review, and revision-that they believe is the "right" way to write, or when they enter "knowing" that an edited text is necessarily a strong one, even if it has no purpose, claim, or contribution. In the second of these misfit situations, beginning college students experience dissonance between community-based beliefs and the required curriculum. We can see this in some international students whose knowledge of citation practices - in their cases using unacknowledged borrowed material in ways acceptable, even expected, in their home countries - puts them in danger of being accused of plagiarism in the United States, or in students whose community-based religious beliefs suggest that certain topics, ranging from evolution to abortion, already have correct answers and thus are not fit subjects for inquiry. ${ }^{3}$ But of course, these three conditions of prior knowledge are not necessarily mutually exclusive. A student can enter college with an elaborated writing process but with community-based beliefs constraining inquiry; likewise, a student might enter college with a restricted writing process but a strong conception of rhetorical purpose and audience. As important and as indicated by research (see, for example, Yancey, 1998), unless and until we ask students, we do not know what prior knowledge(s) influences their encounters with writing in FYC, nor how. What is as interesting is that this three-part, potentially overlapping schema of prior knowledge, as explained above, only begins to map what we might call the landscape of the prior influencing students. This landscape includes several other areas in addition to knowledge. Summarized briefly here are three of them: experience, attitudes, and beliefs. ${ }^{4}$

Considerable research shows the influence of prior experience in influencing students' approaches to writing instruction. Sometimes that prior experience has occurred in a student's childhood out of school: In Roozen's (2010) study of Angelica, we see a student whose personal childhood journal writing first contextualizes both her general approach to writing and her response to critiques of her writing, which then motivates her choice of college major and career. Other times, prior experience is also out of school but more immediate: Cleary (2013) narrates the story of Doppel, a returning adult whose recent experiences in architectural drafting shape his designs for the arrangements of texts through a kind of block patterning. Similarly, Michaud (2011) describes the experiences of another non-traditional student who, in writing for class, borrows from his prior workplace experience of copying and pasting, a practice Michaud labels right-click steal. The extracurriculum provides another site of prior experience: As reported in Yancey et al. (2014), students cite the influences of various extracurricular activities — including high school debate and summer jobs—on their writing practices and knowledge. 
Attitudes toward writing matter, as well. As both Brandt (2001) and Lunsford (2015) have reported from interviews with adults, attitudes are often formed early on; in addition, at least for adults in the United States in the twentieth century, attitudes toward writing have often, perhaps typically, been negative. Attitudes can take other forms, though: Burton (2010) reports a study in which students were invited to see a connection between writing in a given class and their future writing tasks, with the result that students expressed positive attitudes toward writing. Here we see a relationship between the threshold concept regarding context and attitudes: Context helps shape attitudes, which in turn contribute to the prior, shaping new learning.

Last but not least, beliefs contribute to the prior. Some beliefs, as outlined by Driscoll and Wells (2012), point to student behaviors and sense of self. For example, students with a strong sense of self-efficacy bring a sense of agency and possibility with them to new writing tasks. They already believe that they have some agency even in the face of a writing challenge. Other beliefs focus on writing itself: In a study conducted by Sommers (2011), students are invited, as a context for the class and for their own semester-long reflective practice, to identify their beliefs about writing by completing three sentences:

- I believe writing . . .

- I believe revising...

- I believe writing courses...

Sommers' (2011) research demonstrates that such prior beliefs can exert a very strong, even determining, influence on students' approaches to writing, a point not unrelated to the role that beliefs may play in reflective practice.

How these different kinds of prior knowledge can coalesce for even a single writer began to come into focus in an interview with Nicole, a student graduating from Florida State University with a double major in classics and Writing, Editing, and Media. The purpose in interviewing Nicole was to learn from her about the satisfactions and challenges characterizing her college writing experiences, and about how she might have transferred writing practice and knowledge from one site to another. While the prior was not a particular focus of the interview, it played a decisive role in her development as a college writer. More specifically, three observations that emerged from the interview are salient here: (1) that Nicole intentionally drew on prior writing knowledge and was able to adapt it as she moved from site to site; (2) that her sense of self-efficacy, prompted by a negative high school classroom experience, was dispositive and, again, intentional; and (3) that a combined college curricular and extracurricular experience also played a role in her development and provides something of a touchstone for her conception of herself as a writer. Put another way, the prior 
for Nicole is not one kind of prior or another, but a set of priors that interact and characterize her self-identity as a writer.

In thinking about prior knowledge in the How People Learn sense, Nicole talked about the value of a model, specifically the five-paragraph essay she had perfected in her English AP class in high school; she called the class "training for the essay" and remarked on how her knowledge of that format had provided (1) an anchor for her as she traveled from college class to college class and (2) a flexible format that she could expand and adapt as she saw fit. Interestingly, as Irene observes above, we in writing studies might consider this kind of writing knowledge, which is somewhat a-rhetorical and absent any awareness of the essay as genre, limited or even faulty. However, for Nicole, especially in her humanities-based classes (which constituted nearly the full set of her courses), it provided a flexible starting point and an adaptable structure for the writing in each of her classes.

At the same time, Nicole talked about an experience in that same high school class and how that had influenced her even more. For one assignment in her AP language class, Nicole had wanted to use material from pop culture as evidence for a claim she was making; specifically, she wanted to include material from the Harry Potter series. However, she was not allowed to do so, even though, according to Nicole, she had asked repeatedly and was doing well in the class. Instead, she was told to draw exclusively on the canonical material. Interestingly, the issue troubling Nicole was not located in the kind of material; she did not see what we in writing studies might call the difference in cultural capital (Sullivan, 1997) between high canonical, sanctioned material, and low pop-culture references. Rather, what Nicole saw was that the part of herself that was relevant to the writing task at hand-as represented in the Harry Potter material that was hers-was deliberately excluded. In other words, the AP teacher denied what seemed to Nicole to be the reason to write, that is, to contribute something that is uniquely hers. Moreover, at that point five years ago, Nicole made the decision that she would work hard to incorporate her own interests into all academic assignments, with two results. First, this commitment that she enacted was a source of creativity for her and sometimes a challenge: She liked "tak[ing] things that don't belong" and "sticking them in academic papers." Second, and as important, the teacher's refusal prompted a sense of agency in Nicole and a belief that all writing assignments can accommodate her interests; each assignment thus now has an extra feature, what we might call Nicole's self-designed connection. ${ }^{5}$

Not least, this idea of connection, fostered in a high school prohibition and self-designed into college writing assignments so that "things that don't belong" find their place in her academic work, is further supported in a study abroad trip 
Nicole took to London the summer before her senior year in college. The trip acted as a kind of prior for her senior year. In this experience, which is both curricular (through classes) and explicitly extracurricular (through cultural events and day and weekend trips), Nicole found multiple connections-among them, literary, historical, contemporary, pop culture, architectural, and geographical-that she could include in her writing, each of them providing what she called a "moment" when she could do what she liked best in writing, "synthesizing across fields of knowledge," something she "didn't do . . . as much in high school. When I make a connection, that's so cool. I had lots of those moments in London."

The prior for Nicole, as for all writers, was complex. In her case, it was located in knowledge about writing and linked to the five-paragraph essay, which expanded as her experience with adapting it likewise expanded; located in a sense of self-efficacy and agency unintentionally prompted by an English teacher that defined her writing, according to her, in every single college writing assignment; and located in moments of connection hosted in a combined curricular and extracurricular experience-all of which interacted with each other and which provided her with a sense of writing self.

In sum, we are just beginning to theorize the construct of the prior, but it is already clear that it casts a long shadow and that it taps a diverse set of factorsfrom those associated with formal schooling to others occurring in off-school sites. Accordingly, to help students transfer writing knowledge and practice into new sites of writing, Threshold Concept \#5-prior knowledge, experience, attitudes, and beliefs set the stage for writing and shape new writing experiences and learning - provides us with a very good place to begin.

\section{CONCLUSION}

The threshold concepts defined above are important for our writing studies discipline, as they speak to key rhetorical concepts and strategies required for writers to evolve throughout their college journeys. These threshold concepts represent the values and beliefs that shape a community of practice, both oursas instructors and educators of writing - and theirs - as writers and learners. Perhaps as important as epistemological participation in a discipline, though, is the ability to repurpose knowledge across the different writing situations within and beyond that discipline. We believe that the five threshold concepts outlined here encourage this repurposing by laying the groundwork for encouraging writers to be more successful in transferring knowledge and practice across contexts: from assignment to assignment within first-year composition; from first-year composition to other academic writing sites; and from first-year composition 
to other non-academic writing contexts (e.g., workplaces and community sites). We argue that first-year composition cannot be limited to the teaching of process, or to focusing on a particular theme, because foci like these hinder writers' abilities to actively discern and become metacognitively aware (or, in some instances, more metacognitively aware) participants in communities of practice surrounding them, a way of embodying and enacting knowledge that is supported by these five threshold concepts.

Moreover, for writers situated within a community of practice, discerning how to identify differences among that community and others helps them adapt composed knowledge to reflect the expectations of and purposes for varying communities of practice.

This analysis does point to the ways in which the intellectual work of our discipline can play for learners (and teachers) across contexts, as well. That is, writing courses that focus on identifying the role(s) that writing plays in communities of practice are situated within one such community of practice-our own of writing studies. At the same time, when writing courses focus on helping students to identify the boundaries of communities, that knowledge can foster the knowledge writers need to understand and identify roles important from one community to the next, helping them to move between contexts and across genres, using reflection to understand and use prior knowledge, experiences, attitudes, and beliefs as a guidepost, from one community of practice to the next. To be sure, this is foundational in that it fosters a type of knowledge associated with metacognitive awareness and the connection between that awareness and cultivation of strategies that is useful across contexts. One key to successful participation in a community of practice is the understanding that writing is a subject of study as well as an activity; when writing is only an activity and not a subject of study, it can be reduced to either a process or a performance. To become good writers able to analyze purposes, audiences, and contexts for writing and move flexibly among those, writers must study writing, use writing as a process, and understand writing as a performance that is a result of study.

Essentially, in order for writers to move from one community to another, they must be able to transfer knowledge about writing across contexts, first understanding the concept of context (not just a particular context), and second, they must be able to decontextualize the writing in one situation in order to re-conceptualize it to be repurposed for another. They must also be able to learn from explicit instruction in the next context, should it be offered. In other words, writers must learn to transfer successfully through explicit instruction and deliberate practice, which means tapping into prior knowledge. In the process, though, instructors (and others working with learners) must understand 
that writers tap into a larger constellation of the prior, including experiences, attitudes, and beliefs often interacting with one another; the prior is thus extraordinarily complex, orienting writers to writing tasks and setting the stage for new learning. We believe we should not discount the prior but instead need to articulate it, sometimes building on it and other times amending it, as we create opportunities in our classrooms for writers to develop key rhetorical strategies and practices that teach them to participate in the community of practice, but that also give them content they can transfer. One such rhetorical strategy is that of genre awareness, a metacognitive understanding of genre that contributes to the ability to successfully transfer, and a concept that, when mastered, decreases writing anxiety and builds students' confidence in their own writing. In order to achieve a level of metacognition about genre awareness or any rhetorical strategy that will enable successful transfer, reflection must be employed. As a deliberate mode of inquiry and when used as part of a writer's process, reflection will enhance a writer's ability to transfer knowledge. Specifically, the development of an individual writer's theory of writing helps him or her recall, reframe, and relocate knowledge and practices in new and different writing contexts. As students learn to participate more fully in communities of practice, and as they understand how to successfully transfer the knowledge and practices of those communities to multiple contexts within and beyond them, the threshold concepts identified here remain critical. These five threshold concepts of writing provide a framework upon which students can build a foundation of knowledge about writing and from which they can cultivate the ability to understand the concepts foundational to a community, to recognize the roles those concepts serve within that community, and to be able to discern the boundaries between one community and the next.

\section{NOTES}

1. All student names included here are pseudonyms.

2. For more information on the Teaching for Transfer curricular model and for and expanded discussion of the research study excerpted in this section, see Yancey et al., 2014).

3. For an example of the last type, see the Vander Lei and Kyburz (2005) edited collection on faith in the classroom.

4. The prior also includes other dispositions (Driscoll \& Wells, 2012; Wardle, 2012), point of departure (Slomp, 2010); Yancey, Robertson \& Taczak, 2014), and anxiety (Cleary, 2013; Baird \& Dilger, 2013).

5. This episode also appears to constitute what Yancey et al. (2014) call a critical incident. See Writing Across Contexts, especially Chapter Four. 


\section{REFERENCES}

Adler-Kassner, L. \& Majewski, J. (2015). Extending the invitation: Threshold concepts, professional development, and outreach. In L. Adler-Kassner \& E. Wardle (Eds.), Naming what we know: Threshold concepts in writing studies (pp. 186-202). Logan, UT: Utah State University Press.

Adler-Kassner, L., Majewski, J. \& Koshnick, D. (2012). The value of troublesome knowledge: Transfer and threshold concepts in writing and history. Composition Forum, 26. Retrieved from http://compositionforum.com/issue/26/troublesome -knowledge-threshold.php.

Adler-Kassner, L. \& Wardle, E. (Eds). (2015). Naming what we know: Threshold concepts in writing studies. Logan, UT: Utah State University Press.

Baird, N. \& Dilger, B. (2013, June). Writing transfer and the first-generation transfer student. Paper presented at the Elon University Conference on Critical Transitions: Writing and the Question of Transfer, Elon, NC.

Bawarshi, A. (2000). The genre function. College English, 62(3), 335-360.

Bawarshi, A. \& Reiff, M. J. (2010). Genre: An introduction to history, theory, research, and pedagogy. Fort Collins, CO: The WAC Clearinghouse/Parlor Press. Available at http://wac.colostate.edu/books/bawarshi_reiff/.

Bazerman, C. (2002). Genre and identity: Citizenship in the age of the internet and the age of global capitalism. In R. Coe, L. Lingard \& T. Teslenko (Eds). The rhetoric and ideology of genre (pp. 13-38). Cresskill, NJ: Hampton Press.

Beach, K. (2003). Consequential transitions: A developmental view of knowledge propagation through social organizations. In T. Tuomi-Gröhn \& Y. Engeström (Eds.), Between school and work: New perspectives on transfer and boundary-crossing (pp. 39-61). Amsterdam, NL: Emerald Group.

Beaufort, A. (2007). College writing and beyond: A new framework for university writing instruction. Logan, UT: Utah State University Press.

Bergmann, L. S. \& Zepernick, J. S. (2007). Disciplinarity and transference: Students' perceptions of learning to write. WPA: Writing Program Administration, 31(1/2), $124-149$.

Brandt, D. (2001). Literacy in American lives. Cambridge, MA: Cambridge University Press.

Bransford, J. D., Pellegrino, J. W. \& Donovan, M. S. (2000). Learning and transfer. In J. D. Bransford, J. W. Pellegrino \& M. S. Donovan (Eds.), How people learn: Brain, mind, experience, and school: Expanded edition (pp. 51-78). Washington, DC: National Academies Press.

Brunetta, J. (2013, November 27). A Massachusetts student writes: How MCAS changed my education [Web log post]. Retrieved from http://blogs.edweek.org /teachers/living-in-dialogue/2013/11/a_student_writes_how_mcas_dera.html.

Burton, V. T. (2010). Activity systems, genre, and research on writing across the curriculum. College Composition and Communication, 61(3), 583-596.

Carroll, L. A. (2002). Rehearsing new roles: How college students develop as writers. Carbondale, IL: Southern Illinois University Press. 
Carter, M. (1990). The idea of expertise: An exploration of cognitive and social dimensions of writing. College Composition and Communication, 41(3), 265-286.

Clark, I. \& Hernandez, A. (2011). Genre awareness, academic argument, and transferability. The WAC Journal, 22, 65-78.

Cleary, M. N. (2013). Flowing and freestyling: Learning from adult students about process knowledge transfer. College Composition and Communication, 64(4), 661-687.

Conference on College Composition and Communication. (2013). Listening Tour. Retrieved from http://www.ncte.org/cccc/listening-tour.

Dean, D. (2008). Genre theory: Teaching, writing, and being. Urbana, IL, National Council of Teachers of English.

Devitt, A. J. (1993). Generalizing about genre: New conceptions of an old concept. College Composition and Communication, 44, 573-586.

Downs, D. \& Wardle, E. (2007). Teaching about writing, righting misconceptions: (Re)envisioning "first-year composition" as "introduction to writing studies." College Composition and Communication, 58(4), 552-584.

Driscoll, D. L. \& Wells, J. H. M. (2012). Beyond knowledge and skills: Writing transfer and the role of student dispositions. Composition Forum, 26. Retrieved from http://compositionforum.com/issue/26/beyond-knowledge-skills.php.

Elon Statement on Writing Transfer. (2015). Retrieved from http://www.centerfor engagedlearning.org/elon-statement-on-writing-transfer/.

Estrem, H. (2015). Threshold concepts and student learning outcomes. In L. Adler-Kassner \& E. Wardle (Eds.), Naming what we know: Threshold concepts in writing studies. Logan, UT: Utah State University Press.

Gogan, B. (2013). Reading at the threshold. Across the Disciplines, 10(4). Retrieved from http://wac.colostate.edu/atd/reading/gogan.cfm.

Hillocks, G. (2002). The testing trap: How state writing assessments control learning. New York: Teachers' College Press.

Johns, A. M. (Ed.). (2002). Genre in the classroom: Multiple perspectives. Mahwah, NJ: Lawrence Erlbaum Associates.

Kreber, C. (2010). Academics' teacher identities, authenticity and pedagogy. Studies in Higher Education, 35(2), 171-194.

Lave, J. \& Wenger, E. (1991). Situated learning: Legitimate peripheral participation. Cambridge, MA: Cambridge University Press.

Lunsford, A. (2015). Writing is informed by prior experience. In L. Adler-Kassner \& E. Wardle (Eds.), Naming what we know: Threshold concepts in writing studies. Logan, UT: Utah State University Press.

McCarthy, L. (1987). A stranger in strange lands: A college student writing across the curriculum. Research in the Teaching of English, 21(3), 233-265.

McGowan, S. (2014). Embedding threshold concepts in large lecture courses: An examination of uptake of disciplinary actions (Unpublished doctoral dissertation). University of California, Santa Barbara, CA.

Meyer, J. H. F. \& Land, R. (2003). Threshold concepts and troublesome knowledge: Linkages to ways of thinking and practising within the disciplines. In C. Rust (Ed.), 
Improving student learning — Theory and practice ten years on (pp. 412-424). Oxford, UK: Oxford Centre for Staff and Learning Development.

Meyer, J. H. F. \& Land, R. (2005). Threshold concepts and troublesome knowledge (2); Epistemological considerations and a conceptual framework for teaching and learning. Higher Education, 49, 373-388.

Meyer, J. H. F. \& Land, R. (Eds.). (2006). Overcoming barriers to student understanding: Threshold concepts and troublesome knowledge. London: Routledge.

Meyer, J. H. F., Land, R. \& Baillie, C. (2010). Editors' preface. In J. H. F. Meyer, R. Land \& C. Baillie (Eds.), Threshold concepts and transformational learning (pp. ix-xlii). Rotterdam, NL: Sense Publishers.

Michaud, M. J. (2011). The "reverse commute": Adult students and the transition from professional to academic literacy. Teaching English in the Two-Year College, 38(3), 244-258.

Miller, C. (1984). Genre as social action. Quarterly Journal of Speech, 70, 151-167.

Moore, J. L. (2012). Mapping the questions: The state of writing-related transfer research. Composition Forum, 26. Retrieved from http://compositionforum.com /issue/26/map-questions-transfer-research.php.

Nowacek, R. S. (2011). Agents of integration: Understanding transfer as a rhetorical act. Carbondale and Edwardsville, IL: Southern Illinois University Press.

Perkins, D. N. \& Salomon, G. (1992). Transfer of learning. In T. Plomp \& D. P. Ely (Eds.), International encyclopedia of education (2nd ed.) (pp. 2-13). Oxford, UK: Pergamon Press.

Reiff, M. \& Bawarshi, A. (2011). Tracing discursive resources: How students use prior genre knowledge to negotiate new writing contexts in first-year composition. Written Communication, 28(3), 312-337.

Robertson, L. (2011). The significance of course content in the transfer of writing knowledge from first-year composition to other academic writing contexts (Unpublished doctoral dissertation). Florida State University, Tallahassee, FL.

Robertson, L., Taczak, K. \& Yancey, K. B. (2012). Notes toward a theory of prior knowledge and its role in college composers' transfer of knowledge and practice. Composition Forum, 26. Retrieved from http://compositionforum.com/issue/26 /prior-knowledge-transfer.php.

Roozen, K. (2010). Tracing trajectories of practice: Repurposing in one student's developing disciplinary writing processes. Written Communication, 27(3), 318-354.

Russell, D. R. (1997). Rethinking genre and society: An activity theory analysis. Written Communication, 14(4), 504-554.

Russell, D. R. \& Yañez, A. (2002). "Big picture people rarely become historians": Genre systems and the contradictions of general education. In C. Bazerman \& D. R. Russell (Eds.), Writing selves/writing societies: Research from activity perspectives. Fort Collins, CO: The WAC Clearinghouse and Mind, Culture and Activity. Retrieved from http://wac.colostate.edu/books/selves_societies/russell/.

Slomp, D. (2010, March). Rethinking transfer, rethinking pedagogy. Paper presented at the meeting of Conference on College Composition and Communication, Louisville, KY. 
Sommers, J. (2011). Reflection revisited: The class collage. Journal of Basic Writing, (30)1, 99-129.

Sullivan, F. J. (1997). Calling writer' bluffs: The social production of writing ability in university placement testing. Assessing Writing, 4(1), 53-81.

Swales, J. (1990). Genre analysis. Cambridge, UK: Cambridge University Press.

Taczak, K. (2011). Connecting the dots: Does reflection foster transfer? (Unpublished doctoral dissertation). Florida State University, Tallahassee, FL.

Taczak, K. (2015). Reflection is critical in the development of writers. In L. AdlerKassner \& E. Wardle (Eds.), Naming what we know: Threshold concepts in writing studies (pp. 78-84).Logan, UT: Utah State University Press.

Tuomi-Gröhn, T. \& Engeström, Y. (Eds.) (2003). Between school and work: New perspectives on transfer and boundary-crossing. Amsterdam, NL: Emerald Group.

Vander Lei, E. \& Kyburz, B. (2005). Negotiating religious faith in the composition classroom. Portsmouth, NH: Heinemann.

Villanueva, V. (1993). Bootstraps: From an American academic of color. Urbana, IL: National Council of Teachers of English.

Wardle, E. (2007). Understanding "transfer" from FYC: Preliminary results of a longitudinal study. WPA: Writing Program Administration, 31(1/2), 65-85.

Wardle, E. (2009). "Mutt genres" and the goal of FYC: Can we help students write the genres of the university? College Composition and Communication, 60(4), 765-789.

Wardle, E. (2012). Creative repurposing for expansive learning: Considering "problemexploring" and "answer-getting" dispositions in individuals and fields. Composition Forum, 26. Retrieved from http://compositionforum.com/issue/26/creative -repurposing.php.

Wenger, E. (1998). Communities of practice: Learning, meaning, and identity. Cambridge, UK: Cambridge University Press.

Wineburg, S. (2001). Historical thinking and other unnatural acts: Charting the future of teaching the past. Philadelphia: Temple University Press.

Yancey, K. B. (1998). Reflection in the writing classroom. Logan, UT: Utah State University Press.

Yancey, K. B., Robertson, L. \& Taczak, K. (2014). Writing across contexts: Transfer, composition, and sites of writing. Logan, UT: Utah State University Press. 



\section{CHAPTER 2}

\section{ATTENDING TO THE SUBJECT IN WRITING TRANSFER AND ADAPTATION}

\section{Stuart Blythe}

As composition has sought to understand fundamentals like rhetorical situations, literacy development, and genre theory, it has done so by, first, gravitating toward context. Only later does it self-correct to include the impact of the individual learner.

— Driscoll \& Wells, 2012

A good deal of social theory ... has treated agents as much less knowledgeable than they really are.

Writing in 1990, Anson and Forsberg could state confidently that "virtually no research . . . has explored the transitions that writers make as they move into new and unfamiliar writing contexts" (p. 204). By transitions, they meant the ways that students adapted as they moved from classrooms to workplaces. Just over 20 years later, enough research has been reported to prompt Brent's (2011) synthesis of such studies, ${ }^{1}$ which he sorts into three categories: closing-the-gap, glass-half-empty, and glass-half-full.

In closing-the-gap studies, Brent says, scholars study workplace communication in part to describe for instructors the activities that happen there (2011, p. 398). Such studies are motivated by at least two major assumptions: (1) teachers of professional writing cannot merely teach a series of idealized, generic forms, and (2) classroom practices should align with workplace practices_at least to some extent (p. 389). A recent example of a closing-the-gap study includes Hannah's (2011) exploration of legal discourse, which he undertook in order to help technical communication students understand the legal implications of their work. Two other examples include Brumberger's (2007) and Kimball's (2013) explorations of visual design practices and lore among practitioners, educators, and students. As Anson and Forsberg have noted, these studies "explore only in a secondary way what it means to become such a writer" (1990, p. 227). In other words, they show what writers do in a 


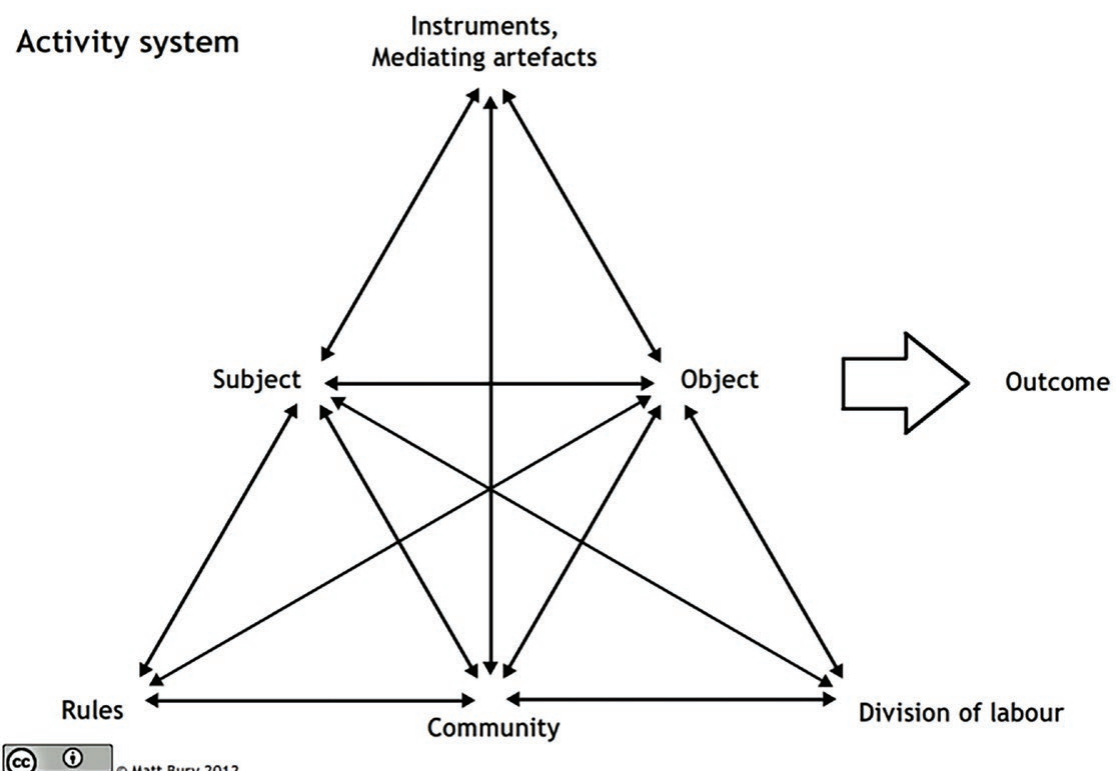

Figure 2.1. Diagram of an Activity System. Source: http://en.wikipedia.org/wiki/File:Activity_system.png

given situation without explicitly questioning how a novice may gain entry to it, and perhaps at what costs.

As compared to closing-the-gap studies, Brent says, two other types of studies do question how a novice may gain entry to a new domain. In glass-halfempty studies, scholars conclude that the possibility of transfer seems doubtful, or at least problematic (2011, p. 399). Brent suggests that one reason for such pessimism is the theory that these scholars often invoke. Specifically, studies that fall into this glass-half-empty category are often informed by rhetorical genre theory, activity theory, situated learning theory, or some combination of the three. As Brent argues, these three theories prompt researchers to see rhetorical performances as "deeply bound with particular exigencies" (2011, p. 399). This problem is illustrated by the triangle diagram used to describe third-generation activity theory. Figure 2.1 shows that activity theory includes multiple reminders to examine situational factors such as rules, mediating artifacts, and division of labor. While the triangle offers a powerful heuristic for examining a situation, ${ }^{2}$ it does not prompt researchers to consider how a subject adapts from one situation to another. The subject is essentially a black box in the theory. 
Influenced in part by activity theory, rhetorical genre theory recognizes that genres are always situated within a specific context, which means that even two seemingly similar types of documents (such as Introduction, Methods, Results, and Discussion [IMRD] reports) can differ significantly from situation to situation. Freedman, Adam, and Smart (1994) wrote that because of this difference, "None of this [workplace] know-how will have been made available through [in-class] simulations, no matter how realistically or elaborately staged" (p. 221; see also Spinuzzi, 1996, p. 299). This glass-half-empty theory implicitly assumes that students will be unable to compare and contrast one setting and another, which runs the risk described in the epigraph by Giddens (1984).

Whereas glass-half-empty studies are pessimistic about the possibilities of transfer, Brent says glass-half-full studies "show increasing interest in strategies that can, if not be transferred neatly to, at least be reapplied to other situations" (2011, p. 409). In this camp, Brent includes at least two kinds of studies (although he does not explicitly identify this distinction). Some studies, such as those by Artemeva, Logie, and St-Martin (1999) and Russell and Fisher (2009), describe classroom practices designed to facilitate professional writing transferpractices such as online simulations of workplace scenarios. In contradiction to Freedman et al. (1994), Russell and Fisher argue that the spread of computermediated communication and classroom management systems make simulations rich enough to aid a student's ability to adapt learning from one setting to another (2009, p. 5). Brent (2011) himself offers pedagogical advice for facilitating transfer, including mindful abstraction, toward the end of his article.

Another kind of glass-half-full study argues that students may accomplish more than glass-half-empty studies suggest. Whereas the first kind of glass-halffull study focuses on affordances created by instructors and learning systems, this second kind of study assumes that previous studies have underestimated, or overlooked, the adaptability that students bring to new tasks. Brent suggests, for example, that "most students seemed to bring to their workplace environment a flexible rhetorical knowledge" (2012, p. 585). Similarly, Smart and Brown (2002) note that the interns they observed, "having previously developed the expert writing practices needed to perform well in academic activity systems ... were able to be situate and extend —or reinvent—-those practices in their new worksites" (p. 122). That is, students were capable of more than some theorists have suggested.

\section{ATTENDING TO THE SUBJECT IN MODELS OF TRANSFER AND ADAPTATION}

If it is true that some social theories may incline researchers toward glass-halfempty studies because they treat the subject as a black box, and if it is true 


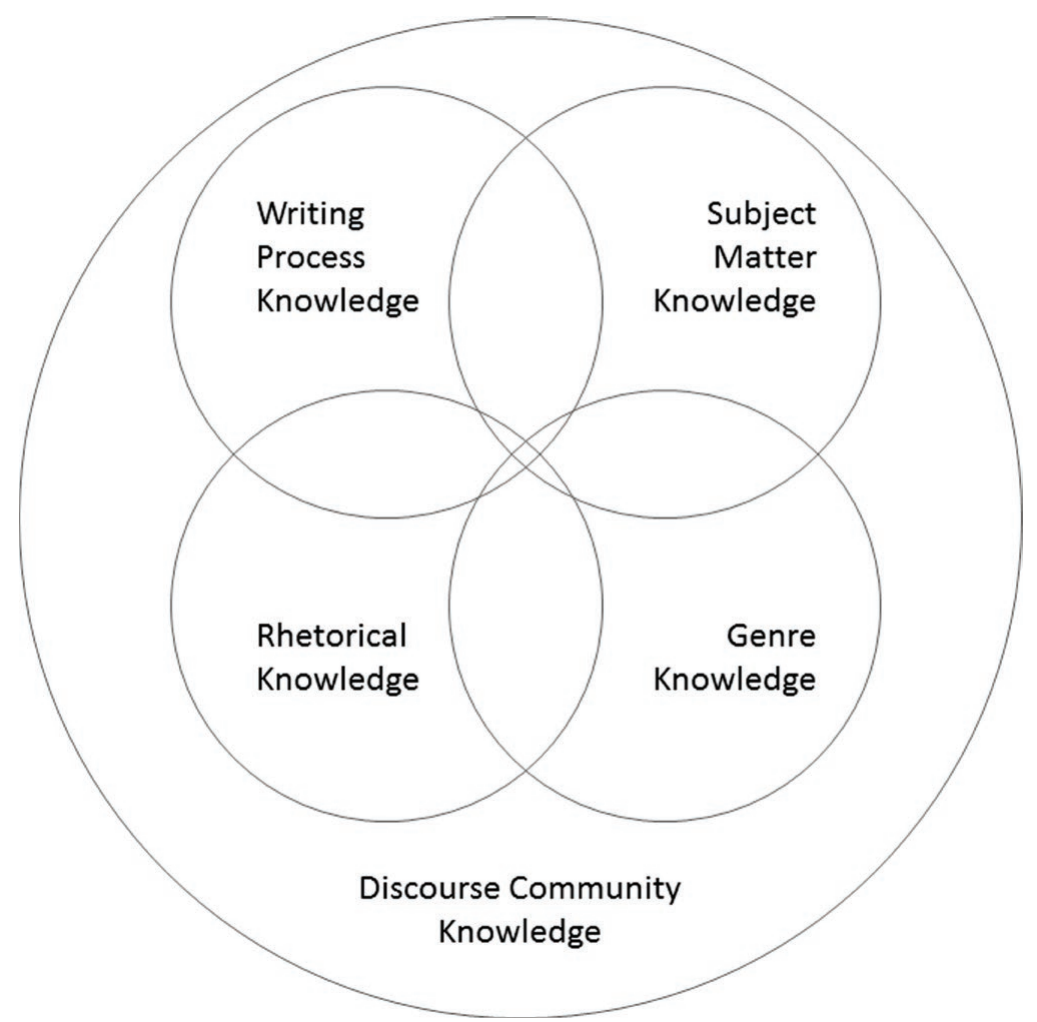

Figure 2.2. Diagram of Beaufort's model of writing expertise (2007, p. 17).

that learners are capable of more than such theories have assumed, then future research into transfer and adaptability in writing - studies informed by social theories of activity or genre-must pay more attention to ways that subjects adapt from one situation to another. Such a model must account for phenomena at several levels: knowledge domains, problem solving, and affordances. In order to engage successfully in a new writing situation, a person must have some grasp of several domains of knowledge, including the subject matter, genre to be produced, and the rhetorical and procedural preferences of a discourse community. In order to put that domain knowledge into practice, a person must be able to solve a problem (or exigence, to use a more neutral term), which includes construing a situation, planning an action, self-regulating as that plan is carried out, and reflecting critically both during and after the fact. In order to be motivated to solve a problem, a person needs to believe that personal and social affordances will make the task possible and worthwhile. Details for these three levels are described in the rest of this section. 


\section{KNOWLEDGe Domains}

As Figure 2.2 illustrates, Beaufort (2007) argues that experienced writers put five domains of knowledge into practice. A theory of writing transfer and adaptation should account for these domains:

- Discourse Community: Beaufort describes a discourse community as a group of people with shared goals, interests, values, and means of communication (p. 18).

- Subject Matter: Members of a discourse community share some degree of background knowledge and awareness of current issues. ${ }^{3}$ Such knowledge may also include "knowing how to frame the inquiry, what kinds of questions to ask or analytical frameworks to use in order to 'transform' or inscribe documents with new meaning(s)" (p. 19).

- Genres: Members of a discourse community must also recognize, and know how to compose, preferred forms of discourse (p. 20). Forms can refer to macro-level issues — such as the organization and purpose of an IMRD report-to micro-level issues-such as a preference for active versus passive voice.

- Rhetorical Knowledge: Members of a discourse community must understand the purposes of a text, the needs and expectations of relevant audiences, and how best to communicate with that audience. And they must be able to do these things within the material and social limitations of a given situation (p. 20).

- Process Knowledge: Given the material and social limitations of a situation, members of a discourse community must know how to proceed through a rhetorical task (p. 20).

Beaufort claims her taxonomy should be seen as a set of overlapping categories: scholars of writing should not assume "either that those categories are fixed and discreet, or that learning is a rote affair, a matter of simply 'banking' such knowledge" (2007, p. 21). This makes Beaufort's choice of a Venn diagram an appropriate image for her model, which provides a rich picture of the concepts and assumptions that writers must call upon. But, like the activity theory triangle, Beaufort's Venn diagram leaves the subject underdeveloped. In a sense, her model accounts for macro-level issues without offering a vocabulary for describing other meso- and micro-level issues, such as problem solving and motivation. 


\section{Problem Solving}

As Brent (2011) and Billet (2012) note, the literature on learning and problem solving is remarkably consistent—at least in its general outline. Despite the use of "distinct concepts and epistemological positions," Billet writes, most descriptions of problem solving and learning "refer to the same foundational processes; that is, individuals aligning what they experience with what they know and acting upon what they have experienced" (2012, p. 9). A comparison of Billet's model with Anson and Forsberg's (1990) illustrates this point. Billet's model of problem solving has these parts:

- Construal occurs when individuals "seek to comprehend, categorize, identify and/or recognize what they encounter" (2012, p. 11) - that is, when individuals attempt to make sense of a new situation by recalling previous, potentially related experiences.

- Reconciliation occurs when individuals attempt to align "what is experienced with what [they] know about what has been comprehended, categorized, identified or otherwise recognized" (2012, p. 11) - that is, when individuals attempt to align a new situation with their memories of past experiences (memories evoked during construal).

- Construction occurs when individuals "generat[e] a particular response as a result of the reconciliation process" (2012, p. 12). Of many possible responses, one may involve "selectively deciding whether this task is worth investing energy in" (2012, p. 12).

Writing more than 20 years before Billet, Anson and Forsberg (1990) identify similar phases in an intern's transition to the workplace:

- Expectation occurs, usually before the internship begins, when "the writer builds a vision, that is, a social construct, of him- or herself working and writing in a new professional setting" (p. 208). Anson and Forsberg's expectation sounds like a moment of the phase Billet (2012) calls construal. Both phases involve anticipating and categorizing experiences.

- Disorientation occurs when an individual realizes that his or her expected construct clashes with the realities of the workplace. "And this in turn can lead to intense frustration and a sense of failure" (Anson $\&$ Forsberg, 1990, p. 208). This sounds like a phase that occurs during what Billet (2012) calls reconciliation, when an intern realizes that his or her attempt to align a new situation with past experiences may be more difficult than expected. 
- Transition and resolution occur "as the writer begins to establish a role and forms new knowledge for adaptation" (Anson \& Forsberg, 1990, p. 208). As this phase progresses, an intern "may begin to take on greater initiative, understanding what is expected and forming new self-concepts" (Anson \& Forsberg, 1990, p. 208). To do this, an intern must of course construct a response to the disorientation.

In Billet's and Anson and Forsberg's taxonomies, the initial phases of problem solving occur when an individual perceives a situation and a problem to be solved within it. That person then calls upon memories of previous experiences to try to make sense of the one currently being faced. If a person decides to proceed, he or she creates, executes, and monitors a reaction-a process that Anson and Forsberg call transition and resolution and that Billet calls reconciliation and construction.

The terms used to describe the phases of problem solving begin to paint a picture of subjects working within novel or familiar domains of knowledge. This description could be taken even further with Bandura's (2001) social-cognitive model of human agency. Bandura's model has four parts:

- Intention is a representation of a future course of action and a "proactive commitment to bringing it about" (2001, p. 6). In this phase, a person constructs a plan in response to an exigence and also decides whether such a plan is worth pursuing at all. This could be considered a first sub-step in Billet's (2012) construction phase and Anson and Forsberg's (1990) transition and resolution phase.

- Forethought occurs when the intention is converted into "motivators and regulators of behavior" (Bandura, 2001, p. 7). If a subject decides that a response is worth pursuing, he or she anticipates the most advantageous way to act on her intentions.

- Self-reactiveness occurs when a person carries out intention through those motivators and regulated behaviors (Bandura, 2001, p. 8). This is similar to what Schön (1983) would call reflection-in-action. Self-reactiveness occurs as a person continually monitors behavior.

- Self-reflectiveness occurs a bit later than self-reactiveness. Selfreflectiveness is the metacognitive capability that occurs when an individual "reflect[s] upon oneself and the adequacy of one's thoughts and actions" (Bandura, 2001, p. 10).

Whether one would want to use Bandura's categories in addition to Billet's would of course depend on the level of detail, the granularity, needed to describe human behavior in a particular study. A researcher could decide even to go one step further. 


\section{Personal and Social Affordances}

First introduced by Norman (1990), an affordance is a perception that leads a subject to believe that an action is possible. Under this definition, an affordance is not objective; it is perceptual. The important question is whether a subject perceives that certain factors will make the effort worthwhile. If, as Billet says, individuals must "selectively decide whether a task is worth the trouble" (2012, p. 12), then they must perceive in most cases that a task can be accomplished through their own efforts. Personal affordances are those beliefs, those habits of mind, that may incline a person to act. Driscoll and Wells (2012) offer a helpful description of such habits of mind. Personal affordances also include concepts relating to self-efficacy and writing (see, for instance, Maimon (2002) and McCarthy, Meier \& Rinderer (1985)).

Not only are there internal, psychological affordances (such as self-efficacy), but also the situation itself may provide affordances-assuming that the subject perceives them. As Billet argues, a subject's ability to adapt must be mediated "both internally (i.e., intra-psychologically) as well as inter-psychologically (from suggestions beyond individuals)" (2012, p. 6). In the case of a new intern, that student needs to perceive that resources are available to help-resources such as mentors, generic models, and reliable sources of subject matter content. In other words, a subject must perceive that he or she is up to the task, not only through his or her own abilities, but also because the situation will make it possible to employ those abilities fruitfully.

\section{Assembling The Model}

Taking into account problem solving and personal and social affordances, a more detailed picture of the subject can be developed and placed at the center of Beaufort's (2007) diagram. Figure 2.3 offers a sense of an individual subject acting within the five domains of knowledge. The boxes to the left in the figure are like an inset on a map. This figure is an attempt to "open" that black box which has remained closed in some social theories of activity. By opening that box, researchers may be able to construct a more detailed understanding of how subjects adapt to new writing situations. This possibility is demonstrated in the remainder of this chapter.

\section{SEEKING EVIDENCE OF TRANSFER AND ADAPTATION IN VIDEO JOURNALS}

Brent $(2011,2012)$ argues that transfer and adaptation will be visible if researchers look in the right places and in effective ways-an assertion similar to Anson 


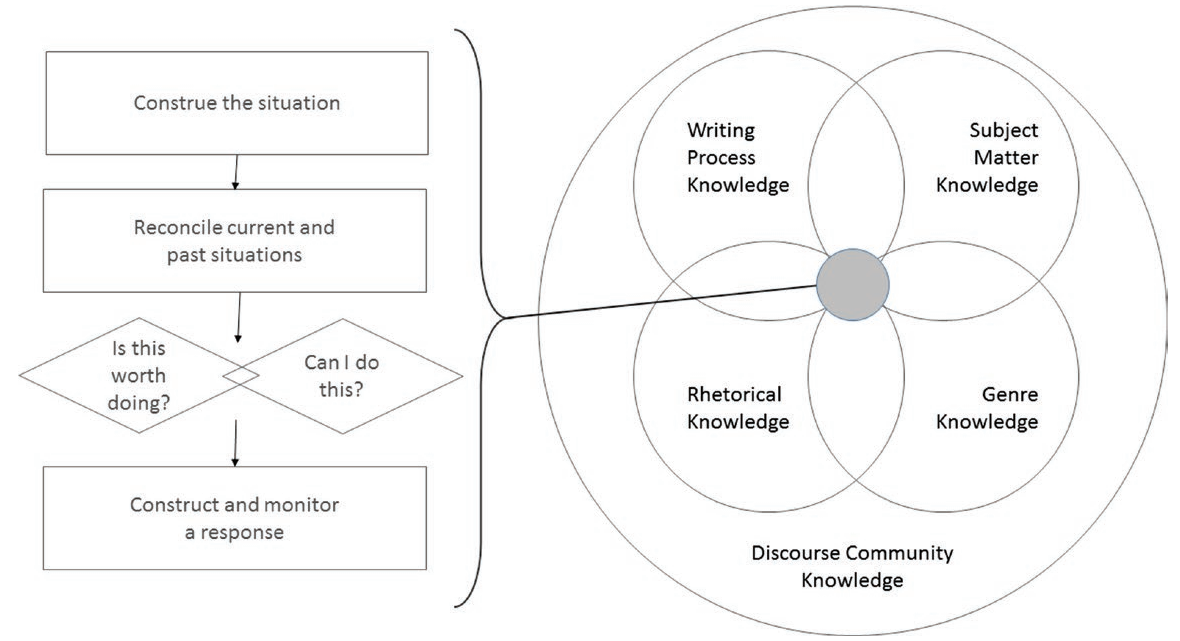

Figure 2.3. Attending to the subject within Beaufort's model of writing expertise. Based on Beaufort's (2007) model of writing expertise.

and Forsberg's (1990). In both cases, researchers claim that transfer will be visible if one looks for "an ongoing process of adapting to a social setting, involving not only the idiosyncratic textual features of a discourse community but a shifting array of political, managerial, and social influences as well" (Anson \& Forsberg, p. 225). In this section, I will use the concepts developed previously to analyze a collection of screencast video journals created by professional writing interns during the 2011-2012 academic year. These interns represent two different professional writing programs-my own at Michigan State University and another the University of California, Santa Barbara. ${ }^{4}$

In both cases, the interns were required to use screencast software to create regular video journal entries. They were encouraged to use screencast software called Jing, ${ }^{\circledR}$, which at the time enabled students to create audio-video recordings from their computer screens. Using Jing, students could present any number of windows on their computer screen and narrate as they went along. Interns at one campus were each required to create six journals throughout the semester. Interns at the other campus were required to create three. In all, more than 120 separate video journals were created.

Students had some flexibility in creating their video journals. They were given a handout with a series of prompts (see Appendix B). Among those prompts were these: 
- Document your work on a particular writing task. Possible tasks include such activities as writing an introduction or conclusion, searching for credible information, deciding how to organize information, and managing multiple documents.

- Document your reaction to feedback from your supervisor.

- Document and reflect on a classroom-workplace disconnect by completing sentences like these:

- In ... class, I learned ...

- But at work, it's different because...

- Here's how I've resolved that disconnect ... .

Students were also given a few guidelines for creating the screencasts. Specifically, students were encouraged to mix images and words and to show something new (i.e., the on-screen images should change) at least every minute-preferably more. Students were also encouraged to show themselves in action. For example, instead of simply saying, "I wrote a press release" and showing the finished press release, students were encouraged to say, "Here's how I began to write a press release" and then to show examples (if they looked for examples) and talk about the features they noticed in them. A student might even say something like, "Given what I noticed, here's how I started writing," and then type an intro paragraph.

The rationale behind using video journals comes from Geisler and Slattery (2007) and Swarts (2004). Namely, the affordances of screencasts change the dynamic of what gets recorded and how it is understood, because screencasts (which Geisler and Slattery call video screen capture) can gather a variety of phenomena simultaneously, including keystrokes, mouse movement, transitions between various windows, and student commentary. (See also Vincelette \& Bostic, 2013.) As Figure 2.4 illustrates, students could show multiple files as they talked about their work. The window to the left in Figure 2.4 shows a document that a student was asked to edit, and the window to the right shows a memo that the student wrote for her supervisor in response to that editing task. During the video, the student described her editing process and explained why she made the changes and wrote the queries that she did. Through this process, we hoped that using screencasts to create a journal entry, or simply turning on the screencast software to record writing activity, "would make visible phenomena that might otherwise have gone unnoticed" in traditional journals and work logs (Geisler $\&$ Slattery, p. 187). That is, screencast journals promised to alter the dynamic of traditional work logs and internship journals.

The screencasts replaced traditional work logs but supplemented other relatively standard assignments during the semester: namely a learning goals memo, a mid-semester progress report, and a final reflection. In other words, the data 


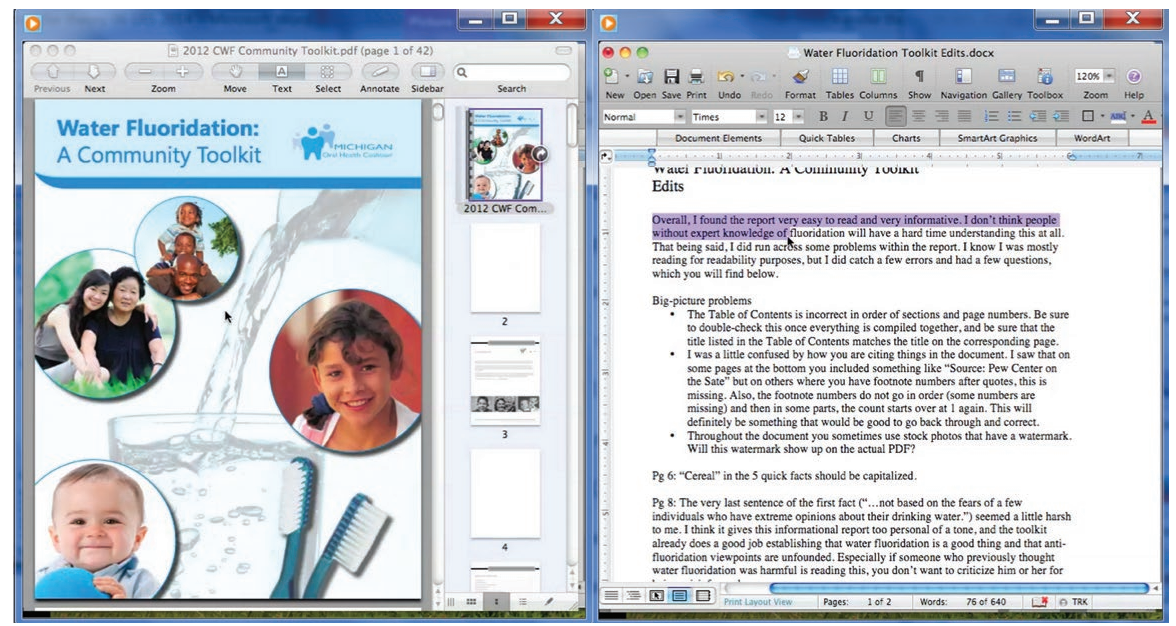

Figure 2.4. Screencasting enables students to narrate as they show multiple files, point to specific places in those files, and even create new files.

for this study are similar to data gathered by Anson and Forsberg (1990) and Smart and Brown (2002). In addition, students in the internship courses were required early in the semester to read Anson and Forsberg (1990) and complete a quiz on the reading. Students were asked to respond to four questions:

1. Anson and Forsberg say that interns went through "a cycle of transition" that included three phases. Name those three phases and describe each one briefly (a couple sentences for each).

2. Have you experienced, or are you experiencing, any of the three phases that Anson \& Forsberg describe? If so, which? What's happening? Or what happened?

3. During interviews with Anson and Forsberg, some students reported feeling occasional frustration. What caused their frustrations? How did they overcome them?

4. How might reading about the experiences of students described in Anson and Forsberg help you anticipate what will happen in your internship?

\section{WHAT THE DATA SUGGEST ABOUT TRANSFER AND ADAPTATION}

In this section, evidence of transfer and adaptation is presented primarily in vignettes. One of the challenges inherent in presenting data on transfer is the 
fact that such data is often best understood in narrative form. To find indications of construal, reconciliation, and construction, one needs to look for stories in which characters (subjects) face some challenge and attempt to resolve it. For that reason, this section is arranged into vignettes, which are grouped into sets that best illustrate certain aspects of problem solving, though the vignettes typically show more than one type of action.

\section{IndicATIONS OF CONSTRUAL AND RECONCILIATION}

The screencasts show how students understand their attempts to construe and reconcile new writing situations. Some accounts from the screencasts illustrate this clearly, although they do not reveal what influenced each act of construalthat is, they do not indicate what kinds of previous knowledge students are calling upon. The next two vignettes illustrate this point.

- One of Emily's primary responsibilities at her internship was to seek ideas and write stories for an organization's newsletter. In one article, she wrote about a town that acted in a way that opposed the values that her organization promotes. As she construed the situation, Emily thought newsletter readers might be interested in this conflict between the town's actions and her organization's values. Her supervisor disagreed, saying that newsletter articles should be "positive." The articles should not describe situations that might present a challenge to the organization's mission and values. Emily discarded her first article and then wrote a new one.

- Irene described writing a letter to alumni of the on-campus program for which she worked. Irene started the letter by inviting them to send information. Her version of the letter began, "We miss having you on campus and would like to know what you're doing." It then invited readers to fill out an enclosed form. Next, the letter described a recent event sponsored by the program. Irene believed this to be the most effective arrangement of the letter because, as she construed the situation, she worried that readers would be uninterested in the event and not read the entire letter. She worried that they would miss the invitation to send in the response card, which she construed as the primary purpose of the letter. Irene's supervisor disagreed and asked that the order be changed. He wanted the event description (which he called "the give") first, and the invitation (which he called the "ask") second. Because he referred to "the give" and "the ask," it seems likely that Irene's supervisor had a generic arrangement in mind. Although 
Irene was not convinced that the supervisor's arrangement was best, she revised the letter according to his preferences.

Although the two preceding cases do not reveal exactly where each student gained the knowledge that she used to construe the task, they do reveal students' conscious efforts at understanding the rhetorical situation and constructing an appropriate response. In other cases, students identify the previous knowledge and experiences that they called upon in order to construe a rhetorical situation.

- Janice worked for a state senator during her internship. One of her most common tasks involved responding to constituents' letters. Janice said that learning about "ethos, pathos, and logos" was important for her. She claimed that she had learned about these concepts in a sophomore-level introduction to professional writing class, and that she had later encountered the concepts in two other professional writing courses. She explained that she was always careful to have each letter address the reader's comments and questions (logos), use credible sources of information (ethos), and convey a sense that the senator understood the constituent's concerns (ethos and pathos). In this case, Janice used past lessons to guide the construction of constituent letters.

- Hillary was asked to create an online feedback-reporting form that would allow members of a steering committee to gather and eventually analyze information. The form gathered feedback submitted by people on campus and presented it in tabular layout for the committee to use. Hillary said that her process of composing and testing the form was influenced by lessons she had learned about usability and web design in a core professional writing course on web authoring. Hillary perceived that lessons about usability could be adapted from a previous situation (testing websites) to the current situation (testing a form).

- Ed's task in his internship was to review and revise a set of fundraising letters for a local public broadcasting station. His supervisor wanted to know two things: (1) whether the letters could be worded and arranged more effectively, and (2) whether each letter was being sent at the most appropriate time. To do that, Ed began by recalling how a junior-level course on writing for non-profits had taught him to start a job by reviewing an organization's communication assets because a lot of "the values of the organization ... comes out in the communication materials." He also said that he had learned basic principles for writing fund appeals and that the course "has definitely been one of my best resources" during the internship. 
- Karen was asked by her supervisor to create a list of concerts and promoters for the upcoming year. The music promotion group for which she worked wanted to know what other groups were doing. Although Karen began by creating a text-only list, she eventually created a spreadsheet in Excel. In one of her screencasts, she compares the columns of her Excel spreadsheet to the sections of a research paper. Column headings, Karen says, are like subject headings. And the text in each column is like paragraphs in a section. In construing her writing task, Karen construes connections between one genre and form (the research paper) and another (the Excel list of tour promoters and acts).

In cases such as these, the screencasts suggest that students do draw upon their memories of previous experiences and genres. Sometimes, though, students' attempts to construe and reconcile a new task were not so successful, at least not immediately.

- Sally reported that she had been asked to write a press release at her internship. Because she had learned to write press releases in an advertising class, she felt that she understood the genre. She construed her current writing task as something nearly identical to a previous writing task. Sally created a text that was divided into sections such as news facts, quotations, and links for more information. It was essentially a collection of lists with information that someone else could use to combine into a story. When Sally showed this press release to her supervisor, she was surprised to hear the supervisor ask for a "traditional" press release. Instead of lists, the supervisor wanted Sally to write an article - in narrative, journalistic style - that other media outlets could quickly adapt. Sally's attempt to construe the situation misfired, so she had to reconcile her previous expectations with her supervisor's feedback. In response, Sally constructed a more traditional press release that read like an article.

Similar to Irene's case, Sally had misconstrued the genre expectations of her supervisor. Sally said that this experience taught her something about genre knowledge and construing new writing tasks. In the future, she said, she would "ask first" when writing a genre for the first time in a workplace, even if she thought she had written that genre elsewhere before.

\section{Indications of Construction and Self-Correction}

Many of the screencasts offer evidence that students consciously monitor their responses and self-correct as they go. 
- Karen, who had been asked to compile a list of major promoters of live music, began by cutting and pasting from promoters' websites into a text-only file. Eventually, Karen realized that her text-only file would not be the most useful format for her employer, so she opened an Excel spreadsheet and created her own "note-taking structure." This suggests that Karen was monitoring her work as she went along, and that she was willing to self-correct when she believed it would be necessary.

- In Sally's first screencast, she described sending a draft to her supervisor because "she [the supervisor] hadn't given me much direction about it, so I didn't really know exactly what she was looking for." The video shows how Sally sent the draft with a note that said, "I have attached what I have so far for the New Hires article. I wasn't sure how many of the quotes you wanted me to include from the press release and how long you wanted the article to be, so if you want me to change anything I can do that." Sally attempted self-correction here by calling upon her supervisor. In other words, Sally suspected that she needed to self-correct, but she did not know how to tell for sure. As a consequence, she called upon her supervisor.

- Like Sally, Janice sought to begin a process of self-correction by contacting her supervisor. She said she had been instructed "to contact the policy analyst for the democratic staff [and gain knowledge from her]." After the call, Janice wrote her response. But "when I sent it in for approval, ... my supervisor said 'you know, you didn't really answer his question.'” Although Janice said that this response was initially unexpected, she recognized the supervisor's point. Janice agreed that she had not really answered the question.

In cases such as these, students self-correct either through their own assumptions (in Karen's case) or by submitting their work to others. When students submit work to others, they are calling upon what they perceive to be social affordances.

\section{Indications of Social Affordances}

The fact that students so often submit their work to supervisors for feedback suggests that supervisors are perceived as social affordances. They are a part of the social setting that makes self-correction possible. ${ }^{5}$ Students draw on other types of social affordances, as well.

- Irene told of being asked to write a newsletter article but being given no other direction, so she called on affordances familiar to her. "I did 
what I do a lot with our social media anyway," she said, which was to go to the offices of the college newspaper and start researching the countries represented by the center for which she worked. In order to write an article with "a different spin," Irene started looking for countries that are "underrepresented" in the part of the world covered by her program. She soon found a story about a band from that part of the world. She saw that they were on tour, so she found their blog and put together a list of questions that she sent to them via email. "I got their email address, which I felt like a creep doing because I had to stalk them through Facebook and MySpace," Irene said. In other words, Irene perceived that she had a number of networked affordances that would enable her to write an article, even when the assignment was "vague." These were affordances that she had called upon in previous tasks (what she "did with social media anyway").

- Whereas Irene used social media, Ed used several print resources to learn about fundraising. Ed consulted Warwick's (2001) How to Write Successful Fundraising Letters and Flesch's (1963) How to Write, Think, and Speak More Effectively. Through those books, Ed said he gathered genre knowledge, which he combined with his study of actual rates of response to the letters that his employer sent in the last year. Ed eventually spoke about "accomplishing a partnership with the reader" of a letter and creating "a strong you-and-I relationship." Mention of a you-and-I relationship suggests that Ed had adapted knowledge gained from the texts he consulted. It is the kind of jargon common in texts about fundraising.

Social affordances are so important that their absence can significantly affect a student's work. This was evident in the videos produced by Gwendolyn. In her first video of the semester, Gwendolyn said she was waiting for the director of the non-profit to return from vacation. In the meantime, she said, she was doing grunt work such as cleaning out file cabinets. She claimed that this situation was "a little frustrating." By her second video, Gwendolyn said that "things are starting to move along, which I'm so grateful for." She had to assemble a list of media contacts. She showed how she searched for that information, and what she did when she could not find information right away. In the third video, it seems probable that Gwendolyn will not have any significant writing tasks. In two cases, she is allowed to try to revise documents that already exist: a flier and a brochure. Because Gwendolyn compares the existing draft to her revision, viewers can see the work for themselves. The revisions seem half-hearted. They are not as fully developed, or visually attractive, as the originals. Gwendolyn points 
out that the group she works for already has a person on the team who designs the brochures and fliers. Gwendolyn knows that her flier is just a demo "to show them sort of what I could do." By the fourth video, it is obvious that her fliers were not accepted. She said she did not get to design new fliers for another campaign. By the end of the semester, Gwendolyn simply hopes that, at best, she can create something to put in her portfolio.

Gwendolyn's story is remarkable because of its lack of affordances. Of the 10 students completing internships that semester, Gwendolyn was the only one who never mentioned feedback from a supervisor. It seems that she was hired to do office work and that her writing tasks were never genuine- at least the writing tasks she documented in her internship videos and reports were not. Although she may have been motivated to construe, reconcile, and construct, the videos suggest that Gwendolyn never perceived an adequate set of affordances to motivate her (she was only revising texts that the group already liked) or to self-correct (she never mentions calling on others, or on other texts, to help her create her revisions).

\section{CONCLUSION}

If schools of thought such as activity theory and rhetorical genre theory underestimate the subject, while cognitive theories underestimate context, then we need ways to meld the study of subject and context. One way to achieve this would be to integrate sets of terminology. For example, activity theory and problem solving. Figure 2.1 shows common terminology from activity theory. The terminology I have used in this paper (construing a situation, reconciling it with previous situations, deciding whether action is worth taking, and then monitoring that action) can be seen as an extension of the activity theory diagram. Specifically, the terminology unpacks the "Subject" in the diagram. Another way to meld subject and context—a way I'm only able to suggest here-could be to adopt an ecological approach to the study of writing transfer and adaptation. According to Fleckenstein, Spinuzzi, Rickly, and Papper (2008) such an approach acknowledges that "the writer is always interdependent with a web of semiotic-material practices" (p. 395). In such a model, interdependence becomes a primary term, one that places subject and context in relationship to one another. The nature of those relationships depends on feedback, on ways that people react to the social and physical settings in which they work (p. 396). Both Billet (2012) and Bandura (2001) include terminology to describe ways that individuals monitor and adjust their behaviors. In other words, their theories attend to feedback. The fact that these sets of theories share an interest in feedback and adaptation suggests that an ecological theory of writing, combined with an ecological approach to 
research, would be a stronger, more detailed approach than any separate theory described in this chapter. As researchers continue to study writing transfer, therefore, we need to take up an ecological mindset.

\section{NOTES}

1. Transfer is tied up with one sense of our mission in US higher education. As Derrida (1992) noted, citing Kant's Conflict of the Faculties (1798), universities are designed to legitimate two groups: members of its academic disciplines, and members of professions (pp. 4-5). When it comes to legitimizing members of its own disciplines, faculty have a rather free hand. In my own program, for example, my colleagues and I are authorized to define and enforce the terms by which potential colleagues (graduate students) become actual colleagues (doctors of philosophy). When it comes to "creating public titles of competence" for undergraduates, things are not always so clear (Derrida, 1992, p. 5). In the case of professions such as engineering, nursing, and accounting, the public titles of competence (the ones that really count in the workplace) are granted by a professional organization or the state. Worries about transfer are, in part, worries about that second mission.

2. Readers of this chapter may be interested in Spinuzzi's (2011) essay on the "object" of activity theory research. Spinuzzi argues that "activity," the object of study in activity theory, was more clearly bounded in the past that it is now.

3. Knowledge of discourse community and subject matter has been the crux of at least one glass-half-empty argument. E.D. Hirsch, Jr. (1983), argues that "important aspects of reading and writing skills are not transferable" because such skills require subject matter knowledge unique to each situation (p. 164). Process knowledge seems unimportant to Hirsch. Instead, writers must grasp the "subtlety and complexity of what can be conveyed" within a particular topic, as well as "the amount of relevant tacit knowledge that can be assumed in readers" (1983, p. 165).

4. My partner in this research for the past couple years has been Madeleine Sorapure at the University of California, Santa Barbara.

5. Students often mentioned positive feedback from supervisors, as well. Emily, who had to discard a newsletter article and write a new one, received from her supervisor a forwarded email from a constituent praising the most recent edition of the newsletter. Along with forwarding the message, the supervisor had written, "Kudos!"

\section{REFERENCES}

Anson, C. M. \& Forsberg, L. L. (1990). Moving beyond the academic community: Transitional stages in professional writing. Written Communication, 7, 200-231. 
Artemeva, N., Logie, S. \& St-Martin, J. (1999). From page to stage: How theories of genre and situated learning help introduce engineering students to disciplinespecific communication. Technical Communication Quarterly, 8, 301-316.

Bandura, A. (2001). Social cognitive theory: An agentic perspective. Annual Review of Psychology, 52, 1-26.

Beaufort, A. (2007). College writing and beyond: A new framework for university writing instruction. Logan, UT: Utah State University Press.

Billet, S. (2012). Recasting transfer as a socio-personal process of adaptable learning. Educational Research Review, 8, 5-13.

Brent, D. (2011). Transfer, transformation, and rhetorical knowledge: Insights from transfer theory. Journal of Business and Technical Communication, 25(4), 396-420.

Brent, D. (2012). Crossing boundaries: Co-op students relearning to write. College Composition and Communication, 63, 558-592.

Brumberger, E. (2007). Visual communication in the workplace: A survey of practice. Technical Communication Quarterly, 14(4), 369-395.

Derrida, J. (1992). Mochlos; or, the conflict of the faculties. In R. Rand (Ed.), Logomachia the conflict of the faculties (pp. 1-34). Lincoln, NE: University of Nebraska Press.

Driscoll, D. L. \& Wells, J. (2012). Beyond knowledge and skills: Writing transfer and the role of student dispositions. Composition Forum, 26. Retrieved from http:// compositionforum.com/issue/26/.

Fleckenstein, K., Spinuzzi, C., Rickly, R. J. \& Papper, C. C. (2008). The importance of harmony: An ecological metaphor for writing research. College Composition \& Communication, 60, 388-419.

Flesch, R. (1963). How to write, think, and speak more effectively. New York: Signet.

Freedman, A. \& Adam, C. (2000). Bridging the gap: University-based writing that is more than simulation. In P. Dias \& A. Pare (Eds.), Transitions: Writing in workplace and academic settings (pp. 129-144). Cresskill, NJ: Hampton.

Freedman, A., Adam, C. \& Smart, G. (1994). Wearing suits to class: Simulating genres and simulations as genres. Written Communication, 11, 193-226.

Geisler, C. \& Slattery, S. (2007). Capturing the activity of digital writing: Using, analyzing, and supplementing video screen capture. In H. McKee \& D. N. DeVoss (Eds.), Digital writing research: Technologies, methodologies, and ethical issues (pp. 185-200). Cresskill, NJ: Hampton Press.

Giddens, A. (1984). The constitution of society: Outline of the theory of structuration. Berkeley, CA: University of California Press.

Hannah, M. (2011). Legal literacy: Coproducing the law in technical communication. Technical Communication Quarterly, 20(1), 5-24.

Hirsch, E. D., Jr. (1983). Cultural literacy. The American Scholar, 52(2), 159-169.

Kimball, M. (2013). Visual design principles: An empirical study of design lore. Journal of Technical Writing and Communication, 43(1), 3-41.

Maimon, L. (2002). The relationship between self-efficacy and the functions of writing. Journal of College Reading and Learning, 33(1), 32-45.

McCarthy, P., Meier, S. \& Rinderer, R. (1985). Self-efficacy and writing: A different view of self-evaluation. College Composition and Communication, 36(4), 465-471. 
Blythe

Norman, D. (1990). The design of everyday things. New York: Doubleday.

Robertson, L., Taczak, K. \& Yancey, K. B. (2012). Notes toward a theory of prior knowledge and its role in college composers' transfer of knowledge and practice. Composition Forum, 26. Retrieved from http://compositionforum.com/issue/26 /prior-knowledge-transfer.php.

Russell, D. R. \& Fisher, D. (2009). Online, multimedia case studies for professional education: Revisioning concepts of genre recognition. In J. Giltrow \& D. Stein (Eds.), Genres in the Internet: Issues in the theory of genre (pp. 163-191). Philadelphia: John Benjamins.

Schön, D. (1983). The reflective practitioner: How professionals think in action. New York: Basic Books.

Smart, G. \& Brown, N. (2002). Learning transfer or transforming learning? Student interns reinventing expert writing practices in the workplace. Technostyle, 18, 117-141.

Spinuzzi, C. (1996). Pseudotransactionality, activity theory, and professional writing instruction. Technical Communication Quarterly, 5(3), 295-308.

Spinuzzi, C. (2011). Losing by expanding: Or, corralling the runaway object. Journal of Business and Technical Communication, 25(4), 449-486.

Swarts, J. (2004). Technological mediation of document review: The use of textual replay in two organizations. Journal of Business and Technical Communication, 18(3), 328-360.

Vincelette, E. J. \& Bostic, T. (2013). Show and tell: Student and instructor perceptions of screencast assessment. Assessing Writing, 18(4), 257-277.

Warwick, M. (2001). How to write successful fundraising letters: Sample letters, style tips, useful hints, real-world examples. San Francisco: Jossey-Bass. 


\section{CHAPTER 3 \\ BUILDING A CONCEPTUAL \\ TOPOGRAPHY OF THE \\ TRANSFER TERRAIN}

\section{Donna Qualley}

\section{SIGNPOSTING: WHERE WE ARE HEADED}

At the close of their essay exploring the role of dispositions in writing transfer, Dana Lynn Driscoll and Jennifer Wells (2012) comment on a problem that plagues researchers as they attempt to understand and explain complex phenomena such as learning. When scholars focus on one kind of theory-just like the six blind men and the elephant - they are likely to end up with a partial or distorted perspective. Driscoll and Wells (2012) ask, "How might the field create a map that simultaneously focuses on multiple theories of transfer?" One way would be to gather key theories of transfer together in one place and, then, starting with a few pieces, gradually begin to chart the relationships between them, as the Elon Statement on Writing Transfer does in its text and visual graphic. In this chapter, I take another step. Working with selected features from the Elon Statement's visual, I offer a conceptual topography of the transfer terrain. In the spirit of the Statement's invitation to "continued inquiry and theory building," I begin forging linkages between selected theories to deepen our understanding of some of the document's core concepts and principles as well as point to new pathways and relationships for further exploration as writing studies teachers and researchers.

To demonstrate the project's adaptability to other kinds of critical transitions, my point of reference for this discussion will be Western Washington University's (WWU) first year writing program where only MA-level graduate students teach the first-year writing course. ${ }^{1}$ These graduate student instructors (GSIs) must learn to occupy dual roles as teacher and learner simultaneously as they continue to re-envision themselves, their teaching, and their course over six quarters. Thus, this population offers a rich site for thinking about multiple theories of transfer and learning during periods of liminality and critical transition, when the relations between individuals and the social activities they are engaged 
in are constantly changing. Mary Jo Reiff and Anis Bawarshi's observations about the first-year writing course as a "transition point" and "site for disrupting the maintenance of strict domain boundaries for new undergraduates" (2011, p. 331) may be even more applicable to the GSIs learning to teach this course.

In the mapping expedition that follows, I focus primarily on the third working principle of the Elon Statement that states: "Prior knowledge is a complex construct that can benefit or hinder writing transfer. Yet, understanding and exploring that complexity is central to investigating transfer" (2015, p. 4). I explore the complexity of the connection-making process between prior knowledge/learning and new knowledge/learning during periods of critical transition by unpacking the subtle distinctions between forward and backward forms of transfer. In forward transfer, the focus is on how prior or current knowledge/ learning influences new or future knowledge/learning. In backward transfer, the focus shifts to the ways that new knowledge/learning can influence prior knowledge, often knowledge that is still developing. I then introduce a new category of backward transfer called "retrospective understanding." Retrospective understanding directs our attention to the transition process itself and illuminates the roles that dispositions, motivations, and meta-awareness play in transformative forms of transfer and in the development and expansion of expertise. Understanding transfer processes in connection with the development of expertise suggests an additional trajectory: As individuals travel deeper into a domain or discourse (and in order for individuals to travel deeper into a discourse), general knowledge becomes "reconstituted" into more specialist and nuanced understanding (which, for all intents and purposes, is new knowledge). This gradual transformation of general knowledge into specialist knowledge also aligns with discussions about the role that threshold concepts play in supporting transfer and furthering expertise. Finally, I suggest how the furthering of expertise is tied to both the individual and the community's capacity for modification. Over the course of six quarters, most GSIs will undergo "significant cognitive retooling." How much retooling occurs depends in part on their capacity for modification of prior knowledge and practice and in part on the First Year Writing (FYW) program's ability to adapt to the ever changing community of practitioners. For some GSIs, this critical transition may eventually become a "consequential transition" as the FYW program makes its mark on them and they make their mark on the FYW program.

I begin with a stripped-down view of the territory represented by the three overlapping spheres (learner, context, and knowledge) from the Elon Statement's visual graphic. As shown in Figure 3.1, I have labeled each of these spheres with the corresponding marker from the WWU first-year writing program: Graduate Student Instructor (learner), WWU First-Year Writing Program (Context), and 


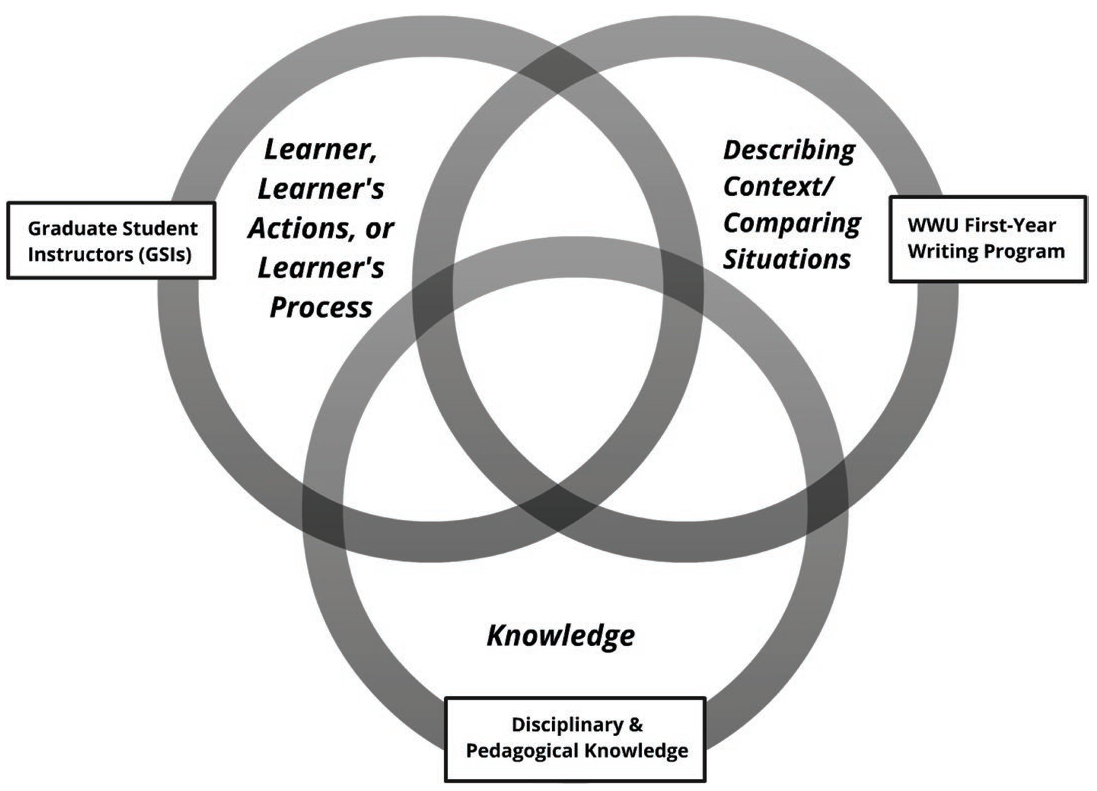

Figure 3.1. Base Camp: The three territories of the Elon Statement's visual graphic and corresponding WWU first-year writing program markers.

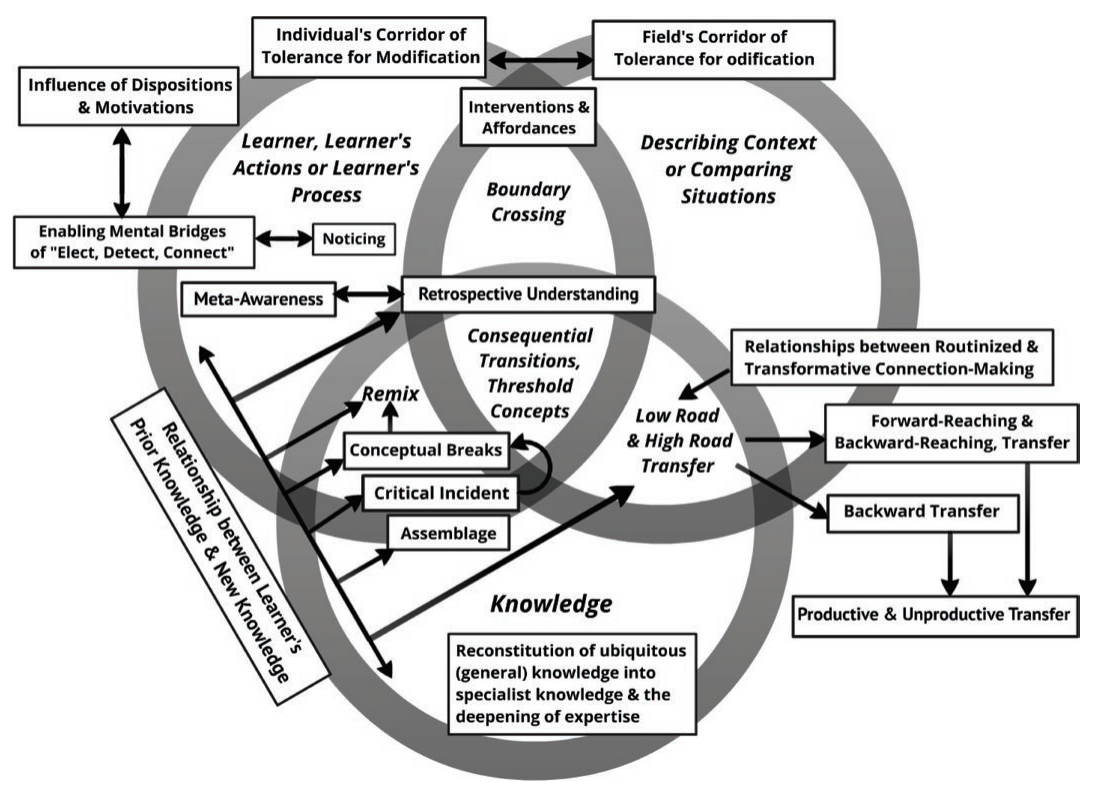

Figure 3.2. A conceptual topography of the Elon Statement's visual graphic populated with additional signposts and new layers. 


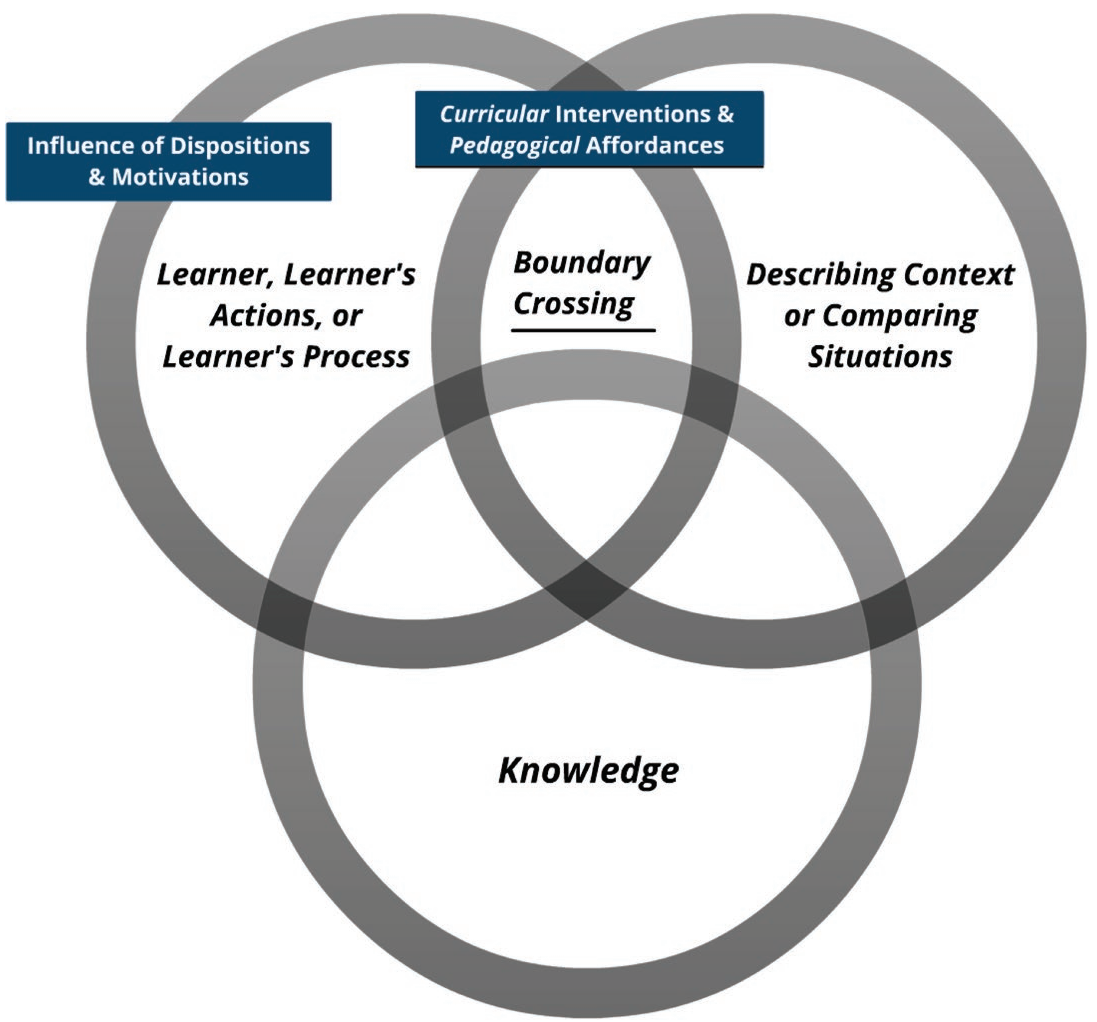

Figure 3.3. Mapping the terrain, first stop.

Disciplinary and Pedagogical Knowledge (Knowledge). Over the course of this chapter, I will slowly repopulate this map by pinning additional signposts from the Elon Statement visual as well as layering in new landmarks that will take us deeper into the conceptual terrain. Figure 3.2 depicts an aerial perspective of where we are headed. This more densely inhabited landscape reveals the general location of things. Gradually, I will bring the concepts and the links and pathways that connect these markers into visible relief as I zoom in to examine GSIs' critical transitions in learning to teach first-year writing.

\section{CONTEXT AND DRIVERS OF THE FIRST- YEAR WRITING PROGRAM \\ Describing Context: The First-Year Writing Program}

Except for the WPA and Assistant WPA, only MA-Level graduate students teach the first-year writing course. Half the staff turns over every year. Thus, the 
first-year writing program functions as a kind of way station where everyone except for the resident WPA is passing through en route to somewhere else. Indeed, Terttu Tuomi-Gröhn and Yrjö Engeström's (2003) concept of "boundarycrossing" (a key landmark in the Elon Statement) captures the experience of GSIs. These GSIs, who have come to Western Washington University for further study in literature or creative writing, are asked to teach composition. They are "entering into territory in which [they] are unfamiliar and to some [large and] significant extent, unqualified" (Tuomi-Gröhn, Engeström, and Young, 2003, p. 4). The constant movement of new teacher-learners into and through the program, where the flow of knowledge, ways of knowing, identities, dispositions, and goals are always in flux, gives rise to a culture where both individual understanding and programmatic approaches to writing, learning, and teaching are continually examined, re-articulated and re-designed.

Almost all graduate students enter the terrain of the first-year writing program with no specialist knowledge of composition and rhetoric, and most have no prior teaching experience. A few bring experience as writing center assistants or teacher aids, and one or two have taught high school or spent a year teaching abroad. Most are in their mid-twenties; a few are thirty or older. Unlike many universities where graduate students are required to complete course work prior to stepping into the classroom, new GSIs begin teaching their first quarter. Both new and returning GSIs arrive on campus a week before fall quarter commences for "Comp Camp," an intensive, weeklong orientation. While returning instructors play a role in ushering new instructors into this community of practice, some of the information at Comp Camp will be new to them as well, since the texts and parts of the curriculum change every year. New instructors take a seminar in composition theory and pedagogy during their first quarter. In addition, all GSIs meet formally throughout the year for weekly staff meetings and daylong, end-of-quarter paper and portfolio readings.

\section{Drivers that Support Transitions}

Like most social contexts, the first year writing program employs certain mechanisms or "drivers" that are intended to support (or "drive") the development of GSIs' practice and to acclimatize them to the discourse. ${ }^{2}$ Curricular and programmatic interventions and pedagogical affordances are external supports. Individual dispositions and motivations are internal drivers.

Curricular and programmatic interventions refer to the actual content of the first-year writing course and the program structures that the WPA puts into place each year to "intervene" and guide GSIs' socialization and enculturation into this community of practice. Specifically, these interventions include the 
aims of the program, the course texts and resource materials, sample assignments, and the intellectual moves and rhetorical strategies that GSIs introduce to their students.

Pedagogical affordances include technological and material supports (having a course management system, teaching in a computer lab every week, and so on); but mostly they refer to specific practices and approaches for teaching the course as outlined in the fall annotated syllabus. Pedagogical affordances comprise everything from the familiar array of "best practices" for teaching writing to more localized ways of doing things within this program to certain "learning" principles (such as the importance of repetition and recursiveness). The usefulness of any particular affordance also changes and evolves as GSIs become more practiced in navigating the terrain. Some affordances (such as the detailed, day-by-day descriptions for approaching each class in the first half of the fall annotated syllabus) are temporary, important for initially ushering GSIs into the landscape of teaching first-year writing. If some of these scaffolding affordances are not eventually dismantled, adapted, or redesigned, they run the risk of turning into constraints that can prevent the further development of expertise. In keeping with an important working principle in the Elon Statement, the program has long maintained that successful transfer and the development of expertise only occurs when GSIs do more than simply draw on knowledge and strategies introduced in their first quarter of teaching; they must continue to "transform or repurpose that prior knowledge, if only slightly."

Pedagogical affordances work in tangent with curricular interventions. Changes in one area often give rise to changes in the other. For example, during his first quarter of teaching, Justin Ericksen ${ }^{3}$ drew on his prior experience of working as a prosecuting attorney and began to develop a practice intended to help students consider their audiences that he called "anticipating objections." In one of his reflective writings for his composition seminar, he explained how this process worked in the courtroom and how he redefined the move to the classroom:

Generally speaking, this move is used more aggressively in persuasive and/or oral rhetoric. It functions as a "stealing of thunder" in a way. In court you could raise the issue, anticipate the opponent's likely argument and deal with it in an effective (very gently condescending) way. Sometimes you'd glance over at your adversary and almost see the wind go out of their sails a bit as evidenced by a scowl, frown, slumping in the chair, or rueful smile accompanied by a subtle head shake. If they did bother to make the argument themselves, it always 
sounded sort of lame and reactionary, instead of momentous and revelatory as they undoubtedly hoped. In writing, I think it's more subtle and used more to open up alternate lines of inquiry. Instead of rejecting a claim, it tends to invite people to look at different perspectives.

Two years later, "anticipating objections" became a formalized part of the FYW curriculum and began to also appear on the evaluation rubric. What started as a pedagogical affordance turned into a curricular intervention.

Finally, as noted in the working principles of the Elon Statement, GSIs' dispositions and motivations for teaching play a "key role" in this process. They determine whether and to what extent GSIs' transitions into and out of the program will become "consequential"- for them and for the program. In other words, it matters whether GSIs demonstrate "problem-exploring" or "answer-getting" dispositions (Wardle, 2012) or exhibit "boundary-crossing" or "boundaryguarding" tendencies (Reiff and Bawarshi, 2011). The four general dispositions that Driscoll and Wells (2012) identify as being important for successful learning (motivation, self-efficacy, theories of attribution, and self-regulatory strategies) also play an important role. ${ }^{4}$

So, while both curricular and programmatic interventions and pedagogical affordances are necessary and important for "cuing" the transfer of learning from quarter to quarter, GSIs' motivations and dispositions generally govern the extent to which the two external drivers will be effective in furthering their expertise via low-road and high-road transfer.

\section{THE INTERACTION BETWEEN HIGH- ROAD AND LOW-ROAD PROCESSING}

Probably some of the most familiar landmarks in the literature on learning transfer are David Perkins and Gavriel Salomon's (2012) concepts of "high-road" and "low-road" transfer (see Glossary). The Elon Statement acknowledges that individuals may engage in both processes (routinized and deliberate or transformative) when they draw on or utilize prior knowledge and learning. In mapping these concepts, however, it is helpful to take a more nuanced look at their relationship and the ways they work together to further the development of GSIs' expertise.

While it may be tempting to dismiss low-road transfer or see it as less desirable than high-road transfer, as with most binaries, the relationships between opposites are usually more complex. Rebecca Nowacek suggests that high-road and low-road connection processes exist along a "spectrum" or progressive 


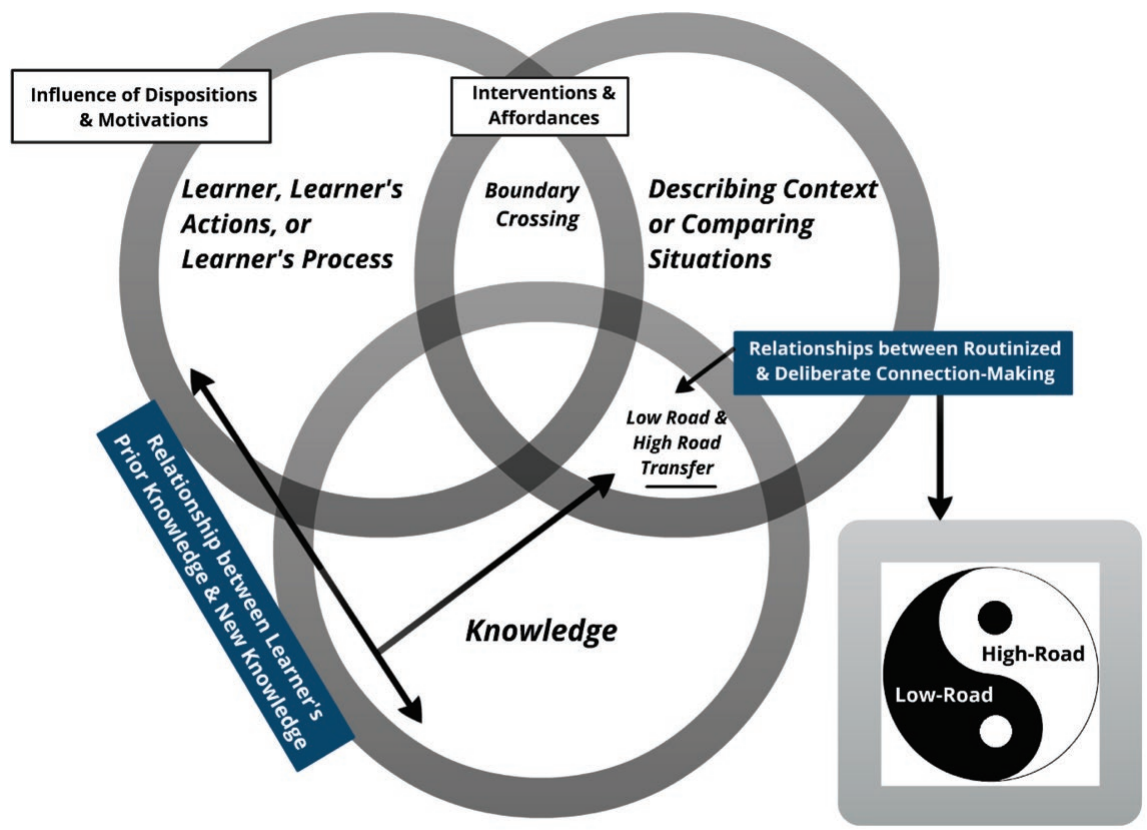

(Close-up view: Duality between High-Road \& Low Road Transfer)

Figure 3.4. Mapping the terrain, second stop.

continuum from "no transfer" to "transfer" to "integration" (2011, p. 33). For Nowacek, "transfer" means low-road transfer while "integration" denotes highroad transfer because it "assumes some degree of meta-cognitive awareness" (Elon Statement, 2015, p. 2). In Nowacek's representation, individuals are situated somewhere on the continuum and either move ("progress") or don't. Perhaps a more fertile representation of the relationship between low-road and high-road transfer would be to see them as "dualities" as shown in the close-up image in Figure 3.4 (Wenger, 1998). That is, it may be more productive to think of these kinds of transfer processes as interactive rather than oppositional or existing as points along a continuum. Etienne Wenger explains that while "a continuum does allow for more nuanced distinctions, it is still a relation between opposites. ... With an interacting duality, by contrast, both elements are always involved, and both can take different forms and degrees" (1998, pp. 66-67)

If both kinds of transfer are always involved in a duality, then we might consider the ways that low-road and high-road transfer often become "coupled." King Beach (1999; 2003) notes that in "developmental coupling," one activity is not "antecedent" or "consequent" to the other; rather they are "correlational or relational in nature" (1999, p. 120). In other words, they are linked. They work 
together, and a change in one of the elements in a duality necessarily affects the other. How we depict the contours of the relationship between low-road and highroad transfer as well as other kinds of transfer relationships-as binary, developmental continuum, or duality - then, will have implications for how we conceptually map these processes as well as how we teach and sequence learning activities.

Furthermore, some forms of low-road-transfer may be necessary so that highroad transfer becomes possible. In the case of new GSIs, it is both necessary and helpful if certain procedural knowledge, habits, and practices take root quickly so that they can indeed "carry" them forward somewhat unconsciously in their teaching each quarter. For example, at the end of his first quarter of teaching, Justin, the former prosecuting attorney, noted: "I plan to more frequently revisit core concepts, ideas, and strategies. Even though, in my past life, I used to find a way to repeat every key point and argument at least three times for a jury, I somehow didn't initially understand that students would also struggle to retain information they only heard once or twice." By the end of his second quarter, this conscious intention of revisiting concepts had become routine in his teaching.

Another way to think about this relationship between routinized and deliberate forms of transfer is via James Paul Gee's concepts of learning and acquisition. He distinguishes between these two process in his discussions of how individuals become "literate" in the particular "saying (writing)-doing-being-valuing-believing combinations" of secondary discourses (2012, p. 151). Learning always involves some form of overt instruction or explanation, while acquisition occurs gradually and unconsciously through ongoing practice and participation in the discourse. If the goal is mastery of performance (such as in teaching or writing), then acquisition is key. If GSIs are to develop their expertise as teachers in the classroom, some of what they initially learn will have to become an unconscious, routinized part of their repertoire. However, learning is essential if the goal is developing a meta-knowledge of the principles that underlie the practices. In order to engage in high-road transfer, GSIs have to be able to articulate the principles operating in one situation to be able to determine their applicability to another situation. At first, Justin didn't see the connection between juries in the courtroom and students in his writing course. It wasn't until he articulated the rhetorical and pedagogical principle that was common to them-the importance of repetition for novice audiences - that he was able to make his acquired knowledge explicit and apply it to the new situation.

\section{CONCEPTUAL BREAKS AND ENABLING BRIDGES}

If GSIs' transitions are to become what Beach (1999; 2003) might call developmentally "consequential," both for them and for the program, they will 


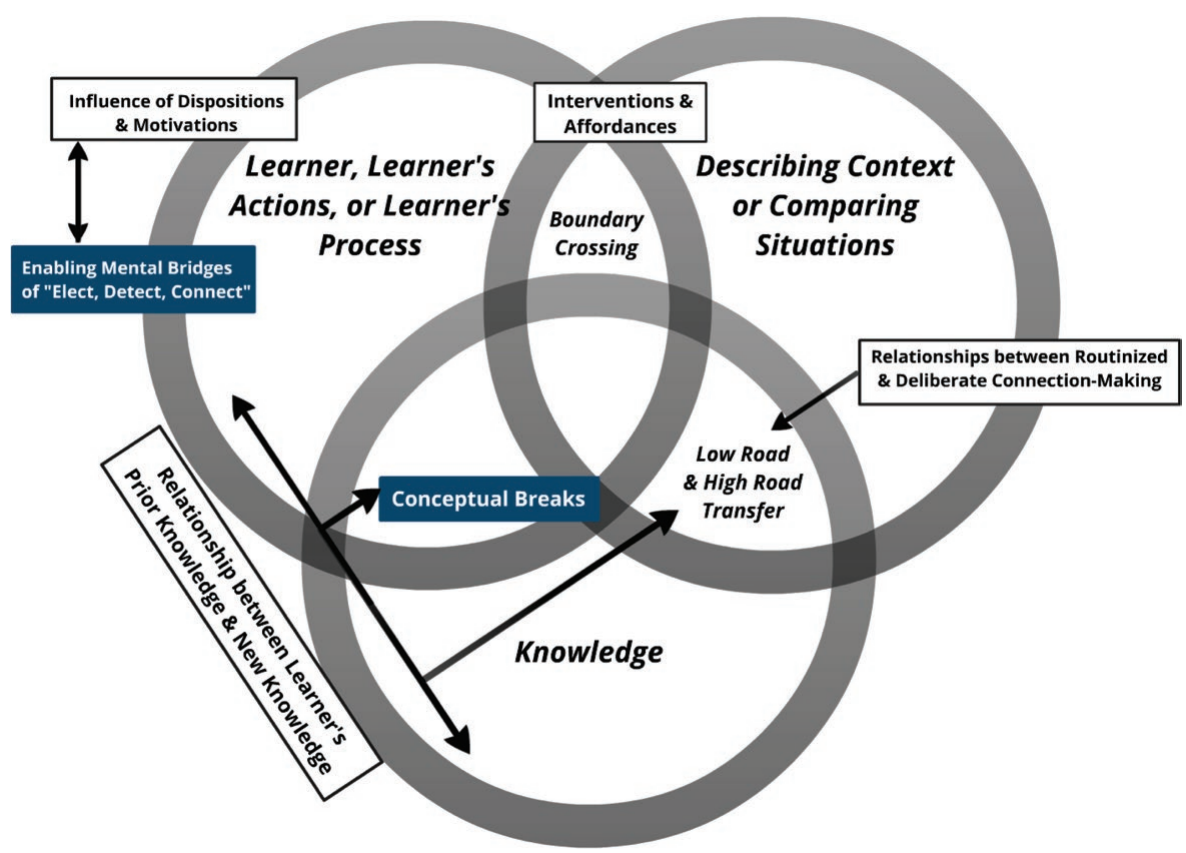

Figure 3.5. Mapping the terrain, third stop.

have to engage in the deliberate and mindful abstraction of high-road transfer in order to "re-understand" the information in the annotated syllabus, their classroom practice, and themselves as teachers. This process typically begins in their composition seminar. As GSIs begin to read composition and pedagogical theory, some of them will start to "translate" their understanding of teaching writing "into a new frame of reference or intelligibility" for themselves (Guillory, 2008, p. 9).

John Guillory argues that when reading difficult and complex texts, readers eventually have to make a "conceptual break" with their current levels of comprehension so that "reading begins anew" (2008, p. 9). Although Guillory focuses on literary texts, a similar principle works for "teaching to begin anew" for GSIs. Teaching and learning, like reading and writing, are always emergent processes. In order to develop further expertise, GSIs will sometimes need to make "conceptual breaks" with the customary ways of thinking and working that they have acquired through prior experience or have only just recently learned. But not always. Sometimes GSIs develop "new frames of intelligibility" for understanding that don't actually necessitate a conceptual break.

Early in his composition seminar, Justin read Nancy Sommers' "Responding to Student Writing" (1982) and "Between the Drafts" (1992). He noted that he 
had already "put a lot of thought into responding to student writing." He figured he had a "pretty good grasp of the genre," saying that "I had always taken pains to include some level of specificity in responses." Sommers' two essays, however, also revealed what he didn't know. "I have never consciously considered the full impact of my written responses and I was woefully ignorant on any research on the subject." While the information in these essays gelled with Justin's proclivities for being positive and specific in his responses to students, they also provided him with a new framework for the purpose of written comments: "Sommers articulated the necessity of developing comments with the awareness and expectation of further revision. It is with this purpose in mind that I intend to make the first essay project during winter quarter a draft for the second essay and to engage in extensive dialogue and revision between the two."

When he read Summer Smith's "The Genre of the End Comment" (1997) a few weeks later, the routine that Justin had established for commenting-being positive and focusing his comments with an eye to further revision-was again destabilized. He wrote:

I didn't realize how generic my commenting format was until I read Smith's essay, and then I immediately wanted to take everything back and rewrite it again. The way in which she pinpointed genres that I had unconsciously been following was uncanny, and created a sense of both wonder and apprehension. I hadn't considered that positivity could be construed as insincerity, nor that suggestions for revision could be construed as punishment for mistakes, and I certainly didn't recognize that I was following a formula that I now realize is appropriated from feedback I've received on my own writing.

Justin did not simply add this new information to his understanding of commenting practices as he did after reading Sommers' essays because Smith's theories were in direct conflict with his prior assumptions and practices. In order to process this new perspective, Justin had to first make a conceptual break with his current understanding, an understanding that had just recently been fortified by his reading of Sommers' work. Justin's feelings of "both wonder and apprehension" perfectly capture the experience of liminality, when one's conceptual moorings have been suddenly loosened. Carl Bereiter and Marlene Scardamalia (1993) remind us that expertise develops only if we reinvest the mental resources freed up by the learned automaticity of routine into more difficult tasks and more complex representations of problems. In other words, expertise is sustained only by the effort to surpass itself or to destabilize the very knowledge and practice upon which the expertise is based. But it is more difficult to utilize these mental 
resources if some parts of the work don't eventually become a matter of routine transfer or "lift and carry."

Perkins and Salomon's (2012) recent discussion of the construction of the transfer-enabling "mental bridges" of "detect, elect, and connect" points to the interactive relationship between low-road and high-road transfer. Individuals "detect" a possible link, "elect" to explore or pursue it, and then make the connection. Alternatively, individuals may "elect" to pursue a possible hunch, "detect" a promising link, and then elaborate on the connection. Finally, individuals might encounter a connection and "elect" to examine the connection more closely so as to "detect" the significance of it. These bridges may be deliberate (high-road), automatic (low-road), or include a mix of high-road and low-road processing. With low-road transfer, less mental effort and motivation is required to construct these bridges so the processes of "detect, elect, connect" are less discernible and can seem to "occur virtually simultaneously." (2012, p. 250). As Perkins and Salomon explain, these processes "unfold relatively automatically" out of habit rather than being triggered by "motivational or dispositional drivers." (2012, p. 251). However, the construction of these bridges is more likely to occur in serial fashion during high-road or mixed high-road and lowroad processing. For example, when the similarities between situations are not immediately apparent and when individuals cannot easily "detect" a possible linkage, they will have to construct one. If they are not disposed or interested enough or otherwise motivated to pursue a perceived linkage, they will have to find a reason to become interested or motivated. Even when individuals detect a possible link and elect to pursue it, they may be unable to make the connection. At any point in the process, each of these bridges may become "a bridge too far" (Perkins \& Salmon, 2012, p. 250).

Perkins and Salomon's discussion here suggests one reason why the internal drivers-GSIs' motivations and dispositions (the extent to which they are interested, willing and able to pursue a potential connection) — may be crucial for engaging in the high-road connection-making that will further their development of expertise. The external drivers, the curricular interventions and pedagogical affordances, are the transfer-enabling bridges that the WPA puts in place so that some aspects of teaching can gradually become more routinized and automatic. These drivers support GSIs by freeing up some of their mental resources while they are acclimatizing to the discourse of the first year writing program.

When new GSIs begin teaching first-year writing, very little of what they have to learn to do is automatic. As Justin noted on numerous occasions, his first quarter of teaching was all about learning to "see the big picture." Until GSIs start to grasp how the many parts of the course fit together, almost everything they do initially requires conscious deliberation. In time, perhaps, some 


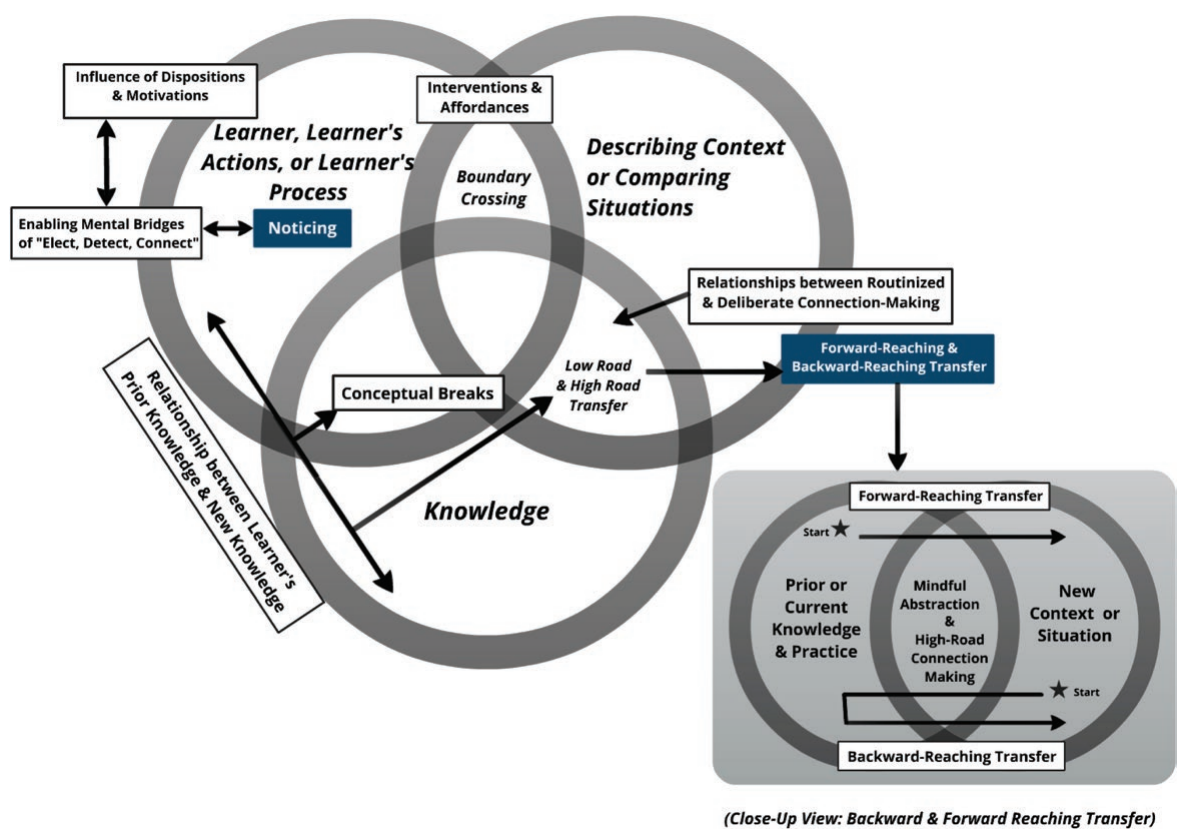

Figure 3.6. Mapping the terrain, fourth stop.

"bridges" may become more automatic (which, of course, comes with its own set of dangers). But as GSIs gain more knowledge and continue to examine and reflect on their practices, they may notice different connections and the bridge building processes will shift back into high-road processing.

\section{FORWARD AND BACKWARD-REACHING TRANSFER}

Perkins and Salomon's (1988) descriptions of "forward-reaching" and "backward-reaching" forms of high-road transfer both depict the utilization of prior knowledge and practice in the development of new knowledge, practice, or application. The focus is on solving a problem or developing knowledge in the new context. As we see in the close-up image in Figure 3.6, the starting place for deliberation differs for each kind of transfer, but the destination is the same.

GSIs engage in both forward-reaching and backward-reaching forms of transfer throughout their time in the program. The WPA typically does a little "curricular intervention" in the first quarter composition seminar to make these processes more visible to GSIs. For example, GSIs write the same inquiry essay that they will be assigning to their own students. When they use their experience of writing this essay to anticipate the kinds of issues that might emerge 


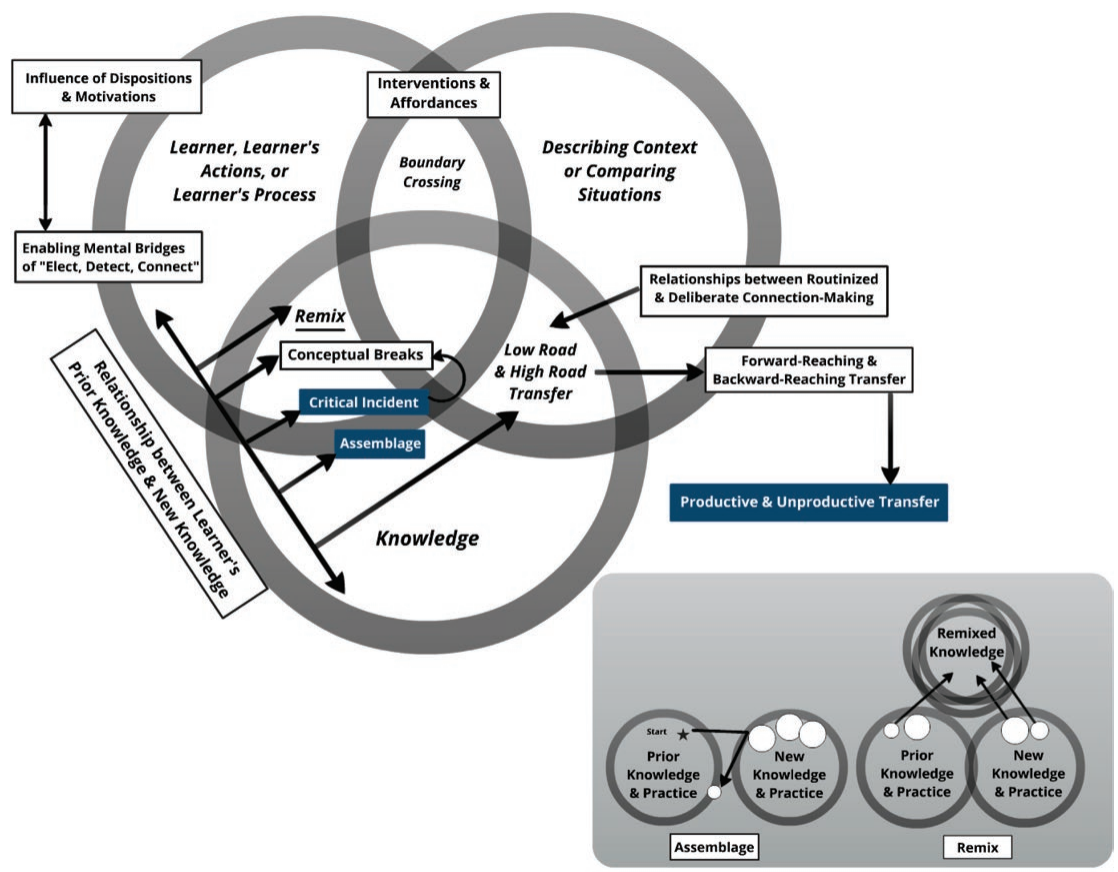

(Close-up View: Assemblage versus Remix)

Figure 3.7. Mapping the terrain, stop five.

for their own students with this assignment, they engage in forward-reaching transfer. When GSIs identify and hypothesize about the challenges or difficulties that their students actually had when completing the assignment, GSIs engage in backward-reaching transfer. They reach back into their own experience of writing this essay or to other relevant information in their course texts and materials to help them explain what they see. In a similar fashion, the winter syllabus that new GSIs construct at the end of fall quarter offers an indication of the extent to which they are engaging in forward transfer of the principles of the first-year writing course. To actually make the syllabus, though, they continually reach back into their seminar readings, course materials, concepts, and practices to be able to "solve the problem" of re-imagining a different course. Forward-reaching transfer and backward-reaching transfer, then, often work together. However, there are other ways to map the relationship between prior learning and new learning.

\section{ASSEMBLAGE, REMIX, AND CRITICAL INCIDENT}

In their discussion of how first year students utilize prior knowledge, Liane Robertson, Kara Taczak, and Kathleen Blake Yancey (2012) identify three ways that 
first-year students "take up" new knowledge of writing in relation to old knowledge: assemblage, remix, and critical incident. These methods are not limited to writing or to first-year students. GSIs also employ these methods in learning to teach writing. Each method offers a different take on Perkins and Salomon's concepts of forward-reaching and backward-reaching high-road transfer.

In their first quarter, GSIs frequently employ assemblage methods especially when their recent prior experience is "somewhat" related to the work of teaching first-year writing, such as teaching high school English, assisting in the writing center, or working in publishing and editing. Because GSIs see their prior experience as being similar or at least constituent to their new experience, their prior knowledge initially exerts a strong pull in the ways they understand and take up key concepts and rhetorical strategies in their teaching. Although Robertson et al. (2012) don't explicitly say, assemblage methods can result in both productive and unproductive learning. Justin's grafting of Sommers' theories onto his current understanding was initially productive for his teaching practice. Assemblage, however, is unproductive when it takes information out of context, distorts it, or overly simplifies it.

Assemblage appears to be more of a low-road connection-making process that can actually by-pass new learning. Often occurring without mindful deliberation, learners assume a similarity between contexts and select elements (such as key terms or rhetorical strategies) in piecemeal fashion from the new domain that seem to fit with their prior knowledge and current practice. They "graft" these new bits on to their prior schema in such a way that their current framework remains supported and intact. In other words, the addition of new knowledge doesn't change or transform their prior knowledge immediately in noticeable ways. Their comprehension of the new knowledge is also limited and constrained because they have only accessed those bits and pieces that can be used to bolster what they already know.

Robertson et al.'s (2012) concept of remix describes how students take elements of new knowledge and integrate them with their prior knowledge to create a new or revised understanding or practice. The close-up image in Figure 3.7 illustrates the differences between the methods of assemblage and remix. In assemblage, selected elements of the new context work as "add-ons." Grafted onto the perimeter of prior knowledge, these elements are never fully integrated, and thus prior knowledge doesn't really change. In the remix method, selected elements from both prior knowledge and new knowledge are combined and reworked together to create something new. Thus, the remix includes features from both domains, but is distinct from either of them.

In the culture of the first year writing program, GSIs are encouraged to repurpose and remix their current knowledge and practice with new knowledge 
and practice-hopefully in generative and productive ways. A remix is only possible, however, when GSIs perceive or "detect" a potential relationship between new knowledge and prior knowledge and "elect" to "connect" elements together from both domains into something new.

The third way that students take up new knowledge is via a "critical incident." Although such incidents can induce temporary "setbacks" or "bottlenecks" that prevent further learning (Middendorf \& Pace, 2004), Robertson et al. (2012), suggest that reflection on these critical incidents can spur "conceptual breakthroughs" that can lead to the creation of new knowledge or understanding. A critical incident seems to function much like the Guillory's notion of the conceptual break; both can set the stage for the possibility of a creative or conceptual breakthrough; but these breakthroughs do not always come easily or quickly for GSIs.

Justin, who typically exhibited characteristics of "boundary crossers" (Reiff $\&$ Bawarshi, 2011) and easily accepted his role of novice (Sommer \& Saltz, 2004), was initially resistant to the notion that mechanical correctness should be of less concern when first responding to student writing. Right before he entered the program he had worked as a copy editor and proofreader, and the program philosophy of focusing on content before correctness was in direct conflict with his prior experience. In a reflection written at the end of his first quarter, he explained that he "physically heard and took note of repeated instructions to mainly avoid correctness and focus on content," but he was "unable or unwilling to internalize this instruction." Justin's observation that he was "unable" or "unwilling" to "internalize" new knowledge suggests how difficult it can be to alter or dislodge a "continuing schema of old knowledge" (Robertson et al., 2012). However, he continued to examine the reasons for this disconnect:

In addition to what I'm now recognizing as a likely fear to deviate from what I perceived as my evaluative strengths and experience, I was more consciously concerned that to ignore mechanical correctness would be a disservice to the students. For instance, whether fair or not, mechanically correct writing is often seen as a marker of social class. Writing with poor spelling and grammar are stereotypically seen as indicative of an uneducated, lower class individual. In short, people are judged on their writing.

Justin has given voice to what is still an unresolved conflict for many writing teachers and scholars: Current disciplinary thinking does not always gel with the recognition that people are judged by their language. Perhaps, by association, Justin felt that he too would be negatively judged as the teacher of these 
students. Even though he was using texts in his first-year writing class that suggested a variety of counters to his position (e.g., Mike Rose's Why School and essays on literacy and social class by Lynn Bloom, Jean Anyon, Earl Shorris, and Professor X), Justin remained unconvinced throughout most of the quarter.

For Justin, Robert Connors' 1985 essay, "Mechanical Correctness in Composition Instruction," was the critical incident that finally precipitated the conceptual break or what he calls a "mental shift" in his thinking about the significance of mechanical correctness. Sounding much like his ex-lawyer self, Justin described how the new information in Connors' essay roughed up his thinking enough so that he could "adjust" his position.

To put it mildly, I had never before thought of evaluating correctness as a "stultifying error-hunt" that had essentially replaced a great rhetorical tradition. After planting the seed, Connors proceeded to cement the point by illustrating specific reasons for the shift. . . These factors combined to create a composition culture focused almost exclusively on "avoidance of error" in lieu of effective rhetorical communication. When he put it that way, my allegiance to mechanical correctness as a vital aspect of composition instruction wavered. The final assault by Connors took that crumbling resistance and basically annihilated it. He discussed composition teachers at the height of the mechanical correctness era and claimed that they "rationalized this sort of reading by claiming that they were giving students what students really needed most" (p. 67). Those words evoked a painful awareness moment for me as I recognized echoes of myself, and was called on to uncover and examine my own values. I consciously recognized for the first time that I was imposing my values and ideas of what mattered in composition. . . . I was forced to come to terms with the truth that it doesn't matter how correctly you say something if you have nothing interesting to say and no rhetorical framework for your words. In short, the grammar police (of which I was a high-ranking officer) act largely pursuant to self-interest while serving to stifle creativity, innovation, and original thought. When forced by Connors to view the inclination toward mechanical correctness in this light, I resolved to adjust my ideas of composition instruction.

In this situation, Justin's prior understanding was at odds with this new perspective, and so he couldn't use what he knew to reach forward. He couldn't 
reach backward because his prior knowledge offered no way to resolve the problem. Instead he had to find a way to make a break with prior knowledge. He did this by identifying and reflecting on his own core values. The new knowledge afforded by Connors' essay coupled with his mindful deliberation enabled him to realize that the values that supported his prior position were not the values he wanted to "impose" on his students. Given his normally open-minded disposition and his strong motivation to serve his students, the essay became the "critical" occasion to complete his "mental shift." Justin used the new knowledge from Connors' essay to revise his prior thinking and construct a new understanding through backward transfer, a process that is quite distinct from backward-reaching transfer.

\section{BACKWARD TRANSFER AND RETROSPECTIVE UNDERSTANDING}

Backward transfer (see the close-up image in Figure 3.8) begins to take us into less explored territory on the transfer map. Backward transfer occurs when the acquisition and learning of new knowledge influences understanding of prior knowledge. Backward transfer more readily allows us to see the dynamic and reconstructive nature of high-road transfer. Meta-awareness and reflection, so important to all forms of learning, are especially critical to the processes of backward transfer.

When individuals must rapidly familiarize themselves with large amounts of new knowledge and gain new levels of competence in a compressed time span, it is unlikely that they will have the chance to fully process this knowledge or, in Gee’s (2012) terms, "acquire" full proficiency before more new knowledge and practice is introduced. Under these circumstances, understanding will be partial in both senses of the word-partial, meaning not full or complete, and partial, meaning idiosyncratic and individualized. In terms of the first-year writing program, GSIs grasp the new texts, concepts, and practices with varying degrees of accuracy, depth, and specificity, and they will understand them differently based on whatever antecedent frames they can initially utilize to connect to the new material. The information gained from their summer reading and Comp Camp will not have had an opportunity to sink in before they have to wrap their minds around new knowledge and new practices-or before it is complicated by the arrival of their own students. Although both the graduate seminar that new GSIs take and the first-year writing course that they teach are purposely sequenced so that new knowledge builds on, reinforces, and complicates prior knowledge, it is hard to build on knowledge that has not fully taken up residence in one's mind. Yet, gradually throughout the quarter and over the next five quarters, GSIs' ongo- 


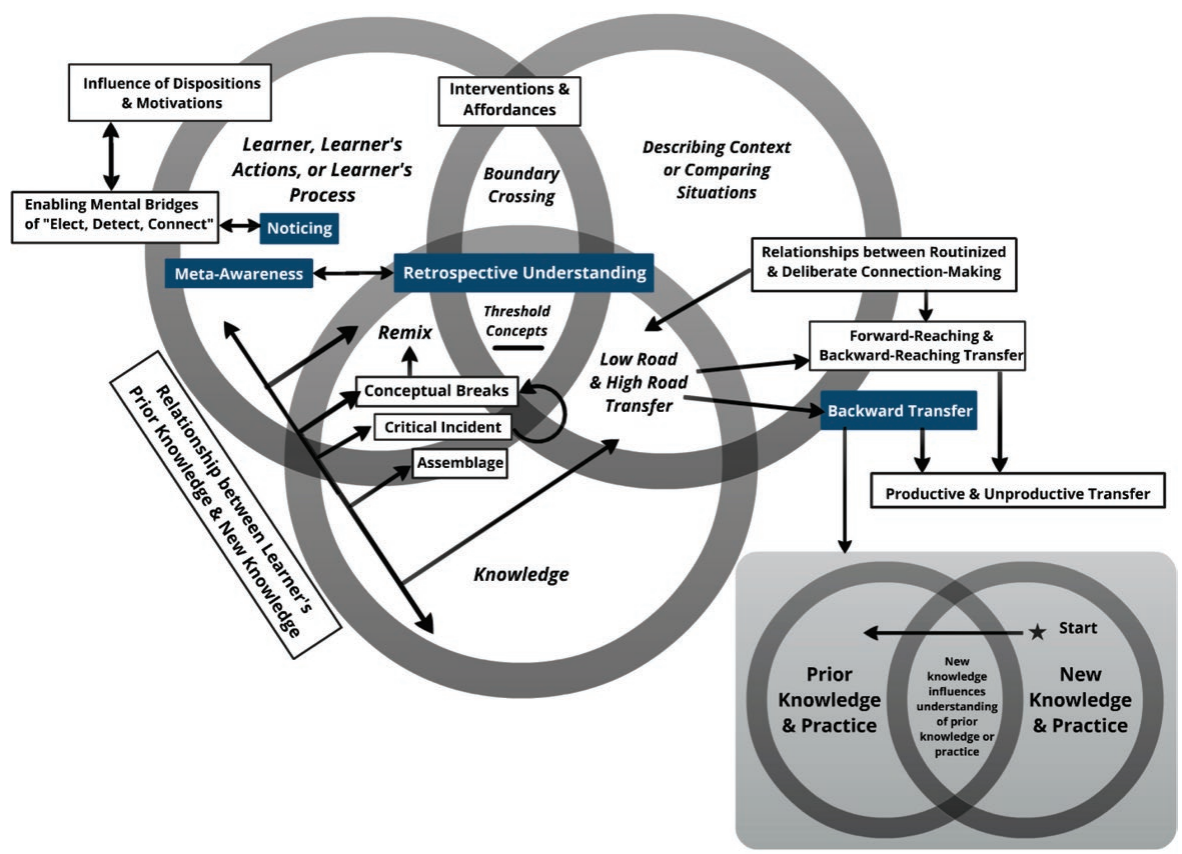

(Close-up View: Backward Transfer)

Figure 3.8. Mapping the terrain, stop six.

ing learning serves to solidify and deepen their previous learning through a process of backward transfer.

There have been a few studies of backward transfer, most notably in transdisciplinary linguistics research examining the influence of L2 language learning on L1 language (e.g., Chen, 2006; Pavlenko \& Jarvis, 2002). In many of these linguistic studies, backward transfer is seen as unproductive; i.e., it had a negative effect on L1 language. ${ }^{5}$ The most extensive study of productive backward transfer that I have located is Charles Hohensee's 2011 dissertation, Backward Transfer: How Mathematical Understanding Changes as One Builds upon It. In this study, Hohensee stipulated that productive backward transfer was more likely to happen when prior knowledge was still developing and when it was considered foundational to the acquisition of new knowledge (which would likely not be the case with L2 influences on L1 language, but is probably often the case with GSIs). Proximity also seems to be a factor in backward transfer, just as it is with forward transfer. When two events occur within close proximity to one another, individuals are more likely to "notice" connections between these two events.

Hohensee found "noticing" to be a useful frame for explaining instances of both productive and unproductive backward transfer. Basically, "noticing" refers 
to the process of detecting, selecting, and attending to certain features of a problem, text, situation or environment. The products of noticing, the specific features that individuals actually select to attend to, are called the "center of focus" (Lobato, Rhodehamel \& Hohensee, 2012). In his ethnographic work on "professional vision," Charles Goodwin (1994) posited that what individuals see (notice) and what they attend to (center of focus) will be related to their current discourses or professional communities. Noticing is a concept, then, that expands Perkins and Salomon's notion of "detecting" by linking it to particular ways of seeing that are employed by professional communities. Much of the work involved in developing and deepening one's expertise as a GSI in the first-year writing program seems to involve learning to notice what the larger discipline and the local community deem important about student writing. Such work sometimes requires GSIs to dramatically shift their center of focus, as we saw with Justin's "mental shift" concerning the importance of mechanical correctness.

Justin's mental shift occurred as the result of consciously noticing something that did not jive with his prior mind-set as a copy-editor and proof-reader, where detecting "error" was the center of focus of his work. As he acquired more control of the "big [disciplinary] picture" in his new discourse, his center of focus gradually, but unconsciously began to shift. However, he did not become aware of this mental shift taking place until he was asked to revisit a text that he had read earlier in his composition seminar.

\section{Distinctions between BaCkWARd Transfer AND BaCKWARD-REaCHING TransFer}

While both backward and backward-reaching transfer represent a break in forward momentum, the exigence for backward-reaching transfer is an encounter with a problem, something that compels individuals to pause, reverse direction, and consult previous knowledge or experience. Backward transfer, on the other hand, may initially need to be "cued" and "guided' even more than other forms of transfer, as Justin noted at the end of his second quarter of teaching: "The only reason I make these connections is because we've been cued or trained to make the connections. And I think it becomes a habit of mind. Once you understand the concept and the strategies for doing this yourself, then it's really easy to pass on to the students." The exigence for backward transfer in classroom situations often comes in the form of some kind of curricular intervention such as a reflective assignment that directs students to shift their center of focus in order to use new knowledge to enlarge or deepen their understanding about prior learning.

Hohensee observed that backward transfer seems to happen more readily when the prior knowledge is foundational to new knowledge, but has not yet been solid- 
ified, which is likely the case for first-quarter GSIs. The new knowledge serves to clarify and enhance the understanding that is still being constructed. On the other hand, when prior knowledge has solidified, backward transfer is more difficult. Here, individuals may be more inclined to adopt an assemblage method (Robertson et al., 2012). Reluctant to dislodge what has already been cemented, they simply add the new information to the old, regardless of fit. Gee alludes to this process in his discussion of learning and acquiring new discourses. He explains that if a person has "not fully mastered a particular secondary discourse"-in this case, teaching the first-year writing course- two things are like to happen: The person may revert back to their primary discourse, "adjusting it in various ways to fit it to the needed functions," or the person might adopt a "simplified" or "stereotyped" version of the discourse they are learning to control (2012, p. 172).

Backward transfer, however, does not always require an exigence in the form of a curricular intervention. Backward transfer can also occur when individuals (typically those who exhibit more "problem-exploring" or "boundary-crossing" dispositions) are involved in gaining new knowledge in multiple contexts simultaneously. Some GSIs will shift their center of focus from their students' writing and reading to noticing their own prior or current ways of writing and reading. For example, in learning how to teach cohesion via the principle of connecting new information to known information, some GSIs have used this information to help them understand their own difficulties with reading dense, critical theory texts in their literature classes. The knowledge GSIs gain from teaching offers a provisional explanation for their own reading difficulties. In this instance, "backward" transfer is not exactly backward; it appears to operate laterally across domains with "similar levels of complexity" (Hohensee, 2011, p. 20). Although GSIs are still in the process of acquiring knowledge in both domains, in this situation, one domain is not necessarily foundational to the other; rather they are linked by their proximity. Thus, the knowledge they are learning in each discourse can serve a meta-function for better understanding the other, as we see with Justin's discussion of hybridity below.

At the end of his fourth quarter, Justin described a paper he had written in one of his literature seminars where he focused on the "hybridity" that comes from occupying two, often conflicting discourses at once: "I ended up showing how linguistic hybridity mirrored social and cultural hybridity. This hybridity ultimately could promote brand-new epistemologies of knowledge, ways of thinking and speaking and communicating that could challenge the dominant discourse." $\mathrm{He}$ then described how his insights into hybridity gained from his seminar paper illuminated his understanding of his own position as a learner attempting to master two (sometimes conflicting) discourses as a graduate student and teacher simultaneously. What he initially viewed as a weakness, he now began to think of as a strength: 
Being the teacher and the student puts us in a position of hybridity and that's a good thing because that's when you can create something new. You have a foot in each group so you can have insights into both discourses, and you can talk about each discourse with the other group in a way that is both credible and makes sense. Being in this hybrid position, or being bi-discoursal, creates a greater sensitivity to both groups.

There is a further distinction between backward transfer and backward-reaching transfer. In backward-reaching transfer, individuals typically reach back into their repertoires for already articulated or fully formed solutions that they can bring "ready-made" to a current problem. Many studies of the composing process (e.g., Flower \& Hayes, 1981) have depicted experienced writers reaching-back into their repertoires for solutions to the current writing problem. These professional writers draw on their already formulated rhetorical knowledge of "what works," bring it forward, and adapt it to fit the new rhetorical situation. On the other hand, revision, understood as a process of re-seeing and re-understanding what is just developing on the page, likely also involves a process of backward transfer.

\section{From Backward Transfer to Retrospective Understanding}

Just as individuals utilize prior knowledge and learning to influence new knowledge and learning in different ways, new knowledge and learning also seems to influence prior knowledge and learning in a variety ways. As we saw above, new learning can inflect or replace prior knowledge in productive or unproductive ways, often via an unconscious, low-road transfer process. Second, new learning can refresh or shore up prior knowledge. Reminiscent of the assemblage method that Robertson et al. (2012) describe, new learning doesn't substantially alter prior knowledge and learning. Third, new learning can build, extend, or deepen prior knowledge in ways that may or may not involve high-road processing. Both the second and third possibilities are the focus of Hohensee's dissertation on backward transfer, subtitled How Mathematical Understanding Changes as One Builds upon It (emphasis added). In both these instances, "the foundational knowledge is usually still developing as the new content is already being taught" (Hohensee, 2011, p. 398).

A fourth possibility occurs when elements of new learning are integrated with elements of prior knowledge and reworked, repurposed, or remixed to create something new or distinct. I include the remix among these seven possibilities because it represents the point where we can see the interaction between forward and backward forms of transfer most clearly. Robertson et al. (2012) identified remix as one of the ways students utilize prior knowledge in new writing situations; however a remix can also entail backward transfer in the process of creating something new. 
Although in Robertson et al.'s example, the student Alice did not totally reinvent her current understanding of writing by inventing a new coherent whole; instead, like many students, she made piecemeal adjustments by editing, patching, and adding bits and pieces together.

A remix can also function on a meta-level, which suggests a fifth way that new knowledge can influence prior knowledge: New knowledge can be used as a lens to examine or critique prior knowledge. This possibility bears similarity to Gee's (1987; 2012) concept of "powerful" or "liberating literacy." Here, individuals use knowledge "learned" in one discourse as meta-knowledge to explain or critique knowledge in another discourse. And finally, a sixth and seventh way: new knowledge can make tacit prior knowledge visible and it can also substantially revise or transform prior knowledge.

The last four possibilities all entail high-road processing and point to a somewhat different kind of influence of new knowledge on prior knowledge. These relationships do not depend on a prior domain that is antecedent or proximal. In fact, changes may occur to prior knowledge that are not obviously connected to the new knowledge or learning. These possibilities also differ from the first three possibilities in that they may entail what Salomon and Perkins (1988) refer to as "far transfer," connection-making between drastically different discourses or domains far removed from each other in time. The last four possibilities then, seem distinct enough to warrant their own category, "retrospective understanding," as well as their own designation on the transfer map.

\section{ReTROSPECTIVE UNDERSTANDING}

Retrospective understanding is similar to backward transfer to the extent that both entail a shift in the center of focus from new knowledge to prior knowledge. In Hohensee's (2011) research, backward transfer, however, was explicitly concerned with what was being learned-the propositional knowledge or skill per se. When individuals brought features of new knowledge to bear on prior knowledge, the results could be assessed as being productive (positive influence) or unproductive (negative influence). However, this backward transfer is not really focused on changes in learners- their identities and relationship to the larger social context-only on their knowledge. On the other hand, most forms of retrospective understanding (with the possible exception of the remix), also focus on qualitative changes in the learner as well. While sometimes startling or troubling, retrospective understanding is almost always "productive" in terms of enlarging, deepening, and complicating, or transforming learners' prior understanding of themselves, their goals, and their ways of knowing, saying, doing, valuing, and so on. Table 3.1 summarizes the seven ways that new knowledges can influence prior knowledge. 
Table 3.1. Seven ways that new knowledge can influence prior knowledge in backward transfer and retrospective understanding

\begin{tabular}{|c|c|c|c|}
\hline $\begin{array}{l}\text { How New Learning } \\
\text { Influences Prior Learning }\end{array}$ & $\begin{array}{l}\text { Relationship between } \\
\text { Prior \& New Knowledge }\end{array}$ & $\begin{array}{l}\text { Near/Far High/ } \\
\text { Low Transfer }\end{array}$ & Focus \\
\hline $\begin{array}{l}\text { 1. New learning can inflect } \\
\text { or replace prior learning in } \\
\text { productive or unproductive } \\
\text { ways. }\end{array}$ & $\begin{array}{l}\text { Prior knowledge may or } \\
\text { may not be still developing. }\end{array}$ & $\begin{array}{l}\text { Near trans- } \\
\text { fer; low road } \\
\text { processing. }\end{array}$ & $\begin{array}{l}\text { Backward } \\
\text { Transfer }\end{array}$ \\
\hline $\begin{array}{l}\text { 2. New learning can refresh } \\
\text { or shore up prior knowl- } \\
\text { edge (assemblage). }\end{array}$ & $\begin{array}{l}\text { Prior knowledge is still } \\
\text { developing. }\end{array}$ & $\begin{array}{l}\text { Near or far } \\
\text { transfer; } \\
\text { low road or } \\
\text { high road } \\
\text { processing. }\end{array}$ & $\begin{array}{l}\text { Backward } \\
\text { Transfer }\end{array}$ \\
\hline $\begin{array}{l}\text { 3. New learning can build, } \\
\text { extend, or deepen (reconsti- } \\
\text { tute) prior learning. }\end{array}$ & $\begin{array}{l}\text { Prior knowledge is still } \\
\text { developing and may be } \\
\text { antecedent or proximal to } \\
\text { new knowledge; general } \\
\text { knowledge may be recon- } \\
\text { stituted into more specific } \\
\text { knowledge. }\end{array}$ & $\begin{array}{l}\text { Near or far } \\
\text { transfer; } \\
\text { low road or } \\
\text { high road } \\
\text { processing. }\end{array}$ & $\begin{array}{l}\text { Backward } \\
\text { Transfer }\end{array}$ \\
\hline $\begin{array}{l}\text { 4. Elements of new learning } \\
\text { are combined with elements } \\
\text { of prior learning to create } \\
\text { something original or } \\
\text { different (remix). }\end{array}$ & $\begin{array}{l}\text { Does not depend on prior } \\
\text { knowledge that is still } \\
\text { developing, antecedent or } \\
\text { proximal. }\end{array}$ & $\begin{array}{l}\text { Near or far } \\
\text { transfer; } \\
\text { high-road } \\
\text { processing. }\end{array}$ & $\begin{array}{l}\text { Forward \& } \\
\text { Backward } \\
\text { Transfer and/ } \\
\text { or Retro- } \\
\text { spective } \\
\text { Understanding }\end{array}$ \\
\hline $\begin{array}{l}\text { 5. New learning can be } \\
\text { used as meta-knowledge to } \\
\text { reflect on or critique prior } \\
\text { learning. }\end{array}$ & $\begin{array}{l}\text { Does not depend on prior } \\
\text { knowledge that is still } \\
\text { developing, antecedent or } \\
\text { proximal. }\end{array}$ & $\begin{array}{l}\text { Far transfer; } \\
\text { high-road } \\
\text { processing. }\end{array}$ & $\begin{array}{l}\text { Retrospective } \\
\text { Understanding }\end{array}$ \\
\hline $\begin{array}{l}\text { 6. New learning can make } \\
\text { tacit knowledge visible. }\end{array}$ & $\begin{array}{l}\text { Does not depend on prior } \\
\text { knowledge that is still } \\
\text { developing, antecedent or } \\
\text { proximal. }\end{array}$ & $\begin{array}{l}\text { Far transfer; } \\
\text { high-road } \\
\text { processing. }\end{array}$ & $\begin{array}{l}\text { Retrospective } \\
\text { Understanding }\end{array}$ \\
\hline $\begin{array}{l}\text { 7. New learning can revise } \\
\text { or transform prior learning. }\end{array}$ & $\begin{array}{l}\text { Does not depend on prior } \\
\text { knowledge that is still } \\
\text { developing, antecedent or } \\
\text { proximal. }\end{array}$ & $\begin{array}{l}\text { Far transfer; } \\
\text { high-road } \\
\text { processing. }\end{array}$ & $\begin{array}{l}\text { Retrospective } \\
\text { Understanding }\end{array}$ \\
\hline
\end{tabular}

To further elaborate on the distinction between backward transfer and retrospective understanding, I will use my "new knowledge" of transfer to revisit my own prior conceptualization of reflexivity. In Turns of Thought (Qualley, 1997), I 
define reflexivity as a response triggered by a dialogic (back and forth) encounter with an "other." The "other" might be a person, concept, text, theory, culture, discourse, and so on. In the process of trying to understand and make sense of the other, individuals shift their center of focus back to the self by making a "reflexive turn." This description of reflexivity, which, at the time, was influenced by my reading of ethnographers' reports of their experiences in the field, shares aspects of backward-reaching transfer, backward transfer, and what I am now calling "retrospective understanding."

In backward-reaching transfer, when individuals encounter a problem with new knowledge, they scan their prior knowledge for something that will help them access or understand the new knowledge. In backward transfer, individuals shift their center of focus from new knowledge to "re-connect" to prior knowledge. A similar process initiates the reflexive turn, but with a difference. In trying to make sense of an "other," individuals don't necessarily reach back to their prior knowledge and repertoires for solutions to a problem; they reach back to identify and examine their own sense-making instruments. In other words, they shift their center of focus from what is being observed to themselves, the observer. They make a meta-move. Backward-reaching and backward transfer, then, describe problem-solving, cognitive processes. Reflexivity and retrospective understanding stimulate meta-cognitive processes that are better suited to problem-finding and problem-exploring. In all three cases, individuals shift their centers of focus, but they shift them for different purposes in order to achieve different goals.

Forward and backward transfer involve a movement in a single direction, either forward toward new knowledge or backwards toward prior knowledge. In backward-reaching transfer, the movement goes forward toward new knowledge, then backward toward prior knowledge and then forward again. As already noted, the center of focus in backward-reaching transfer is still on solving the problem of understanding the new knowledge.

On the other hand, both the movement and the center of focus in the reflexive process are bi-directional. In this instance, individuals consciously direct their attention back and forth between trying to understand the new situation while they are examining their own prior knowledge, understanding, and ways of knowing-ideally, with an eventual gain of understanding in all domains. Retrospective understanding then might be thought of as the successful outcome of this bi-directional, reflexive movement. With retrospective understanding, individuals don't just build on recent, prior knowledge as they do in backward transfer; they become consciously aware of it. This prior knowledge and understanding, when viewed from the perspective of new knowledge and experience, may become "complicated" or questionable in the process. It may be 
seen and experienced as "troublesome" in ways that it wasn't previously. Again, we might recall Justin's response to reading Robert Connors' essay. The essay revealed a conflict in his own student-centered values and he had to examine his values and reassess his goals. Retrospective understanding, then, may also add a dimension to our understanding of the challenges that threshold concepts pose (Adler-Kassner et al., this volume; Meyer \& Land, 2003, 2006). Threshold concepts involve encounters with "troublesome knowledge," require a conceptual break with previous understanding, enlarge the possibilities for noticing, connection-making, and integration, and are generally irreversible (i.e., we can't un-know them). Furthermore, grasping threshold concepts often involve "messy journeys, back, forth, and across conceptual terrain" (Cousins, 2006).

Backward transfer and retrospective understanding are virtually uncharted territory in writing studies research, and yet they both seem important to our understanding of transfer and the ongoing deepening of expertise in both writing and writing instruction. So many of our disciplinary truisms - writing is a recursive process; all writing is rewriting; writers write from a position of not-knowing - point to the necessity of some form of retrospective understanding. In addition, many recent conceptualizations about writing - writing as repurposing and writing as remixing-depend on being able to re-envisage old knowledge in new ways. Most forms of reflective writing are designed to elicit backward transfer or retrospective understanding. Finally, the concept of revision as re-seeing and re-envisioning would seem to depend on backward transfer and retrospective understanding. If students (or teachers) are to bring new knowledge and information to bear on the subjects they are writing about (or teaching) and, thereby deepen, extend, and transform their understanding, then we need to map a theory of backward transfer and retrospective understanding. Retrospective understanding also directs our attention back to the transition process itself.

\section{CONSEQUENTIAL TRANSITIONS, RECONSTITUTION OF KNOWLEDGE, AND DEVELOPMENT OF EXPERTISE}

Beach (2003) describes a transition as a "developmental change." Changes to the individual or to the activity lead to changes in the relation between the individual and the activity. As we saw with Justin, these changes are often understood retrospectively. In one sense, retrospective understanding may be a process that both activates the transition and serves as a by-product of that transition-a transition that may at some point become consequential. Transitions, according to Beach, become "consequential" when they are "consciously reflected on, struggled with, and shift the individual's sense of self or social position" (2003, 


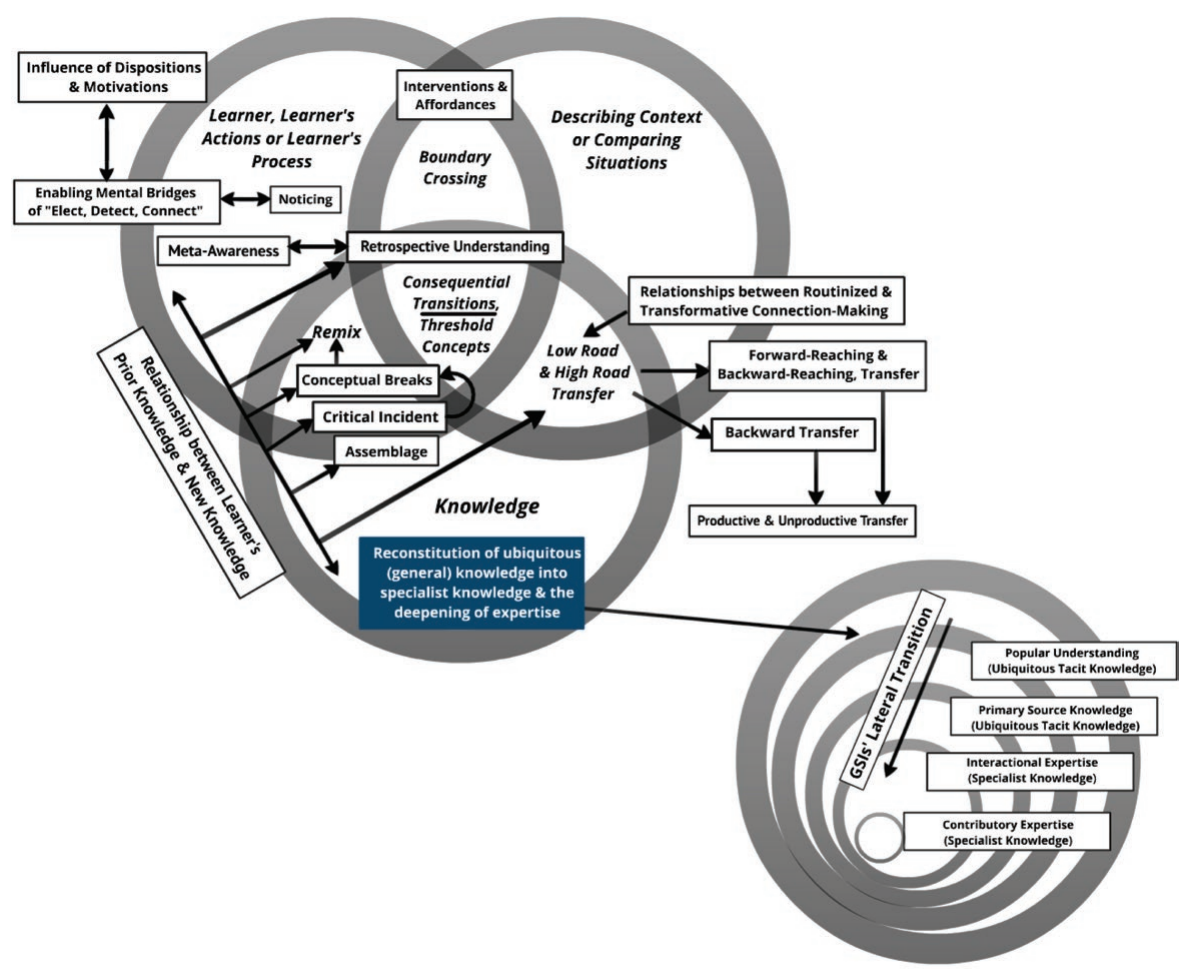

(Close-up View: Deepening of Specialist Expertise)

Figure 3.9. Mapping the terrain, seventh stop.

p. 42). But these transitions affect more than the individual, which is why consequential transitions are located at the intersection of learner, knowledge and context on the Elon Statement's visual map.

Although Beach $(1999 ; 2003)$ is most closely associated with the concept of consequential transition, Nowacek (2011) and Hagar and Hodgkinson (2009) offer slightly different perspectives. Nowacek's (2011) concept of transfer as "recontextualization" also allows for consequential changes in the individual's knowledge, ways of knowing, identities, and goals, but foregrounds the rhetorical dimensions of these changes. Both Beach and Nowacek see a relationship between individuals and contexts; however, an important distinction is that Nowacek focuses more on the individual, while Beach highlights the relationship between the changing individual and changing social activities within the domain.

Like Nowacek, Paul Hagar and Phil Hodkinson are concerned with how knowledge is specifically reconstituted within individual learners. They claim that 
both knowledge and skill "become changed and reconstituted within the person who has gone through and is going through a learning process" (2009, p. 632). For them, a more useful metaphor would be to think "of learning as becoming within a transitional process of boundary crossing" (emphasis added, 2009, p. 635). The extent to which individuals "become" (reconstituted) when they encounter new knowledge and situations depends in part on prior knowledge, in part on the motivation, dispositions, and various forms of capital (Bourdieu) that individuals have acquired, and in part on the new social context in which they enter. As I noted earlier, however, there is only so much the first-year writing program can do in the way of curricular interventions and pedagogical affordances to assist GSIs in their processes of becoming (teachers). A great deal depends on their own goals and motivations for further developing their expertise.

\section{The Reconstitution of KNowledge and the Development of Expertise}

In terms of their specific knowledge of first-year writing and teaching, GSIs bring various levels of "ubiquitous tacit knowledge," knowledge and skill that they have acquired just by navigating their way through life and interacting in human society (Collins \& Evans, 2011). In their research on the nature of expertise, sociologists Harry Collins and Robert Evans differentiate between three kinds of ubiquitous knowledge. When they enter the program, GSIs generally have more than what Collins and Evans refer to as a "beer mat" knowledge of teaching, the kind of fact-like knowledge needed to succeed in knowledge or trivia quizzes. Much of the knowledge that GSIs bring when they enter the program stems from a "popular understanding" of writing and writing instruction. Such general knowledge, of course, hides detail and nuance and is especially questionable on matters that are complicated or not "settled" (such as the teaching and evaluating of writing). A few GSIs bring some "primary source knowledge" from their reading (or perhaps from their own prior course work). Familiarity with the primary source knowledge of a field is necessary, but not sufficient for developing more specialist forms of expertise.

If their transition into the first-year writing program is to be (at least somewhat) generative for them (and the program), GSIs will need to turn their ubiquitous prior understanding of writing and the teaching of writing into more complex and specialized forms of knowledge and meta-expertise. Accomplishing this task requires more than simply replacing or adding to their prior levels of general knowledge via a process of assemblage. To develop their expertise, GSIs must use new knowledge to reconstitute their "popular understanding" into a more nuanced understanding of writing and the teaching of writing. This process involves the kind of backward transfer as indicated by possibility 3 ("new learning can 
build, extend, or deepen (reconstitute) prior learning") in Table 3.1. ${ }^{6}$

Similar to Salomon and Perkins' (1989) and Michael Carter's (1990) theories about the usefulness of general knowledge for developing local knowledge, Collins and Evans note that ubiquitous tacit knowledge is always exercised in the course of gaining more explicit and specialized forms of knowledge (2011, p. 17). This process requires opportunities for both acquisition and learning (Gee, 1987; 2012). Through their ongoing conversation and interaction with the activities of other domain specialists, GSIs gradually acquire more specialized expertise. Through their learning (explicit instruction), GSIs develop the meta-knowledge of writing and the teaching of writing that they need to evaluate and critique the "what's" and "why's" of performance for both themselves and their students.

GSIs' relationships to the activities of teaching first-year writing change as their ubiquitous knowledge evolves into more specialized understanding and know-how. In the process, both GSIs and the first-year writing program may be reconstituted in multiple ways. Similar to the irreversibility of the awareness that comes from mastering a threshold concept, when knowledge is reconstituted into deeper individual understanding, it is unlikely to be "un-constituted."

Collins and Evans (2011) distinguish between two kinds of specialist expertise, contributory and interactional. Contributory expertise equates with most people's general understanding of what an expert is. Contributory experts $d o$ things with their specialist knowledge and contribute to furthering the knowledge and practice in their fields. Interactional experts are individuals who acquire fluency in the language of the domain through their interaction and ongoing conversation with specialists. Interactional expertise "is expertise in the language of a specialization in the absence of its practice" (Collins \& Evans, 2011, p. 28). Here, "practice" would refer to the practice of being a rhetoric and composition scholar and not to the practice of teaching writing. Even though teachers "contribute" much, teaching in all forms would be considered a form of interactional expertise. ${ }^{7}$ Over their two years in the program, most GSIs develop varying degrees of interactional expertise; only a very few become or go on to become contributory experts. This gradual deepening of specialist expertise represents what Beach $(1999 ; 2003)$ calls a lateral transition.

\section{Lateral Transitions.}

Beach $(1999,2003)$ identifies four kinds of consequential transitions, two of which (lateral and encompassing) I'll reference here with respect to GSIs and the first year writing program. Lateral transitions describe a developmental progression in a single direction e.g., from novice to expert, and are generally seen 
as positive and transformative. Grasping a threshold concept is an example of a lateral transition. The close-up image in Figure 3.9 depicts GSI's "lateral transitions" from more ubiquitous forms of knowledge to the more specialized knowledge of interactional expertise. The movement through the concentric circles is meant to suggest that this transition represents a deepening of expertise. As GSIs become more enculturated into the language and practices of the domain, they begin to notice or detect different things, and as their centers of focus shift, they make finer and finer distinctions. Thus, popular understanding knowledge is not replaced with specialized knowledge; it is reconstituted, gradually thickened and layered with more nuance. Like a prior draft that has been typed over and revised, these kinds of lateral transitions are irreversible.

\section{EnCOMPASSING Transitions.}

Beach notes that "learners and social organizations exist in a recursive and mutually constitutive relation to one another across time" (1999, p. 111). GSIs adapt and change to fit the requirements of the writing program; but the writing program also morphs to meet the needs of a constantly shifting demographic of graduate student teachers. This dynamic captures different forms of what Beach describes as "encompassing transitions," transitions that "occur within the boundaries of a social activity that is itself changing" (1999, p. 117). The degree to which GSIs and the program are changed by their "mutually constitutive" relationship, and whether these changes reflect small, incremental adjustments or represent more substantive, fundamental shifts, may depend, in part, on the program's and the individual GSI's capacity for modification at a given time.

\section{CORRIDORS OF TOLERANCE OF ACCEPTABILITY AND AREAS OF MODIFICATION}

The concept of the "corridor of tolerance" offers a way to link theories of developing expertise to the "motivational and dispositional drivers" (Perkins \& Salomon, 2012) that activate new learning and lead to changes in the relations between individuals and activity systems during periods of transition. This hypothetical construct was originally posited to explain why teachers decide to make changes in instruction on the basis of their own self-evaluation and reflection (McAlpine \& Weston, 2001; McAlpine, Weston, Beauchamp, Wiseman \& Beauchamp, 1999; McAlpine, Weston, Berthiaume, Fairbank-Roch \& Owen, 2004). When teachers' self-evaluations are negative, or lie outside of their "corridor of tolerance" or limits of acceptability for themselves, they will typically make changes to their teaching. When their evaluation is positive, teachers are 


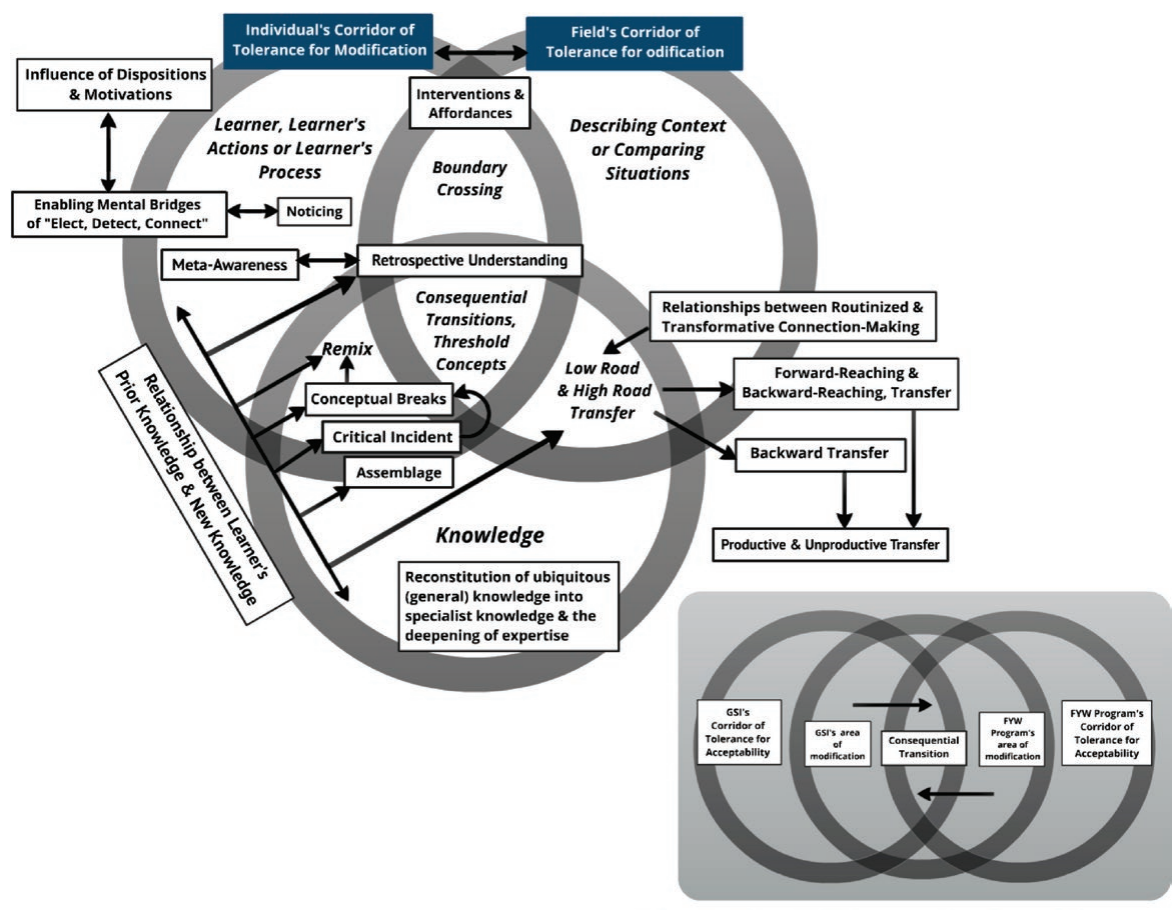

(Close-Up View: GSI \& Program Corridors of Tolerance)

Figure 3.10. Mapping the terrain, eighth (and final) stop.

less likely to make changes. When their evaluations are neutral or fall on the outer edge of the perimeter of the corridor, some teachers may make small, incremental adjustments. The smaller the corridor for acceptability, the more likely teachers will decide to revise and modify their practices. The larger the corridor of acceptability, the less likely teachers will make changes since their "tolerance" for what falls into the acceptable range of performance is greater. The level and kind of expertise is also pertinent. Teachers with the least amount of specialist expertise tend to have larger corridors of tolerance for acceptability and are less likely to modify their practices because they are less likely to notice the fine points of distinction that teachers who have developed more specialist expertise see. Thus, if individuals are to develop their levels of expertise further, they may need to "shrink" the size of their corridors.

In the above studies, experienced teachers made adjustments when they recognized that something was not working in terms of their specific goals and expectations. However, to move beyond current levels of expertise, teachers also need to think about what could be made to work more effectively-even when 
their assessment of their teaching is generally positive. In the following reflection, Justin explained why he was going to revise an assignment that he believed had resulted in some of the strongest work from his students that quarter. In this assignment, students produced a short piece of writing where they consciously tried to emulate the mindset and rhetorical sensibilities of Mike Rose.

Rose's tone and style forced them [his students] to be more rational, thoughtful, and open-minded. As it turned out, the assignment instilled some enduring lessons about tone, attitude, ethos, generous countering, audience awareness, and so on. Gratifyingly, I saw that many students maintained some noticeable influences of Rose's approach in future writing. This quarter I plan to alter the assignment slightly so that they use Rose's approach to respond to or counter one of the other authors and I hope that this results in an even more beneficial exercise. (Emphasis added).

Many new GSIs would have simply engaged in low-road transfer, carrying the exact same assignment into their next quarter's course because it had been effective and fell within their corridor of tolerance for acceptability. Understandably, when designing their course, new GSIs typically put their mental energies into changing what they know didn't work, leaving what did work alone. However, Justin's corridor of tolerance for acceptability was rapidly shrinking by the end of his first quarter.

GSIs' internal drivers (dispositions and motivations) also seem to play a role in the size of their corridors and the speed in which they contract or expand. Justin not only had to have enough specialist understanding of the larger course to notice or detect what he might do differently; he had to be motivated enough to elect to make this change, and he had to see himself as capable of doing so. The external drivers that the WPA introduces to support GSIs' development and integration into the first-year writing program are also intended to permeate and shrink GSIs' corridors of tolerance so as to accustom them to the possibilities of ongoing course revision and innovation. The extent to which these external drivers succeed in this endeavor is in part connected to GSIs' internal drivers, and in part related to their length of time in the program.

Just as individuals have a corridor of acceptability and areas where modification is possible or likely, so too do institutions and fields. The close-up view in Figure 3.10 depicts the respective corridors of tolerance for modification for the first-year writing program and for GSIs. While GSIs (are expected to) do the bulk of modifying and "cognitive retooling" during their lateral transition from ubiquitous to specialist expertise, the first-year writing program does change in 
response to the constant flow of new GSIs through its borders. However, the pace of change for the program is much slower and the scope of these modifications much smaller and more incremental in nature. The intersection of the two areas of modification represents the space where changes to both GSI and program may eventually result in a consequential transition in the relations between them. For instance, Justin's assignment on "anticipating objections" that I mentioned earlier in the chapter led to changes in the curriculum and assessment of writing.

The construct of the corridor of tolerance, then, adds another element to the conceptual topography of the transfer terrain by suggesting the important function that specialist knowledge plays in both forward and backward forms of transfer. As GSIs begin to integrate more specialist knowledge into their current understanding of teaching writing, the areas in which they are likely to modify their prior knowledge and practice expand. The constant flow of new GSIs through the first-year writing program likewise keeps the program's corridor of tolerance elastic and permeable to further modification.

\section{WHERE WE ARE NOW (OR WHERE ARE WE NOW?)}

A map is only effective to the extent that it can help us locate where we are so we can see where we might go. In this chapter, my aim has been to forge more detailed linkages between selected points in the Elon Statement on Writing Transfer as well as scout further afield into less explored territory.

Many of the terms and concepts that the Elon Statement uses to describe transfer depict movement of some kind, for example: (expansive) learning, (critical) transition, boundary-crossing, remix, and integration. I have suggested possibilities for what might trigger or activate this movement, what this movement looks like, what direction this movement might take, and how deep it might go. Newton tells us that a body at rest stays at rest. And, unless acted upon by some outside force, the body in motion can resist speeding up, slowing down, or changing direction. The curricular interventions and pedagogical affordances operating in the first-year writing program remind us that movement is more likely to happen when cued and prompted by some outside force or exigence. Of course, human beings are subjects, not objects. They have volition, will, and desire (dispositions and motivations) that can shape and impact their learning trajectories through space and over time. Unlike objects, subjects have at least partial navigational control of their speed, velocity, and pace of acceleration/ deceleration in response to a multitude of forces-political, institutional, economic, cultural, social, educational, and psychological. As we continue the project begun with the Elon Research Seminar on Critical Transition: Writing and 
the Question of Transfer, how can we better describe the directions, rhythms, and pace of these movements in other locations, especially during times of critical transition? What other factors influence whether individuals go-with-theflow, push back, slow down, speed up, idle, stall, retreat, or change direction?

Like geographical maps, conceptual maps that endeavor to depict a dynamic and multi-dimensional reality in a two-dimensional medium can distort as well as illuminate. However, what is clear is that the many, overlapping paths that lead through transfer's theoretical thickets sometimes only become visible in hindsight, perhaps through a process of backward transfer. And when they do become accessible, they will continue to require further modification. My preliminary efforts in plotting potential relationships between selected pieces of the transfer map are necessarily partial and provisional, but I hope they will prove generative for future treks into this terrain. Right now, you are here, but I trust that this vantage point can provide some direction for locating a more complex there.

\section{NOTES}

1. In this chapter, I draw from interview and document data collected for a research study that I began while I was a participant in the Elon Research Seminar on Critical Transitions. The study examines what GSIs say they routinely utilize and creatively repurpose in their teaching and graduate studies classes. Because of their dual status as teachers and learners, I was initially interested in the boundary-crossing exhibited by GSIs in their development of expertise. My hypothesis was that being learner and teacher at the same time may contribute to a heightened meta-awareness in each discourse, especially when explicitly "cued" to look for connections.

2. My use of the term, "driver" comes from Perkins and Salomon's 2012 article where they note that high road transfer often require "significant motivational and dispositional drivers" because of the "extended cognitive effort" necessary to pursue connection making. (p. 251). I have repurposed the concept to also include external drivers that might nudge and support GSIs motivations and dispositions.

3. Justin Ericksen was one of six GSI "co-inquirers" in the study I describe in my first note. All references to his work in this chapter come from taped interviews and course work that he did while he was a graduate student. After he graduated with his MA degree, he served as my Assistant Director of Composition for a year. He is now employed in a full-time, tenure track position in a local community college. He read every draft of this chapter and offered helpful feedback and editorial suggestions.

4. Examples of how Driscoll and Wells' four general dispositions apply to GSUs include: (1) What is their motivation? What do GSIs value about teaching? Are GSIs teaching primarily to pay for their graduate education or to make themselves at- 
tractive on their applications to Ph.D. programs? To be part of a community? Do they see teaching as an important and integral part of their graduate education? As an end in itself? (2) What is their level of self-efficacy? How capable do they feel as teacher-learners? How do they deal with uncertainty? How do they approach difficulty? How do they respond or persevere in the case of setback or failure? (3) What is their theory of attribution? Who or what do they see as being responsible for what happens in the classroom? When they become stressed with the demands of the work or when things do not go well in class, do they attribute these difficulties to the unreasonable expectations of the WPA, to a time-consuming or overly-difficult curriculum, to their dis-interested, under-prepared, or lazy students, or to their own lack of preparation, understanding, or engagement? (4) What are their self-regulatory strategies? To what extent can they juggle their many competing demands? What is their work-ethic? How do they plan and organize their time? Can they get the work done without compromising their performance in the classroom or their graduate studies courses?

5. In these linguistics studies, "unproductive" seems to mean interference or "contamination" of the "norms" of conventional L1 language structures by L2 language structures. We also see the fear of "unproductive" contamination from backward transfer at work in every literacy crisis all the way back to Plato's fear of writing. Currently, this fear manifests itself in concerns that texting will interfere with students' ability to write extended prose in Standard English. In other words, texting will exert an unproductive influence.

6. Haskell's (2006) taxonomy of transfer noted in the Elon Statement doesn't include knowledge reconstitution as one of his fourteen kinds of transfer, but it seems important to mark on the map.

7. The contributory-interactional distinction becomes blurred when we think about the differences between being a writer and a writing scholar, a movie-maker and a movie critic, or a studio artist and an art historian. The expertise of some contributory experts, especially in the arts and humanities where the expertise is based on knowledge about texts, is a case in point. In the case of the scholar, critic, and historian, expertise really means specialized forms of judgment or meta-expertise. We can also see the different levels of interactional expertise when we consider the difference between being a graduate student instructor who is the teacher of record for his or her own classroom and a teaching assistant who assists another professor in teaching a course.

\section{REFERENCES}

Beach, K. D. (1999). Consequential transitions: A sociocultural expedition beyond transfer in education. Review of Research in Education, 24, 101-139. 
Beach, K. D. (2003). Consequential transitions: A developmental view of knowledge propagation through social organizations. In T. Tuomi-Gröhn \& Y. Engeström (Eds.), Between school and work: New perspectives on transfer and boundary crossing (pp. 39-61). Boston: Pergamon.

Bereiter, C. \& Scardamalia, M. (1993). Surpassing ourselves: An inquiry into the nature and implications of expertise. Chicago: Open Court.

Bourdieu, P. (1990). The logic of practice. Stanford, CA: Stanford University Press.

Carter, M. (1990). The idea of expertise: An exploration of cognitive and social dimensions of writing. College Composition and Communication, 41(3), 265-286.

Chen, F. (2006). Interplay between forward and backward transfer in L2 and L1 writing: The case of Chinese ESL learners in the US. Concentric Studies in Linguistics, 32 (1), 147-196.

Collins, H. \& Evans, R. (2009). Rethinking expertise. Chicago: University of Chicago Press.

Connors. R. (1985). Mechanical correctness as a focus in composition instruction. College Composition and Communication, 36(1), 61-72.

Cousins, G. (2006). An introduction to threshold concepts. Planet, 17, 4-5.

Driscoll, D. L. \& Wells, J. (2012). Beyond knowledge and skills. Writing transfer and the role of student dispositions. Composition Forum, 26(Fall). Retrieved from http:// compositionforum.com/issue/26/prior-knowledge-transfer.php.

Flower, L. \& Hayes, J. (1981). A cognitive process theory of writing. College Composition and Communication, 32(4), 365-387.

Gee, J. P. (1987). What is literacy? Teaching and Learning; The Journal of Natural Inquiry, 2(1), 3-11.

Gee, J. P. (2012). Social linguistics and literacies: Ideology in discourses (4th ed.). New York: Routledge.

Goodwin, C. (1994). Professional vision. American Anthropologist, 96 (3), 606-633.

Guillory, J. (2008). On the presumption of knowing how to read. ADE Bulletin, 145 (Spring), 8-11.

Hager, P. \& Hodkinson, P. (2009). Moving beyond the metaphor of transfer of learning. British Educational Research Journal, 35(4), 619-638.

Haskell, R. E. (2001). Transfer of learning: Cognition, instruction, and reasoning. San Diego, CA: Academic Press.

Hohensee, C. (2011). Backward transfer: How mathematical understanding changes as one builds upon it. (Unpublished doctoral dissertation). University of California, San Diego and San Diego State University, San Diego, CA.

Lobato, J., Rhodehamel, B. \& Hohensee, C. (2012). "Noticing" as an alternative transfer of learning process. Journal of Learning and Sciences, 21(3), 433-482.

McAlpine, L. \& Weston, C. (2001). Reflection: Issues related to improving professors' teaching and students' learning. In N. Hativa \& P. Goodyear (Eds.), Teacher thinking: Beliefs and knowledge in higher education (pp. 59-78). Norwell, MA: Kluwer.

McAlpine, L., Weston, C., Beauchamp, J., Wiseman, C. \& Beauchamp, C. (1999). Building a metacognitive model of reflection. Higher Education, 37 (1), 105-131. 
McAlpine, L., Weston, C., Berthiaume, D., Fairbank-Roch, G. \& Owen, M. (2004). Reflection on teaching: Types and goals of reflection. Educational Research and Evaluation, 10 (4-6), 337-363.

Meyer J. H. F. \& Land, R. (2003). Threshold concepts and troublesome knowledge: Linkages to ways of thinking and practicing. Enhancing teaching-learning environments in undergraduate courses project. Edinburgh, UK: University of Edinburgh. Retrieved from http://www.etl.tla.ed.ac.uk/docs/ETLreport4.pdf.

Meyer, J. H. F. \& Land, R. (2006). Threshold concepts and troublesome knowledge: An introduction. In J. H. F. Meyer \& R. Land (Eds.), Overcoming barriers to student understanding: Threshold concepts and troublesome knowledge (pp. 3-18). New York: Routledge.

Middendorf, J. \& Pace, D. (2004). Decoding the disciplines: A model for helping students learn disciplinary ways of thinking. New Directions for Teaching and Learning, 98 (Summer), 1-12.

Nowacek, R. S. (2011). Agents of integration: Understanding transfer as a rhetorical act. Carbondale, IL: Southern Illinois University Press.

Pavlenko, A. \& Jarvis, S. (2002). Bidirectional transfer. Applied Linguistics, 23(2), 190-214.

Perkins, D. N. \& Salomon, G. (2012). Knowledge to go: A motivational and dispositional view of transfer. Educational Psychologist, 47(3), 248-258.

Qualley, D. (1997). Turns of thought: Teaching composition as reflexive inquiry. Portsmouth, NH: Heinemann/Boynton Cook.

Reiff, M. J. \& Bawarshi, A. (2011). Tracing discursive resources: How students use prior genre knowledge to negotiate new writing contexts in first-year composition. Written Communication, 28(3), 312-336.

Robertson, L., Taczak, K. \& Yancey, K. B. (2012). Notes toward a theory of prior knowledge and its role in college composers' transfer of knowledge and practice. Composition Forum, 26(Fall). Retrieved from http://compositionforum.com/issue /26/prior-knowledge-transfer.php.

Salomon, G. \& Perkins, D. (1988). Teaching for transfer. Educational Leadership (September), 22-32.

Salomon, G. \& Perkins, D. (1989). Are cognitive skills context bound? Educational Researcher, 18(1), 16-25.

Smith, S. (1997). The genre of the end comment: Conventions in teacher response to student writing. College Composition and Communication, 48(2), 249-268.

Sommers, N. (1982). Responding to student writing. College Composition and Communication, (33)2, 148-156.

Sommers, N. (1992). Between the drafts. College Composition and Communication, 43(1), 23-31.

Sommers, N. \& Saltz, L. (2004). The novice as expert: Writing in the freshman year. College Composition and Communication, 56(1), 124-149.

Tuomi-Gröhn, T., Y. Engeström \& M. Young. (2003). From transfer to boundarycrossing between school and work as a tool for developing vocational education: An introduction. In T. Tuomi-Gröhn \& Y. Engeström (Eds.), Between school and work: New perspectives on transfer and boundary crossing (pp. 18-38). Boston: Pergamon. 
Qualley

Wardle, E. (2012). Creative repurposing for expansive learning: Considering "problemexploring" and "answer-getting" disposition in individuals and fields. Composition Forum, 26 (Fall). Retrieved from http://compositionforum.com/issue/26/prior -knowledge-transfer.php.

Wenger, E. (1998). Communities of practice: Learning, meaning, identity. New York: Cambridge University Press. 


\section{CHAPTER 4}

\section{WRITING AND GLOBAL TRANSFER NARRATIVES: SITUATING THE KNOWLEDGE TRANSFORMATION CONVERSATION}

\section{Christiane Donahue}

In their decades of intersecting and co-evolving histories, writing studies, composition, and composition and rhetoric have experienced a series of phases. Each phase produces its master narrative, its story attempting to account for everything that matters to the field. Some of these phases become significant "turns" with permanent paradigm-altering effects; others are woven into our ongoing history as insightful periods that are complemented over time with additional research, new influences, and problematizing of perspectives. It is difficult, in a given moment, to know whether we are seeing a phase or a turn; years later, the history clarifies itself.

The US discussion about writing knowledge transfer is a powerful and promising current phase in our thinking. It appears to be a frame for research and pedagogy that can help us account for and understand how students learn to write and how they appropriate usable knowledge about writing, as well as how teachers can best enable and support that learning. But as with all new phases, there is more to the story. This chapter is designed to complement, extend, and in some ways challenge our existing US conversations about transfer. It is time to contribute back to the broader cross-disciplinary and international research about transfer that composition has recently picked up, and to see our US writing studies discussions in light of that broader research.

As Moore suggests in her 2012 article mapping the current US transfer writing research, "The map of writing-related transfer research has vast areas of uncharted territory" ("Adding Detail," para. 1). This chapter fills in a bit of that uncharted territory, adding to the possible theoretical/conceptual frames provided by many scholars, including those who attended the three-year Elon University Research Seminar on Critical Transitions: Writing and the Question of Transfer. It does so by drawing from additional disciplines and traditions, as recommended in the Elon Statement on Writing Transfer, a document that also 
calls our attention to the diversity of meanings in play under the "transfer" umbrella and indicates specifically that the work of naming and understanding the facets of transfer is far from complete. The chapter will suggest that those other traditions give us reasons to rethink transfer, as a term and as an operationalized concept, and offer new ground in two key ways: (1) by critiquing US transfer discussions with a European lens and (2) by exploring uses of the term transfer from diverse disciplinary traditions and domains outside of writing studies. I hope to convince readers that the rich diversity of European scholarship about transfer, as well as the intriguing alternative domains of research that focus on transfer, can be useful to growing our understanding, opening up our options, taking us further, sharpening our place, and delineating our unique contributions. In exchange, our focus on transfer in university student writing can contribute to that global and cross-disciplinary conversation, which is complicated, messy, dialogic, and ongoing-a Burkean parlor of global proportions that we are joining, not initiating.

I have argued elsewhere (Donahue, 2008; Horner, NeCamp \& Donahue, 2011) that we must de-center ourselves in the global field of writing studies if we do seek growth in the context of the international landscape. The transfer phase in US writing studies opens up the opportunity to de-center and re-calibrate in both global and cross-disciplinary contexts. ${ }^{1}$ In so doing, composition scholars might determine that transfer is useful as a term that sparks conversation, but its multivalence and diversity and its metaphoric limitations might suggest it is not a long-term solution, but a term of passage toward more complex approaches. One of the limitations of master narratives is that, by their nature, they resist problematizing information. Allowing "transfer" to play the role of overarching term in a master narrative about learning might prevent growth in understanding the phenomenon at hand. There have been arguments for maintaining focus on the single term in order to position the field more powerfully in the disciplines and in the more public and political discussions of writing instruction and learning. But words matter, in our field of words, and positioning with reference to other disciplines is more likely to be strengthened by the depth of our embrace of complexity.

One additional question the writing knowledge transfer discussion provokes is about writing knowledge itself. What kind of knowledge or knowing is writing? What is writing? That is fortunately a question we share with scholars from contexts outside the US and outside writing studies. This chapter, then, brings forward the many ongoing explorations of the history and currency of transfer in US narratives, global scholarship, and cross-disciplinary research, in relation to our notions of language and of writing - writing knowledge, writing knowing, and troublesome knowledge. It argues that we must connect what we know 
of language acquisition and language functions to our discussions and debates about writing, writing knowledge, and notions of knowledge transformation.

\section{THE TRANSFER DISCUSSION: SOME US AND EUROPEAN PERSPECTIVES}

Discussions of and research about writing knowledge transfer have fairly recently taken center stage in writing research and teaching in the US. Much of the recent US work has explored whether some kind of writing knowledge (know-how, process knowledge, etc.) is serving in some way, or not, across linear, lateral, or recursive contexts. More recent writing studies work has considered the dispositions of students in the transfer equation. The US constructs of transfer to which this section responds are detailed in many contributions in the volume. ${ }^{2}$ Several of the points about transfer referenced in this section are also covered in the Elon Statement on Writing Transfer (2015; Appendix A) that anchors this volume, and in particular the section "Working Principles" (p. 4-5).

Just briefly: as Moore (2012), Donahue (2012), and others have noted, while the notion of transfer has been developed in various educational domains, in both Europe and the United States and as early as the 1920s, its presence in studies about writing in higher education is generally newer. The term's origin is from the Greek "to transport oneself," evoking the role of one's self and autonomy mentioned earlier. Transfer has both simple and complex definitions. Young, Tuomi-Gröhn, and Engeström (2003) suggest that basic transfer is survival activity, and we adapt to new demands without metaknowledge. But educational settings are not basic life settings. Perkins and Salomon concur, suggesting that "the entire educational enterprise of formal education depends on transfer" (2007, p. 1) as a conscious activity. Scholars range in their thinking, from the idea that transfer is always occurring (Perrenoud, 1999a) to the concept that transfer is impossible and knowledge is always recreated (Lave, 1988). Transfer has been thought to be, variously, in the individual who carries knowledge, in the context that enables the knowledge to be used and transformed, and in the moment of transformation when the individual interacts with the context.

Moore (2012) notes that US work in progress is focusing on several aspects of writing knowledge transformation. Drawing on writing studies' interest in the way transfer has been conceptualized and categorized, she highlights the near/far and high/low transfer forms, foregrounds Beach's (2003) consequential transitions, and connects transfer work to activity theory and genre theory. She points out that longitudinal studies have, to date, been some of the most productive research sites for learning about transfer, even though they were not al- 
ways designed to study that transfer. Out of this work has developed the earliermentioned Elon Statement (2015; Appendix A), a recent conference about the question of transfer, and a series of research projects, many featured in this collection. This research includes classroom to workplace transitions (with roots, of course, in the earliest work on this subject—see Paré, Dias \& Farr, 2000; Tuomi-Gröhn \& Engeström, 2003); students' personal connections, dispositions, and motivations linked to transfer; links across curricular, extracurricular, and personal writing; meta-cognition and effective (or not) reflection; social identity and transfer (Wardle, Roozen \& Casillas, 2013); transfer from first-year composition to writing in the disciplines; multilingual students and transfer; and student expectations and transfer.

The writing transfer discussion has drawn, to date, from some scholarship outside of the US-indeed, two central figures in launching the current discussion, Engeström and Tuomi-Gröhn, are Finnish, and their initial work was accomplished with European Cooperation in Science and Technology (COST) funding and European Association for Research on Learning and Instruction (EARLI) sponsorship in the late 1990s - but on the whole, the US discussion has remained US-centric. This might partly be because US scholars often claim that first-year composition, the site of a fair amount of the transfer research, is unique to the US — and that is perhaps more or less accurate ${ }^{3}$ — but we have also tended to equate first-year composition with writing more broadly, and based on this the field has made many tenuous claims about the state of writing research and instruction around the world. This section will suggest that in terms of the transfer discussion, US writing studies is the newcomer. Indeed, the European scholarship was already very active in the 1990s.

In this section, I will review some of the research about what is, in US discussions, frequently called transfer, from European perspectives. I will suggest complements or alternatives to some of the principles, offering European perspectives that in many cases predate the US discussions. The chapter is certainly not a comprehensive overview of work in other cultural and disciplinary domains. For example, many of the sources I reference are French, not world-wide. But I believe they are indicators: If this much work has been done in France, it is highly likely that similar scholarship has been produced in many other countries and languages; certainly we have seen this work in Europe more generally.

In 1999, Swiss scholar Perrenoud was already pointing out that "a good part of what students assimilate in school is only useable in the same context in which they learned it; . . . in another context, students act as though they had learned nothing — although we know that is not the case" (1999b, p. 1). ${ }^{4}$ This is undoubtedly familiar-sounding; many of us have experienced the awkward moment when a colleague teaching a class following ours in the curriculum laments 
that students seem to know nothing of citation, or organization, or syntax. Teachers, Perrenoud notes, are not prepared to address this issue: "Should they create 'transfer situations'? Focus on decontextualizing and re-contextualizing knowledge? Develop intentional transfer, a favorable metacognitive stance, a culture of transfer?" (1999b, p. 2).

Samson outlines several cognitive factors that directly affect the way the transfer he studied might work: "Our cognitive structure is constituted, from birth on, of knowledge acquired and integrated into existing knowledge. This knowledge creates the mental representations of organized and integrated declarative, procedural, or conditional knowledge that serves as a tool for interpreting reality" (2002, p. 2). In order to facilitate this kind of transformation, learners need the tools for being aware of what they know, categorizing knowledge usefully, identifying the meaningfulness of what is being learned, and reusing it in other learning contexts and in contexts outside of learning (Samson, 2002). In this realm of empirical cognitive research, Doly (2002) further suggests that the learner has to be able to activate metacognitive knowledge intentionally, at the necessary moment; has to be independently carried out by the student, though the teacher often needs to prompt it; and has to, as Cauzinille-Marmèche says, "be able to elaborate specific solutions at the abstract level" (as cited in Doly, 2002, Transfert et Métacognition section). In addition, Tardif and Meirieu (1996) insist on the moves of decontextualization and re-contextualization as both essential to knowledge transformation: the work of uncoupling knowledge from its initial context in order to reinvest it in a different context.

While it has not been called transfer, parallel work in other disciplines focused on cognitive schema research shares some of the same questions and answers them differently. Schema theories posit that new information is "learned and interpreted in terms of relevant pre-existing schemata" (Haskell, 2000, p. 82). Schema theory from research about writing offers another way to think about what might enable transfer, transformation, and expansive learning. Cognitive research clearly demonstrates the importance of understanding how working memory and long-term memory function in writing development, in novice and expert functions, in addressing new writing challenges, etc. (see for example Foertsch, 1995). This aspect of development, often explored in terms of linguistic development, should directly inform our studies of writing knowledge transformation. For example: What kind of knowing (about writing) is held in working memory long-term (like schemas)?

The cognitive basis for learning writing has evolved via attention to situated cognition. Bransford et al.'s (1999) more general summary reminds us of the situated cognition model that is at the heart of so much writing studies work in both the US and Europe. Lave's (1988) report about Brazilian street children's 
math skills and grocers' math abilities in context, as compared to their performance in test situations, is a powerful reminder that a competence is always situated. In addition, scholars have been able to establish that a new context can have as important a role as the previous one in affording transformative reuse of knowledge. Extensive research has suggested that experts and novices function differently when entering new contexts, but we can also establish that those expert-novice roles are constantly in flux. The communities of practice model (Lave, 1991; Lave \& Wenger, 1991) that has become more widespread in writing research supports that version of dynamic flux, depicting any participant entering, working through, and perhaps exiting a community as sometimes novice, sometimes expert, and sometimes in-between, depending on the activity, the stance, and so on. This seems to suggest that more fixed models such as the discourse community might not fully account for individual roles and layers of knowledge, as well as for the fluidity of community boundaries.

Samson (2002) describes a continuum, from application (using what is learned in a new, but similar context) to generalization (using what is learned in a different context). He suggests that transfer should be the term only when the knowledge is reused in an entirely new context. Application is thus the most superficial move (Desilets, 1997) and the least likely to transform across disciplines because it is so narrow. The more knowledge is utilitarian, in Samson's view, the less it is transformable; usefulness takes on a new meaning, challenging the applied versions of higher education far more than the liberal arts ones.

A context that offers affordances for transformation is more likely to enable students to adapt and negotiate effectively. Careful construction of a course, to scaffold from explicit teaching of how to transfer toward student-driven transformative moves, could support this (Samson, 2002). The teacher's responsibility is to "construct learning situations that enable students to understand the knowledge (or know-how or way of being) but to be able to use it long-term and autonomously" (Meirieu, 1994, p. 1). The moves of the student writer as appropriation or material ownership figure into the autonomy that Meirieu and Develay (1996) cite. Astolfi notes that transfer is above all an attitude, an awareness of transversal knowledge, based on accepting "the principle that what's learned will be useful for the rest of [a learner's] life" (2002, p. 9). Meirieu suggests that this autonomy must include self-sponsored use, at the learner's initiative (1994, p. 2).

There is strong emphasis in this French educational research on autonomy as a key aspect of successful, re-usable, transferrable learning. The learner needs to be able to use learned knowledge autonomously, not connected to its initial context, and the appropriation of knowledge that autonomy entails demands an awareness - an attitude of acceptance by the learner-about the transferability of what is learned (Astolfi, 2002; Meirieu \& Develay, 1996). Autonomy is what 
enables and is enabled by decontextualization. Perkins has also emphasized that the learner's stance has tremendous importance: Teachers can organize experiences, but students engage with those experiences through their own interests, dispositions, and skills (2006, p. 36). They might take a deep or surface approach; they might be strategic or unsystematic in their learning (Perkins, 2006, p. 36). The same context can be ritualized routine for some students and genuine inquiry for others (Perkins, 2006, p. 42).

The work on transformation in general has been applied to writing studies in several ways. Scholars differentiate between the more automatized or habitual phenomenon of transfer that, after repeated practice, may occur even without reflection and in everyday settings, and the meta-reflective form of transfer that decontextualizes what was learned (Meirieu \& Develay, 1996; Salomon \& Perkins, 1989) so that it might take new shapes in new contexts. As noted in this volume's Introduction and Glossary, low-road transfer draws on processes that are "automatic, stimulus-controlled, and extensively practiced" (Salomon \& Perkins, 1989, p. 124). High-road transfer involves "mindful [non-automatic] deliberate processes that decontextualize the cognitive elements which are candidates for transfer" (Salomon \& Perkins, 1989, p. 124). While we might assume that high-road is somehow better than low-road, without the "socialization, acculturation, and experience-based cognitive development, resulting in the acquisition of habitual behavior patterns, response tendencies, personality traits, cognitive strategies and styles" (Salomon \& Perkins, 1989, p. 122) of low-road work, learners would be at a loss. What seems clear is that there is a role for automated knowledge and for transformative knowledge; indeed, one area worth exploring might be the process by which what begins as transformative knowledge can become automated.

Except in some models of first-year writing instruction, on the whole, US conversations focus on a goal of assimilation or integration. As US strands of writing studies become increasingly aware of both international and translingual research, this question becomes more pressing. While more US scholars are linking the transfer discussion to the existing research about dispositions, self-efficacy, and student writers' values, and the research model allows for exploration of resistance, negotiation, etc., the pedagogical model remains focused in most cases on optimizing integration. The research about students' work sometimes explores resistances, but few tansfer scholars are arguing that the job of writing teachers should be to foster resistance, and the transfer models in play to date have similarly not been focused on reuse, adaptation, transformation, and repurposing of knowledge in order to resist educational influences, reshape the landscape, and so on. Nowacek emphasizes, for example, students as agents of integration (2011, p. 38)—agents, yes, but agents of integration. Troublesome 
knowledge and boundary-crossing disrupt integration, in some ways, but the implication in the scholarship is that the disruption is useful insofar as it can enable further integration over time.

The "communities of practice" model suggests negotiation and resistance are both omnipresent and productive. E. Wenger-Trayner and B. Wenger-Trayner note that "learning is not merely the acquisition of knowledge. It is the becoming of a person who inhabits the landscape with an identity whose dynamic construction reflects the trajectory through that landscape" (2014, p. 8), describing the landscape itself as a landscape of practice made up of the multiple and complex communities of practice into and through which we move (p. 4). They suggest, however, that the modes of identification we use to find ourselves in these landscapes include engagement, imagination, and alignment. None of these, even though they suggest that alignment is a two-way and fluid dynamic process (Wenger-Trayner, E. \& Wenger-Trayner, B., 2014, p. 10), is an active encouragement of resistance or strong negotiation. Within students' texts we can find, on the other hand, moves of quite active resistance and negotiation (see Bartholomae, 1986; Ivanič, 1998; Lillis, 2001; Scott, 2013)—including in texts that are deemed successful in school settings (Donahue, 2004, 2008). The idea that resistance or negotiation might be an essential goal is deeply developed in fields such as "ac lits" (academic literacies) in the U.K. (Street et al., 2009). European scholarship has included a focus on the importance of power relations in knowledge transformation (Hilaricus, 2011). The actors are not seen as all on equal footing (though the communities of practice model offers a way to see an individual's footing as also dynamic, in flux, rather than in a static novice or expert state).

The effects of boundary-crossing or disruption have been shown to be important to knowledge transformation. Pushing learners into "far" contexts and situations in which boundaries are unclear (interdisciplinary work, for example, or liminal situations such as the move from high school to college) and the usual worldview is disrupted appears to foster transformation of knowledge, though it is not yet clear at what degree this is productive, and likely different for different learners (see Vygotsky, 2012).

Driscoll and Wells (2012) argue that students' individual backgrounds and dispositions are a key and understudied factor in writing knowledge transfer, based on their studies of first-year writers in the term after they completed the course and writers making the transition from high school to college. This complements general writing research that has explored in detail the relationship between individual students and writing worlds (U.K. research has developed this in particular, though not exclusively; see Delcambre, 2001; Guibert, 2004; Ivanič, 1998; Lillis, 2001). 


\section{TERMINOLOGY}

As has become evident in the development of this chapter, and as is evident in other chapters in this volume, different-and multiple_-terms are in play for the transformative reuse we are trying to get at, each with its own particular contribution. As we map some of the uncharted territory Moore mentions, the Elon Statement encourages us to "explicitly reconcile new terms—and new usage of existing terms - with the scholarship's existing vocabulary" (2015, p. 1; Appendix A). The list of terms developed by some scholars as described in the Elon Statement, including transfer, generalization, consequential transition, remix or repurposing, and integration, is a list that this section builds on and from. The multiple universes of meaning and the meaning-making that happens with each new use is generative. Additional terms and concepts from European scholarship support the value of complexifying our terminology rather than moving toward a unified narrative and cementing a single term. Writing knowledge might be different enough from other kinds of disciplinary knowledge to make it important to maintain diversity. Words organize thought, Perrenoud reminds us, and "the metaphor of 'transfer' evokes no transformation, only movement, a kind of "trip"” (1999b, p. 5). He questions the spatiality of the transfer metaphor, likening it to the way we think of using a flash drive to transfer information from one computer to another, rather than focusing on the "cognitive mechanisms underlying the reinvestment of knowledge" (Perrenoud, 1999b, p. 6) (italics mine).

In 1996, Meirieu and Develay suggested problems with "a 'transport' metaphor that designates an object that moves from one point to another, staying identical, when we know that in relation to knowledge, this can't be the case; if it were so, there would never be acquisition and progress" (p. 39) They go on to say that transfer implies a linear model in which something is first acquired, and subsequently transferred, when in fact most research suggests the opposite (Meirieu \& Develay, 1996, p. 1). While acknowledging the convenience of a single term, they caution that in educational settings, the tradeoff of that convenience is the entrenchment of a term and a concept, in policy and curriculum, that loses the rich diversity and nuance of the actual phenomenon, with sometimes quite damaging results.

Perrenoud (1999b) adds that maintaining the term transfer can actually hide aspects of the way knowledge transformation functions. For example, "the source of transfer is far from associated with precise situations; we are always drawing on knowledge from multiple and diverse situations, each one having a range of similarities-differences with the current situation" (Perrenoud, 1999b, p. 7); complex activities demand orchestration and integration of multiple cognitive resources. Perrenoud suggests that transfer does not exclude but certainly 
does not support the idea that the knowledge being transferred is transformed en route.

Meirieu (1994) points out that the carry model also posits what is carried as static, fixed, or objectified - much like a consumer good—and again not itself transformed in the use and the relationship. And finally, Perrenoud suggests that we advantage students who are more focused on product than on process, as well as students who are better at accumulating knowledge than at applying it, if we maintain the transfer metaphor. Perrenoud goes so far as to call this an elitist version of education (1999b, p. 9) supported by testing; actual study of knowledge transformation is, of course, much harder to achieve.

In European and US discussions, transfer has been alternately called generalization (Hatano \& Greeno, 1999), expansive learning (Davydov, 1990; Engeström, 2001), or even simply effective learning (Meirieu \& Develay, 1996) in educational research. Alternate terms developed or adopted in European writing studies in more recent years have included:

(1) Acculturation: Developed in particular in French scholarship, as we see in the work of Deschepper (2008) and Reuter (2006). Deschepper proposes that a "didactics of university discourses" depends on acculturation to ensure the reuse and reinvention of writing abilities at liminal stages (2008, p. 3). Reuter highlights J. Goody's influence on our understanding of literacies and reflective distance, two key transfer notions, in particular when they are used in the context of seeing a continuum of writing development. "Entry into writing," Reuter suggests, "is a process of meaning construction and acculturation" (2006, p. 133). He underscores, connecting to both J. Goody and Vygotsky, that writing by its nature privileges the very things that enable transfer: reflection, abstraction, distance, analysis, awareness, and intentionality (Reuter, 2006, pp. 135-136).

(2) Appropriation: This concept has been developed by hundreds of scholars over decades and covers the given that knowledge must be appropriatedowned, wholly integrated into one's worldview, capacity base, way of working, and in the process transformed-if it is to function over time and in new tasks and settings. Subsets of this appropriation might be what Meirieu and Develay (1996) call re-ordering, regulating, or orchestrating.

(3) Autonomisation (see Astolfi, 2002): The insistence on knowledge becoming autonomous from its initial learning environment, topic, or framing; knowledge transformation is thus knowledge decontextualisation that enables subsequent recontextualization.

(4) Didactic transposition (see Chevallard, 1985): This didactics notion, mentioned earlier, is certainly not equivalent to transfer but is still quite aligned. Didactic transposition is, roughly, the transformation of scholarly knowledge into 
knowledge that is accessible in learning contexts. If writing knowledge transformation from one context to another is a goal, then the research on didactic transposition offers a particular way to model that writing knowledge.

(5) Reinvesting: Perrenoud suggests that "reinvesting is synonymous with transfer: transfer as reinvesting of acquired knowledge . . . the capacity to reinvest cognitive knowledge in new situations" (2000, p. 57). This term complexifies the activity by emphasizing the personal motivation, the awareness, and the choice (we invest in activity that matters) over the more mechanical "movement from $=>$ to" of transfer.

(6) Translation: The concept has been developed by various French scholars drawing from Serres (1974) and defined as a "process in which the transport entrains transformation" and that demands a continuity "in which practices emerge, develop, transform into routines, and eventually disappear" in organizations (Hilaricus, 2011, p. 5). This concept draws from linguistics, social anthropology, political science, sociology, and ethnomethodology to emphasize the social nature of knowledge construction and transformation (Hilaricus, 2011). French sociolinguist Bernard Gardin proposes that language interactions and genres can be described on a translatable-to-untranslatable continuum: "All learning is movement from the known to the unknown, scaffolded in particular ways, and always understood as neither entirely the same (no movement in meaning) nor entirely different (resulting in a total breakdown in communication)" (as cited in Donahue, 2008, p. 126). The overly similar and the overly different both prevent transformative reuse and exchange.

(7) Mobilization of cognitive resources: Perrenoud argues for this much stronger term for the transformative action of knowledge reuse. He suggests that "it does not postulate the existence of analogies between current and previous situations; covers as much the creation of original responses as the simple reproduction of routinized responses; describes mental work, costly, visible, of varying lengths; evokes a dynamic rather than a displacement; targets diverse obstacles (cognitive, affective, relational); leaves open the question of situation-specific concepts, representations, and knowledge; suggests orchestration of multiple and heterogeneous resources (1999b, p. 11).

These largely European frames can offer useful parallels to transformative reuse (Beach, 2003) or, in terms of discourse specifically, reprise-modification (François, 1998). The work on understanding the relationship between the individual-specific utterance and the generic or shared social fabric of language is quite relevant (François, 1998). In this understanding, the application changes the use; François calls this reprise-modification, literally "re-taking-upmodifying," which he posits as the irrevocable nature of all language production, whether spoken or written, from a child's first word onward. François also offers 
us the concept of orientation for modeling the learner's ability to orient in new situations. The orienting ability applies to behavior as well as previous knowledge: someone who orients can read a new context's cues and expectations, can expect to have to do that reading (an expectation generally associated with expertise), and is already oriented by previous experiences (François, 1998). Every learner, every language-user, every writer is pre-oriented by past experiences; every learner can engage in orientation and can recognize his or her orientation, as well (Donahue, 2012). Orientation as a linguistic-discursive notion is the fundamental cognitive activity that enables what transfer studies have identified as transfer to occur. The beauty of its implications is in its fluidity and antideterminism: pre-orientation is not pre-direction.

\section{TRANSFER FROM OTHER DISCIPLINARY POINTS OF VIEW}

If we pursue the implications of the uncharted territory metaphor provided by Moore (2012), we can imagine that hazards, unexpected encounters, troubling sights, and different kinds of terrain are part of the mapping process. I believe we can deepen and grow our own knowledge about transformative reuse by troubling our understandings via these kinds of encounters. As we have just seen, the scholarly sense of transfer has been evolving and developing fruitfully, in ways that can lead us to question whether indeed "transfer" is the best term to continue to use to capture the complex phenomenon we are after. In the previous sections, both critiques of the term and alternative ways of thinking about the term from US and European scholars provided some ways to do this questioning. Now I will turn to transfer as seen from alternative disciplinary points of view as an additional way to embrace conceptual complexity.

Here, I am pointing not to uses that resist or reject the term transfer, but to uses that develop transfer as something other than what education research and US writing studies have posited. That is: the concept of transfer has different histories, a broader scholarship, that can push us to explore the perhaps assumed pedagogical goals on which the current discussions about transfer have stood until more recently, and enable rich integration of complementary strands of twenty-first-century thought. They raise a question for composition about the potential value of entering the global marketplace of ideas about writing and knowledge transformation.

It is the right time in our trajectory to consider multiple other ways the term transfer is used and understood in that global marketplace, which includes other disciplines: the domains of psychoanalysis, L1 to L2 interrelationships, corporate practices, researchers' knowledge dissemination, education sciences, and linguistics. Most of these other uses of transfer have developed outside of the US; 
all have developed outside of the discipline of writing studies. It is worth noting that writing scholarship outside the US is quite often rooted in disciplines such as linguistics, didactics, or language learning, so the international is often tightly linked to different disciplines that can illuminate our thinking.

Attention to these uses and developments, some quite old and some quite new, can usefully trouble us and can fill in some of the gaps we see evoked by Moore (2012) and others, helping us to look forward. Each offers a way of thinking about the mechanisms of transfer and can thus lead to alternate terms and alternate understandings. Perhaps even more importantly, we can sharpen the distinctions among different threads and situate US and writing studies work very effectively in the broader transfer landscape. Of course, in maybe the most distant and most generally well-known use of the term, transfer or transference in psychology and psychoanalysis is an affective relationship - with a new person or object by association with a previous one-the principle of assigning feelings to someone other than the person actually involved. While psychology and psychoanalysis at first glance seem far from our interests, connections between our study of transfer and the work done in that field in affect and identity might prove very useful. For example, as we study student-teacher relationships and their effects on enabling or inhibiting transformative work, this angle could help us to understand how previous learning experiences or experiences outside of school could be shaping students' willingness to engage with a particular instructor or peers. The psychology of these interactions must be part of what we study.

In L1-L2 research, transfer is a frequently studied and central concern. The question here is whether the linguistic and discursive knowledge of an individual speaker or writer in one language can be used, adapted, and transformed in another, and indeed whether that is productive or obstructive. There is a rich body of scholarship around the world about language and discourse knowledge transfer between L1 and L 2 contexts, in writing and speaking, with extended debates about its role in developing writers. This transfer research, most often by linguists or didacticians, has focused on the connections between L1 and L2 (that is, how is $\mathrm{L} 1 \mathrm{a}$ resource and an obstacle for L2 and vice versa). For example, it suggests that L1 literacy abilities and strategies do not automatically lend themselves to successful work in L2 writing. Some writing process strategies transfer but, in particular in lower-proficiency writers, others do not (Wolfersberger, 2003); L1 abilities can have long-term effects on L2 development of those abilities (Sparks, Patton, Ganschow \& Humbach, 2009); L1 abilities can only be tapped once L2 proficiency is far enough along to enable it (Ito, 2009). Work on multilingualism and these transfer effects is also taking shape, grounded in 1990s research on multilingualism and multicompetence (Cook, 1992). Of particular interest is the research suggesting that third-language acquisition may reuse, transform, 
and manipulate more from the speaker or writer's second language than the first (Heidrick, 2006). This language knowledge transfer scholarship is a resource by and large untapped to date in discussions about university writing and knowledge transformation more broadly.

Fairly recently, the term transfer has been used largely outside of the US to designate the ways in which research results are made available to a broader public. Earlier work in education sciences, notably in Europe in my experience, also tilled the ground quite handily for these current discussions of transfer and transformation. Most notably, research grounded in the concept of didactic transposition (Chevallard, 1985) or cognitive transposition has emphasized that it is teachers who must transform their knowledge, in school settings, to move it from expert insider knowledge states to learnable states. That is, scholarly knowledge itself must be transformed in order to be transformable. European and Canadian conferences share how to best create the transfer of scholarly knowledge to non-scholarly audiences in other contexts than school learning. The 2013 Association Française Pour le Savoir (ACFAS) conference strand on knowledge transfer featured some 30 sessions on the topic, with titles such as "Can Academics Survive by Creating Transfer Activities?" and "Mixed-Method Research about the Factors that Influence Knowledge Transfer Activities among Faculty at the University of Montreal." The University of Montreal (2013) web page specifies the many forms of this kind of knowledge transfer. This angle seems more closely tied to the work done in and by technology transfer offices in universities in the international commerce practice of using knowledge developed in university settings for public good or patented products (see Chen, 1996; Teece, Rumelt \& Winter, 1994).

But here the transfer is in realms other than technology, and its purpose is to underscore other kinds of knowledge, non-commercial knowledge, as public good. In addition to the very useful attention to faculty knowledge- how it works, how it builds, how it transforms in its dissemination-this sense of transfer offers a way to think about transfer in reverse, transformation that opens knowledge to transfer. But it also implies transfer is linear movement, the movement of knowledge from expert knowers to non-expert recipients. Knowledge production seems to be understood in a consumer model.

Corporate practice also embraced the concept of transfer as early as the 1980s. In this venue, transfer is what allows organizations to function effectively. Research and practice focus heavily on the ways to ensure transfer of knowledge and know-how within corporations. Indeed, full-day workshops are offered in companies to support and enable this transfer. Hilaricus (2011) notes that this research has fallen into two camps: the rationalist perspective that commodifies knowledge (what Bacon, 2013, has called the "pack and carry" version 
of transfer) and the social constructivist version. Most studies, she notes, have been in the rationalist tradition. But the social constructivist perspective sees organizations' knowledge as situated, relational, mediated by artifacts, rooted in interactions and acquired by participation in communities of practice, and always temporary and renegotiable (Hilaricus, 2011, p. 5). Firms, seen as social communities (Kogut \& Zander, 1995), have of course long been studied for their modes of working, in particular in organizational psychology. In the past 10 years, the research has informed explicit employee development workshops for fostering transfer of internal knowledge to ensure company strength and individual integration. In some ways, these widespread models of transfer are precisely what we seek to resist in higher education writing work: uniformity, commodification, and preservation of sameness. Reading this scholarship helps us to sharply delineate our work.

In a useful contribution to that resistance, the European scholarship is closely tied to research on the social construction of knowledge. The argument made is precisely that transfer suggests commodification of knowledge, knowledge as a good to be exchanged, while in fact the way knowledge is co-constructed in every context would suggest that we need a term that resists such commodification. Indeed, Perrenoud, echoing US composition discussions about social construction, notes that "transfer implies a portable knowledge. But we know that knowledge is a never-completed construction, dependent on the context in which it is constructed, and incorporated in the actor" (1999b, p. 5).

These versions of the transfer concept emphasize learning in different ways and function as alternate lenses in the transfer discussion. New synthesized knowledge from these uses serves us well in US composition discussions, helping us to remember that much of what has been discussed recently in transfer scholarship finds strands and echoes in many diverse domains. I hope these other transfer discussions can help us to encounter our own boundary-crossing in knowledge that makes trouble for us: troublesome knowledge that is generative for our conversation (see Moore \& Anson, and Qualley, this volume, for a discussion of "troublesome knowledge"; Perkins, 2006). It is not clear how much boundary-crossing is needed or how far the usual worldview should be disrupted in order to generate learning and transformation, though certainly we know that some degree of trouble is important for learning and transformation of knowledge (see Vygotsky, 2012, for a related discussion of zones of proximal development). I would argue that research-including all of the active current scholarship around transformation of writing knowledge-can have precisely this role for writing teachers and scholars.

Perkins interestingly ties troublesome knowledge to constructivism, a knowledge-development model that has long been at the heart of both educa- 
tional theory and writing studies; knowledge "makes trouble for learners, and . . . the constructivist toolkit speaks to those troubles" (2006, p. 34). Perkins credits much earlier scholarship, including Bransford, Franks, Vye, and Sherwood (1989) and Bereiter and Scardamalia (1985), for helping us understand knowledge that can be troublesome because it is routine (non-meta-cognitive) or is inert (not activated) and thus not transferrable (2006, p. 37). But Perkins' other categories are equally useful: conceptually difficult knowledge, alien knowledge, and tacit knowledge can all trouble forward movement; indeed, tacit knowledge can be particularly troublesome (as in, causing trouble to learning) (2006, pp. 44-45).

Perkins, though, seems to imply that troublesome knowledge is knowledge that obstructs learning, knowledge to get past somehow, in order to transfertransform. Kumashiro (2004) uses the term troubling knowledge, suggesting that it is this kind of knowledge that generates learning. While much has been made of troublesome knowledge in the transfer discussion, we might perhaps find it useful to also reference troubling knowledge. For Kumashiro, learning and teaching should result in a crisis state, a "state of emotional discomfort or disorientation that calls on [us] to make some change" (2004, p. 28), knowledge that problematizes and that disrupts the taken-for-granted. We can, Kumashiro suggests, "work paradoxically with knowledge, simultaneously see what different insights, identities, practices, and changes it makes possible while critically examining that knowledge (and how it came to be known)" (2004, p. 29). It is not about mastery, but about examining different uses and effects. Kumashiro contrasts this with comforting knowledge, the kind of knowledge that makes us feel mastery is possible, achieved via the repetition of familiar practices and understandings. I would like to suggest, then, that alternate transfer research can serve as both troubling and troublesome knowledge for us, of the kind that can be generative.

The wealth of research available about human development in general (and in particular child, adolescent, and early adult development) can add another essential layer to our understanding of how a learner might be able or not to transform and reuse knowledge adaptively and flexibly at any given point in life. Any number of variables, we thus see, could be affecting this ability. I would like now to look more closely at a particular domain of European research: linguistics, the study of language, a field whose direct links to writing have been understudied in the US knowledge-transformation research. This domain can provide productively troubling research knowledge for us. Linguistics, university writing development, and studies of writing knowledge reuse and transformation might be imagined as a triangle in which transformation research, transformation models, and linguistics research inform our understanding of writing 
development, while studies of writing knowledge transformation and linguistics inform each other.

Perkins and Salomon proposed in 2007 that everyday knowledge and knowhow transfer naturally. Linguistics does not use the term transfer, but the conceptual work of linguistics suggests that transfer or adaptive transformation in language acquisition and language function is always occurring, in its routinized but also in its transformative modes. We might thus focus, as Perrenoud (1999a, 1999b, 2000) has suggested, more on the "what," the "how," and even the "why," than the "whether," as some form of transfer is always occurring. As Meirieu and Develay argue, "Knowing whether transfer is itself possible is meaningless . . . knowing which practice enables transfer and which conditions are essential to it" is where our interest should lie (1996, p. 1).

If we acknowledge that writing is a language act - though of course it is not always or only that-linguistics offers a particular window on the knowledge we hope will transfer and how transformation and generalization work. Linguistics thus has significant implications for the evolving research on transfer in terms of both method and conceptual framework. In particular, it leads us to additional concrete questions about what kind(s) of knowledge linguistic knowledge is, and how writing knowledge is a linguistic knowledge whose transformation and reuse we can study in particular empirical ways. Linguistic knowledge has been cited as one of the domains that needs charting. The kinds of linguistics I am referencing here are in two domains: European functional linguistics (which is not systemic functional linguistics), and Bakhtinian/Volosinovian-style linguistics.

For traditional linguists, language acquisition is always transformation in process. Language functions in precisely that way. Children acquire words, meanings, phonology, morphology, and syntax in an ongoing process that cannot function without transfer-transformation. Every single learned aspect is used, reused, extended, and generalized. In fact, generalization is a necessary part of acquisition of the grammar of a language, as is reuse, in new contexts of existing linguistic knowledge. Every utterance, spoken or written, is transferring something, or we would have to perpetually start anew or never speak (see also Samson, 2002). Linguistic rules (in the descriptive sense) are generalized in this process. Every utterance, every language user's combination of words, syntax, grammar, and semiotics, is both already there (in part or sometimes in whole) and new, shaped to a new context, purpose, or meaning.

Of course, learning writing involves many components in addition to learning language. But my thought is that we can see new ways to conceptualize and understand transfer by looking at language knowledge transformation. Beyond basic linguistics developments, European functional linguistics and the evolution of Bakhtinian/Volosinovian linguistic theory about language, genres, and 
discourse have focused on understanding the ways in which sounds, words, and meaning-making constructions-utterances-function. In Bakhtinian/Volosinovian terms, the utterance is always new, though never original. Language use, spoken or written, is transformation. French linguist François (1998) has shown in multiple analyses of both children's texts and published texts that individual utterances work in relation to the shared social fabric of utterances already said and to be said. Children acquiring language are acquiring words, sounds, syntax, and grammar, with no particular effort, and Bakhtinian thinking suggests that children acquire genres in the same way. Genres, in this case, structure and are structured by thought; they flex and adapt; they offer stability and innovation. Years of subsequent analyses, operationalizing Bakhtinian notions, support this suggestion (e.g., Kara, 2004; Lillis \& Rai, 2012; Reuter, 2004; Rinck, 2006).

In terms of written and spoken discourse, the study of given/new constructions (grounded in the Prague School's analyses of theme/rheme structures) offers similar insight at the level of syntactic coherence and larger discursive units: Utterances co-construct meaning most effectively in a given-new sequence, one which in fact moves knowledge from existing to new-simultaneously transferring and transforming it.

As I noted above, in linguistics terms, an utterance of any kind is some form of transformation. Every utterance, spoken or written, is transferring-transforming something; otherwise we would perpetually start anew—very inefficient—or never speak. So, we can already imagine some of the parallels between linguistics research and writing knowledge transfer concerns. If, as Donahue has suggested, "all learning [is] movement from the known to the unknown, scaffolded in particular ways, and always understood as neither entirely the same (no movement in meaning) nor entirely different (resulting in a total breakdown in communication)" (2012, p. 162), then the close relation between this and transfer is clear. The linguistic generalization cited above is a natural human learning activity, in particular in terms of language, as is hypercorrection (overgeneralization). Overgeneralization in particular, a well-known linguistic phenomenon, is potentially quite illuminating for thinking through how students' previously developed writing knowledge might reappear in unhelpful ways.

Bakhtinian notions of speech genres, their adaptive flexibility and their affording structuring quality also bear much more exploration in relation to the transfer discussion. Certainly some strong work has been done in this area already (e.g., Bawarshi, 2007, on antecedent genres), though not generally from a Bakhtinian genre perspective and not always from a perspective of genres as themselves adaptive and flexible. Rinck and Sitri suggest that understanding these genres is key to understanding student progress, but that Bakhtin/ Volosinov did not supply us with extended categories useful to analyzing genres 
(2012, p. 3). I believe, however, that Bakhtinian/Volosinovian thought provides us the tools for creating the necessary dynamic categories.

Linguistic work about student writing has also evolved, focused in part on transversal versus specific knowledge. Grammar knowledge, for example, is cited by Rinck and Sitri (2012) as transversal knowledge in their linguistic analyses of university student writing. While its use may differ in different contexts, linguistic knowledge of, say, syntax or morphology is transversal, as opposed to conventional knowledge of something like grammatical sentence construction. The US discussion of transfer has not focused much on this aspect of language use, though research in other US writing studies domains has. It has focused on disciplinary versus general education writing, but not in terms of linguistic knowledge (see below).

There are also key differences between writing and more general language knowledge, and these differences can be just as important for insights into transformative-adaptive reuse. Here are just a few:

- Is writing a "higher order" construction? (Is "higher order" even a legitimate term?) Russell (1995) has famously described writing knowledge using a ball metaphor: "ball-ness" as the generic quality of a ball that does not, for all that, allow ball users to know how it applies in different ballgame contexts. But in initial spoken language acquisition, we do generalize effortlessly. That is our whole purpose as linguistic beings. As Bakhtin notes, we do not live in the dictionary but in used and transformed linguistic experiences. What kind of writing knowledge parallels this? When does writing knowledge not automatically generalize? Those contexts are worth studying.

- Decades of scholarship underscore that writing in educational contexts often has a learning purpose that is only valued in school. This is not like typical language learning (though certainly it is the case for other forms of language learning such as learning a new language at school). We know we do not need meta knowledge in initial language learning, at least not consciously. Most of us can use grammatical structures correctly without being able to explain them. We are not sure how much meta we need in writing; some studies suggest that without the meta we cannot say the learning happened (e.g., as reviewed in Bransford et al., 1999); others say learning often occurs without the ability to articulate it (Donahue, 2010). In language it seems that speakers take for granted the transferability (though perhaps not in different registers).

- It is possible that a difference between linguistics/language and writing is in the user's assumption about transfer. In language acquisition 
and reuse, every language user's assumption is that language (phonology, morphology, syntax, etc.) is fundamentally reusable, although there are of course layers of social-discursive conventions to take into account. In writing, Bergmann and Zepernick (2007) suggest that students do not look for that reuse because they do not assume it is possible. An intriguing area for future research can be to explore this very difference. Could part of the way to enable transfer be to explore with students their assumptions about language in relation to writing? This distinction has been amply discussed in expansive research on speech and writing. I am not so much interested in that distinction as in a different purpose - to suggest looking at language acquisition (in speech) and language function (in speech and writing).

Some scholars have critiqued the fact that much transfer or transformation research has focused on one feature at a time, one determinant of transfer. What is needed, Hilaricus suggests, is complex studies that account for the interaction of multiple determinants in enabling writing knowledge reuse or transformative adaptation (2011, p. 5). This volume offers some of these; replicable, aggregable, data-driven (RAD) research supports the building and the dialogue across research projects that enable such multi-layered work. We know that transformative reuse of any learned knowledge is exceedingly difficult to study empirically, in the same way it is difficult with any assessment to establish what a learner has learned and what might account for that learning; multiple points of entry into the learning moment—or the transformative moment—are essential.

Both education and linguistics research from Europe can open up immense possibilities for the methods of US research on writing knowledge transformation. Linguistics can contribute via specific methods useful to studying writing knowledge transformation, reuse, and adaptation. The Elon Statement on Transfer notes the typical methods we have seen in US higher education writing research about transfer, "a variety of qualitative and quantitative methods to identify evidence of and measure transfer, including surveys, focus groups, interviews, classroom observations, text analysis, discourse analysis, composing-aloud and think-aloud protocols, group discussion logs, and analysis of students' course work and faculty comments" (2015, p. 5). While the methods outlined suggest a broad base, in fact text-based analyses of students' reuse and appropriation of knowledge have been rare to date. Text-in-context analysis is an approach that has been less frequently used in US research about writing transitions; while it can never give the whole picture, it is perhaps a neglected window into students' evolutions. The text analysis process can lead us to treating qualitative data quantitatively, via segmenting and coding of verbal data; this powerful approach 
contributes extensively to knowledge transfer-transformation research via direct artifact analysis. More generally, methods in linguistics cover a range, from sequestered (experimental) to in situ work. Linguistic methods of analysis have enabled much of the knowledge explored here in very specific ways, for example, through descriptive linguistics and discourse analysis (see Rinck \& Sitri, 2012, on this topic). Education research has decades of history in setting up carefully constructed experimental or intervention studies (see Doly, 2002, for comparison study between two teaching styles and students' metacognitive abilities). We stand to gain from strong research traditions and study results that will increase our status as a research field among the disciplines.

Finally, the transfer discussion focuses on the mechanisms or moments of knowledge reuse and transformation. Because we need to understand the interaction between the mechanism and what is being transformed, it has also raised questions about the nature of the knowledge in question. What kind of knowledge is writing? Do we want students to transform writing knowledge? Writing knowing? Writing know-how? Or all of these, and what more? Linguistics helps us here, as well, to tease out possible answers. If we are to study how that knowledge transforms, generalizes, applies, and extends, we need to grapple with this question.

Traditionally defined, knowledge can be theoretical or practical. It might

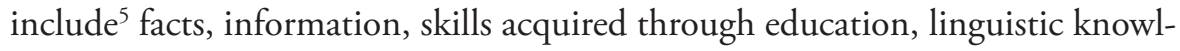
edge (descriptive), rules and conventions, understanding, abilities, structural knowledge, generic knowledge, rhetorical knowledge, and knowledge as epistemological frames. ${ }^{6}$ In philosophy, knowledge is understanding, as opposed to opinion. Writing knowledge can range from how to hold a pen to extremely sophisticated know-how in intertextual movements. The types of knowledge that interest composition studies—strategies, processes, values, rhetorical flexibility, linguistic knowledge, and knowledge of self as writer-are sometimes different from those that other disciplines develop. This makes them tricky to study. French scholar Le Boterf (1994) offers an additional possibility for knowledge as savoir-mobiliser, which means both in action and intentionally motivatedknowing how to mobilize.

Knowledge (in a field) is also method. We might consider method as a site for particular emphasis in transfer or knowledge transformation research. The method of knowledge generation differs in, say, anthropology, or writing, or education, or biology. Anthropology studies humans in context. Education studies humans as learners. Biology studies material workings. Writing studies writers and texts, production and process, how we craft arguments, and how we rhetorically move. These methods, as disciplinary knowledge, lead to different frames for knowledge transformation. 
Some transfer research addresses the knowledge question specifically through analysis of threshold concepts (Meyer \& Land, 2003) and troublesome knowledge (Perkins, 2006). Concepts are categorizers that open up new ways of thinking. They function in activity networks. The threshold concepts model that Meyer and Land (2003) initially presented allows us to ask how a threshold concept functions in writing, in a discipline that itself is caught in a timeless pushpull between broad-based, cross-disciplinary ownership and application and writing studies' epistemological specificity. How is it like or not like a threshold concept in another discipline?

Genre has been cited as a possible threshold concept (Adler-Kassner, Clark, Robertson, Taczak \& Yancey, this volume; Adler-Kassner, Majewski \& Koshnick, 2012). Threshold concepts are transformed ways of understanding that open up new ways of thinking and learning, once the learner steps over that threshold. Genre is an interpretable notion, certainly re-imagined and re-studied from a range of different vantage points, a concept that shapes itself to different epistemological purposes and is owned — as is writing knowledge more broadly—by all disciplines. How standard or flexible can a threshold concept be to do its job? In a way, this leads back to the question, what is writing knowledge, and indeed back to the question, what is writing as a discipline? Writing seems to be uniquely both its own discipline and a shared knowledge base across all disciplines. It is trans-disciplinary, and in fact makes possible the intellectual work among the pre-liminal-liminal-postliminal stages of knowledge development cited in threshold concepts work, but it is not yet clear how they are the equivalent of these concepts in, say, biology or sociology.

Threshold concepts thus lead us right to another timeless and rich question about disciplinary knowledge, general education, the liberal arts, writing courses, and, ultimately, ownership of writing and writing knowledge. The question is at the heart of models of education out there and indeed at the heart of the history of higher education-for example, in the liberal arts versus professional preparation split, as Adler-Kassner et al. (2012) remind us. If general education is supposed to offer a common experience of values, of knowledge, and the major is meant to offer disciplinary specialization (which we would expect to include both values and knowledge specific to that discipline), then it would seem that interest in transfer would be widespread. It is possible that general education courses confront difficulties because their nature as an introduction to a discipline for non-specialists does not lend itself to threshold concepts, or perhaps that these courses call on different threshold concepts.

In a mild way, we see this at my institution with our first-year writing sequence. The first course is taught by writing faculty. The second course, taught by faculty in disciplines other than writing, cannot teach writing for a discipline, 
yet it cannot not be disciplinarily infused. Dartmouth is currently carrying out a study of first-year writers as they transition from a general writing course to thatdiscipline-inspired, first-year seminar, both courses part of a required first-year sequence. This is a critical transition for our students, from an entry-level college course in which writing is the primary focus to a bridge course that introduces them to faculty who are not primarily writing specialists, to a second new phase in their college writing experience. The study examines 200 first-year students as they work through the two-term sequence, analyzing their early and late work in each course: methods of organizing material, thesis statements, coherence, types of evidence, citation practices, and so on. The students' work is followed both in case studies of individual students across the sequences they took and in aggregate analyses of patterns of change in the practices evidenced in their texts. It will benefit us to study what writing threshold concepts would work in this context.

\section{CONCLUSION}

What we really want, I think, is to study and understand the transformation-inevolution of writing knowledge, writing knowing, and writing know-how. Our pedagogical goal of helping students know how to write drives our interest in transfer. The research about writing knowledge and how it is flexibly reused, adapted, translated, transitioned, and generalized is thus a vitally important development in our field. This volume makes that quite clear. Both education research and linguistics research suggest that transfer is always happening, and the deeper interest is not whether but how it happens. However, when we consider how transfer has developed in other domains, it seems both that other points of view can shake up our thinking and that perhaps a different meta-term or a packet of terms would move us collectively forward at this point. "Transformation" could be such a term. Every researcher comes back to transformation as the real activity of transfer. Every article evokes transformation, and every use of transfer in the domains evoked here-L1/L2, making knowledge available to the public, language acquisition, and so on-has transformation at its heart. Transformation is not as handy in a sentence, but it might be truer to the actual way writing knowledge works. It may not be just the term we need either, but the discussion about how to name what we are looking for will surely itself be transformative.

In addition, research about this knowledge transformation is still young enough to resist the desire to begin applying it to curricular decisions. The number of studies is growing, as Moore (2012) and others report. But the results do not always concur, the methods and populations are quite different, and the tapestry of research results that should provide a support for action has not yet been woven. It is providing a new way to think about our relationship to other 
disciplines and to our work as writing faculty. For example, when we talk about writing knowledge transfer across years and disciplines in school, it sometimes seems our colleagues in other disciplines want all knowledge about writing to become automatic, while we argue as writing faculty that it cannot be. The writing knowledge transformation discussion offers specific evidence about this tension, and indeed the vast writing across the curriculum scholarship and writing in the disciplines scholarship—in the US, Europe, and other contexts—can be tapped in this particular inquiry. It would be well worth studying the many forms of transfer covered in this chapter, in a way that could uncover shared threads and universals across them; that might be a future step in the work this chapter sets out.

Other future domains of writing research might focus on understudied aspects of knowledge transformation such as its connection to developmental research. It's interesting that Bloom's taxonomy of cognitive domains, for example, posits application as a lower-order activity over analysis and synthesis, the kinds of cognitive activities that would seem most likely to support writing knowledge transformation. Other longstanding cognitive research in education suggests that different individuals are simply developmentally able to transform particular knowledges at different stages. In terms of writing knowledge transformation, this is potentially a very fruitful additional direction. We know, too, from this research that new knowledge can build on previous knowledge but it can also displace that previous knowledge. Studying these different paths is essential to our growing understanding; research in other disciplines and other national contexts can directly contribute. Taking the path of increasing complexity, with its accompanying uncertainties and diversities, will lead us in US writing studies to having a strong voice in the global conversation about writing, knowledge, and transformative, forward-moving reuse.

\section{NOTES}

1. In some ways, "global" and "cross-disciplinary" are tightly linked, as different cultural contexts foster different disciplinary grounds for similar research questions.

2. Bransford, Brown, and Cocking's (1999) How People Learn: Brain, Mind, Experience, and School, a non-writing-specific review of transfer scholarship, primarily in Chapter 3, "Learning and Transfer," is one of several key reasons for much of the interest in knowledge transfer that has developed in the US writing studies community recently. See Donahue's (2012) Transfer, Portability, Generalization: (How) Does Composition Expertise "Carry"? and Moore’s (2012) Mapping the Questions: The State of Writing-Related Transfer Research for overviews of much of the recent work in writing contexts. 
3. This article isn't the place for contesting that claim, but it has been clearly contested elsewhere. See for example Donahue 2009; Anson and Donahue 2014.

4. All translations of French scholarship in this chapter were done by this author.

5. This is one way to divide it up — and this is surely quite incomplete, just a first attempt to think about what we might mean.

6. Scholarship about or pedagogical treatment of writing knowledge transfer should always specify which knowledge(s) are targeted.

\section{REFERENCES}

Adler-Kassner, L., Majewski, J. \& Koshnick, D. (2012). The value of troublesome knowledge: Transfer and threshold concepts in writing and history. Composition Forum, 26. Retrieved from http://compositionforum.com/issue/26/troublesome -knowledge-threshold.php.

Alexander, P. A. \& Murphy, P. K. (1999). Nurturing the seeds of transfer: A domainspecific perspective. International Journal of Educational Research, 31(7), 561-576.

Anson, C. \& Donahue, C. (2014). Curricular topographia: Deconstructing "writing program administration" in an international context. In D. Martins (Ed.), Transnational writing program administration (pp. 21-47). Logan, UT: Utah State University Press.

Astolfi, J. P. (2002). Savoir, c'est pouvoir transférer [To know is to be able to transfer]. Cahiers Pédagogiques, 408, 9.

Bacon, N. (2012, June). Working paper presented at the meeting of Elon University Research Seminar on Critical Transitions: Writing and the Question of Transfer, Elon, NC.

Bartholomae, D. (1986). Inventing the university. Journal of Basic Writing, 5(1), 4-23.

Bawarshi, A. (2007). Accessing academic discourse: The influence of first-year composition students' prior genre knowledge. [Flyer].

Beach, K. (2003). Consequential transitions: A developmental view of knowledge propagation through social organizations. In T. Tuomi-Gröhn \& Y. Engeström (Eds.), Between school and work: New perspectives on transfer and boundary-crossing (pp. 39-62). Amsterdam, NL: Pergamon.

Bereiter, C. \& Scardamalia, M. (1985). Cognitive coping strategies and the problem of inert knowledge. Thinking and Learning Skills, 2, 65-80.

Bergmann, L. S. \& Zepernick, J. (2007). Disciplinarity and transfer: Students' perceptions of learning to write. WPA: Writing Program Administration, 31(1-2), 124-149.

Bourdieu, P. (1977). Outline of a theory of practice. (R. Nice, Trans.) Cambridge, UK: Cambridge University Press.

Bransford, J. D., Brown, A. \& Cocking, R. (1999). How people learn: Mind, brain, experience, and school. Washington, DC: National Research Council.

Bransford, J. D., Franks, J. J., Vye, N. J. \& Sherwood, R. D. (1989). New approaches to instruction: Because wisdom can't be told. In S. Vosniadou \& A. Ortony (Eds.), 
Similarity and analogical reasoning (pp. 470-497). New York: Cambridge University Press.

Cauzinille-Marmèche, E. (1991). Apprendre à utiliser sa connaissance pour la résolution de problèmes: Analogie et transfert [Learning to use one's cognition for problem solving: Comparisons and transfers]. Bulletin de Psychologie, Tome XLIV, 399, 156-164.

Center for Engaged Learning. (2013). Conference program. Elon University Research Seminar on Critical Transitions: Writing and the Question of Transfer. Elon, NC: Elon University.

Chen, M. (1996). Managing international technology transfer. London: International Thompson.

Chevallard, Y. (1985). La transposition didactique: Du savoir savant au savoir enseigné [Didactic transposition: From expert knowledge to knowledge that is taught]. Grenoble, FR: La Pensée Sauvage.

Cook, V. J. (1992). Evidence for multi-competence. Language Learning, 42(4), 557-591.

Davydov, V. V. (1990). Types of generalization in instruction: Logical and psychological problems in the structuring of school curricula. Soviet Studies in Mathematics Education, 2.

Delcambre, I. (2001). Formes diverses d'articulation entre discours d'autrui et discours propre: Analyses de commentaires de textes theoriques [Diverse forms of articulation between the discourse of others and one's own discourse: Analysis of commentaries on theoretical texts]. LIDIL: Revue de Linguistique et de Didactique des Langues, 24, 136-166.

Deschepper, C. (2008, April). Rapport à l'écrit, dimension pragmatique, ancrage disciplinaire, par ou passe l'acculturation aux discours universitaires? [Relationships to writing, pragmatic dimensions, disciplinary anchoring: What path does acculturation to university discourses take?]. Paper presented at the meeting of Journée Internationale du FLE (JIFLE), Université de la Réunion, Saint-Denis, Réunion.

Desilets, M. (1997). Connaissances déclaratives et procédurales: Des confusions à dissiper [Declarative and procedural knowledge: Confusions to dissipate]. Revue des Sciences de L'éducation, XXIII(2), 289-308.

Doly, A-M. (2002). Métacognition et transfert des apprentissages à l'école [Metacognition and transfer of learning at school]. Cahiers Pédagogiques, 408. Retrieved from http://www.cahiers-pedagogiques.com/Metacognition-et-transfert-des-apprentissages -a-l-ecole.

Donahue, C. (2004). Student writing as negotiation: Fundamental movements between the common and the specific in French essays. In F. Kostouli (Ed.), Writing in context(s): Textual practices and learning processes in sociocultural settings. Amsterdam, NL: Kluwer Academic Publishers.

Donahue, C. (2008). Ecrire à l'université: Analyse compare, France-Etats Unis. [Writing at the university: Comparative analysis, France-US]. Villeneuve-d'Ascq, FR: Presses Universitaires du Septentrion.

Donahue, C. (2009). "Internationalization” and Composition Studies: Re-orienting the discourse, College Composition and Communication 61(2), 212-242. 
Donahue, C. (2010). Évolution des pratiques et des discours sur l'écrit a l'universite: Étude de cas [Evolution of practices and discourses about university writing: Case study]. LIDIL: Revue de Linguistique et de Didactique des Langues, 41, 137-160.

Donahue, C. (2012). Transfer, portability, generalization: (How) does composition expertise "carry"? In K. Ritter \& P. Matsuda (Eds.), Exploring composition studies: Sites, issues, and perspectives (pp. 145-166). Logan, UT: Utah State University Press.

Driscoll, D. L. \& Wells, J. (2012). Beyond knowledge and skills: Writing transfer and the role of student dispositions. Composition Forum, 26. Retrieved from http:// compositionforum.com/issue/26/beyond-knowledge-skills.php.

Elon Statement on Writing Transfer. (2015). Retrieved from http://www.centerfor engagedlearning.org/elon-statement-on-writing-transfer/.

Engeström, Y. (2001). Expansive learning at work: Toward an activity theoretical reconceptualization. Journal of Education and Work, 14(1), 133-156.

Foertsch, J. (1995). Where cognitive psychology applies: How theories about memory and transfer can influence composition pedagogy. Written Communication, 12(3), 360-383.

François, F. (1998). Le discours et ses entours [Discourse and its surroundings]. Paris, FR: L'Harmattan.

Gagné, R. (1985). The conditions of learning and theory of instruction. New York: CBS College.

Guibert, R. (2004). Formation aux dialogismes [Formation for dialogisms]. Pratiques, $121,28-44$.

Haskell, R. E. (2000). Transfer of learning: Cognition, instruction, and reasoning. San Diego, CA: Academic.

Hatano, G. \& Greeno, J. G. (1999). Commentary: Alternative perspectives on transfer and transfer studies. Educational Research, 31(7), 645-654.

Heidrick, I. (2006). Beyond the L2: How is transfer affected by multilingualism? Columbia University Working Papers in TESOL and Applied Linguistics, 6(1), 1-3.

Hilaricus, J. R. (2011, April). Toward a sociomaterial approach to knowledge transfer. Paper presented at the meeting of the International Conference for Organizational Learning, Knowledge and Capabilities (OLKC), Kingston upon Hull, UK.

Horner, B., NeCamp, S. \& Donahue, C. (2011). Toward a multilingual composition scholarship: From English only to a translingual norm. College Composition and Communication, 63(2), 269-300.

Ito, F. (2009). Threshold to transfer writing skills from L1 to L2. Retrieved from http://files.eric.ed.gov/fulltext/ED506378.pdf.

Ivanič, R. (1998). Writing and identity: The discoursal construction of identity in academic writing. Amsterdam, NL: John Benjamins.

Kara, M. (2004). Reformulation et polyphonie [Reformulation and polyphony]. Pratiques, 123/124, 27-53.

Kogut, B. \& Zander, U. (1995). Knowledge and the speed of transfer and imitation of organisational capabilities: An empirical test. Organisation Science, 6(1), 76-92.

Kumashiro, K. (2004). Against common sense: Teaching and learning towards social justice. New York: Routledge. 
Lave, J. (1988). Cognition in practice: Mind, mathematics, and culture in everyday life. New York: Cambridge University Press.

Lave, J. (1991). Situating learning in communities of practice. In L. Resnick, J. Levine \& S. Teasley (Eds.), Perspectives on socially shared cognition (pp. 63-82). Washington, DC: APA.

Lave, J. \& Wenger, E. (1991). Situated learning: Legitimate peripheral participation. Cambridge, UK: Cambridge University Press.

Le Boterf, G. (1994). De la competence: Essai sur un attracteur étrange [About competency: Essay on a strange attractor]. Paris, FR: Editions D’Organisation.

Lillis, T. M. (2001). Student writing: Access, regulation, desire. New York: Routledge.

Lillis, T. \& Rai, L. (2012). Quelle relation entre l'écrit academique et l'écrit professionnel? Une étude de cas dans le domaine du travail social [What relationship between academic and professional writing? A case study in social work]. Pratiques, 153(4), $51-70$

Meirieu, P. (1994). Apprendre . . oui, mais comment? [Learn . . yes, but how?]. Paris, FR: ESF.

Meirieu, P. \& Develay, M. (1996). Le transfert de compétences analysé a travers la formation de professionnels [Transfer of competencies analyzed through professional training]. In P. Meirieu, M. Develay, C. Durand \& Y. Mariani (Eds.), Le concept de transfert de connaissances en formation initiale et en formation continue [The concept of knowledge transfer in initial and ongoing education] (pp. 31-46). Lyon, FR: CRDP.

Meyer, J. \& Land, R. (2003). Threshold concepts and troublesome knowledge: Linkages to ways of thinking and practising within the disciplines. Enhancing TeachingLearning (ETL) Project Occasional Report, No. 4. Retrieved from http://www.etl.tla .ed.ac.uk//docs/ETLreport4.pdf.

Moore, J. L. (2012). Mapping the questions: The state of writing-related transfer research. Composition Forum, 26. Retrieved from http://compositionforum.com /issue/26/map-questions-transfer-research.php.

Nelms, G. \& Dively, R. L. (2007). Perceived roadblocks to transferring knowledge from first-year composition to writing-intensive major courses: A pilot study. WPA: Writing Program Administration, 31(1-2), 214-240.

Nowacek, R. S. (2011). Agents of integration: Understanding transfer as a rhetorical act. Carbondale, IL: Southern Illinois University Press.

Paré, A., Dias, P. \& Farr, M. (Eds.). (2000). Transitions: Writing in academic and workplace settings. New York: Hampton Press.

Perkins, D. (2006). Constructivism and troublesome knowledge. In J. Meyer \& R. Land (Eds.), Overcoming barriers to student understanding: Threshold concepts and troublesome knowledge (pp. 33-47). London: Routledge.

Perkins, D. N. \& Salomon, G. (1992). The science and art of transfer. In A. L. Costa, J. A. Bellanca \& R. Fogarty (Eds.), If minds matter: A foreword to the future (Vol. 1) (pp. 201-210). Palatine, IL: IRI/Skylight.

Perkins, D. N. \& Salomon, G. (2007). The science and art of transfer. Harvard University Learnweb. Retrieved from https://learnweb.harvard.edu/alps/thinking/docs /trancost.pdf. 
Perrenoud, P. (1999a). Construire des compétences, est-ce tourner le dos aux savoirs [Does constructing competencies mean turning one's back on knowledges?]. Pédagogie Collégiale, 12(3), 14-17.

Perrenoud, P. (1999b). Transférer ou mobiliser ses connaissances? D’une metaphore l'autre: Implications sociologiques et pedagogiques [Transferring or mobilizing knowledge? From one metaphor to another: Sociological and pedagogical implications]. Retrieved from http://www.unige.ch/fapse/SSE/teachers/perrenoud/php _main/php_1999/1999_28.html.

Perrenoud, P. (2000). D'une métaphore l'autre: transférer ou mobiliser ses connaissances? [From one metaphor to another: Transferring or mobilizing knowledge?]. In J. Dolz \& E. Ollagnier (Eds.), L'énigme de la compétence en éducation [The enigma of 'competence' in education] (pp. 45-60). Brussels, BE: De Boeck.

Reuter, Y. (2004). Analyser les problèmes de l'écriture de recherche en formation [Analyzing writing research problems in training]. Pratiques, 121/122, 9-27.

Reuter, Y. (2006). À propos des usages de Goody en didactique. Éléments d'analyse et de discussion [About using Goody in didactics. Elements of analysis and discussion]. Pratiques, 131(132), 131-154.

Rinck, F. (2006). Gestion de la polyphonie et figure de l'auteur dans les parties théoriques de rapports de stage [Managing polyphony and authorial figures in the theory section of internship reports]. LIDIL: Revue de Linguistique et de Didactique des Langues, 34, 85-103.

Rinck, F. \& Sitri, F. (2012). Pour une formation linguistique aux écrits professionnels [In support of linguistic formation for professional writing]. Pratiques, 153/154, 71-84.

Russell, D. (1995). Activity theory and its implications for writing instruction. In J. Petraglia (Ed.), Reconceiving writing, rethinking writing instruction (pp. 51-78). London: Routledge.

Salomon, G. \& Perkins, D. N. (1989). Rocky roads to transfer: Rethinking mechanisms of a neglected phenomenon. Educational Psychologist, 24(2), 113-142.

Samson, G. (2002). Le transfert a-t-il un avenir dans l'apprentissage et l'enseignement? [Does transfer have a future in learning and teaching?]. Cahiers Pédagogiques, 408. Retrieved from http://www.cahiers-pedagogiques.com/Le-transfert-a-t-il-un-avenir -dans-l-apprentissage-et-l-enseignement.

Scott, M. (2013). From error to multimodal semiosis: Reading student writing differently. In M. Böck \& N. Pachler (Eds.), Multimodality and social semiosis: Communication, meaning-making, and learning in the work of Gunther Kress (pp. 195-203). New York: Routledge.

Serres, M. (1974). La traduction [Translation]. Paris, FR: Les Editions de Minuit. Sparks, R., Patton, J., Ganschow, L. \& Humbach, N. (2009). Long-term crosslinguistic transfer of skills from L1 to L2. Language Learning, 59(1), 203-243.

Street, B., Lea, M, Russell, D., Parker, J. \& Donahue, C. (2009). Exploring notions of genre in "academic literacies" and "writing across the curriculum": Approaches across countries and contexts. In C. Bazerman, A. Bonini \& D. Figueredo (Eds.), Genre in a Changing World. Fort Collins, CO: WAC Clearinghouse/Parlor Press. Available at http://wac.colostate.edu/books/genre/. 
Tardif, J. \& Meirieu, P. (1996). Stratégie pour favoriser le transfert des connaissances [Strategy for fostering knowledge transfer]. Vie Pédagogique, 98(7), 4-7.

Teece, D. J. R., Rumelt, G. \& Winter, S. (1994). Understanding corporate coherence. Journal of Economic Behavior and Organization, 23, 1-30.

Tuomi-Gröhn, T. \& Engeström, Y. (2003). Conceptualizing transfer: From standard notions to developmental perspectives. In T. Tuomi-Gröhn \& Y. Engeström (Eds.), Between school and work: New perspectives on transfer and boundary-crossing (pp. 19-38). Amsterdam, NL: Pergamon.

University of Montreal. (2013). Le transfert de connaissances [The transfer of knowledge]. Retrieved from http://www.recherche.umontreal.ca/valorisation-de-la -recherche/le-transfert-de-connaissances.

Vygotsky, L. S. (2012). Thought and language. Cambridge, MA: Massachusetts Institute of Technology.

Wardle, E. (2007). Understanding transfer from FYC: Preliminary results of a longitudinal study. WPA: Writing Program Administration, 31(1-2), 65-85.

Wardle, E., Roozen, K. \& Casillas, S. (2013, June). Transfer and the work of identity: Considering the role of social identity in moments of critical transition. Paper presented at the meeting of Elon University Research Seminar on Critical Transitions: Writing and the Question of Transfer, Elon, NC.

Wenger-Trayner, E. \& Wenger-Trayner, B. (2014). Complex landscapes and systems convening. New York: Routledge.

Wolfersberger, M. (2003). L1 to L2 writing process and strategy transfer: A look at lower proficiency writers. TESL-EJ, 7(2), 1-12.

Young, M., Tuomi-Gröhn, T. \& Engeström, Y. (2003). From transfer to boundary-crossing between school and work as a tool for developing vocational education: An introduction. In T. Tuomi-Gröhn \& Y. Engeström (Eds.), Between school and work: New perspectives on transfer and boundary-crossing (pp. 1-19). Amsterdam, NL: Pergamon. 


\section{PART 2. \\ SUPPORTING WRITERS' TRANSFERS \\ AT CRITICAL TRANSITIONS}





\section{CHAPTER 5}

\section{MINDING THE GAP: WRITING- \\ RELATED LEARNING IN/ ACROSS/WITH MULTIPLE ACTIVITY SYSTEMS}

\section{Regina A. McManigell Grijalva}

In the face of budget reductions and reorganizations, universities and colleges have been confronted with calls for greater accountability in the education they provide, at all levels. Professionals deeply invested in education should be involved in actions that assess the effect of programming, curricula and the instruction that takes place in our classrooms. Approaching assessment in a manner that accounts for the kind of deep critical thinking and situated learning that leads to successful transfer of knowledge and skills from the classroom to new environments is a daunting challenge. Even using the term transfer comes with inherent problems that imply what Wardle (2012) refers to as a "carry and unload model" of learning, which suggests that students transport their learned knowledge and skills to new communicative contexts (see also Donahue, this volume). Unfortunately, universities today are pressured by legislators and other stakeholders to use simplified terms for learning such as "transfer" and measures of learning such as standardized testing that "limit the kind of thinking that students and citizens have the tools to do" (Wardle, 2012, par. 7). The study presented here is part of ongoing research into how we can best understand the learning students undergo in the critical transition from high school to college and how they transfer that learning into new situations.

\section{RESEARCH QUESTIONS AND PURPOSE}

A theory prevalent in the Elon Statement, which operates as a framework for the present study, involves activity systems. This three-year study progressed toward an examination of the way "[s]tudents routinely move among activity systems (including curricular, co-curricular, and extra-curricular contexts)" in order to develop a better understanding of learning transfer (Elon Statement, 2015, p. 3). The purpose of this research is to identify for stakeholders in the field of composition 
and beyond the skills and knowledge (learning) that transfer with high school students as they become first-year college students and then navigate their ways through their undergraduate academic experiences. To that end, the term transfer is used, but is thought of in a messier sense, like that which Wardle (2012) envisions when using "repurpose" (see Glossary). This research explores how service learning in higher education affects learning transfer of composition knowledge and skills. Though there are studies looking at bridging programs, none focus on four-year scholarship programs that bridge the gap during this critical transition from high school to college, for composition students or in any other discipline. There is currently a paucity of research into summer bridge programs (Barnett et al., 2012). This research examines the impact of helping students who are part of a four-year scholarship program bridge the gap from high school to college and make connections to both their communities and their composition curriculum for greater success and learning transfer. This study provides an overview of three research phases and the concepts they offer about learning transfer.

\section{LITERATURE REVIEW AND RESEARCH RATIONALE}

Faculty members outside writing studies often question the learning students do in composition classrooms. According to Beaufort (2007), a common problem for writing students is their inability to transfer writing-related learning in college composition to classes beyond first-year writing. Beaufort explained that faculty often question "why graduates of freshman writing cannot produce acceptable written documents in other contexts" (2007, p. 6). Carroll also noted that faculty outside English composition "who are faced with student writing that does not meet their expectations, ask why students who have completed English I and II, usually with good grades, still cannot 'write'" (2002, p. 61). Knowledge that students acquire from composition instruction not being considered useful in other writing contexts has been a growing concern since the early 1990s. Nowacek says that "faith in the transfer of writing-related knowledge has been challenged by questions about the viability of first-year composition curricula" (2011, p. 2). Yet, as noted above, Wardle (2012) points out that at least part of this problem stems from the way people outside composition studies talk about and view the process of learning, especially in the area of written composition.

Clearly, writing practitioners must research instruction in writing and its effect, which is why the ERS was developed and the different ERS cohorts studied a variety of transitions critical to learning composition and the transfer of that learning. As a larger cohort, we ERS participants drew on several writing studies theories and concepts to research learning transfer. The framework most prevalent in this current study was activity systems theory, informed primarily by two approaches 
to activity systems theory, the first by Tuomi-Gröhn and Engeström (2003) and the second by Russell and Yañez (2003) (see Glossary). For this study, I have expanded and applied their notions of boundary-crossing to the learning students take with them when they travel to one community from another within a larger community - such as when they go from co-curricular activities to curricular or extracurricular activities, in the college environment or beyond college contexts, especially when crossing such boundaries intentionally and collaboratively.

In addition to the boundary-crossing concept and activity systems theory, the present research explores the question Moore makes in "Mapping the Questions: The State of Writing-Related Transfer Research" where she asks, "How do institutional characteristics shape activity systems?" (2012, para. 11). The research here maps progress in writing-related learning of four small groups of students in three related but diverse approaches to research in order to explore what makes for successful learning transfer. The college where the bulk of data were collected is a small, private, liberal arts college. The high school where some data were collected is similar. Moore notes, "Research-intensive universities play a dominant role as cartographers of writing-related transfer maps" (2012, "Adding Detail," para. 3), so it is prudent to look to the research of those studies. However, it is also important to look briefly to other transfer studies done by researchers in college contexts more similar to mine, such as those conducted by Carroll (2002), Nowacek (2011), and Moore, Pyne, and Patch (2013) to think about how, where, and why common and divergent findings emerged in the less dominant and less research-intensive institutions.

Carroll's (2003) findings from a study of students at a small liberal arts college reiterated the notion that writing is a complex activity that students learn over time while developing skills and knowledge, in the process of engaging with and crossing boundaries into a variety of activity systems of communities of people, tools, and texts. Her findings, however, might not be applicable to student populations that diverge greatly from the students in her study or at significantly different institutions. Nowacek (2011), who also studied student learning at a another small liberal arts college offers interesting insights about the ways the term transfer is used, distinguishing differences between kinds of transfer along a spectrum including successful, frustrated, negative, and zero. She contrasts these notions of transfer to her concept of integration, which she also puts on a spectrum perpendicular to the transfer spectrum (Nowacek, 2011 , p. 41). Nowacek uses the term integration, or integrative learning, saying that successful integration is a metacognitive action, while transfer in its various forms suggests a degree of unconscious transfer of knowledge/skills in writing. Moore et al. conducted a study of the transfer of learning that connects in many ways to the present study in terms of context, focusing on 
a bridging program to better prepare underrepresented students by offering "mentorship, support, cognitive and social enrichment, and a space to practice college-ready skills (both academic and personal)” (Moore et al., 2013, para. 4). Their study examined the Elon Academy/writing program partnership at a small liberal arts college and writing program modifications made to support Elon Academy students. The Elon Academy course focused solely on writing so students could learn to "hone strategies for balancing the additional responsibilities many underrepresented students might bring with them to the college classroom" (Moore et al., 2013, para. 8). The Elon Academy was fully funded, so students in the study were given "the opportunity to earn free college credit as a tangible financial benefit, especially given the cost of a regular Elon summer session" (Moore et al., 2013, "Understanding Our Students," para. 4). The study looked at the students' participation in the larger goals of the overall program. One finding especially resonates with the present study, which was that student reflections on learned practices in the program should be intentionally integrated throughout, as they were successful in helping students document their learning.

\section{INSTITUTIONAL CONTEXTS}

The study presented here progressed through three phases of research. It began with an initial collection of high school and college students' perceptions about the goals of English classes in high school and/or college. For the second phase, based on phase one data, like-minded college administrators, faculty, and staff developed a summer bridging course with measurable goals and offered it to a cohort of incoming first-year students who were accepted into a four-year scholarship program. Surveys designed to measure the program's success were administered at the end of the summer and again at the end of the first academic year. For the third phase, I conducted a focus group with three of the scholars at the end of their second academic year; they looked back at their college experience thus far and discussed their learning. The results are rhetorically driven and situational in that the learning environment and the communities developed within it played a large role in shaping the perceptions of the students' learning and experiences.

\section{Context of Phase One: Harding Fine Arts ACademy and OKLahoma City University}

Part of the first phase of the research was conducted with a group of Harding Fine Arts Academy (HFA) high school seniors in the second semester of school in late March, after many of them had taken placement tests and applied for admittance 
into colleges. This high school is a small charter school located just northwest of the city center in Oklahoma City. It has a diverse student population of $29 \%$ white students and $71 \%$ underserved ethnicities and mixed-race students, and a growing waiting list for admission each semester. HFA is within walking distance of the Paseo Arts District where First Friday Art walks take place each month. Many of the artists and gallery owners in the Paseo are actively involved with HFA. The high school's mission is "preparing students for college in an academically challenging, arts-integrated environment" (Harding Fine Arts, 2014). It has been designated an Oklahoma A+School, which is a prestigious designation in Oklahoma and requires a stringent evaluation process. Performing and fine arts are integrated into the curricula, and creativity in teaching and learning are highly encouraged. Another important HFA value is community service. Seniors conduct year-long projects that involve community service, which they write and give presentations about. HFA is only a mile and half from Oklahoma City University (OCU) and has developed a strong connection to it in the past three years. The number of HFA students who attend the university has doubled each year, from two in 2012, to four in 2013, to eight in 2014.

The other part of the phase one research was made up of first-year composition students at OCU, which, like HFA, is located in the northwest quadrant of the city, but within the city center near the state Capitol. It is a small, private university affiliated with the United Methodist Church, and it has a student population of about 2,000 undergraduate students. OCU has a religious foundation and strong commitments to service and interfaith dialogue. Like Elon University, OCU is a college primarily dedicated to undergraduate education and engagement, though OCU does have graduate programs in business, creative writing, dance, law, music, nursing, public administration, theatre, and religion. OCU is well known for its performing and fine arts programs, and the university is strongly connected to the arts locally and nationally. There is much overlap in values between HFA and OCU, especially with regard to the arts, service to the community, and diversity. Close to a fourth of the incoming student population over the past three years at OCU has come from underserved ethnicities. Service is required at both schools.

\section{Context of Phases Two and Three: Mind the GaP AND Clara LuPER aNd AMERICAN Indian SCHOlarS}

The students in phases two and three of the study were from a group of scholars coming into OCU in the summer of 2012 through the Clara Luper and American Indian Scholarship program, a program designed to attract diverse students from underserved populations who have a strong commitment to servant-leadership. Administrators, faculty, and staff involved in a faculty learning community 
designed a summer bridging program that all incoming Clara Luper and American Indian Scholars were required to attend called Mind the Gap. One overarching goal was to help the students create and become part of a stronger and more cohesive community of first-year scholars through various co-curricular, extra-curricular, and curricular activities to help them grow and sustain their sense of community as a cohort for their four years at OCU.

Other goals of the Mind the Gap program were to strengthen students' learning at a critical transition, to provide multiple contexts across which students could practice their learned skills/knowledge, and to fortify the connections students made between academics and serving their communities. Mind the Gap was not a regular bridging program. There were some similarities to other bridge programs, as most summer bridge programs are designed for underserved populations (Barnett et al., 2012). However, Mind the Gap was different in at least two important ways. One, many bridge programs also seek to "reduce or eliminate the need for developmental education in colleges" (Teachers College, 2013). Mind the Gap was not looking to place would-be developmental students. Mind the Gap students were talented students whose admissions files were similar to the rest of the incoming first-year students with grade point averages (GPAs) that were slightly higher and SAT/ACT scores slightly lower, but not to a statistically significant degree in either case. The other major difference from other bridging programs is that Mind the Gap students were coming into a four-year scholarship program—not the norm for bridging programs, which typically provide that connection between high school and college but do not usually monitor those students in an intentional way throughout their time in college. Mind the Gap students who were coming in as Clara Luper and American Indian Scholars were required to complete 150 hours of community service per year, so students were also selected by their community service experience. This study focuses on the data gathered from the students who were in first-year composition in Mind the Gap.

\section{RESEARCH METHODOLOGY}

\section{Methods for Phase One}

The first phase of research was exploratory in that grounded theory approach was used to conduct a naturalistic type of inquiry employing Lincoln and Guba's (1985) emergent design concept. To guide more focused research in later phases and to better understand writing-related transfer, questionnaires were used to discover what HFA senior English students and OCU first-semester college composition students thought they learned in their required English classes. The 
first phase in the study was designed to offer a general picture of learning from these students' standpoints and to allow hypotheses and conclusions about writing-related learning to begin emerging naturally.

The student groups responding to the initial questionnaires consisted of 47 HFA seniors who volunteered to participate out of the senior class of 80 , and 59 first-year OCU students who self-selected to participate from four English Composition I classes with 20 students in each (Composition I is the first of the two-sequence general education requirement for first-year composition). Two of the seniors in the HFA group were already admitted to OCU at the time and planned on going to OCU in fall 2012. The questionnaire was focused on the following questions about students' perceptions of the English classroom:

1. Based on your experience, whatever you have seen, heard, or discussed, tell me what you perceive to be the goals for reading, writing, or using technology in [high school English and/or writing classes/college English and/or writing classes].

2. Please describe any skills or strategies that you have learned in your English classes that you have been able to apply outside the specific class where they were learned? (These could be in other classes, or outside the school context.)

\section{Methods for Phase Two}

The second phase of the research highlighted whether students' intentional boundary-crossing and entering (and reentering) multiple activity systems with a cohort and a common set of goals would make for stronger transfer of learning regarding students' perceptions of their own preparedness for new situations beyond first-year composition. This secondary research, prompted by answers from the first phase, became the topic of many conversations in a faculty learning community attended by a handful of administrators and staff from the Clara Luper and American Indian Scholarship program and faculty who were interested in connections among learning in and out of the classroom, community service, and democratic education - a concept coined by Saltmarsh and Hartley (2011) to refer to a curriculum that encourages students to act intentionally as agents of change in the community. The Mind the Gap summer bridging program was conceived in the course of these lengthy discussions as one that would require the incoming scholars to take one of three required general education courses-College Algebra, English Composition I, or World Religions-in addition to a one-unit studies skills class. The curricular activities worked together with co-curricular and extra-curricular activities that would strengthen 
community engagement and collaboration. We constructed a survey instrument to assess learning transfer and community building to be given to students just after the summer Mind the Gap program and again at the end of the academic year. This second phase of the study focused on the survey results from the English Composition I scholars and the level of success and preparedness they felt the bridging program gave them.

Forty-two incoming first-year students were selected for the four-year scholarship program and Mind the Gap. One student was from the HFA phase one research group, and all were from socially, economically, or ethnically underrepresented groups. Fifteen of the students were in English Composition I, 15 were in College Algebra, and 12 were in World Religions. The entire group was also in a one-unit studies skills class. The number of composition students completing the survey was 12 at both points in the year. (The 13 survey questions and student responses are found in Table 5.2, Phase Two Results.) Two different statistical tests were run with a $95 \%$ confidence level on the two sets of survey data: the T-test for a difference in means and a general linear model regression with fixed effects to look for probable statistical difference between the two sets of responses. ${ }^{1}$

\section{Methods for Phase Three}

The third phase of the research was a case study focused on perspectives from three of these Mind the Gap scholars who engaged in much reflection about their learning in the initial bridging program, their two composition classes (the second of which was a service learning course), the many contexts in which they continued to serve, and formal presentations they offered about their learning and community engagement experiences.

These three students in the first Mind the Gap cohort in 2012 volunteered to collaborate on sharing their discoveries and experiences at a regional service learning conference and subsequently engaged in a conversation about their learning in an informal focus group discussion. These students represent the diversity of the scholarship program: Harley is Native American, Juan is Hispanic, and Josh is African-American. These young men are also first-generation college students. Harley is a sports science major, Juan is a business major, and Josh is a pre-medical major. These three students have become very close to one another because of their scholarship program, Mind the Gap, and their participation in the present research despite being in different degree programs. The focus group itself was informal in that it was a conversation, which was video-taped in a conference room. That conversation was prompted by three questions. The section titled "Findings for Phase Three" below goes into greater detail about those questions and the students' responses. 


\section{RESEARCH FINDINGS}

\section{Findings for Phase ONe}

The initial research suggested that the OCU students were more confident about their knowledge and skills in writing than the HFA students. In general, the students who engaged in experiential learning in the contexts of serving their communities seemed to have a strong sense of community in addition to demonstrating writing-related transfer. This conclusion is supported by Tuomi-Gröhn and Engeström (2003) and Russell and Yañez (2003) in notions of boundary-crossings, genres, and activity systems.

Two important trends emerged from the questionnaires, which provided some insight into learning transfer and helped shape the research that followed in the second phase. The two areas of focus were based on (1) specific answers to the questions that speak to categories and contexts of writing and (2) responses that stood out as more articulate than the other responses demonstrating strong writing abilities, which may have been learned or were at least strengthened in the students' English classes.

In terms of writing and the contexts where it happens, the categories of writing that emerged in the students' answers fell into eight different writing skills/knowledge areas. Two research assistants and I looked for common trends in the students' responses and used the "OCU English Department Composition Outcomes Statement" (see Appendix C) developed collaboratively by OCU composition faculty in conjunction with the national "WPA Outcomes Statement" (Council of Writing Program Administrators, 2014). Using the OCU outcomes as a general guide, two research assistants and I identified emerging trends in skills/knowledge areas, which became categories for the purpose of reporting these results (see Table 5.1, Phase One Results). The categories progress from lower-order writing skills/knowledge that are looking at language and writing at the sentence level to higher-order skills/knowledge that are more global. Higher-order skills/knowledge are conceived of here as more global following Bean's explanation as "ideas, organization, development, and overall clarity," while lower-order concerns are more surface-level, such as "grammatical errors, punctuation mistakes, and awkwardness of style" (2001, pp. 243-246). Citation as a technical skill will be categorized as lower-order skill/knowledge. In addition to the categories of writing, student responses referred to nine specific writing contexts where they said their writing occurred (Table 5.1).

Of the eight categories of writing, college students spoke specifically to seven of the categories significantly more than high school students, suggesting that in college, a greater number of the OCU students perceived themselves to have learned more skills/knowledge than their HFA high school counterparts. The 
Table 5.1. Phase One results, questionnaire with high school and college student-Percentage of student responses addressing each category and context of writing

\begin{tabular}{lrr}
\hline & \multicolumn{1}{c}{ High } & \\
Specific Writing Skills \&/or Strategies & School & College \\
\hline Syntax, grammar, punctuation, or spelling & $8.69 \%$ & $15.87 \%$ \\
Style, word choice, or citation formats & $36.17 \%$ & $22.22 \%$ \\
Composition organization, structure, or cohesion & $4.25 \%$ & $14.29 \%$ \\
Strategies or processes for approaching reading, writing, or speaking & $14.89 \%$ & $60.32 \%$ \\
Researching, evaluating, or analyzing sources & $12.76 \%$ & $33.33 \%$ \\
Use of support, evidence, details or explanations & - & $22.22 \%$ \\
Critical thinking, reading, writing, or speaking & $25.53 \%$ & $38.1 \%$ \\
Modes, genres, forms or types of written compositions & $4.25 \%$ & $32.14 \%$ \\
\hline Specific Tasks or Contexts in Which Strategies or Skills are Used & & \\
\hline Standardized tests & - & $9.52 \%$ \\
College applications & $42.55 \%$ & - \\
Scholarship applications & $6.38 \%$ & $3.12 \%$ \\
Job applications & - & $1.59 \%$ \\
Literacy tasks in other classes & $25.53 \%$ & $20.63 \%$ \\
Self-expression/personal enjoyment & $6.38 \%$ & - \\
Serving/volunteer work & $2.1 \%$ & $5 \%$ \\
Collaborative work & $2.1 \%$ & - \\
\hline
\end{tabular}

seven categories included all but the category of "Style, word choice, and citation formats." The HFA high school students spoke more to that one category than the OCU college students. Another category that was not expressed by any HFA high school students was the category "Use of support, evidence, details, or explanation." Thus, the OCU college students spoke to one more writing category of higher-order thinking than the HFA students, and the HFA high school students spoke to one more lower-order writing category than did the OCU students.

With regard to contexts where students said they used their writing abilities, responses that referred to contexts where students used writing varied more than the categories of writing. HFA high school students referred only to contexts of "College applications," "Scholarship applications," "Literacy tasks in other classes," "Self-expression/personal enjoyment," Serving/volunteer work," and "Collaborative work." They did not mention "Standardized tests" or "Job applications" (this is expected because, according to the HFA principal, only a 
very small number of HFA students work while in school or take standardized tests requiring written portions such as the SAT). The contexts that both groups mentioned were "Scholarship applications," "Literacy tasks in other classes," and "Serving/volunteer work." The two remaining contexts that only the college students referred to (as noted above) were "Standardized tests" and "Job applications." The responses about contexts of "Serving/volunteer work" were mentioned by three students, one HFA and two OCU students. These three responses claimed and demonstrated successful integration, to use Nowacek's term, of writing skills/knowledge, meaning they were cognizant of their knowledge and skills and demonstrated it.

\section{Findings for Phase Two}

The survey data gathered shows an interesting trend numerically, though, as noted above, it is not statistically significant (see Table 5.2, Phase Two Results, for the numerical breakdown). The survey used a Likert scale ranging from 1 to 6 asking students to rate their level of success in each of the 13 subject areas with a " 6 " being the highest success and a " 1 " being the lowest. As noted above, two different statistical tests were run with a 95\% confidence level: the T-test for a difference in means and a general linear model regression with fixed effects. Results suggest that we can say there is not a significant difference between the mean of the first data set and the mean of the second. Nonetheless, there is a definite upward trend happening.

The average of all but one survey response in the initial survey completed in early fall fell between 4.5 and 5.5. The one that fell below 4.0 was "Your ability to work toward learning goals set up in your degree program." The average of the 12 student responses for that particular subject area was 3.31, making it the area in which students initially saw the least success. The strongest response in the initial survey was a 5.17 average to "Your belief that the program has influenced your individual growth." Overall, the students' initial responses were generally positive toward reaching the goals we set up for the Mind the Gap program, as shown in the initial survey results just a few weeks after they finished the summer program and began their fall semester. Our second set of survey data from these students with the same survey showed an increased sense of success by the students, which suggests that students had a stronger sense of learning transfer in the subject areas we outlined as important to the program and students' learning in it. All of the averages in the answers to the second survey done at the end of the spring semester were higher. The one subject area that engendered the biggest jump in numbers was the one that had the lowest response in the first survey taken: "Your ability to work toward learning goals set up in your degree 
Table 5.2. Phase Two results, survey response from summer 2012 Mind the Gap students

\begin{tabular}{|c|c|c|}
\hline On a Scale From 1-6 Rate Your Level of Success in Each Area & $\begin{array}{l}\text { Fall Data } \\
\text { Average }\end{array}$ & $\begin{array}{l}\text { Spring Data } \\
\text { Average }\end{array}$ \\
\hline Your academic learning/development so far this semester & 4.69 & 4.75 \\
\hline Your ability to change how you're studying when you see a need & 4.54 & 4.67 \\
\hline $\begin{array}{l}\text { Your general feelings of marked progress toward accomplishing } \\
\text { learning goals in your classes }\end{array}$ & 4.69 & 4.75 \\
\hline Your continued development or progress in your academic writing & 4.54 & 4.67 \\
\hline $\begin{array}{l}\text { Your ability to work toward learning goals set up in your degree } \\
\text { program }\end{array}$ & 3.31 & 4.67 \\
\hline $\begin{array}{l}\text { Compared to other freshman, how do you rate your understanding } \\
\text { of what it means to be a university student? ( } 1 \text { is less, } 6 \text { is more) }\end{array}$ & 4.62 & 4.75 \\
\hline $\begin{array}{l}\text { Your belief that having academic work in both classes that worked } \\
\text { together to acclimate to college life }\end{array}$ & 4.77 & 4.83 \\
\hline $\begin{array}{l}\text { Your belief that the academic work you did in conjunction with } \\
\text { your servant leadership activities in OKC community helped to } \\
\text { acclimate you to college life }\end{array}$ & 4.92 & 5 \\
\hline $\begin{array}{l}\text { Your belief that the synergy of academic work, servant-leadership } \\
\text { activities, and Mind the Gap cohort activities you did acclimated } \\
\text { you to college life }\end{array}$ & 5.08 & 5.17 \\
\hline $\begin{array}{l}\text { Your belief that your leadership skills have been enhanced as a } \\
\text { result of this program }\end{array}$ & 4.67 & 4.83 \\
\hline $\begin{array}{l}\text { Your belief that the program has influenced your individual } \\
\text { growth }\end{array}$ & 5.17 & 5.25 \\
\hline $\begin{array}{l}\text { Your belief that your sense of responsibility to the community (OCU } \\
\text { and/or OKC) has been enhanced as a result of this program }\end{array}$ & 4.92 & 5.08 \\
\hline $\begin{array}{l}\text { Your belief that the overall program has helped you prepare for } \\
\text { college success }\end{array}$ & 5 & 5.25 \\
\hline
\end{tabular}

program." The average of the second survey answers to that subject area was 4.67, up 1.36 points from 3.31 in the initial survey.

\section{Findings for Phase Three}

The aim of the Phase Three informal focus group was informed by the study of Bergmann and Zepernick, who, in reviewing research on the development of writers in the academy, noted that there is a widely held "optimistic fiction" by students and faculty across universities that there is an "orderly progression implied by FYC-to-writing-in-the-disciplines model” (2007, p. 125). They also explained that many studies show that "students' conceptions of learning to write 
are composed of some combination of individual experience and peer culture" (Bergmann \& Zepernick, 2007, p. 126). The third phase focus-group discussion about writing with these three student-scholars pointed to the importance of experiences and peer collaborations as they were each learning to write for the academy in general, and more specifically in each one's prospective discipline. Also, the experiences these three had in crossing boundaries into a variety of different activity systems over the past year and a half gave them a stronger sense of transfer of learning in writing knowledge/skills. Using Nowacek's spectra will help flesh out the complexity of their responses in greater depth in the "Discussion" section below.

\section{Table 5.3a. Phase Three results, focus group responses to question one}

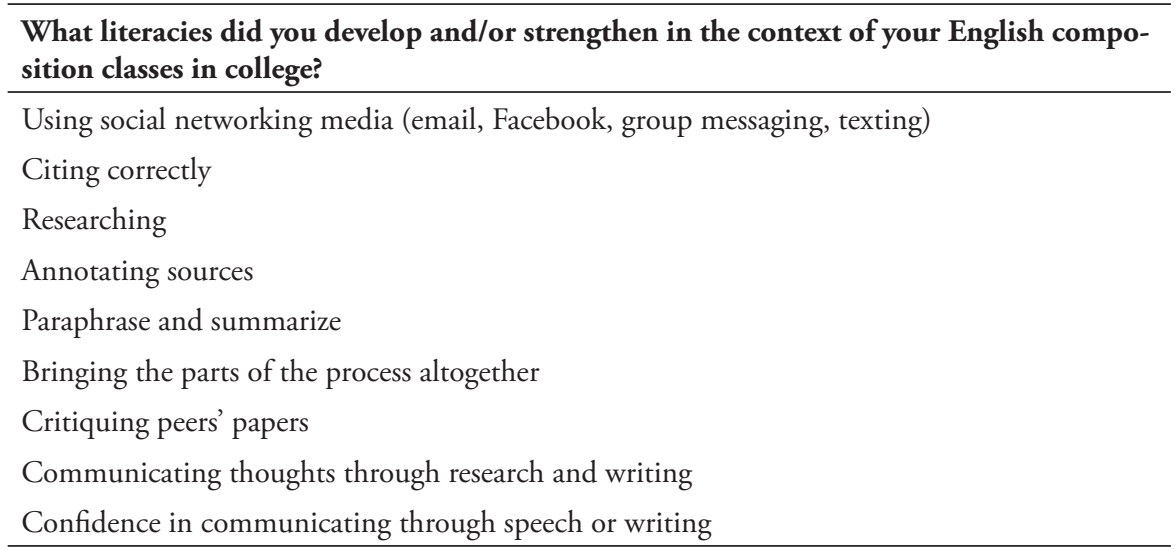

Table 5.3b. Phase Three results, focus group responses to question two

Of the literacies from your answer to question one, which of those literacies have you continued to use, build on or develop and how?

Researching

Using research to interpret literature/interpreting literature

Writing essays/papers in other classes

Collaborating on presentation projects

Presenting/speaking about research to academic audiences

Answering questions in a formal presentation

Working with people/public in work contexts

Writing papers for a public audience

Confident in writing for new situations

Service learning experience (as opposed to learning out of books, computers, etc.) 
Table 5.3c. Phase Three results, focus group responses to question three

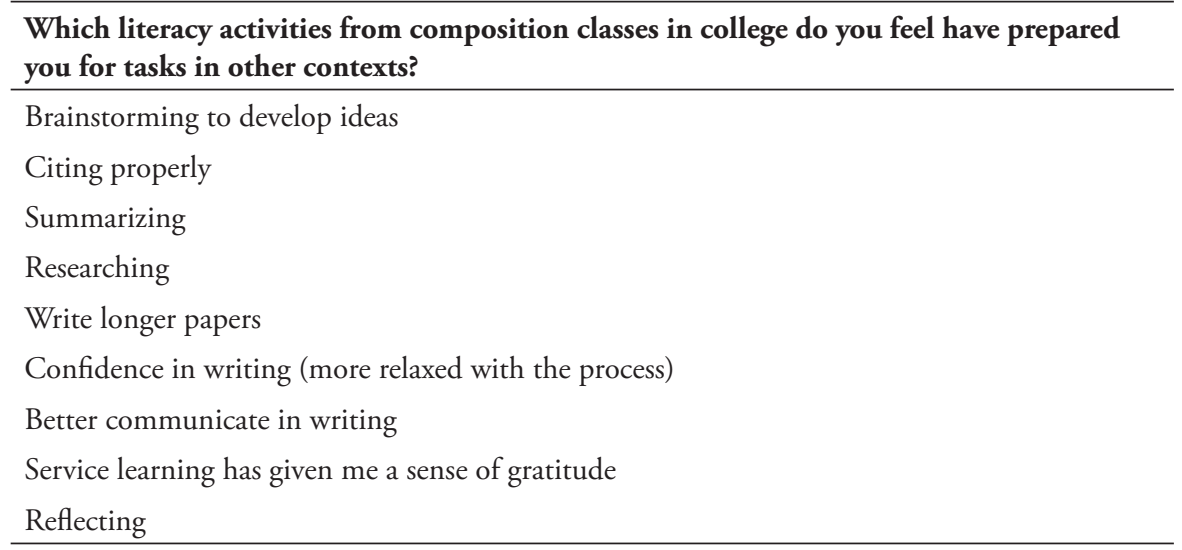

\section{DISCUSSION}

This study began in the first phase with an emergent design in grounded theory, which allowed for salient themes to guide the direction of the subsequent two phases of the study. It was assumed that when students claimed that they had learned knowledge or skill in writing, at some level they had. Nowacek's (2011) two spectra of transfer and integration of learning are useful here to understanding students' learning: on one axis are the various levels of transfer, and on a perpendicular axis are the various levels of integration. The transfer axis refers to their learning, which is more of an unconscious activity, while integration refers to their metacognitive awareness of learning. All but three of the HFA and OCU students said they gained knowledge and skills but seemed not to be cognitively aware enough to also demonstrate that learning in their responses. Three students, one HFA high school student and two OCU college students, said they gained knowledge and skill and were consciously aware enough about the meaning of those claims to also show those gains.

Also useful to consider is the research of Bergman and Zepernick, who explored students' sense of literacy learning and found that their understandings of their learning could be "read as representations of students' own perceptions of how and where they learned to write and, most of all, what students believe themselves to be learning-what knowledge and skills they understood themselves to acquire" (2007, p. 126). When, in responding to the questionnaire, students talked about their learning with terms that referred to different skills or knowledge in writing, they were indicating familiarity with writing and the ways they learned to refer to those various aspects of writing — both higher-order and 
lower-order aspects. But in doing so, many of them did not also demonstrate their ability to use the knowledge and skills they discussed.

The one HFA high school student and two OCU college students who talked about higher- and lower-order skills and knowledge, and who also demonstrated their use of them, were also the students who were describing crossing boundaries of activity systems. These three detailed and articulate responses stood out from the rest because of their understanding and use of writing knowledge/ skills and of the subject matter about which they wrote. There might be many reasons they did this while others did not. Perhaps they took the questionnaire more seriously than others or they just enjoyed talking about writing and their experiences more. The emergent design does not necessarily lead to conclusions; rather, it allows for possible hypotheses to be formed at an early, exploratory stage in the research by encouraging researchers to look at salient themes.

The themes here that seemed most striking were about service learning or volunteer work. The writing stood out because the three students' responses demonstrated strength in seven of the eight categories of writing, in addition to speaking specifically toward many of them. They were the only student responses that provided specific examples of the writing contexts and thereby demonstrated "Use of support, evidence, details, or explanations." One of the student responders was an HFA high school student, who did not speak specifically to this category, and two of the student-responders were college students. The three students were also among the responders who spoke to the greatest number of writing categories for their group of students.

These three responses are noteworthy in that the writing was distinctively specific and detailed, making claims about learning and supporting the claims. They were also noteworthy when considered in light of Tuomi-Gröhn and Engeström (2003) and their emphasis on the importance of boundary-crossing. The researchers explain the notion of transfer in the context of activity systems:

[T] his conceptualization expands the basis of transfer from the actions of individuals to the collective organizations. It is not a matter of individual moves between school and workplace but of efforts of school and workplace to create together new practices. (Tuomi-Gröhn \& Engeström, 2003, p. 35)

Thus, when organizations and schools work together to create learning opportunities for students, and are intentional about it, there is great potential for transfer. Students who cross boundaries into multiple domains where teaching and learning are specifically connected stand to have learning experiences that they retain. Tuomi-Gröhn and Engeström (2003) further state that "the best way to learn is to become engaged in real-life processes of change" (p. 32). The 
responses of these three who wrote articulately about their writing-related learning and service seem to confirm this claim because they explained that they knew writing concepts well and demonstrated it. The three were engaged in boundary-crossing that was intentionally connected to learning in their English classrooms. The HFA high school student was doing volunteer work at his local library, helping people with computer technology for citation format and with literature in the context of a program tied to his senior English capstone project. The two college students were in service-learning English composition classes and were working in the community, their work also being directly connected to a writing curriculum. One was working at a national memorial museum updating archives, and the other was working in the office at a school for the disabled creating and updating informative literature for the school.

All three students used their learning about language and writing from one space, the English classroom, in another space where they saw its value in a new light. That this boundary-crossing from one activity system to another and back makes for greater learning transfer is supported by Russell and Yañez (2003). They explain that students often feel a sense of alienation in meeting general education requirements in college such as the writing requirements. They further note that the alienation "may be overcome when students, with the help of their instructors, see the textual pathways (genre systems) of specialist discourse leading to useful knowledge/skill in their activity systems beyond the course as specialists in other fields or as citizens" $(2003$, p. 3). The learning that happens in the classroom can often be better understood by students when they are able to see its value and use beyond the classroom. Boundary-crossing seemed to have aided in the learning transfer for the three students such that their learning experiences stayed with them longer or more dominantly than for their counterparts.

This line of thinking about the students' responses, boundary-crossing, and activity systems led to the second phase in the present study, which was more intentionally focused on learning as it relates to students crossing boundaries into multiple activity systems. Lave called for "a rethinking of the notion of learning, treating it as an emerging property of a whole person's legitimate peripheral participation in communities of practice" (1991, p. 63). Thus, for Phase Two, the Mind the Gap program was built so students could be part of a community of practice within the larger university community that would aid them in the critical transition from high school to college, but would also give them multiple activity systems to cross boundaries into as a cohort to foster strong learning transfer.

The Clara Luper and American Indian Scholarship program was designed to give access and opportunity to underserved student populations. For the 20122013 academic year, 42 students were selected for the four-year scholarship pro- 
gram and the summer Mind the Gap program; all were from social, economic, or ethnic minorities. Fifteen of the students were in English Composition I, 15 were in College Algebra, and 12 were in World Religions. All three classes met general education requirements. The entire group was also in a one-unit studies skills class. Mind the Gap incorporated co-curricular activities for the all of the students. The 15 students placed in the English Composition I class had 62 hours of class time with their teacher (for three college units of credit), 12 hours of studies skills (for one college unit of credit), 35 hours of community service, and 15 hours of fun and/or team-building activities over the five weeks of summer school. All students lived in the dormitories. For the community service, students worked one of three places engaging in literacy tasks: at the Native American Student Services Office of Oklahoma City Public Schools, the Boys and Girls Club of Oklahoma County, or Positive Tomorrows, a small, private school for homeless children. For team-building and fun activities, the students started off with a ropes course, then visited cultural centers together; throughout the five weeks, they also had movie nights and shopping trips together. Faculty and staff accompanied students on many of the activities.

The larger Mind the Gap group was divided in small groups of four or five led by one or two English Composition I students starting in the third week, where they began to construct reflective digital projects to present on the final day of class. Composition students also did a significant amount of writing about their experiences and were asked to make connections between contexts they were in and the learning that took place. Like in many bridging programs, the 62 hours of composition class time included extra time scheduled for strengthening the academic piece of the program. Unlike most bridging programs, these students were part of a scholarship cohort and, as such, were a smaller community within the larger university society and will have spent much time together throughout their four years at the university. The final reflective projects were designed to help students tie together the various components of their experience, which is especially important to learning with respect to service learning and community engagement projects (Campus Compact, 2003).

Though averages of the survey responses for each subject area were slightly higher in the second survey, the difference was not statistically significant. However, this study was constructed with an emergent design for its foundation, and the trend that emerged from these surveys is consistently upward. The trend may suggest that as students gained greater perspective on their learning experiences in Mind the Gap, they looked back and saw it as being more of a success. That the averages of the answers were higher for each subject area that the survey explored may suggest the program was a success and that students saw the learning as foundational to the subsequent year they spent in college. 
The results prompted the research to continue into a third phase with three of the Mind the Gap students who have shared their service learning and community engagement activities at a regional conference together, as well as reflected on the past two academic years in a focus group format. Two of the students' responses revealed strong memories of learning against the backdrop of individual experiences in the service-learning context and peer collaborations. The responses they gave demonstrate learning transfer from college composition as they finished their second year. The quotes below provide a sample of the most poignant of responses that reflect a sense of transfer of learning.

Whenever we went to present, it was really different. What I took away from that I use at my job. I have to contact people and I was very nervous. That presentation helped me to open up and be more confident talking to people I don't know as well as being able to tell them about what our company offers.

Last semester, Harley and I interviewed the head of Positive Tomorrows. I have already used those research skills I learned then to interview my manager at work for my summer class, as well as similar questions Harley and I used to learn more about his thoughts on the current state of the company and its organizational patterns.

These comments stood out as learning transfer, or of integrated learning as Nowacek (2011) might call it. In the first comment, the student recognized an area of communication he was cognizant of struggling with in one context and saw how the learning activities helped him become better at it in the same context. The boundary-crossing from one activity system (the workplace) to others (the learning and presentation contexts) and back again supported his learning and his awareness of the learning. The second comment also shows integrative learning: The student was conscious of the learning activity he did in one activity system that he was able to integrate successfully into the communication needs in another activity system, even though the specific context and situational needs were different.

Because these students worked together in their first year during three semesters (summer, fall, and spring) in service-learning contexts where they engaged children from the Boys and Girls Club and Positive Tomorrows in literacy activities, they participated in multiple activity systems together. Each servicelearning class required much research, writing, reflection, and presentation of their experiences and research. Moreover, being scholars in the same scholarship program further engaged them with each other's development, though not as 
much as the learning they did that was tied to specific curricula. Finally, their participation in the regional service-learning conference, which was largely attended by academic professionals, also served as yet another activity system in which they worked together using their language-learning from college composition. Carroll's (2002) research suggested that the interactions among different cultures and among people, including peers, tutors, teachers, and texts, helped students develop better writing-related knowledge and skills. All three of these students in the third research phase spoke to collaborating with others on presentations and critiquing each other's writing, which also strengthens the idea that their peer collaborations were an important part of the learning transfer, as supported by Carroll's findings.

The themes and trends that emerged in the Phase Three focus group conversation reflected more global thinking with regard to writing than those emerging in Phase One. In fact, the only lower-order skill/knowledge mentioned in Phase Three was citing sources, which all three agreed was developed and strengthened in college composition and useful in preparing them for tasks in other contexts. All three students gave similar answers for all three questions with regard to two literacies: confidence in writing, and researching. Also, all three students mentioned service learning in response to literacies they "continue to use, build on, or develop" and literacy activities from composition classes that they felt "prepared them for tasks in other contexts" - on one hand, as the preferred kind of learning over learning with books and computers, and, on the other, as helping them develop a deep sense of gratitude for their own situations. Another noteworthy concept is that they expressed a strong level of preparation for and comfort with speaking to public audiences, which they attribute to their learning in college composition.

The focus group conversation suggests that what stands out as most salient in their learning of composition is their confidence with taking on new writing tasks in new contexts, which is to be expected as novice writers move toward greater expertise. According to Carroll, "Students learn to accommodate the often unarticulated expectations of their professor readers, to imitate disciplinary discourse, and as juniors and seniors, to write in forms more diverse and complex than those they could produce when they arrived in college" (2002, p. 23). The responses of Harley, Josh, and Juan suggest this movement toward adaptability to new rhetorical situations they confront. Some of that confidence they developed can be attributed to the work they did in their service-learning activity systems as is suggested by the fact that it also stands out in their minds.

The contexts where these three Mind the Gap graduates saw an application of the learning they experienced in college composition also had some overlap with the responses the earlier OCU college students gave in Phase One in three 
contexts: service learning, writing essays for other classes, and building resumes (similar to the job application context). Other contexts not mentioned in Phase One, but referred to in the focus group by these three students, include using research to interpret literature, collaborating on presentations, presenting/speaking about research to academic audiences, answering questions in formal presentations, working with the public/people, and writing for a public audience. All of these contexts suggest learning transfer happening as they crossed boundaries into and participated in new activity systems, while negotiating the rhetorical demands in each.

Looking back over the successes and failures of the first (the 2012 program in this study) and subsequent summer Mind the Gap programs led the administrators, faculty, and staff to conclusions about what works best to facilitate learning in an intense summer program for a diverse group of scholars. The transfer research here led the administrators overseeing the Clara Luper and American Indian Scholars program to continue with the Mind the Gap program in summer 2013 and summer 2014. The above data, the reflective presentations students did together, and the research by Moore et al. (2013) support the idea that reflection activities may have played a large role in the learning we saw. We Mind the Gap program planners felt that reflection is important, perhaps most important to the learning - that asking students to reflect on learning, to document, think about, and communicate to others what they have learned helps them to "ma[k]e note of practices to try in the future" (Moore et al., 2013, "Reflections and Recommendations," par. 5). These reflective activities were done at a variety of points, especially for the three second-year scholars in Phase Three who entered multiple activity systems of learning and communication and demonstrated learning transfer or integrated learning. Though the exploratory nature of the three research phases creates some limitations for identifying statistically significant trends, this study nonetheless offers helpful program assessment and can provide insights for similar programs and/or institutions and the learning that transpires there.

\section{NOTE}

1. Special thanks goes to Jon Willner at Oklahoma City University for talking me through implications of statistics in general and trends in one data set specifically.

\section{REFRENCES}

Barnett, E. A., Bork, R. H., Mayer, A. K., Pretlow, J., Wathington, H. D., Weiss, M. J. \& Weissman, E. (2012). Bridging the gap: An impact study of eight developmental 
summer bridge programs in Texas. National Center for Postsecondary Research. Retrieved from http://www.tc.columbia.edu/centers/ncpr/index.html?Id=Publications \&Info=NCPR+Publications.

Bean, J. C. (2001). Engaging ideas: A professor's guide to integrating writing, critical thinking, and active learning in the classroom. San Francisco: Jossey-Bass.

Beaufort, A. (2007). College writing and beyond: A new framework for university writing instruction. Logan, UT: Utah State University Press.

Bergmann, L. \& Zepernick, J. (2007). Disciplinary and transference: Students' perceptions of learning to write. WPA: Writing Program Administration, 31(1/2), 124-149.

Campus Compact. (2003). Introduction to service-learning toolkit: Reading and resources for faculty (2nd ed.). Providence, RI: Brown University.

Carroll, L. A. (2002). Rehearsing new roles: How college students develop as writers. Carbondale, IL: Southern Illinois University Press.

Council of Writing Program Administrators. (2014). WPA outcomes statement for firstyear composition. Retrieved from http://wpacouncil.org/positions/outcomes.html.

Elon Statement on Writing Transfer. (2015). Retrieved from http://www.centerfor engagedlearning.org/elon-statement-on-writing-transfer/.

Harding Fine Arts Academy. (2014). About Us. Retrieved from http://hardingfinearts .org/about-us.

Lave, J. (1991) Situated learning in communities of practice. In L. Resnick \& S. E. Teasley (Eds.), Perspectives on socially shared cognition (pp. 63-82). Washington, DC: APA.

Lincoln, Y. S. \& Guba, E. G. (1985). Naturalistic inquiry. Beverly Hills, CA: Sage Publications.

Moore, J. L. (2012). Mapping the questions: The state of writing-related transfer research. Composition Forum, 26. Retrieved from http://compositionforum.com /issue/26/map-questions-transfer-research.php.

Moore, J. L., Pyne, K. B. \& Patch, P. (2013). Writing the transition to college: A summer college writing experience at Elon University. Composition Forum, 27. Retrieved from http://compositionforum.com/issue/27/elon.php.

Nowacek, R. S. (2011). Agents of integration: Understanding transfer as a rhetorical act. Carbondale/ Edwardsville, IL: Southern Illinois University Press.

Pepperdine University. (n.d.). About Pepperdine. Retrieved from http://www.pepperdine .edu/about/.

Russell, D. \& Yañez, A. (2003). "Big picture people rarely become historians": Genre systems and the contradictions of general education. In C. Bazerman \& D. Russell (Eds.), Writing selves, writing societies (pp. 1-28). Fort Collins, CO: The WAC Clearinghouse/Parlor Press. Available at http://wac.colostate.edu/books/selves_ societies/.

Saltmarsh, J. \& Hartley, M. (2011). "To serve a larger purpose": Engagement for the democracy and the transformation of higher education. Philadelphia: Temple University Press.

Teachers College. (n.d.). Developmental summer bridges. In Columbia University National Center for Postsecondary Research. Retrieved from http://www.postsecondary research.org/index.html?Id=Research\&Info=Developmental+Summer+Bridges. 
Tuomi-Gröhn, T. \& Engeström, Y. (2003). Conceptualizing transfer: From standard notions to developmental perspectives. In T. Tuomi-Gröhn \& Y. Engeström (Eds.), Between school and work: New perspectives on transfer and boundary-crossing (pp. 19-38). Oxford, UK: Elsevier Science.

Wardle, E. (2012). Creative repurposing for expansive learning: Considering "problem-exploring" and "answer-getting" dispositions in individuals and fields. Composition Forum, 26. Retrieved from http://compositionforum.com/issue/26/creative -repurposing.php. 
CHAPTER 6

DOUBLE BINDS AND

CONSEQUENTIAL TRANSITIONS:

CONSIDERING MATTERS OF

IDENTITY DURING MOMENTS

OF RHETORICAL CHALLENGE

\author{
Elizabeth Wardle and Nicolette Mercer Clement
}

\title{
INTRODUCTION
}

Scholars in rhetoric and composition, as well as other fields interested in teaching and learning, have debated the concept of knowledge transfer for some time. As the opening chapters of this book explain, there is much we do not know about transfer, but we do agree that achieving transfer of knowledge can be difficult. Thus far, scholarship in composition studies has considered various sites of transfer, including the individual, the context, and the task (Tuomi-Gröhn \& Engeström, 2003); examined the types of genre knowledge that students carry across activities (Devitt, 2007; Reiff \& Bawarshi, 2011; Rounsaville, 2012); detailed learners' perceptions of the relationship between contexts (Bergmann \& Zepernick, 2007; Jarratt, Mack, Sartor \& Watson, 2009); and critiqued the terms used to think and talk about transfer (DePalma \& Ringer, 2013; Donahue, this volume). Most recently, scholars have begun exploring (or re-exploring) the role of dispositions (see glossary) in transfer (Driscoll \& Wells, 2012), including the kinds of individual and systemic dispositions that afford or constrain the problem-solving attitudes necessary for meaningful transfer of knowledge (Wardle, 2012; Yancey, Robertson \& Taczak, 2013). However, we are only beginning to inform transfer research with theories of identity. Given the important relationship that theorists have posited between learning and the construction of self (Bakhtin, 1986; Beach, 2003; Holland, Lachiocotte, Skinner \& Cain, 1998; Scollon, 1996; Wenger, 1998), this connection feels long overdue.

Our field and closely related ones such as Teaching English to Speakers of Other Languages (TESOL) are full of studies about the ways that literacy and 
identity are inextricably interrelated (Burgess \& Ivanik, 2010; Casanave, 2002; Cushman, 2008; Hartman, 2006; Ivanik, 1998; Kitchens \& Larkin, 2004; Norton, 2000; Soliday, 2013). These concerns echo those of scholars in other fields who note the connection between identity and learning. Educational theorist Wenger reminds us that "learning is first and foremost the ability to negotiate new meanings" and that such learning "transforms our identities" (1998, pp. 226-227). Similarly, as noted in the Elon Statement on Writing Transfer (2015; Appendix A), developmental psychologist Beach (2003), in his seminal chapter on knowledge transfer, uses the term transition to describe the ways that "knowledge is generalized, or propagated, across social space and time" (Beach, 2003, p. 42). Such a transition, he argues, is "consequential when it is consciously reflected on, struggled with, and shifts the individual's sense of self or social position. Thus, consequential transitions link identity with knowledge propagation" (Beach, 2003, p. 42). Consequential transitions "weave together changing individuals and social organizations in such a way that the person experiences becoming someone or something new" (Beach, 2003, p. 41). When a person experiences a consequential transition during which home and school activity systems are in conflict, Beach calls that experience a "collateral transition" (2003, p. 44). Consequential transitions present some of the greatest challenges of higher education, although it is likely that teachers are frequently unaware when their students experience such challenges.

When individuals experience rhetorical challenges that entail consequential transitions, they must find creative ways to respond to and navigate what Beach calls the "discontinuities and contradictions" at play during these times (2003, p. 42). The discontinuities and contradictions inherent to consequential transitions may place literate learners in what activity theorist Engeström describes as a double bind: "In double bind situations, the individual, involved in an intense relationship, receives two messages or commands which deny each other-and the individual is unable to comment on the messages, i.e., he [sic] cannot make a metacommunicative statement" (1987, Chapter 3, par. 15).

Individuals will respond to consequential transitions differently depending, in part, upon what Bourdieu (1999) calls habitus, which he describes as "a set of dispositions which incline agents to act and react in certain ways" (Bourdieu \& Thompson, 1999, p. 12). Habitus "provides individuals with a sense of how to act and respond in the course of their daily lives. It 'orients' their actions and inclinations without strictly determining them. It gives them a 'feel for the game,' a sense of what is appropriate in the circumstances and what is not" (Bourdieu \& Thompson, 1999, p. 13). As the Elon Statement (2015; Appendix A) also suggests, the set of dispositions that literate learners possess when they encounter consequential transitions can either afford or constrain their abilities 
to navigate those transitions; in any case, that set of dispositions will certainly affect how they understand the transition, and even whether they encounter such a transition at all. For example, if a literate learner's dispositions incline him or her to be an obedient problem-solver no matter what the context, then the learner may encounter a critical transition when attempting to read and write assigned coursework as the teacher directs, even though material conflicts with the learner's home values and beliefs. Another literate learner whose dispositions do not incline him or her to follow the teacher's directions and earn a good grade may simply refuse to engage in work that conflicts with his or her home values and beliefs, and in this way the learner may avoid experiencing a consequential transition.

In this chapter, we draw on data from a case study that we conducted together in order to illustrate the notion of consequential transitions, and we consider how one literate learner encountered and navigated the double bind presented during a consequential transition. While the rhetorical challenge the student faced entailed many of the usual challenges described by transfer research, it also entailed challenges deeply tied to identity issues of family, gender, values, and cultural experiences and beliefs.

\section{DESCRIPTION OF THE STUDY}

While multiple methods are necessary for rhetoric and composition scholars to gain a fuller understanding of writing-related knowledge transfer, case studies are useful for providing in-depth understanding of how concepts and phenomena work in specific contexts. While larger data sets can provide more generalizable data about what happens, smaller and richer data from case studies can provide more nuanced explanations of why and how transfer happens. In this chapter, we discuss some of the data collected in a study wherein Nicolette Clement served as both the focus of the case study and a co-researcher with Elizabeth Wardle. Below, we explain in more detail why we felt this collaboration was important, and how we carried out the study.

Nicolette was a pre-nursing student when she enrolled in Elizabeth's Honors Composition II course during the fall of her first year at the University of Central Florida (UCF). Nicolette conducted her research in that composition class on repurposing, looking at how students at different levels of college responded to new writing situations and how easily they were able to repurpose what they knew in order to respond to those situations. Her research suggested that repurposing remains "persistently difficult" as students encounter new discourse communities across their coursework, or are asked to delve more deeply into the knowledge of the discourse community of their majors. 
After the composition course ended, Elizabeth asked Nicolette if she would like to be a co-researcher in a project on how college students engage rhetorical challenges. Nicolette agreed. As the Elon Statement notes, "Adding student voices as participants, or even as co-inquirers, facilitates [a] more holistic examination of learners' development, boundary-crossing, remixing, and integration" (2015, p. 6; Appendix A). Together, we considered how best to gather data for this project. Many previous studies of knowledge transfer (including Wardle, 2007) predetermined the data points; for example, the researcher set out to examine how the material in first-year composition informed how students write in subsequent history or biology courses. However, predetermining data points in this way entails making a number of faulty assumptions, including that we know what (and how well) students learned in a particular setting, that the subsequent setting is one in which students need that prior knowledge, that the subsequent setting requires prior knowledge from that previous setting, and that the prior knowledge a student draws on is actually drawn from that one setting and not some other setting not included in the study.

For this project, we wanted to predetermine much less and be open to challenges and use of prior knowledge in whatever context and form they might occur. We did not want to assume that Elizabeth knew in advance what rhetorical tasks would be important to Nicolette, or what prior knowledge would be relevant in tackling that rhetorical task. This is why it seemed particularly important to understand Nicolette's role not only as case study participant but also as a co-researcher. Only she could know what tasks were challenging to her and why, and only she could consider the broad history of her prior knowledge and consider what she was bringing to bear on any given task. Thus, after an initial interview and discussion of Nicolette's literacy history, we agreed that Nicolette would text Elizabeth whenever she encountered what she felt to be a challenging rhetorical task. She would then upload to the software Evernote ${ }^{\oplus}$ all the documents related to that task (including drafts, assignment instructions, etc.), and the two of us would meet and discuss the task and how she approached it. This process worked well, and several times Nicolette determined that she should also record herself conducting think-aloud protocols as she drafted some texts and/or keep a log of her invention process. She also uploaded to Evernote everything she wrote each semester. Due to the material we covered in Nicolette's composition course, she also brought some analytical lenses and knowledge of writing-related research methodologies to the study. The composition course goals included "studying writing as situated, motivated discourse" and "studying the conversational and knowledge-creating nature of researched writing." Students read about activity theory, intertextuality, and genre theory and studied examples of research that used those theories before conducting their own liter- 
acy studies. As a result of this experience, Nicolette was able to talk reflectively and analytically about her experiences (for example, describing affordances and constraints and pointing to the lexis of new discourse communities as problematic) and also make informed suggestions about new ways to collect data (for example, she recommended using a think-aloud protocol when she drafted a text she felt would be challenging). This research process adhered to many of the principles outlined in the Higher Education Academy's (n.d.) "Students as Partners" document: authenticity, inclusivity, speaking with and not for, and taking time to build trust.

At the time final revisions of this chapter were submitted, Nicolette just completed her junior year, having successfully completed the first two semesters of her nursing program. Together, we have conducted seven interviews and collected 30 documents over seven semesters.

This data set has been analyzed and coded by a team of faculty researchers at UCF as well as by members of Elizabeth's cohort at the 2011-2013 Elon University Research Seminar on Critical Transitions, and by Elizabeth herself. We examined the interview transcripts for indications of rhetorical challenge, what made the tasks challenging, and the affordances and constraints Nicolette perceived and drew upon in responding to them. We have been particularly interested in Nicolette's perceptions of the challenges, affordances, and constraints at play in her writing experiences. Very often, for example, she considered tasks to be challenging due to what she perceived as a lack of support that a researcher would never have recognized without Nicolette's participation. For example, in her western civilization class, she noted that the teacher did not provide examples or instructions related to the content and that this effect was such that she would rather take a low grade than approach him for help. We conducted additional analysis of some of the texts Nicolette indicated to be challenging. For the purposes of this particular chapter, we analyzed the papers she wrote in her honors seminar to see how she textually navigated the challenges she had named, and whether the strategies she had explained in interviews had enabled her to effectively complete the rhetorical task. In other words, we wondered whether the prior knowledge, strategies, and skills she brought to bear were effectively used and whether they were sufficient to enable her to complete the challenging tasks. In addition, we looked at the context of the rhetorical challenge to see what supports and new knowledge were made available to assist her in repurposing and successfully using prior knowledge and skills. Several times, we went back and conducted text-based interviews after analyzing the papers so that Nicolette could talk further about specific strategies or difficulties. The concepts of the double bind and consequential transitions emerged as important after the analysis, enabling us to understand what we had seen emerge from the data. 
For this chapter, we draw on Nicolette's course papers in her honors seminar, teacher instructions and comments regarding those papers, and interviews we conducted before, during, and after she enrolled in that course. This data illustrates how Nicolette grappled with the double bind she experienced during the consequential transition in that course.

\section{NICOLETTE'S DISPOSITIONS AND HABITUS}

Nicolette is from Lakeland, a conservative town in central Florida; she has lived in Florida and attended public schools her entire life. As an oldest child and only daughter, she describes herself as having some dispositions that are almost stereotypically associated with that role: a desire to do well, a need to set a good example for her younger brothers, and a deep unwillingness to accept failure. Her first memory of reading was her impatience with the time it took to master: "I was really young ... but I thought I should be able to do it immediately." Her parents' expectations of her were high and were ones that she internalized: "I was expected to do well ... good grades, be polite, be a good kid. That is rooted in me very deeply and that is why I always expect myself to do well."

Neither of her parents attended college. Her father earned a General Education Development (GED) certification, and most of her father's side of the family, including all of her cousins, did not graduate from high school. Her mother attended a vocational school for a while. Nicolette believes that one reason her mother pushed her was because she herself had not been pushed; in other words, Nicolette's parents wanted for her what they did not have themselves in terms of academic opportunity. As a result, she enrolled in Advanced Placement (AP) classes, and her parents supported her desire to go to college; however, since neither of them had attended, she looked to her high school's college and career office and to her AP literature teacher for help. At UCF, 20\% of first-time in college (FTIC) students are, like Nicolette, first-generation students; also like her, they are typically high-achieving, with an average SAT for entering FTIC students of 1261 and an average GPA of 4.0. At UCF, first-generation college students graduate at the same rate as other students. Nicolette was admitted to the Honors College at UCF, which she also attributed to her parents' expectations: "I was expected to do well, get As, and my parents just really encouraged it, there was no other option. I couldn't even think about oh, getting a C; no, that is not even a possibility."

This combination of parental expectation for academic success, coupled with lack of family experiences to support that success, imbued Nicolette with a "tenacious problem-exploring disposition" (Wardle, 2012, para. 27). Across her courses and writing assignments, she has demonstrated the ability to methodi- 
cally and strategically look for and find multiple resources when she encounters rhetorical challenges. She finds sample texts when she can and looks for similarities and differences across them; she pays close attention to teacher feedback; and she frequently relies on feedback from others-classmates, roommates, and even family members.

During her first year of college, she made efforts to connect her college activities with her home activities. She mentioned several times that she asked for her mother's feedback on school assignments to which her mother could relate. For example, she asked for her mother's feedback on an email to a high school principal that she wrote as part of a service project for her LEAD Scholars course.

In sum, Nicolette's dispositions and family support inclined her to be consistently successful at most of the challenging rhetorical tasks she encountered in school. She brought with her a desire to succeed and please her teachers, as well as the critical thinking and analysis skills that enabled her to puzzle out solutions to new rhetorical problems. She cultivated support networks and took teacher feedback seriously when she received it. Her abilities enabled her to transfer prior knowledge and build on it to learn new rhetorical skills and knowledge in a variety of school situations. Many of her experiences illustrate how a literate learner can successfully transfer and repurpose prior knowledge during moments of rhetorical challenge (see Wardle, 2012; Wardle \& Clement, in press).

However, in her second year of college, Nicolette encountered a collateral, consequential transition (Beach, 2003, p. 44) wherein her experiences within her family and home community activity systems affected and constrained her experiences in a classroom activity system, and her school tasks asked her to engage in critiques of her family culture.

\section{THE CHALLENGES OF HONORS SEMINAR}

In the fall of her sophomore year, Nicolette enrolled in what she described as "an honors interdisciplinary seminar on high culture, low culture, good taste, and bad taste." This class was co-taught by one philosophy and one literature professor, both of whom had won multiple teaching awards. In writing for the honors seminar, Nicolette encountered a whole host of challenges: the conventions of writing for the humanities were new to her, the co-teachers took turns grading the papers so she was not sure what to expect from paper to paper, and the class readings were in different genres using different conventions, so she struggled to know what examples to follow in her own writing. These were the sorts of challenges she had already demonstrated time and again that she could overcome with the set of problem-solving behaviors she had been honing throughout her school life. 
However, the challenges of this course went beyond the rhetorical challenges she had been accustomed to overcoming. The material of the course was theoretically difficult and asked her to consider matters of race, class, gender, and sexuality that were outside of her experiences thus far. To be clear, Nicolette enjoyed the class, describing it as fun and complimenting the teachers. But her experiences and identities as a high-achieving oldest daughter, a conscientious student, a first-generation college student from a working-class family, the product of a conservative family and community, and a pre-nursing science student resulted in a complexly laminated set of difficulties that had as much to do with who she was as with her writing abilities. The ideas she encountered in the course were not only unfamiliar but also in direct conflict with her home values and experiences; the work of the course asked her to accept these new views and, further, write about them as though she accepted them-all without acknowledging the double bind in which that rhetorical activity placed her.

In the honors seminar, Nicolette wrote papers on a work of art called Black Mona Lisa, on a drag queen named Vaginal Davis, and on pornography and Lolita. The initial grades she received were not up to her usual standards or expectations: She received a C- on the first paper she wrote, a grade she found entirely unacceptable: "I was overwhelmed," she said afterward. "I wanted to walk out and cry ... this is not me." She was able to rewrite that first paper and receive a $\mathrm{B}$, but the work of this class remained "persistently difficult," to use her own words from her first-year composition research study. The work of the seminar continued to challenge her in ways that illustrate the complex interactions of identity, culture, and knowledge during consequential transitions.

In this section, we discuss three of the most difficult challenges that the rhetorical tasks of this course posed and examine how those difficulties manifested themselves in Nicolette's writing, how her teachers responded to those difficulties, and how she worked through the challenges.

\section{First Challenge: Content Knowledge}

The first unit's paper was on what Nicolette described as "art and avant-garde versus kitsch," the latter of which were terms she had never heard before enrolling in that class. She thought other students were better prepared: "I felt like that was kind of a disadvantage, too, because most of the kids in the class already knew what they were talking about a little bit. And I had no idea."

In an interview, she explained that art was not something she had any prior experience with: "I don't think art has ever come up in conversation in my family at all. So I guess that would be another reason that it's very new to me, because it's just not in my background at all." Although she had been to several 
museums before, she had "never had anyone explain anything significant about them"; rather, she had been "one of the ones who 'like it because it's pretty," not because she "appreciate[d] a statement it makes or a design." The other students, she explained, worked at art museums and were humanities majors: "They've already kind of been exposed to all of these thing. But I've never taken an art class." The work of the class, according to Nicolette, suggested that "it takes practice and conditioning to truly appreciate art." Nicolette noted that she did not have that practice.

Nicolette was helped with these challenges by class discussions: "Every time we have class, the class is basically us just talking about the article we read the night before. So even if there's a lot of references in the article which I don't get-which usually happens every time-we talk about the important aspects of it in class and that helps me kind of understand what they are talking about. It's ... the details, and the terminology and, you know, specific references."

\section{Second Challenge: Cultural Differences}

The second paper was equally unfamiliar. She wrote about drag queen Vaginal Davis and discussed issues of gender, race, class, and sexuality in that paper. All of this, she said, was "pretty much new to this class." Her only prior experience thinking about these differences came from leaving home for college: "There's a lot of people here," she said, "that aren't exactly like what society would deem 'normal."

Nicolette's difficulties, then, were partially about content knowledge and partially about her upbringing and attitudes: She certainly knew what the terms gender, race, and class meant, but she had never experienced them as matters to be explored and theorized. She was only beginning to consider consciously the idea of difference as she encountered people in college who were clearly unlike what she had grown up understanding as "normal."

She was open to what she learned about cultural differences, though, and reflected on that learning during one of our interviews:

I think I kind of see things differently just because my eyes are opened up to things I didn't really know were out there at this point. Like with Davis' drag, I thought, you know, a drag queen's like "oh girly girly but I'm a man." I didn't know there was drag like on this deep level that really made people think and was really subversive to a lot of, like, norms of society and stuff like that. So I think I see things a lot differently just because I feel like my mind is more open to what's out there ... [Now] if I did ... meet a drag queen ... I would probably be 
thinking about what they were portraying, what they represented, why they were doing what they were doing-instead of just being like "oh that's fun."

While the course material was challenging and unfamiliar, it helped her think differently: "I see things differently just because my eyes are opened up to things I didn't really know were out there at this point." She says that now looking back, although she did not "feel successful during the class, the class was useful and did what it was set out to ... I learned how to see things through a different lens and analyze the 'why' behind a lot of formerly unquestioned behaviors/ideas."

\section{Third Challenge: Alienation from Family}

Although the ideas of the course were challenging, new, and provided insight into cultural differences Nicolette had not considered before, she was open to learning them and was assisted in this learning through class discussions and teacher feedback. However, the fact the topics being taken up in the class were ones she felt at that time she could not share with her family was a challenge less easily overcome.

I think a lot of the things from college are just things that would set me apart from [my family] ... my family has very conservative views. And even though I've never been a very conservative person, I think college has made me more liberal than I have been before. Just in like social aspects I guess . . . there's things I don't want to talk to my family about because I feel like it would just start an argument, there wouldn't be any productivity from it. It's things you would avoid in my house, like politics, religion, social norms I guess. They wouldn't be things I would talk to them about.

Regarding the drag queen essay, in particular, she noted that sharing it with her family had never crossed her mind: "They're going to be like: 'You're paying tuition for WHAT?!'” When the topic of sharing her essay with her mother, as Nicolette often did in other classes, came up during one of our interviews, she emphatically noted, "She does NOT know what's going on in this class!"

\section{FACING THE DOUBLE BIND}

Although Nicolette was willing to engage with the new and challenging material in her honors seminar, the three challenges we have outlined above, combined 
with her dispositions, all came to bear on the double bind in which she found herself when she sat down to write the papers in the honors seminar.

On the one hand, Nicolette embodied the role of the good student who wants to be successful and ambitious and who is willing to work hard and be "open to new work/ideas" to succeed at the school tasks she is given; as she said, a C "is not even a possibility" for her. On the other hand, the school tasks she was expected to master in her honors seminar were ones that her family would neither understand nor approve. Thus, in order to succeed at these school tasks, she had to engage in work that pulled her away from some of her communities. However, she points out, this double bind may have been eased slightly because "I never really held the same ideas and values as my family or small-town conservative neighbors." The ideas in the class were new to her because she was "never exposed" to them before. Although the ideas in the class did not mesh with the ideas of the community from which she came, she says she was open to them because she felt that although she was a product of that community, she was not like the others in that community. In addition, she notes that she and her friends from home who went to college "are in the same boat as far as coming from working-class families, trying to rise above how we were raised and become conscientious, analytical adults who can improve their worlds in some way." Thus, although the work of the class was difficult for her in many ways, she did not feel completely alone in her efforts to embrace that work.

The assignments required her to critique her own class and culture. The content of the course readings presented a choice between working-class conservative values and elite liberal values; Nicolette's dispositions to "get it right" and never give up, combined with her sense of herself as not really sharing the values of her home community, led her to work diligently to respond to the teacher's comments and the voices of the scholars she was reading, reconciling the ways these conflicted with her own history and upbringing. These attempted resolutions placed her in what Engeström (1987) calls a dilemma situation, and the dilemmas were evident in the papers themselves.

Nicolette began the first draft of the first paper like this:

There is no question that within every culture, there are representations of good art and bad art. How we define good versus bad art, however, always quickly proves to be a challenge.

Next to this, the teacher had written EM; according to the detailed key code she provided, it meant "empty phrase."Nicolette went on:

Much of what the masses are exposed to on a daily basis that they may term "art" or describe as "artistic" can be argued to 
be garbage based on the perspectives of some of these critics. As arguable as any is a digital work by NegroSaki titled Black Mona Lisa.

Nicolette's history and cultural experiences were being brought to bear as she wrote these words. Not least of all is the fact that in Nicolette's family experience, there was no discussion of art at all. Nicolette set this aside to try to restate what she had read and heard in class, but her phrasing suggests some discomfort, or at least lack of exposure. There is a lot to wonder about in this paragraph: Would the objects of attention and beauty in Nicolette's home be considered kitsch by the critics to whom she refers? Would they argue that this meant her family was misrecognizing such artifacts as art (even if they did not call them art) when they are, instead, what she calls "garbage"? Engaged in the double bind, Nicolette was silent about such questions.

Nicolette continued:

Clement Greenberg in his essay ... makes the argument that avant-garde art is respectable, meaningful, and indicative of enjoyment within the higher socio-economic classes ... while kitsch is something enjoyed superficially by the masses.

Nicolette went on to try to explain why Black Mona Lisa would not be considered avant-garde, but she struggled trying to apply Greenberg's distinctionskitsch is watered down, mechanical, formulaic, synthetic, a debased copy, he tells us. She seemed unable to comment on his assertions; after all, she was a member of the group she was calling "the masses," whom Greenberg (according to her own analysis) accuses of only superficially enjoying formulaic and debased copies.

Rather than comment, she asked a series of questions: "What is more mechanical than ... What is more synthetic than ... ?" The teacher wrote and circled RQ next to this segment, instructing her to "avoid excessive rhetorical questions in your writing." Here we can see Nicolette caught between two competing messages "which deny each other" and finding that she "cannot make a metacommunicative statement" (Engeström, 1987)—so she asks questions instead.

The teacher focused on the phrase "genuine culture," asking Nicolette what she meant. This is, of course, the seminal question. Considerations of culture and art were new to Nicolette, and she was struggling to speak about them. What is culture? What is art? And what statements could she make about them, given her own positionality?

Nicolette could have resolved her double bind by commenting on the course material from her own positionality, speaking to her own experiences growing up as a member of "the masses," interacting with what the authors she is citing might 
consider kitsch. But she did not comment; her own experiences remained absent.

The activities of the course, the focus of the readings, and the teacher comments simply glossed over Nicolette's experiences and identity. As a conscientious and ambitious student, she learned the material she was asked to learn and attempted to stand outside herself and her experiences, commenting on them as though they were not her own, using a language that was not her own, coming to conclusions that she wrote as questions. In other words, she was critiquing the experiences and values of people who were very much like her, or at least the people who raised her, in the way that a cultural theorist would-without acknowledging her relationship to what she was critiquing.

Nicolette's silence in the face of the course material was even louder when she tackled Bourdieu's view of art. In her paper, she writes that Bourdieu notes "a work of art has meaning and interest only for someone who possesses the cultural competence, the code." She might have been able to grapple with Bourdieu's theories by directly considering her own upbringing, which did not give her access to this "code" and did not even introduce her to the idea of art at all; but she avoided her own experience, concluding that Black Mona Lisa is not art because its fans "seem to love it without much deep thought." In response, the teacher corrected her BQ (incorrect use of block quote), CP (incorrect citation of page numbers), WO (wordy phrasing), and R-O (run-on sentence) and suggested that she "rephrase for greater clarity and efficiency of prose."

To engage in the work of this class, Nicolette bracketed prior knowledge, experience, culture, and beliefs - that is, she attempted not to transfer and repurpose those in order to embrace the material of the class. The responses of the teacher seemed to encourage that sort of bracketing. Whereas transfer researchers might hope for a literate learner in this situation to draw on and use what she knows as a way in to the difficult material, this class did not seem to provide an invitation for Nicolette to do that. Instead, she attempted to engage the material as though she did not have any prior knowledge and experience about it. In fact, she did, but her experience was more of a lack, an absence, a source for elite academic critique, than an affordance she felt she could bring to enrich the task and make it more meaningful to her.

\section{CONCLUSION}

Nicolette's consequential transition included the struggles that transfer research has taught us to look for: difficulties with new material and with writing about it using new conventions, for example. But her experience in her honors seminar also illustrates what transfer research has not as clearly described: the ways that a challenging rhetorical task can place learners in a double bind regarding their 
identity and sense of self, wherein they receive competing messages from home and schooling activity systems that make completing new writing tasks difficult.

Nicolette's attempts to resolve these competing messages engaged her in what Wenger calls the "work of reconciliation," "constructing an identity that can include ... different meanings and forms of participation into one nexus" (1998, p. 160). Her attempts at reconciliation, at resolving her double bind, were colored by her dispositions to be, among other things, a good student who always works diligently to succeed at doing what her teachers ask of her and to embrace and understand new ideas. She forged ahead in tackling material in her honors seminar that critiqued her home culture and her family's values, responding carefully to her teacher's comments and bracketing the experiences and values she was exposed to at home. This work pulled her away but did not completely disconnect her from her other "activity systems of family [and] neighborhood" (Russell, 1997, p. 532).

While in our interviews Nicolette acknowledged the divide between home and school, she remained silent about it in her writing. Her very silence and her writing "leaked clues" (Rubin, 1995, p. 4) about her struggle; she used language that was not her own to come to conclusions she could only write as questions. Wenger warns us that the "work of reconciliation can easily remain invisible" (2003, p. 161), and in Nicolette's case, it certainly did: Nicolette's leaked clues were glossed by her teachers and ignored by her. In our interviews, she focused on grammar and punctuation, problems easily corrected with a little more revision, rather than on the concerns of the texts she was writing about.

Nevertheless, the clues are there, present on every page and in our interviews, testifying to the difficult double bind presented by her consequential transition. This transition, as Wenger reminds us, is not a one-time experience: "the process [of reconciliation] is never done once and for all ... Proceeding with life . . . entails finding ways to make our various forms of membership coexist" (2003, pp. 160-161). Wenger reminds us that this process is not secondary; "it is at the core of what it means to be a person" (2003, pp. 160-161).

Despite the tendency of researchers to fixate on one moment, class, or assignment, literate learners keep moving on and engaging in new experiences, experiencing growing and changing identities. Nicolette completed her honors seminar, and then she moved on toward her nursing degree. She has not experienced another class like the honors seminar since, and the activities of her subsequent schooling have not focused on the questions and ideas that had produced her dilemma situation in the honors seminar. She moved on to rhetorical challenges that more closely resembled the ones she was skilled at masteringlearning the new genres and lexis of nursing - with the sort of scaffolding and collaborative learning that enable her to flourish. The struggles of the honors 
seminar soon became a distant memory, part of, but in no way the primary structure or fabric of her identity. Looking back now, however, she notes that she has changed in the interim:

At that particular time, I would not have been too comfortable talking to my family about the topics discussed in this class. However, now is a different story. I feel like I have authority in my own life and am much more of an adult than at that time, which gives me more of an "I'm an adult so shoot me if you don't agree with me or think what I am talking about is obscene" kind of attitude, for better or worse.

Her perspective helps us to consider that a rhetorical task that might present a consequential transition at one point in a literate learner's life might not be a consequential transition if encountered at another point. As a new college student, she felt uncomfortable sharing ideas about art, drag, and pornography with her family; now as a junior nursing student, recently married, and living independently, she might well have an entirely different reaction to the material in the class if she were encountering it for the first time today.

Nicolette's experiences in this regard are also a caution to transfer researchers not to attribute too much to any single course or experience. It might be easy to look at Nicolette's growing confidence and her embodiment of values more liberal than those she was exposed to growing up, and to attribute these changes at least in part to the work of her honors seminar. Seeing such a correlation would be satisfying to researchers, but Nicolette's experience suggests that such a correlation would be false. That one course was part of an ongoing experience of being and becoming, of proceeding with life. She engaged in the work of the course early in her college years, even as she was already recognizing her values as distinct from her family's values, but at a time when she was not yet able to speak back to her family about them. In other words, the honors seminar did present a consequential transition and a double bind for Nicolette, but those did not exist acontextually. They were part of a larger fabric of life, meaningful and consequential because they occurred at a particularly kairotic moment.

\section{IMPLICATIONS}

What are the implications of this case? What can we learn about literate learners and times of transition? What can we learn about how best to study such transitions?

First, this study underlines the importance of methodology and study design. Without Nicolette's active engagement in the research project, it would have 
been impossible to understand what was consequential and what was not, and also why some transitions were consequential and others were not. In addition, it would have been easy to overemphasize the importance of some aspects of the transition, or to attribute too much meaning to any one rhetorical challenge or learning moment. In addition, Nicolette's experiences underscore the fact that researchers should be cautious about predetermining the sites of transfer. Anticipating what students have learned and where they might use that knowledge is extremely limiting, given the complexity of literate learners' lives, histories, and experiences. Of course, many courses are designed to assist students in later courses, and thus we should study how effective they are in that regard. However, we should be open to attributing students' successes or failures in the later courses to more than what occurred in the one prior course.

Second, Nicolette's case affirms the importance of class discussions, teacher comments, peer and other feedback, and personal dispositions in helping to facilitate effective learning transfer and students' abilities to engage in new and challenging rhetorical tasks. Teachers can assist students by integrating and considering these variables when designing activities and assignments. Yet Nicolette's experience in the honors seminar also indicates that rhetorical challenges and their accompanying affordances and constraints go far beyond effective assignment design and revision opportunities. At times of consequential transition, the learning and growth may simply be difficult. Failure may be an unavoidable part of how students learn something new and integrate their previous experiences and knowledge into their current experiences and learning. Nicolette says that "looking back ... although I didn't feel successful during this class, the class was useful and did what it was set out to for the students enrolled ... even though I didn't do as well as I wanted, I certainly am what I would consider a successful alumni of the class."

There may be ways to assist students during these times of struggle; that assistance, however, may not lead to better grades but simply to a better understanding of what is occurring, and to clearer ways to integrate and reconcile previous knowledge with new and competing knowledge. For example, the honors seminar teachers in this case might have assigned some low-stakes assignments asking students to consider how the ideas in the course readings relate to their own previous experiences, values, and knowledge. What is their relationship to and experience with art, pornography, and drag, for example? How do the ideas in the readings correspond to or conflict with the ideas students bring with them? Students might be invited to actively explain the relationship of what they are learning to what they already know and believe. Such reflective, low-stakes assignments might not make the higher-stakes analysis easier, but they may assist students in understanding why the assignments are difficult and assist teachers 
in knowing why some students might be struggling. None of this work of integration may be visible in the course grades, but it might enhance and deepen the learning.

Perhaps these suggestions will be difficult to implement given the current climate of higher education. The focus on measurable outcomes, higher grades, retention, reduced time on task, and predictive analytics intended to steer students away from experiences where they might struggle may all simply be incompatible with what we know and are coming to understand about how learning happens. However, this is a reason for us to continue conducting this type of research and find clear and persuasive ways to share it with stakeholders who design tests, curricula, and funding models.

\section{REFERENCES}

Bakhtin, M. M. (1986). Speech genres and other late essays. (V. W. McGee, Trans.) Austin, TX: University of Texas Press.

Beach, K. (2003). Consequential transitions: A developmental view of knowledge propagation through social organizations. In T. Tuomi-Gröhn \& Y. Engeström (Eds.), Between school and work: New perspectives on transfer and boundary-crossing (pp. 39-61). Bingley, UK: Emerald Group.

Bergmann, L. \& Zepernick, J. (2007). Disciplinarity and transfer: Students' perceptions of learning to write. WPA: Writing Program Administration, 31(1-2), 124-149.

Bourdieu, P. \& Thompson, J. B. (Ed.). (1999). Language and symbolic power. (G. Raymond \& M. Adamson, Trans.). Cambridge, MA: Harvard University Press.

Burgess, A. \& Ivanik, R. (2010). Writing and being written: Issues of identity across timescales. Written Communication, 27(2), 228-255.

Casanave, C. (2002). Writing games: Multicultural case studies of academic literacy practices in higher education. Mahwah, NJ: Lawrence Erlbaum.

Cushman, E. (2008). Toward a rhetoric of self-representation: Identity politics in Indian country and rhetoric and composition. College Composition and Communication, 60(2), 321-365.

DePalma, M. \& Ringer, J. (2013). Adaptive transfer, writing across the curriculum, and second language writing: Implications for research and teaching. In M. Cox \& T. Zawacki (Eds.), WAC and second language writers: Research towards linguistically and culturally inclusive programs and practices. Fort Collins, CO: The WAC Clearinghouse/Parlor Press. Available at http://wac.colostate.edu/books/l2/.

Devitt, A. (2007). Transferability and genres. In C. Weisser \& C. Keller (Eds.), The locations of composition (pp. 215-227). New York: State University of New York Press.

Driscoll, D. \& Wells, J. (2012). Beyond knowledge and skills: Writing transfer and the role of student dispositions. Composition Forum, 26. Retrieved from http://compos itionforum.com/issue/26/beyond-knowledge-skills.php. 
Elon Statement on Writing Transfer. (2015). Retrieved from http://www.centerforengaged learning.org/elon-statement-on-writing-transfer/.

Engeström, Y. (1987). Learning by expanding: An activity-theoretical approach to developmental research. Helsinki, FI: Orienta-Konsultit Oy. Retrieved from http://lchc .ucsd.edu/MCA/Paper/Engestrom/expanding/toc.htm.

Hartman, P. (2006). "Loud on the inside." Working-class girls, gender, and literacy. Research in the Teaching of English, 41(1), 82-117.

The Higher Education Academy (2015). Students as partners. Retrieved from https:// www.heacademy.ac.uk/workstreams-research/themes/students-partners.

Holland, D., Lachiocotte, W., Skinner, D. \& Cain, C. (1998). Identity and agency in cultural worlds. Cambridge, MA: Harvard University Press.

Ivanik, R. (1998). Writing and identity: The discoursal construction of identity in academic writing. Philadelphia: John Benjamins.

Jarratt, S., Mack, K., Sartor, A. \& Watson, S. (2009). Pedagogical memory: Writing, mapping, translating. WPA: Writing Program Administration, 33(1-2), 46-73.

Kitchens, M. \& Larkin, L. (2004). The transgender and transgressive student: Rhetoric and identity in trans-queer ethnography. Computers and Composition Online. Retrieved from http://www2.bgsu.edu/departments/english/cconline/kitchenslarkin /index.html.

Norton, B. (2000). Identity and language learning: Gender, ethnicity, and educational change. New York: Longman.

Reiff, M. \& Bawarshi, A. (2011). Tracing discursive resources: How students use prior genre knowledge to negotiate new writing contexts in first-year composition. Written Communication, 28(3), 312-337.

Rounsaville, A. (2012). Selecting genres for transfer: The role of uptake in students' antecedent genre knowledge. Composition Forum, 26. Retrieved from http://comp ositionforum.com/issue/26/selecting-genres-uptake.php.

Rubin, D. L. (1995). Introduction: Composing social identity. In D. Rubin (Ed.), Composing social identity in written language (pp. 1-30). Hillsdale, NJ: Lawrence Erlbaum.

Russell, D. (1997). Rethinking genre in school and society: An activity theory analysis. Written Communication, 14, 504-539.

Scollon, R. (1996). Discourse identity, social identity, and confusion in intercultural communication. Intercultural Communication Studies, 6(1), 1-16.

Soliday, M. (2013). Writing a self in/outside school. Literacy in Composition Studies, $1(1), 48-50$.

Tuomi-Gröhn, T. \& Engeström, Y. (Eds.). (2003). Between school and work: New perspectives on transfer and boundary-crossing. Bingley, UK: Emerald Group.

Wardle, E. (2007). Understanding transfer as generalization from FYC: Preliminary results of a longitudinal study. WPA: Writing Program Administrators, 31(1/2), 65-85.

Wardle, E. (2012). Creative repurposing for expansive learning: Considering "problem-exploring" and "answer-getting" dispositions in individuals and fields. Composition Forum, 26. Retrieved from http://compositionforum.com/issue/26/creative -repurposing.php. 
Wardle, E. \& Clement, N. (in press). "The hardest thing with writing is not getting enough instruction": Helping educators guide students through writing challenges. In J. L. Moore \& R. Bass (Eds.), Understanding Writing Transfer and Its Implications for Higher Education. Manuscript in preparation.

Wenger, E. (1998). Communities of practice: Learning, meaning, and identity. Cambridge, UK: Cambridge University Press.

Yancey, K., Robertson, L. \& Taczak, K. (2013). Writing across contexts: Transfer, composition, and sites of writing. Logan, UT: Utah State University Press. 



\section{CHAPTER 7}

\section{DYNAMIC TRANSFER IN FIRST- YEAR WRITING AND "WRITING IN THE DISCIPLINES” SETTINGS}

\section{Hogan Hayes, Dana R. Ferris, and Carl Whithaus}

Nearly two decades ago, Russell (1995) prompted composition scholars to consider the ways in which changes across writing contexts might undermine the mandate of first-year composition (FYC). It was not the first nor the last time scholars called into question the function and goals of FYC. The scrutiny is warranted. FYC had already been a fixture at US universities for more than half a century when Braddock, Lloyd-Jones, and Schoer (1963) reviewed the field and found that most who had been studying writing pedagogy went about the work "lacking any broad theoretical notion of writing abilities" (Faigley, 1986, p. 527). Since that review, composition theorists have engaged in a number of debates regarding the theoretical underpinnings of writing studies (Faigley, 1986) and the appropriate methods of assessing writing ability (Yancey, 1999). These debates have often been spurred forward by a new idea presented as a reaction to-or even a rejection of-previous ideas. Such theoretical concerns are compounded by the oft-heard practical complaint that Beaufort sums up as, "Why [is it] graduates of freshman writing cannot produce acceptable written documents in other contexts?" (2007, p. 6). So, it should be clear why the critical examination of FYC has and will continue to take place.

In terms of learning transfer and college-level writing, it is worth taking note of the impact Russell (1995) made when he introduced activity theory to the disciplinary conversation about FYC and writing ability. The introduction took place shortly after genre theory had become influential in the composition community (Bawarshi \& Reiff, 2010). Like genre theory, activity theory focuses on systems where people share goals, interact, and are bound by context. Because goals can only be attained in these systems via social means, Russell argued that "all learning is situated within some activity system" and that "adolescents and adults do not 'learn to write,' period" (1995, p. 59). Russell asserted that skills learned in a writing context like FYC do not effectively transfer into other contexts. The result was a reframing of questions about learning transfer that resonates to this day. Composition scholars have since been attempting to strike a 
balance between a social theory of learning-to-write, like the one Russell (1995) described, and the widely acknowledged understanding that "writing transfer both occurs and is necessary for successful writing" (Elon Statement on Writing Transfer, 2015, p. 4; Appendix A). One key factor in finding that balance has been education research that suggests learning transfer is possible but is more difficult and occurs less frequently than previously assumed (Perkins \& Salomon, 1988). The ongoing effort to understand the challenge of writing transfer has provided a new avenue for exploring theories of writing ability.

For this study, we build on that theoretical discourse by introducing a transfer mechanism from education research called dynamic transfer (Martin \& Schwartz, 2013). Dynamic transfer occurs over time as a learner coordinates prior knowledge along with other resources available in the environment to produce new understandings (Martin \& Schwartz, 2013). When such coordination is productive, those new understandings improve performance. Our interest in this transfer mechanism is influenced by Bizzell's (2003) call to investigate the tension between the theoretical lines of inner- and outer-directed composition research. According to Bizzell, inner-directed theorists are interested in the cognitive processes of the writer, and outer-directed theorists are interested in the social factors that shape language-learning processes. Bizzell argues that composition researchers seeking to understand writing ability "need to explain the cognitive and the social factors in writing development, and even more important, the relationship between them" (2003, p. 392). The mechanism of dynamic transfer describes an important interaction in that relationship.

In order to observe dynamic transfer, data for this study are collected through our examination of the ways students interact with the writing contexts at the University of California, Davis (UCD). The research design was influenced by two strands of research: (1) education research that has focused primarily on learning contexts and (2) composition research that has focused primarily on learner knowledge, identity, and attitude. The investigation suggests that a writing program with consistent, explicit, and intentional transfer-oriented learning objectives in both FYC and advanced composition courses provides a curricular setting that facilitates the transfer of writing skills across contexts. Such a setting fosters the development of discipline-based rhetorical awareness.

\section{CONTEXT-ORIENTED AND LEARNER-ORIENTED RESEARCH}

In education research literature, the term transfer refers to a wide range of phenomena where knowledge gained in a learning context affects performance in a target context (Royer, Mestre \& Dufresne, 2005). Several researchers have categorized transfer phenomena using spectra (Barnett \& Ceci, 2002; Perkins 
Table 7.1. Taxonomy for far transfer. Contexts: When and where transferred from and to (Barnett \& Ceci, 2002, p. 621)

\begin{tabular}{|c|c|c|c|c|c|}
\hline Near & & & & & Far \\
\hline $\begin{array}{l}\text { Knowledge } \\
\text { Domain }\end{array}$ & $\begin{array}{l}\text { Mouse vs. } \\
\text { rat }\end{array}$ & $\begin{array}{l}\text { Biology vs. } \\
\text { botany }\end{array}$ & $\begin{array}{l}\text { Biology vs. } \\
\text { economics }\end{array}$ & $\begin{array}{l}\text { Science vs. } \\
\text { history }\end{array}$ & $\begin{array}{l}\text { Science vs. } \\
\text { art }\end{array}$ \\
\hline $\begin{array}{l}\text { Physical } \\
\text { Context }\end{array}$ & $\begin{array}{l}\text { Same room } \\
\text { at school }\end{array}$ & $\begin{array}{l}\text { Different room } \\
\text { at school }\end{array}$ & $\begin{array}{l}\text { School vs. } \\
\text { research lab }\end{array}$ & $\begin{array}{l}\text { School vs. } \\
\text { home }\end{array}$ & $\begin{array}{l}\text { School vs. } \\
\text { beach }\end{array}$ \\
\hline $\begin{array}{l}\text { Temporal } \\
\text { Context }\end{array}$ & $\begin{array}{l}\text { Same } \\
\text { session }\end{array}$ & Next day & Weeks later & Months later & Years later \\
\hline $\begin{array}{l}\text { Functional } \\
\text { Context }\end{array}$ & $\begin{array}{l}\text { Both clearly } \\
\text { academic }\end{array}$ & $\begin{array}{l}\text { Both aca- } \\
\text { demic but one } \\
\text { nonevaluative }\end{array}$ & $\begin{array}{l}\text { Academic vs. } \\
\text { filling in tax } \\
\text { forms }\end{array}$ & $\begin{array}{l}\text { Academic } \\
\text { vs. informal } \\
\text { questionnaire }\end{array}$ & $\begin{array}{l}\text { Academic } \\
\text { vs. at play }\end{array}$ \\
\hline $\begin{array}{l}\text { Social } \\
\text { Context }\end{array}$ & $\begin{array}{l}\text { Both } \\
\text { individual }\end{array}$ & $\begin{array}{l}\text { Individual vs. } \\
\text { pair }\end{array}$ & $\begin{array}{l}\text { Individual vs. } \\
\text { small group }\end{array}$ & $\begin{array}{l}\text { Individual vs. } \\
\text { large group }\end{array}$ & $\begin{array}{l}\text { Individual } \\
\text { vs. society }\end{array}$ \\
\hline Modality & $\begin{array}{l}\text { Both writ- } \\
\text { ten, same } \\
\text { format }\end{array}$ & $\begin{array}{l}\text { Both written, } \\
\text { multiple choice } \\
\text { vs. essay }\end{array}$ & $\begin{array}{l}\text { Book learning } \\
\text { vs. oral exam }\end{array}$ & $\begin{array}{l}\text { Lecture vs. } \\
\text { wine tasting }\end{array}$ & $\begin{array}{l}\text { Lecture } \\
\text { vs. wood } \\
\text { carving }\end{array}$ \\
\hline
\end{tabular}

\& Salomon, 1988). Two of those spectra are near/far transfer and high-road/ low-road transfer. While examining key concepts that inform these ways of categorizing transfer phenomena, we will pay particular attention to how such categorization sheds light on two distinct research approaches used to investigate transfer. To clarify how those approaches affect research in composition studies, we will draw up a simple thought experiment: participants writing across three different contexts. Context L (the learning context) is a writing-for-literature course that teaches Modern Language Association (MLA) citation conventions and requires a term paper. Context $\mathrm{T}$ (a target context) is a subsequent literature course that requires a term paper. Context $2 \mathrm{~T}$ (a second target context) is a psychology course that requires a research proposal.

In a study working to describe near/far transfer, the researcher's focus would be the writing contexts. Events on the near-transfer end of the spectrum occur when the learning contexts and the target contexts are similar, while events on the far-transfer end of the spectrum occur when contexts differ to a greater extent. Barnett and Ceci (2002) developed the taxonomy of far transfer as an effective way to describe the distances between two tasks (see Table 7.1). The taxonomy demonstrates how two transfer events can be placed on the near/far transfer spectrum.

To demonstrate, we refer to two transfer events from our thought experiment. First, the students are required to learn MLA citation conventions and write papers using those conventions in Context L. In Context T, they are asked to 
write a paper similar to those written in Context $\mathrm{L}$ using MLA citation conventions. The taxonomy of far transfer shows that transferring knowledge of MLA citation conventions between these two performances involves near transfer in every context other than perhaps the temporal context. To demonstrate greater distance between contexts, we have Context $2 \mathrm{~T}$, the psychology course and its research proposal that requires American Psychological Association (APA) citation conventions. With the taxonomy, we can discern there is greater distance between Context $\mathrm{L}$ and Context $2 \mathrm{~T}$ along three additional dimensions: knowledge domain, social context, and modality. The taxonomy's focus on task-related contexts is especially useful in composition studies; without such focus, researchers may get bogged down in every potential difference between contexts, of which there are many. Composition research that is interested in near/far transfer must focus on definable differences between contexts that are likely to affect knowledge transfer processes. One example of such a focus in composition studies is Wardle's (2009) account of the assignments from an FYC course. In that study, Wardle (2009) examined the prompts, presentation, and execution of course assignments in a large university's FYC program. That data was used to describe the resulting genres of FYC and to consider the utility of those genres.

To date, however, most research in composition studies has focused on learner knowledge. This kind of learner-oriented focus uses Perkins and Salomon's (1988) low-road/high-road model of describing and categorizing transfer. The low-road/high-road transfer spectrum describes how much writers must consciously interact with their own knowledge in order to use that knowledge in a new setting. A researcher running our thought experiment with a learneroriented design would focus on a student's knowledge of MLA citation conventions as that knowledge moves from Context $\mathrm{L}$ to Context $\mathrm{T}$ and on to Context 2T. Low-road transfer occurs when a writer has to do almost nothing to transfer prior knowledge- the transfer of knowledge happens without reflection or conscious thought (Perkins \& Salomon, 1988). If a learner grasped the MLA citation conventions thoroughly enough in the writing-for-literature course, that knowledge could be used while composing a term paper for the later literature course without a great deal of conscious reflection on the act of inserting a citation, making the phenomenon an example of relatively low-road transfer.

High-road transfer, on the other hand, describes instances when the use of prior knowledge requires a learner to explicitly abstract the knowledge and repurpose it to suit the demands of a new context. A researcher seeking out an example of this in the thought experiment must focus on the abstracting and repurposing of knowledge. A learner drafting the psychology research proposal for Context $2 \mathrm{~T}$ might abstract prior knowledge of MLA citation conventions into a broader concept, such as citation conventions in academic writing, then 
use that abstract knowledge to understand APA citation conventions. According to Perkins and Salomon (2012), if such transfer is to occur, the learner must first recognize the utility of knowledge related to MLA citation conventions, then decide that the knowledge is appropriate for the task at hand, and finally make the connections necessary to apply repurposed knowledge of the conventions in the new setting. Perkins and Salomon's "detect-elect-connect" model demonstrates how the learner must actively engage prior knowledge to make it useful in the target context (2012, p. 248).

Studies that use the near/far transfer framework are seen more often in education research. The most influential study is Gick and Holyoak's (1980) investigation into analogical thinking. The clinical study asked participants to read a story that provided a problem-solving strategy relevant to a medical case. The researchers then altered several experimental conditions in a target context where participants proposed solutions to the medical case. The results demonstrated factors in the target context that influence the way learners use prior knowledge to solve a problem. The results also showed researchers that transfer is more difficult than previously assumed. Chen and Klahr (1999) focused on how changes in learning contexts affect performance. For their study, grade school children were given three different types of instruction on how to design a successful science experiment. Later, the effect of each instruction method was assessed across a variety of target contexts. The researchers were seeking to find which learning context promoted the acquisition of the most transferable strategies. The results showed that direct instruction of generalizable strategies improved performance in target contexts the most.

More recently in education research, Engle, Lam, Meyer, and Nix (2012) drew on a set of studies to propose that learning contexts foster transfer when they are framed expansively, a finding that supports much of the programmatic developments that prompted this study. Specifically, transfer is fostered when new knowledge and skills are presented as "resources for productive action in potential future transfer contexts" (Engle et al., 2012, p. 218). That is what it means to frame a context expansively. "Framing is the metacommunicative act of characterizing what is happening in a given context and how people are participating in it" (Engle et al., 2012, p. 217). The researchers present a metaanalysis that demonstrates how social interactions in the learning context have an effect on framing and influence transfer. While the above three studies from education research all acknowledge the role of individual learners in the transfer of knowledge, the focus of the research is on characteristics in the contexts where learning and/or performance take place.

The low-road/high-road approach to transfer shifts the research focus squarely onto learners and their knowledge. Perkins and Salomon (1988) were 
focused on learner knowledge when they developed the low-road/high-road spectrum of transfer phenomena. This learner-oriented approach is used in the majority of composition studies' research on transfer. For example, Driscoll (2011) used surveys and interviews to investigate the beliefs and perceptions students have about the transferability of their writing knowledge. Brent (2012) interviewed student-interns in a study that suggests learners draw on a wide range of experiences-not only writing instruction-to negotiate new writing contexts. Robertson, Taczak, and Yancey (2012) used student accounts of the writing process to demonstrate the ways students use prior knowledge when taking on new writing tasks. These studies do not ignore the writing contexts, but the data used to draw conclusions are drawn from participants' self-reported reflections on their own knowledge and perceptions. Understanding the distinctions between near/far transfer and low-road/high-road transfer is crucial for aligning theory with research design and analysis.

\section{RESEARCH CONCERNS ARISING OUT OF FRUSTRATED TRANSFER}

In our thought experiment, each hypothetical transfer phenomenon improved performance in the target context. Both disciplinary consensus (Elon Statement, 2015; Appendix A) and research in composition studies (e.g., Beaufort, 2007; Nowacek, 2011) have shown, however, that the kind of transfer required to write effectively across contexts does not come so easily. Literature in education research says much the same thing (Lobato, 2012; Perkins \& Salomon, 2012). In particular, our thought experiment's example of high-road transfer is at odds with previous findings on transfer. When writing for a psychology course, it is more likely that learners' knowledge of MLA citation conventions would either not transfer or the MLA citation conventions would transfer wholly into an upper-division course in psychology where MLA-style citations would be inappropriate. According to Perkins and Salomon (2012), education research finds these kinds of results far more often than the clear-cut successful instances of transfer our thought experiment envisioned. Researchers are quick to apply a label of failed, frustrated, problematic, or negative transfer to instances when learners do not appropriately repurpose prior knowledge (Lobato, 2012). This is, however, where we perceive a limitation in learner-oriented research derived from the low-road/high-road theoretical framework.

In the framework of low-road/high-road transfer, the label of frustrated transfer focuses on failings of learners and/or their prior knowledge. This limitation is built into any theoretical framework that focuses primarily on how learners interact with their prior knowledge: the learner did not recall the prior knowledge, 
the learner did not repurpose the knowledge, or the knowledge was not learned in an easy-to-abstract format. If we accept social theories of learning-to-write, however, then researchers must examine target contexts as factors that influence transfer as well, whether it be frustrated transfer, successful transfer, or even the absence of transfer. These contexts are where students encounter and develop the discourses that contribute to literacy (Gee, 1989). Therefore, research design must take the target context into account. In her seminal study of a student's experience writing across the curriculum, McCarthy asserted that a student writing as a novice must use prior experience to assess "the rules of the game" (1987, p. 234). That is clearly a description of prior knowledge affecting performance. However, even when the student has the appropriate prior experience, assessing a community's rules takes more than time and practice. In addition to all the qualities a novice must possess, the new community must make the social function of a writing task clear to newcomers (McCarthy, 1987). So, when learning to write in a new setting, McCarthy simultaneously acknowledged both a student's prior writing-related knowledge and the function of situated, socially constructed resources.

It is true that the characteristics of two writing contexts are often different (or distant) enough that researchers have observed skill transfer alongside a flawed performance in the target context. Documented instances of such performances have been used to demonstrate the ways prior writing instruction is ineffectual (e.g., Smit, 2004). Unless the features of the target context have been taken into account, however, it is a leap to assume that frustrated transfer demonstrates a shortcoming in the learner or the learning context. If writing abilities are socially constructed, as composition scholars have argued (Bizzell, 2003; Gee, 1989; Kent, 1999; Petreglia, 1999; Russell, 1995), the way newcomers encounter resources in the target context must be taken into account when assessing transfer. Gee (1989) argues that a student seeking to develop a new discourse must have access to the community associated with that discourse and the ability to practice within it. Researchers often describe an instance as failed or frustrated transfer when a learner does not reach a benchmark set by the community in the target context (Lobato, 2012). How these benchmarks are presented to novices is bound to affect transfer. For example, a benchmark such as genre awareness can be difficult for a novice to discern because, as Bazerman (1997) demonstrated, genres are often tacitly constructed abstractions intended to mitigate challenges presented by highly complex social situations.

To demonstrate how this can present a design problem, we will return briefly to our thought experiment. Our hypothetical example of high-road transfer described a learner's effective abstraction of MLA citation conventions to gain an 
understanding of APA citation conventions for a psychology research proposal. Even for a talented student, that is a very high bar to set. The bar might be set impossibly high, however, if the only citation-related instruction given for the psychology research proposal is "Be sure to cite all sources." Without enough instruction on APA citation style, that instruction is likely to cue the use of an unchanged MLA citation style, because the student knows how to cite sources. There is nothing in the instruction to cue the abstraction of that prior knowledge. Such an instance could be described as low-road transfer, or it could be described as an instance of what Schwartz, Chace, and Bransford describe as overzealous transfer-when "people transfer solutions that appear to be positive because they are working well enough," but those solutions block additional learning (2012, p. 206). No matter the case, in this thought experiment, highroad transfer would require more than the cueing of prior knowledge; it would require a cueing of the abstraction of prior knowledge. The target context must tell learners that the knowledge they arrived with, while potentially useful, is likely not enough. Only then will the learners know to seek the resources required to create new understandings.

\section{USING DYNAMIC TRANSFER TO EXAMINE INTERACTIONS BETWEEN LEARNERS AND CONTEXTS}

Our thought experiment on writing transfer is presented here to demonstrate the perspective that motivates this study. The dynamic transfer of prior knowledge can contribute significantly to a learner's successful transition into a new writing context. Dynamic transfer occurs when a learner's prior knowledge interacts with the target context through the act of coordination. Through this coordination, the learner creates new knowledge and understandings (Martin \& Schwartz, 2013). What this mechanism introduces to the discourse is less than radical: It explicitly incorporates the resources in target contexts as a factor in learning transfer. We believe many theorists and researchers have already assumed this factor influences transfer. In fact, Brent (2012) reports a number of specific resources his participants drew on in the target contexts in order to become better writers in their internship settings. We believe it is important, however, to explicitly incorporate this factor into our theoretical framework and research design in order to improve our understanding of transfer.

This study is a test of our theory of dynamic transfer, inspired, in part, by a reaction to the article that prompted Russell (1995) to introduce activity theory to the composition studies discourse. Russell quoted several points Kitzhaber (1960) made in a critique of FYC, most of which are well-reasoned and supported by research. There is one point, however, that rings false today, 
that sounds like an oversimplification we have heard too often and now reject. Kitzhaber described the aim of FYC as follows:

... to eradicate, in three hours a week for 30 or 35 weeks, habits of thought and expression that have been forming for at least 15 years and to which the student is as closely wedded as he is to his skin; and to fix indelibly a different set of habits from which the student will never afterwards deviate. (1960, p. 367)

It is important to recognize Kitzhaber (1960) was calling for change. It does not seem reasonable, however, for Russell (1995) to level this same critique 35 years later. By 1995, composition studies had been affected by the contributions of expressivism and cognitive process theory-theories that emphasize traits a learner brings to each writing task (Faigley, 1986). We reject the assertion that students finish high school with a set of writing skills that must be eradicated by the instructors of FYC. Through work with the National Writing Project, we have come to understand that the context for learning to write in secondary school is different, but the knowledge gained there is valuable in FYC and beyond. For example, the often-derided five-paragraph essay is an important genre for students seeking to attend US colleges and universities because it is repeatedly assessed on standardized admissions tests. In a constructive FYC setting, students' familiarity with the five-paragraph essay should be treated as useful prior knowledge of genre, writing assessment, and audience awareness. Students should not unlearn the five-paragraph essay; they should use their knowledge of it to better understand their own writing abilities (see Adler-Kassner, Clark, Robertson, Taczak \& Yancey, this volume). All of that knowledge is ready for transfer if the writing contexts in FYC have the resources available to help students coordinate prior knowledge and produce new understandings.

The development of transfer-related learning objectives and pedagogies has done a great deal to put such resources in place. Smit reconceptualized a composition curriculum, seeking to teach appropriate dispositions by offering varied writing experiences such as "writing-to-learn, writing-to-think, and thinkingto-write" (2004, p. 185). Beaufort (2007) introduced a teaching for transfer pedagogy that prompts students to explicitly abstract and reapply concepts such as discourse community, genre, rhetorical situation, and process knowledge. Downs and Wardle (2007) have developed a "writing about writing" curriculum that provides students with the concepts they will need to metacognitively reflect on each writing situation they encounter and then abstract principles of good writing from that reflection. Driscoll's (2011) study of student perceptions of transfer argues for forward/backward-reaching transfer pedagogy supported by metacognition. This work has had an effect on many college writing programs. 
The program at UCD is among those that have taken these ideas into account while developing learning objectives, program assessments, curricula, and assessment methods. This study seeks to identify the resources those developments have put in place and then to examine how students coordinate those resources along with their existing writing-related knowledge.

\section{METHODS}

We collected data in two stages for our study. First, we conducted surveys and collected data about the composition program at UCD. That data was then used to determine the features we would examine in the second stage of data collection, during which we collected writing samples and text-based interviews.

\section{ConTeXt}

All of our research participants were students at UCD, a large public research university with competitive admissions that enrolls about 25,000 undergraduates. UCD bachelor degree programs require both general education credits and a major specialization. The university requires all undergraduates to complete or test out of a two-course general education writing requirement. The first course for the writing requirement is a lower-division class recommended for first-year students. The second course is an upper-division class that students can enroll in after attaining third-year status. UCD has a standalone writing program that was the focal site for this study.

The standalone writing program offers a course that meets the lower-division writing requirement. Three other departments offer a course that meets this requirement as well, but the writing program's course is the most highly enrolled. Graduate students teach the lower-division writing courses for the writing program. The instructor pool is composed primarily of Ph.D. students from the English department. Instructor support is robust. Graduate student instructors are all required to take a for-credit writing pedagogy course before they begin teaching. During their first term teaching, they are enrolled in a for-credit practicum. Instructors all work from a standard teaching-for-transfer syllabus during their first term as teachers. After the first term, instructors can develop their own syllabi under the supervision of a lower-division writing program administrator. Online instructor resources include a standard syllabus, lesson plans, assignment prompts, and lecture notes. Experienced instructors have formed a voluntary mentoring system that has high rates of participation. Annual formative assessments of the instructors are based on a program administrator's classroom visit, review of syllabi, review of assignment prompts, evaluation of instructor 
feedback on student drafts, instructor self-evaluations, and student evaluations. All lower-division writing courses in the program, even those with instructorgenerated syllabi, require students to complete a portfolio. Students select two artifacts and compose a reflective letter for the portfolio.

The upper-division courses are all administered by the university's standalone writing program. The upper-division courses are taught by lecturers and tenure-line faculty in the writing program. Though course and program rubrics exist, they are not uniformly used by faculty due to the distinctions in course content across the curriculum. There are three types of courses that fulfill the upperdivision writing requirement. The first is an advanced composition course. It focuses on general principles of composition both within and beyond the university setting. The second type of upper-division course has a "writing in the disciplines" (WID) focus. There are 12 such courses, and each emphasizes the various kinds of academic and scholarly writing done in specific disciplines. Classes in the third and final type of upper-division writing course are concerned with writing in the professions. Six such courses were being offered at the time of this study, with programmatic plans to expand the offerings in the future. Students in these courses approach writing problems with professional discourse communities in mind.

The writing program has developed five learning objectives that are incorporated into the course objectives for both lower- and upper-division courses: (1) incorporating evidence appropriate for the task, (2) demonstrating awareness of audience, (3) producing purpose-driven texts, (4) using language effectively, and (5) collaborating with others during the writing process. In this study, these learning objectives are considered part of the programmatic context. They are factors working across lower- and upper-division contexts. As such, they informed the development of the interview protocols and the approach to data analysis.

\section{RECRUITMENT}

\section{SURVEYS}

Recruitment for the surveys $(\mathrm{N}=728)$ was facilitated by instructors in the upper-division writing courses who provided their students with a link to an online survey. Students were told that the survey was voluntary, anonymous, and that the results were primarily for research and program evaluation purposes.

\section{SAmple TeXts ANd InTerviews}

Sample texts $(\mathrm{N}=37)$ and interviews $(\mathrm{N}=14)$ were collected from volunteers who were recruited through the lower- and upper-division writing courses. Near 
the end of the term, instructors informed their students that researchers were looking for interview subjects for a research project that would focus on writing. Students were given an opportunity to provide their contact information if they were interested in volunteering for interviews. Students were informed that the interviews would take place after grades for the writing course were finalized and that participation was voluntary. Students were also informed that interviewees would receive a $\$ 10$ gift card valid at a national retail chain. Thirty students provided contact information. These students were contacted via email shortly after the new term commenced. The email informed each volunteer that the interview questions would focus on the writing produced for their writing course, that the researcher would request and read writing samples prior to the interview, and that the interview would take between 30 and 45 minutes. The email message prompted volunteers to set up an appointment. Volunteers who signed up for an appointment were sent a request for writing samples and informed that they all had the right to cancel or end the interview at any time.

\section{PARTICIPANTS}

\section{SURVEYS}

Surveys $(\mathrm{N}=728)$ of students enrolled in writing program courses at UCD yielded the following descriptive results. Over $80 \%$ of the student respondents were born in the US, nearly all obtained most or all of their education in the US, and nearly all graduated from US secondary schools. However, about $60 \%$ of the students were raised in homes where the primary language used was not English or where it was English and another language. About 35\% of students were required to take one or more remedial entry-level writing courses before they were allowed to enroll in a lower-division writing course.

Among the upper-division students surveyed, $37.5 \%$ had never taken a prior writing course at UCD. In most instances, that meant that they had tested out of the lower-division writing requirement through an advanced placement examination taken in high school, but some students had transferred from other twoor four-year colleges and had completed an equivalent lower-division course there. Of the upper-division students who had taken a previous writing course at the university, the previous writing course experiences were typically not recent.

\section{INTERVIEWEES}

For the text-based interviews, we worked with 14 students, eight of whom had recently completed the writing program's lower-division course and six of whom 
Table 7.2. Summary of interviewees

\begin{tabular}{|c|c|c|c|c|}
\hline $\begin{array}{c}\text { Student } \\
\#\end{array}$ & Major & Course Taken & $\begin{array}{l}\text { Lower- or } \\
\text { Upper-Division }\end{array}$ & Text Samples Provided \\
\hline 1 & $\begin{array}{l}\text { Science and } \\
\text { Technology } \\
\text { Studies }\end{array}$ & Expository Writing & Lower-division & $\begin{array}{l}\text { Portfolio letter, ad analy- } \\
\text { sis, personal narrative }\end{array}$ \\
\hline 2 & Spanish & Expository Writing & Lower-division & $\begin{array}{l}\text { Portfolio letter, essay } \\
\text { on computers, essay on } \\
\text { cyber-bullying }\end{array}$ \\
\hline 3 & Economics & Expository Writing & Lower-division & $\begin{array}{l}\text { In-class academic essay, } \\
\text { social narrative, ad } \\
\text { analysis }\end{array}$ \\
\hline 4 & $\begin{array}{l}\text { Computer } \\
\text { Science }\end{array}$ & Expository Writing & Lower-division & $\begin{array}{l}\text { Portfolio letter, personal } \\
\text { narrative, social narrative }\end{array}$ \\
\hline 5 & Economics & Expository Writing & Lower-division & $\begin{array}{l}\text { Portfolio letter, literacy } \\
\text { narrative, argumentative } \\
\text { essay }\end{array}$ \\
\hline 6 & $\begin{array}{l}\text { Biological } \\
\text { Science }\end{array}$ & Expository Writing & Lower-division & $\begin{array}{l}\text { Portfolio letter, research } \\
\text { essay, argument }\end{array}$ \\
\hline 7 & Undeclared & Expository Writing & Lower-division & $\begin{array}{l}\text { Rhetorical analysis, } \\
\text { literacy narrative, problem } \\
\text { paper }\end{array}$ \\
\hline 8 & Undeclared & Expository Writing & Lower-division & $\begin{array}{l}\text { Literacy narrative, rhetori- } \\
\text { cal analysis }\end{array}$ \\
\hline 9 & $\begin{array}{l}\text { Philosophy } \\
\text { and Sociology }\end{array}$ & $\begin{array}{l}\text { Advanced } \\
\text { Composition }\end{array}$ & Upper-division & $\begin{array}{l}\text { Critical response } 1 \text {, criti- } \\
\text { cal response } 2\end{array}$ \\
\hline 10 & Food Science & Business Writing & Upper-division & Memo \\
\hline 11 & $\begin{array}{l}\text { Human } \\
\text { Development }\end{array}$ & $\begin{array}{l}\text { Writing for Health } \\
\text { Sciences }\end{array}$ & Upper-division & $\begin{array}{l}\text { Rhetorical analysis, pro- } \\
\text { file, collage }\end{array}$ \\
\hline 12 & Microbiology & $\begin{array}{l}\text { Writing for Health } \\
\text { Sciences }\end{array}$ & Upper-division & $\begin{array}{l}\text { Profile, case study, ad } \\
\text { analysis }\end{array}$ \\
\hline 13 & Economics & $\begin{array}{l}\text { Advanced } \\
\text { Composition }\end{array}$ & Upper-division & $\begin{array}{l}\text { Mid-term, critical } \\
\text { response }\end{array}$ \\
\hline 14 & $\begin{array}{l}\text { Mechanical } \\
\text { Engineering }\end{array}$ & $\begin{array}{l}\text { Writing for } \\
\text { Engineering }\end{array}$ & Upper-division & $\begin{array}{l}\text { Engineering management } \\
\text { report, memo, revision } \\
\text { plan }\end{array}$ \\
\hline
\end{tabular}

had recently completed one of the upper-division options. We selected participants from the volunteer pool to obtain a cross-section of majors, writing courses taken, and assignment/text types. A summary of information about our student participants is shown in Table 7.2. 


\section{DATA SOURCES}

\section{SURVEYS}

A survey was administered in the upper-division courses to gain a better understanding of its student population. The descriptive results of that survey have been incorporated into this study. The 21-item survey was administered online. Students self-reported on three areas: (1) history of writing instruction, (2) linguistic background, and (3) perceptions of academic writing. All survey items were either multiple choice or Likert scale questions. The questions on perceptions of academic writing included an option to leave additional comments, an option that many participants took advantage of using.

\section{STUdent TeXTs}

Student volunteers provided us with samples of work they had produced for a recent upper- or lower-division writing course. The texts were delivered electronically in a Microsoft Word ${ }^{\circ}$-compatible format. The lower-division students who participated in this study each converted their web-based portfolios into Word documents. Upper-division students each selected two to three assignments, all of which were submitted as Word documents.

\section{STUdent INTERVIEWS}

Each of the students who shared sample texts met individually with researchers. Interviews were conducted in university office spaces where a computer was available. Interviews focused on the sample texts provided by interviewees. One of the main functions of any interview is to help researchers gather data on what we cannot see, such as feelings or the way people interpret the world (Merriam, 2009). This study employed a variation of the discourse-based interview developed by Odell, Goswami, and Herrington because, as researchers, we could not "determine what assumptions writers made or what background knowledge they had concerning the audience, the topic, and the strategies that might be appropriate for achieving their assigned purpose with a given audience" (1983, p. 222). This is what made the text-based interview such a suitable method for investigating how student writing processes involved "un-seeable" factors such as prior knowledge. We prepared for a semi-structured interview because we were interested in the unique ways each participant defined their surroundings and how participants described their prior knowledge (Merriam, 2009).

Questions were written up in a non-specific way that would allow the interviewer to interpret and re-interpret the interviewer/interviewee rapport. 
Miscommunication in interviews often occurs because interviewers fail to appropriately consider the linguistic norms and conventions of research participants (Briggs, 1986). Without demographic data on each specific interviewee, researchers planned to remain flexible enough to respond to the three variables Dexter (as cited in Merriam, 2009) ascribes to every interview situation: (1) interviewer personality, (2) interviewee attitude and orientation, and (3) the way both participants define the situation.

The interviews ranged from 30-45 minutes long. They began with several introductory questions, and the rest of the interview was spent asking the student to select and reflect on portions of their own texts that illustrated program-based transfer goals. These goals had been adapted from the writing program learning objectives: (1) incorporating evidence appropriate for the task, (2) demonstrating awareness of audience, (3) producing purpose-driven texts, (4) using language effectively, and (5) collaborating with others during the writing process. The student being interviewed used the highlighting tool on the computer to mark text portions that exemplified these principles, and the interviewer then prompted the student to explain or talk more about why the highlighted text portion illustrated the chosen construct. Student-coded texts were saved as a new document. Camtasia ${ }^{\circ}$ software was used to record the interviews; this allowed for the simultaneous capture of audio and video of interactions with the text on the computer screen.

\section{DATA ANALYSIS}

\section{Coding of UnMarked TeXTS}

To obtain a sense of what was taking place in the texts across the entire sample, the research team coded all of the student texts we had collected. There were 37 focal student texts analyzed in this study. These ranged from traditional academic research papers and argumentative essays to less traditional assignments such as professional profiles, memos, patient case studies, and collage essays for which students composed fragments in several genres and assembled them into a larger creative work.

The coding of texts began with the five transfer goals we had explored in the interviews, but over a series of team coding sessions, the five categories were both expanded and refined through a process of constant comparative analysis (Glaser \& Strauss, 1967). Once the team had identified and operationalized a set of codes for a sample of the texts, the remaining texts were divided among the researchers to complete the coding. Examples of codes used during the analysis are presented along with an explanation and text excerpt in Table 7.3. We used Dedoose $e^{ø}$ qualitative research software to complete the coding. 
Table 7.3. Descriptions and examples of researcher codes

\begin{tabular}{|c|c|c|}
\hline Code & Description & Sample Text Excerpt \\
\hline Audience & $\begin{array}{l}\text { The writer directly addresses } \\
\text { the audience or provides text } \\
\text { that explicitly guides the } \\
\text { reader. }\end{array}$ & $\begin{array}{l}\text { The S\&M research team believes this report } \\
\text { will satisfy your company's needs for the up- } \\
\text { coming Light Force car design presentation in } \\
\text { July. (Student \#14) }\end{array}$ \\
\hline Purpose & $\begin{array}{l}\text { The writer explicitly or implic- } \\
\text { itly signals the overall purpose } \\
\text { of the text (similar but not } \\
\text { identical to "thesis"). }\end{array}$ & $\begin{array}{l}\text { What's really happening is the media per- } \\
\text { sistently displaying unrealistic standards [of] } \\
\text { beauty which fuel our obsession with looks. } \\
\text { (Student \#12) }\end{array}$ \\
\hline Claim & $\begin{array}{l}\text { The writer makes a claim, } \\
\text { whether from his or her own } \\
\text { opinion or from a source. }\end{array}$ & $\begin{array}{l}\text { White culture is strong, white culture is indi- } \\
\text { vidualism. (Student \#9) }\end{array}$ \\
\hline Evidence & $\begin{array}{l}\text { The writer uses information } \\
\text { from sources and/or real-world } \\
\text { examples to support claims. }\end{array}$ & $\begin{array}{l}\text { For the online news article, the writing is } \\
\text { divided up into small paragraphs, some as short } \\
\text { as two sentences. (Student \#7) }\end{array}$ \\
\hline Reflection & $\begin{array}{l}\text { The writer describes a lesson } \\
\text { learned or an insight about an } \\
\text { experience and/or his or her } \\
\text { own writing. }\end{array}$ & $\begin{array}{l}\text { It has changed the way I perceived school work } \\
\text { and life, and has helped me find my passion for } \\
\text { the sciences. (Student \#6) }\end{array}$ \\
\hline
\end{tabular}

\section{INTERVIEW MEMOS}

A separate stage of analysis involved the independent review of the interview recordings. Each interview was listened to by a member of the research team who had neither done the interview nor coded the student's text sample. The reviewer composed a memo while listening to the recording. The memo included notes and observations, often tied to specific time stamps in the recording. The observations and notes were primarily focused on the codes generated during the analysis of student texts.

Once these analyses were complete, the research team held a series of meetings to discuss the observations from the coded set of text samples and from the 14 interview memos. Themes were identified and potential paths for the follow-up stages of analyses were proposed.

\section{Program Resources}

The data used to describe the resources available to learners through the UCD writing program come from the student surveys, program and course descriptions, student texts, and interviews. Following the initial rounds of coding, these sources were reviewed for data describing resources that learners could use to ad- 
Table 7.4. Descriptions and examples of writing context resource codes

\begin{tabular}{|c|c|c|}
\hline Code & Description & Example of a Data Source \\
\hline $\begin{array}{l}\text { Constructive } \\
\text { feedback via } \\
\text { instructor } \\
\text { conferences }\end{array}$ & $\begin{array}{l}\text { Meetings with instructors during } \\
\text { which specific writing projects } \\
\text { are discussed and the instructor } \\
\text { provides constructive feedback }\end{array}$ & $\begin{array}{l}\text { Student Interview: } \\
\text { Student \#9 finds a weakness in the draft } \\
\text { that was later improved. Student } \# 9 \\
\text { states that the weakness was identified } \\
\text { during a meeting with the instructor and } \\
\text { a solution was developed during that } \\
\text { meeting. }\end{array}$ \\
\hline Model texts & $\begin{array}{l}\text { Texts that model specific styles or } \\
\text { techniques }\end{array}$ & $\begin{array}{l}\text { Student Text: } \\
\text { Student \#6 explains in a reflective port- } \\
\text { folio letter how specific course readings } \\
\text { provided ideas on how to compose a } \\
\text { non-traditional narrative essay. }\end{array}$ \\
\hline $\begin{array}{l}\text { Revision } \\
\text { opportunities }\end{array}$ & $\begin{array}{l}\text { Timeframes and/or planning for } \\
\text { writing tasks allow or require } \\
\text { multiple revisions }\end{array}$ & $\begin{array}{l}\text { Course Requirement: } \\
\text { The lower-division course requires } \\
\text { students to submit work for peer-review } \\
\text { and instructor review before submitting } \\
\text { a final portfolio. }\end{array}$ \\
\hline $\begin{array}{l}\text { Explicit } \\
\text { metacognitive } \\
\text { reflection }\end{array}$ & $\begin{array}{l}\text { Course activities that require } \\
\text { students to reflect on their own } \\
\text { writing process }\end{array}$ & $\begin{array}{l}\text { Student Text: } \\
\text { Student } \# 2 \text { composed a portfolio cover } \\
\text { letter that described the writing process. }\end{array}$ \\
\hline $\begin{array}{l}\text { Peer } \\
\text { collaboration }\end{array}$ & $\begin{array}{l}\text { Opportunity or requirement to } \\
\text { share drafts with peers }\end{array}$ & $\begin{array}{l}\text { Course Requirement: } \\
\text { The standard syllabus of the lower- } \\
\text { division course required a peer-review } \\
\text { workshop for all major writing tasks. }\end{array}$ \\
\hline
\end{tabular}

vance their understandings of various writing contexts. Examples of these codes are presented in Table 7.4 .

\section{Analyzing for Dynamic Transfer}

After the first and second rounds of coding were complete, another pass of the data was done to identify instances that showed connections between student writing processes and writing program context. In order to identify such instances, critical events were identified in the data. Critical events are "judged to be illustrative of some salient aspect of" the phenomenon being examined (Wragg, 1994, p. 67). Events were designated as potential examples of dynamic transfer when there was a demonstrable link between a reference to prior knowl- 
edge and a reference to the resources in the writing environment-a link that influenced the creation of new knowledge or understanding. Identifying these events involved seeking relationships between the previously generated codes, or axial coding (Strauss, 1987). This resulted in a set of high-inference codes, codes for which researcher interpretation is used to make connections across different points in the data. Therefore, each critical event requires explicit explanation that takes the code's larger context into account. In order to report results that rely on this kind of high-inference analysis, much of the results will be reported through detailed description of four critical events.

\section{FINDINGS}

\section{Lower-Division Writing ConteXT}

Examination of the data from the lower-division setting reflects a course that introduced college composition as an expansively framed context (Engle et al., 2012). The standard syllabus used concepts from Beaufort's (2007) teaching for transfer pedagogy and Downs and Wardle's (2007) writing about writing pedagogy. This syllabus was designed to introduce instructors to the course learning objectives. All instructors taught from the syllabus at least once. It was the syllabus used by the vast majority of instructors teaching the course. Students composed literacy narratives and performed rhetorical analyses of both scholarly and popular texts. The vocabulary of composition and rhetoric was introduced in readings and lectures. Assignments and course objectives were explicitly presented as ways to apply rhetorical concepts while working on texts with specific purposes and intended for a defined audience. All reflective letters included backward-reaching reflection; students described the skills and attitudes they had upon entering the course. All reflective letters required metacognitive reflection on how the act of composing texts for the course influenced the development of writing skills.

The texts collected for this study further support the interpretations that UCD presents college composition as an expansively framed context (Engle et al., 2012). The students in lower-division courses composed texts for a broad range of audiences and purposes. Students composed academic writing tasks, reflective memos, narratives, scholarly research, texts intended for social media outlets, and problem papers calling on specific student-selected audiences to act. All of the student portfolios included at least two artifacts that each had distinct purposes and audiences. In portfolio letters, students all explicitly reflected on how circumstances, audiences, and purposes affected their writing processes. 


\section{UpPer-Division Writing ConteXt}

There was far more variation of resources and expectations in the upperdivision courses. This variation is a product of differing course objectives, as well as the varied professional backgrounds of the continuing lecturers and tenure-line faculty who taught the courses. The WID courses, for example, focused on how to compose scholarly texts within a discipline. Students in Writing in the Professions courses, on the other hand, would compose some texts that described the profession itself and other texts that approximated established genres in the profession. The advanced composition courses presented even more variation. Some versions of the course focused on various ways writers approach a specific topic. For example, two participants from different sections of the same advanced composition course wrote a variety of texts on the issue of race and racism. Other advanced composition courses required students to produce texts related to their individual majors. These courses asked students to learn about the writing conventions they encountered while studying for their major and then share their insights with students from other majors.

Two consistencies were notable across the upper-division writing courses. First, all of the courses worked toward the five writing program learning objectives. Second, the upper-division writing courses made an assumption about the students: The courses expected students to rely on the knowledge they had gained during their first two years of college experience. Assignment prompts, readings, and research requirements assumed that students understood concepts such as academic discipline, scholarly writing, academic audiences, disciplineappropriate evidence, and scholarly exigence. Students were not expected to know these concepts by name, but a familiarity was assumed. Many of the assigned readings and writing tasks would be beyond the abilities of a student who had not experienced two years of college-level general education or introductory courses in a specific discipline.

\section{Upper-Division Student Dispositions on Writing Skills and Transfer}

The results related to student dispositions come from the final portion of the survey of upper-division students. The section was concerned with student perceptions of college-level writing skills and the role writing instruction played in the development of those skills. The two items in that portion of the survey asked students to self-report their comfort level with 15 academic writing subskills that ranged from "writing for a specific audience" to "conducting research on a topic" to "avoiding plagiarism." See Table 7.5 for full results. The majority 
of students reported being comfortable with all the items listed except for "Preparing for and taking a timed writing exam."

Of the upper-division students who had taken a lower-division writing course $(\mathrm{N}=698), 84.6 \%$ reported that they felt their lower-division class had helped them to solidify the subskills they had just ranked. That previous writing courses "helped a lot" was stated by $31.7 \%$, and $52.9 \%$ reported that the courses "helped somewhat." Students were also invited to add comments to explain their choices, and many did so. There was quite a range of responses. Some students felt that they had acquired most of their academic writing skills from experiences of reading/writing in their own major courses. Some said they had learned everything they knew about writing in high school. Some highly praised their lower-division college writing courses, while others strongly criticized them.

The majority of upper-division students reported being comfortable with their own abilities across a broad range of writing subskills, most of which are emphasized by the writing program's learning objectives. When prompted to reflect on prior college-level writing instruction, most stated the instruction helped develop those skills. These results suggest that the majority of students believe there is a link between their prior writing instruction and their comfort with certain writing skills. These results cannot be generalized, as they are bound to the UCD writing program. They do, however, provide a contrast to the survey results Wardle (2009) reported from a different research site, where most students did not see any connections between early writing coursework and later writing. This contrast is particularly arresting because Wardle's description of that study's site is the opposite of what Engle et al. (2012) consider to be an expansively framed context. Wardle explains that the students "have been learning discrete skills not connected to any specific academic genres, and they did not appear to make even near connections of those skills ... to very different contexts" (2009, p. 775). This is what Engle et al. would term a bound context, a context that does not foster transfer. In the UCD writing program, the upperdivision students' sense of a connection between the two writing courses may have been affected by the way the lower-division course is framed.

\section{ANALYSIS OF CRITICAL EVENTS}

Here, we will present findings from four critical events that demonstrate how UCD's writing program takes into account the concept Engle et al. (2012) describe as expansively framed contexts, contexts that foster the dynamic transfer of writing skills. The writing program includes three key stages: (1) the introduction of rhetorical knowledge in lower-division courses, (2) two or more years of experience in a college setting before enrolling in an upper-division writing 


\section{Table 7.5 Comfort level with writing subskills}

Prompt: Now we'd like to ask about specific writing goals and skills you have developed at college. Please complete the table below. For each skill listed, please check how comfortable/confident you are with your writing ability in that area.

\begin{tabular}{|c|c|c|c|c|c|}
\hline & $\begin{array}{c}\text { Very } \\
\text { Comfortable }\end{array}$ & $\begin{array}{l}\text { Comfort- } \\
\text { able }\end{array}$ & $\begin{array}{l}\text { Uncomfort- } \\
\text { able }\end{array}$ & $\begin{array}{c}\text { Not sure/ } \\
\text { No opinion }\end{array}$ & Count \\
\hline $\begin{array}{l}\text { Writing for a specific } \\
\text { audience }\end{array}$ & 123 & 452 & 81 & 41 & 697 \\
\hline $\begin{array}{l}\text { Planning and organiz- } \\
\text { ing an assigned paper }\end{array}$ & 176 & 407 & 106 & 9 & 698 \\
\hline $\begin{array}{l}\text { Reading challenging } \\
\text { academic texts }\end{array}$ & 130 & 343 & 201 & 20 & 694 \\
\hline $\begin{array}{l}\text { Preparing for and } \\
\text { taking a timed writing } \\
\text { exam }\end{array}$ & 84 & 274 & 318 & 20 & 696 \\
\hline $\begin{array}{l}\text { Choosing a specific } \\
\text { research topic }\end{array}$ & 135 & 404 & 133 & 24 & 696 \\
\hline $\begin{array}{l}\text { Conducting research } \\
\text { on your topic }\end{array}$ & 189 & 370 & 120 & 16 & 695 \\
\hline $\begin{array}{l}\text { Citing your sources } \\
\text { appropriately }\end{array}$ & 188 & 363 & 125 & 18 & 694 \\
\hline Integrating evidence & 205 & 394 & 86 & 10 & 695 \\
\hline Avoiding plagiarism & 316 & 331 & 43 & 7 & 697 \\
\hline $\begin{array}{l}\text { Working collaboratively } \\
\text { on writing tasks }\end{array}$ & 101 & 356 & 196 & 41 & 694 \\
\hline $\begin{array}{l}\text { Using technology to } \\
\text { improve writing }\end{array}$ & 204 & 382 & 58 & 52 & 696 \\
\hline $\begin{array}{l}\text { Giving feedback to } \\
\text { others on their writing }\end{array}$ & 139 & 366 & 169 & 23 & 697 \\
\hline $\begin{array}{l}\text { Using feedback from } \\
\text { others to revise your } \\
\text { writing }\end{array}$ & 198 & 425 & 52 & 17 & 692 \\
\hline $\begin{array}{l}\text { Editing your writing } \\
\text { to correct errors and } \\
\text { improve language use }\end{array}$ & 217 & 381 & 87 & 12 & 697 \\
\hline $\begin{array}{l}\text { Reflecting on your own } \\
\text { writing progress }\end{array}$ & 146 & 411 & 94 & 41 & 692 \\
\hline $\begin{array}{l}\text { Additional Comments } \\
\text { (optional) }\end{array}$ & & & & & 6 \\
\hline
\end{tabular}


requirement, and (3) the explicit goal of developing more specialized writing skills. These stages assume institutional factors such as the university's two-course writing requirement and the consistency of programmatic goals. Students and instructors accept these as fixed factors that are supported across the university. The consistency of such factors allows students and instructors to frame writing tasks as part of the social reality of learning to be a student, learning to communicate in a discipline, learning to communicate as a professional, and/or learning to be a scholar. The first two critical events presented here are drawn from lower-division coursework, and the latter two are drawn from upper-division coursework.

\section{Struggling with Cyborgs}

Student \#1 was asked to find and highlight places in her portfolio where she used evidence to support a claim. She highlighted a section from a rhetorical analysis of an advertisement in which she was attempting to incorporate ideas from Haraway's (1991) chapter "A Cyborg Manifesto: Science, Technology, and Socialist-Feminism in the Late Twentieth Century." Student \#1 highlighted the following text from her own essay:

Sony wants to make people aware of the way we have raised an entire generation on machines, creating cyborgs to alert people to the way technology is changing society, not just the impact of Sony products.

Student \# 1 described the above text as a claim and said that "two paragraphs" served as supporting evidence. When asked to highlight evidence that supported the claim, she moved to the previous paragraph and told the interviewer, "Well, some of it kind of starts here, talking about the lifestyle that goes along with the [Sony PlayStation ${ }^{\oplus}$ ] PS, like the culture, along with the PS3 ${ }^{\text {TM }}$ gamers and stuff." After a long pause, Student \#1 scrolled down to a paragraph that contained the highlighted claim and said that "it continues through ..."- - there was another long pause as she scrolled to the next paragraph and then said- "I'm going to say that it kind of continues on until I get to my next point about the nature of the company."

Student \# 1 was suggesting that the three-and-a-half paragraphs should all be highlighted as evidence. The interviewer pressed Student \#1 to choose between (a) highlighting a series of selected sentences from within the paragraphs or (b) highlighting the entire 596 word block of text as evidence. Student \#1 confirmed with confidence that she would mark the 596 word block of text as evidence.

When the researchers discussed this section of text, we were struck by the number of claims that were not clearly linked to any evidence. The result is a 
passage that suffers from issues of incoherence and a number of un/under-supported claims. A writing assessment that only took the ad analysis into account would likely attribute Student \#1's unwieldy use of claim-evidence structures to a weak understanding of the relationship between claims and evidence. That assessment would be contradicted, however, by the personal narrative in the same portfolio, a well-wrought complex argument that depends on skillful use of claim-evidence structures. There is clearly an instance of frustrated transfer. What is striking is that Student \#1 worked so hard during the interview to understand evidence use in her own ad analysis.

An examination of the resources Student \#1 named sheds light on the nature of the challenge she faced. In the interview, while discussing the highlighted section of the essay, Student \#1 referred to the writing prompt, the advertisement, the Haraway (1991) text, the instructor's written feedback, and an email exchange with the instructor. The first resource available to Student \#1 went unnamed; it is her prior knowledge of claim-evidence structures that she demonstrated in her personal narrative. The rhetorical analysis, however, is a departure from such narratives, a point emphasized by the instructor feedback Student \#1 described: suggestions to cut down on expressive or overly descriptive language. Another resource is Haraway's text, a scholarly, multidisciplinary treatise on technology and feminist thought. While the text does model scholarly writing conventions, it is not a model of the kind of rhetorical analysis the ad analysis calls for. Also, Haraway assumes in-depth content knowledge that would be unfamiliar to most lower-division undergraduates. The instructor feedback, the scholarly text, and the assignment prompt all made Student \#1 aware of the newness of the writing task. However, in the time allowed to compose a lowerdivision portfolio, Student \#1 could not coordinate these resources.

Despite the shortcomings of her text, when Student \#1 was asked to find and highlight an effective use of evidence in her portfolio, she struggled for nearly 15 minutes with the poorly constructed claim-evidence structures in her rhetorical analysis. No other participant in the study spent this much time on one question. She was not instructed to answer the claim-evidence question using that specific essay. She could have drawn more effective examples from her personal narrative, but she decided to focus on the rhetorical analysis because, according to Student \#1, the writing process for the rhetorical analysis was more demanding. She was almost dismissive of the effort required for the personal narrative, which "came together in less than a week" because it was a familiar task. The rhetorical analysis involved more time, effort, and reflection. Student \#1 chose to examine the more challenging text because, according to her, it better demonstrated the kind of writing she was working to learn in the lower-division class. This data from the interview and sample texts suggest that after submitting final 
drafts of her work, Student \#1 is continuing her struggle to coordinate the resources in a new writing context.

\section{SEARChing for EXIGENCE}

When Student \#7 was asked to highlight a sentence that she struggled to write, she resisted. She did not want to highlight a single sentence. Instead, she highlighted the final two paragraphs from an informative essay. This data was coded as a critical event because the student text and the interview demonstrate a struggle to change prior knowledge, specifically knowledge of how to write a conclusion for an unfamiliar writing task. In her interview, Student \#7 described how she had previously approached the writing of conclusions: "Before this class, I guess, I would . . . look at each paragraph, and thentopic sentence, rephrase it, and then just kind of copy and paste it into the conclusion." While revising the essay, she decided such a conclusion would be unsuitable. She highlighted her two-paragraph conclusion, describing it as something she struggled to write because she was unsure about how to compose a conclusion for a new task.

After indicating that she struggled to compose the passage, Student \#7 went on to describe the functions of the conclusion she eventually wrote. She stated that her conclusion for this task "[is a] two-part" conclusion with the "first one summarizing [and] the second part ... going back to [explain] how to apply what the reader learns from this paper." Student \#7 then paused, trying to decide how to clarify further what her second paragraph was doing. After eight seconds of examining her own text, she said, "So, here I guess . . . it addresses the exigence of this paper, and that is something I struggle with, the conclusion usually, just because I don't really know how to end something, to wrap it up." Here are the two paragraphs that prompted Student \#7 to make those statements:

With the comparison of the two articles we can analyze where different genres contrast by convention: audience, purpose, exigence, tone, diction, format, design, and constraints. Each rhetorical situation gives rise to a different genre, aiming to affect the reader in some way. A writing [sic] in one genre may want to inform their audience while the goal of another may want to plant a new notion in the reader's mind. The paper is then shaped and tailored to address the audience's needs using tools like tone and diction.

After breaking down the two articles into their rhetorical components, these sample analyses can be used as precedents for analyzing writing of any genre in a student's undergradu- 
ate career. With the help of rhetorical analysis, it will be easier to zone in on the author's message and thesis along with why the authors wrote the way they did.

It is important to note here that increased understanding of rhetorical concepts was one of the learning objectives in the lower-division writing course, so the use of rhetorical terms by a student, while heartening, does not on its own indicate a critical event. The data represent a critical event because Student \#7 used the term exigence when reflecting on how she composed a new kind of conclusion for an unfamiliar writing task. The data suggest that Student \#7 made changes to her prior knowledge using newly acquired rhetorical knowledge as a resource to facilitate the change. Both the text sample and the interview suggest that Student \#7 is still developing her ability to apply these concepts in new settings. She does not wield the rhetorical concepts with complete confidence. Nevertheless, this is a demonstration of a student coordinating rhetorical concepts with her previous understandings of the writing process in order to create understandings that better suit a new writing context.

\section{"Who Would Want to Read This?"}

Student \#11 brought in three text samples from her Writing in the Professions course. She discussed an in-class reading response and a professional profile with rhetorical fluency, clearly identifying the way her writing addressed the purpose and audience for those tasks. The critical event we will focus on here is concerned primarily with the third text sample, a non-traditional narrative collage. The student claimed she had trouble "wrap[ping her] head around" this task and described it as "definitely different" and "a little bit broken up."

For the task, Student \#11 wrote and assembled a series of news updates, diary entries, online forum posts, and a web-based reference article. The interviewer asked Student \#11 to find a place where she addressed the audience or made a writing choice because of her audience. She responded as follows:

Yeah, so the audience in this case, I was thinking is just my professor, because I personally didn't like reading the example collage papers that we read. So I was thinking, who would want to read this [stifled laugh]? Because I think it's not a very interesting way to read a paper. It's definitely different.

On its own, the answer suggested that an upper-division writing task designed to get students thinking about non-academic audiences was having the opposite effect. This perception of the project as purely academic was reemphasized when Student \#11 went on to say the project would "get done" simply for 
the sake of getting it done. Here the student effectively described the collage as a mutt genre (Wardle, 2009), then said, "I had fun writing this, but I didn't think about the audience very much." This suggested an apparent reluctance or inability to engage with the rhetorical concepts the task assumed, which was surprising because the collage that Student \#11 composed demonstrated strong audience awareness.

The interviewer accepted Student \#11's assertion about writing for the professor and asked her to indicate a place where she made a writing choice for the professor. That is what prompted Student \#11 to roll the cursor over a portion of her text and give this response:

I will say that this is a fictional news update, and it was kind of fun thinking, "Okay, so the person who would be reading this would be, um, somebody looking up on CNN.com or something." So I looked up examples, and they format it this way. So I was thinking, "Okay, this looks like a news article right now," or [highlighting another portion of the text] this looks like what I looked up when I saw at WebMD, and this looks like [highlighting a third part of her text], if somebody wanted to read just the thread here, that's the diary entries, they would be reading ... a very interesting narrative by this person that I made up. So, I was actually thinking, in the individual threads, about how to make it stylistically interesting for different audiences.

Student \#11 said this less than 45 seconds after saying that she "didn't think about audience very much." Not only does she note how the various perceived expectations of readers affected her format and writing style, but also she names resources she sought out to help her formulate those styles. The task and her prior experience told her that she needed to seek out model texts in order to find an appropriate format and style.

Given the opportunity to interact with her own text, Student \#11 decided that her negative reaction to the assignment was separate from her act of writing. This is made most clear by her reproduction of the internal dialogue she had when writing; she gives a second voice to the decisions she made while writing. The result is two seemingly contradictory answers of "I didn't think about audience" and "I was actually thinking [ ... ] about [ ... ] different audiences." This suggests that while she was writing, Student \#11 made the decision to consider audience expectations without fully consciously reflecting on that decision. For her, the act of thinking about audience was a relatively low-road transfer event that triggered a search for resources she could use to write in a new format and style. 


\section{“Something That I Expected People to Enjoy"}

The final critical event we will examine demonstrates how a firm grasp of rhetorical concepts can be coordinated with prior college experience to help a student navigate discipline-based writing situations. Without being prompted to do so, Student \#12 brought in writing samples from two courses. She brought in two texts from her upper-division Writing in the Professions course, and she brought in one text from the writing program's lower-division course. This prompted the interviewer to ask directly about the utility of the skills she developed in the lower-division writing course. Student \#12 said that the texts she wrote for the lower-division course did not inform her upper-division work. She cited a section from the patient case study she wrote for the Writing in the Professions course as an example, stating that the case study's style and organization were informed more by the writing she did for lab reports in her microbiology courses. Those lab reports, like the patient case study, were more about the direct reporting of data. The texts she wrote in the lower-division writing course, on the other hand, involved more analysis and interpretation. The text sample from her lower-division writing course, a rhetorical analysis, demonstrated this difference effectively.

If this study's design relied exclusively on student-reported data on transfer, this exchange would not support our findings that an appropriately situated two-course writing program facilitates the transfer of writing skills and the development of discipline-based awareness. However, after this interview underwent three analytical passes, it is clear that Student \#12's writing is informed by both experience in her major and a firm grasp on rhetorical concepts. That combination is what helps her compose an unfamiliar text. For the Writing in the Professions course, she wrote a patient case study. She explained that she had never written such a text prior to that course. When asked about audience, Student \#12 said the following:

The case study is meant - usually nurses write these up so that doctors will have them and be able to read it quickly and catch up with what is going on with this new patient they have. ... I guess the more important part would be the symptoms, because doctors are constantly hearing symptoms. They get used to hearing certain symptoms associated with certain diseases, and that gives them an idea of where to start. ... I suppose the difference is if I were writing this for something that I expected people to enjoy reading, they'd want other details about the person, their name, their physical description, something like that. But this has a different purpose. 
Student \#12 links audience and purpose in a fluid and effective way, and she is able to reflect on those choices with clarity. She is correct to observe that her patient case study does not draw directly from the skills required to write a rhetorical analysis. Her in-interview reflection, however, suggests that she uses the rhetorical concepts that are the explicit learning objectives of the lower-division course. The ability to wield those concepts with the confidence exhibited in the interview give Student \#12 the tools needed to interrogate a reader's motivation. She does not expect her reader "to enjoy reading" her case study. The link between audience and purpose may even have cued the prior knowledge of lab report writing conventions. Student \#12 understands that lab reports are not written to be enjoyed because she has interacted with them as a writer and as a reader. She states explicitly in the interview that she has never written a patient case study before. Nevertheless, she is able to compose a successful case study through the coordination of the assignment prompt, her prior knowledge of audience and purpose, and her prior knowledge of writing for transactional purposes in a clinical setting.

\section{DISCUSSION}

Critical events from lower-division courses suggest two important factors influencing the dynamic transfer of writing skills. First, the lower-division writing course is understood not only as a learning context but also as a target context. It is a place where students are introduced to the work it requires to use, analyze, and develop their prior knowledge to gain new understandings of the writing process. Students reflected on their prior knowledge of writing and how it influenced the new tasks they were working on. Students also focused on how the newness of the tasks in the lower-division course affected their writing processes. The course presented students with the resources required to assess their own knowledge, transform it, and then apply that knowledge to new tasks, a set of resources that should facilitate transfer (Elon Statement, 2015; Appendix A).

The second factor relates to students understanding that the lower-division course was not an end point. In interviews that took place after the course was complete, students described their writing skills and challenges in the present tense, acknowledging that the process of development was ongoing. It is crucial that students continue to develop their understandings of the university as a social context after they finish the lower-division writing course. This continued development is facilitated by the following programmatic cue: Students must not only reflect on prior knowledge, but also they must project into their future academic careers and consider how their knowledge of writing will be changed by new tasks, 
new audiences, and new conventions. There are several ways such projection can be cued, but one important way we observed is the upper-division writing requirement. An upper-division writing course is listed among the major requirements at UCD, informing students that the effort to move from lower-division status to upper-division status will require new knowledge of writing.

Another important way the UCD writing program cues projection is the programmatic effort to frame the learning contexts in the writing classroom expansively. The lower-division course presents writing strategies as "resources for productive action in potential future transfer contexts" (Engle et al., 2012, p. 218). This framing acknowledges the way abstract writing concepts are continuously developing and gaining relevance through context. In doing so, such framing demonstrates the expectation that students should use their experiences in other UCD courses to reflect on how abstract writing concepts are relevant in different settings. This is an essential part of the multi-year writing requirement because it emphasizes how the learning, relationship building, and growth that take place throughout the college experience all contribute to a student's writing development.

The work done by lower-division students demonstrates some of skills that require time within the institution to develop. Students in the lower division writing courses displayed an ability to reflect on abstract writing concepts, but this kind of reflective work was a challenge. Nearly all of the students struggled to give answers, taking long periods of time to explain or consider how their writing demonstrated the concepts being examined. This was best demonstrated by the effort students put into answering interview questions about audience, purpose, the effective use of evidence, and writing conventions. That this was challenging is not a failing of the writing course; the lower-division students were just beginning their active engagement with the university as a writing environment. They had very limited experience with the practical application of the abstract writing concepts taught in the lower-division writing course.

As Day and Goldstone argue, while the teaching of abstract concepts may efficiently provide learners with easy-to-transfer knowledge, "it seems to do so at the expense of comprehensibility" (2012, p. 157). This suggests comprehension of the abstract writing concepts will continue to grow as students engage in the variety of writing situations across the university. This time in the university environment gives students opportunities to reflect on how abstract writing concepts inform practical writing tasks. These opportunities represent the access and practice within a community that Gee (1989) named as a requirement for developing literacy. Conceptual understanding varied across participants, but data that describe interactions between student knowledge and environmental resources suggest that students in lower-division courses are in the early stages 
of coming to understand the university as a social context with complex writing expectations.

Upper-division students, on the other hand, demonstrate a familiarity with the expectations and resources available to student writers at UCD. Critical events with upper-division students not only involve less hesitation but also include more examples of constructive metacognitive reflection and rhetorical awareness. This is certainly a result of their familiarity with university expectations, much of which would have been gained in courses and experiences outside of the writing program. That experience was gained in an environment that explicitly expects continued writing skill development. This study suggests that such student experience can be coordinated with the resources made available across the university and highlighted by the consistent, explicit, and intentional transfer-oriented learning objectives set forth by the multi-year writing requirements.

These findings shed a new light on the research approaches our thought experiment examined. When a student moves from a learning context to a target context in which the writing expectations have changed, the learner's prior knowledge must interact with resources in the new writing environment if it is to be useful. For example, a student new to the discipline of psychology who knows how to cite sources using MLA citation conventions may be able to learn a new set of citation conventions faster than a student with no knowledge of citation conventions. For that to happen, however, the student will need to be able to use resources in the new setting to transform the knowledge of MLA citation conventions. That is more likely to occur if the environment has consistent, explicit, and intentional transfer-oriented learning objectives. Many studies in composition research collect data from the students and focus on the high-road/low-road transfer spectrum. That is, the studies focus on self-reported data describing what students do to transform their prior knowledge. That is valuable data, but dynamic transfer demonstrates how that transformation of prior knowledge relies on resources in the target context, as well as a student's ability to recognize those resources. This acknowledges an important learningto-write component in the transfer process, thus helping to resolve the conflict Russell (1995) highlighted when he introduced activity theory to the discussion of FYC and composition studies. Dynamic transfer shows that appropriate prior knowledge can affect later performances, but only when learners have the time and capacity to use resources in a new environment and make appropriate changes to the prior knowledge.

While the writing program at UCD demonstrated an environment that facilitates such knowledge transfer, the generalizability of this study is limited. The qualitative nature of the study keeps these results bound to the UCD context. 
However, the results do suggest that the way resources in target contexts are presented must be considered when we investigate the development and transfer of writing skills. Dynamic transfer, as a learning mechanism, provides a way to interrogate the relationships between a writer's knowledge and the environment in which the writer is working. One major implication is the need to understand writing contexts outside of the writing classroom, to treat the resources in those settings as tools students will use to repurpose the knowledge they already have. As composition and education researchers continue to consider this issue, investigators ought to turn to settings where there is no direct writing instruction and novice writers are expected to look to the writing environment for cues and resources. As we learn more about the characteristics of such settings, it may be possible to consider whether or not a writing course can teach students how to seek out and use resources in situations beyond the classroom where little or no formal writing instruction is available. No course on writing will ever teach every writing skill required in such settings, but the discipline's evolving concept of how writing skills develop may speed the transition of novices into new communities of writers.

\section{REFERENCES}

Barnett, S. M. \& Ceci, S. J. (2002). When and where do we apply what we learn? A taxonomy for far transfer. Psychological Bulletin, 128(4), 612-637.

Bawarshi, A. S. \& Reiff, M. J. (2010). Genre: An introduction to history, theory, research, and pedagogy. Fort Collins, CO: The WAC Clearinghouse/Parlor Press. Retrieved from http://wac.colostate.edu/books/bawarshi_reiff/.

Bazerman, C. (1997). The life of genre, the life in the classroom. In W. Bishop \& H. Ostrom (Eds.), Genre and writing, issues, arguments, alternatives (pp. 19-26). Portsmouth, NH: Boynton Cook Publishers.

Beaufort, A. (2007). College writing and beyond. Logan, UT: Utah State University Press.

Bizzell, P. (2003). Cognition, convention, and certainty: What we need to know about writing. In V. Villanueva (Ed.), Cross-talk in comp theory: A reader (2nd ed.) (pp. 387-411). Urbana, IL: National Council of Teachers of English (NCTE).

Braddock, R., Lloyd-Jones, R. \& Schoer, L. (1963). Research in written composition. Urbana, IL: National Council of Teachers of English.

Brent, D. (2012). Crossing boundaries: Co-op students relearning to write. College Composition and Communication, 63(4), 558-592.

Briggs, C. (1986). Learning how to ask: A sociolinguistic appraisal of the interview in social science research. Cambridge, UK: Cambridge University Press.

Chen, Z. \& Klahr, D. (1999). All other things being equal: Acquisition and transfer of the control of variables strategy. Child Development, 70(5), 1098-1120. 
Day, S. B. \& Goldstone, R. L. (2012). The import of knowledge export: Connecting findings and theories of transfer of learning. Educational Psychologist, 4(3), 153-176.

Downs, D. \& Wardle, E. (2007). Teaching about writing, righting misconceptions: (Re)envisioning "first-year composition" as "introduction to writing studies." College Composition and Communication, 58(4), 552-584.

Driscoll, D. (2011). Connected, disconnected, or uncertain: Student attitudes about future writing contexts and perceptions of transfer from first year writing to the disciplines. Across the Disciplines, 8(2). Retrieved from http://wac.colostate.edu/atd /articles/driscoll2011/index.cfm.

Elon Statement on Writing Transfer. (2015). Retrieved from http://www.centerfor engagedlearning.org/elon-statement-on-writing-transfer/.

Engle, R., Lam, D., Meyer, X. \& Nix, S. (2012). How does expansive framing promote transfer? Several proposed explanations and a research agenda for investigating them. Educational Psychologist, 47(3), 215-231. doi:10.1080/00461520.2012.695 678.

Faigley, L. (1986). Competing theories of process: A critique and a proposal. College English, 48(6), 527-542.

Gee, J. P. (1989). What Is literacy? Journal of Education, 171(1), 18-25.

Gick, M. L. \& Holyoak, K. J. (1980). Analogical problem solving. Cognitive Psychology, 12, 306-355.

Glaser, B. G. \& Strauss, A. L. (1967). The discovery of grounded theory: Strategies for qualitative research. Chicago: Aldine.

Haraway, D. (1991). Simians, cyborgs and women: The reinvention of nature. New York: Routledge.

Kent, T. (1999). Introduction. In T. Kent (Ed.), Post-process theory (pp. 1-6). Carbondale, IL: Southern Illinois Univerity Press.

Kitzhaber, A. R. (1960). Death—or transfiguration? College English, 21, 367-373.

Lobato, J. (2012). The actor-oriented transfer perspective and its contributions to educational research and practice. Educational Psychologist, 47(3), 232-247. doi:10 .1080/00461520.2012.693353.

Martin, L. \& Schwartz, D. L. (2013). Conceptual innovation and transfer. In S. Vosniadou (Ed.), International handbook of research on conceptual change (2nd ed.) (pp. 447-465). New York: Routledge.

McCarthy, L. P. (1987). A stranger in strange lands: A college student writing across the curriculum. Research in the Teaching of English, 21, 233-265.

Merriam, S. (2009). Qualitative research: A guide to design and implementations. San Francisco: Jossey-Bass.

Nowacek, R. (2011). Agents of integration: Understanding transfer as a rhetorical act. Carbondale, IL: Southern Illinois University Press.

Odell, L., Goswami, D. \& Herrington, A. (1983). The discourse-based interview: A procedure for exploring the tacit knowledge of writers in nonacademic settings. In P. Mosenthal, L. Tamor \& S. A. Walmsley (Eds.), Research on writing: Principles and methods (pp. 221-236). New York: Longman. 
Perkins, D. \& Salomon, G. (1988). Teaching for transfer. Educational Leadership, 46(1), 22-32.

Perkins, D. \& Salomon, G. (2012). Knowledge to go: A motivational and dispositional view of transfer. Educational Psychologist, 47(3), 248-258. doi:10.1080/00461520 .2012.693354.

Petraglia, J. (1999). Is there life after process? The role of social scientism in a changing discipline. In T. Kent (Ed.), Post-process theory (pp. 49-64). Carbondale, IL: Southern Illinois University Press.

Robertson, L., Taczak, K. \& Yancey, K.B. (2012). Notes toward a theory of prior knowledge and its role in college composers' transfer of knowledge and practice. Composition Forum, 26. Retrieved from http://compositionforum.com/issue/26 /prior-knowledge-transfer.php.

Royer, J. M., Mestre, J. P. \& Dufresne, R. J. (2005). Introduction, framing the transfer problem. In J. P. Mestre (Ed.), Transfer of Learning from a modern multidisciplinary perspective (pp. vii-xxvi). Greenwich, CT: Information Age Publishing.

Russell, D. (1995). Activity theory and its implications for writing instruction. In J. Petraglia (Ed.), Reconceiving writing, rethinking writing instruction (pp. 51-78). Hillsdale, NJ: Erlbaum.

Schwartz, D. L., Chase, C. \& Bransford, J. (2012). Resisting overzealous transfer: Coordinating previously successful routines with needs for new learning. Educational Psychologist, 47(3), 204-214. doi:10.1080/00461520.2012.696317.

Smit, D. W. (2004). The end of composition studies. Carbondale, IL: Southern Illinois University Press.

Strauss, A. L. (1987). Qualitative analysis for social scientists. New York: Cambridge University Press.

Wardle, E. (2009). "Mutt genres" and the goal of FYC: Can we help students write the genres of the university? College Composition and Communication, 60(4), 765-789.

Wragg, E. C. (1994). An introduction to classroom observation. New York: Routledge.

Yancey, K. B. (1999). Looking back as we look forward: Historicizing writing. College Composition and Communication, 50(3), 483-503. 



\title{
CHAPTER 8
}

\section{CULTIVATING CONSTRUCTIVE METACOGNITION: A NEW TAXONOMY FOR WRITING STUDIES}

\author{
Gwen Gorzelsky, Dana Lynn Driscoll, Joe Paszek, \\ Ed Jones, and Carol Hayes
}

Writing studies scholars have highlighted the concept of metacognition in various settings, including the Framework for Success in Postsecondary Writing (2011) and recent research on the transfer of writing knowledge into new contexts (Nowacek, 2011; Reiff \& Bawarshi, 2011; Rounsaville, Goldberg \& Bawarshi, 2008; Taczak, 2011; Wardle, 2009). Understood broadly as thinking about thinking, metacognition has been defined more specifically as "the ability to monitor one's current level of understanding and decide when it is not adequate" (National Research Council, 2000, p. 47) or "the ability to reflect on one's own thinking as well as on the individual and cultural processes used to structure knowledge" (Council of Writing Program Administrators, National Council of Teachers of English \& National Writing Project, 2011, p. 5). Further, metacognition and related terms have been used to describe practices linked to writing transfer. For instance, writing studies scholars have considered students' meta-monitoring of composing processes, rhetorical situations, and genre knowledge (Negretti, 2012; Nowacek, 2011; Reiff \& Bawarshi, 2011). Despite conceptual and methodological differences, much writing studies work on transfer has suggested ties between metacognitive capacities and the ability to transfer writing skills and concepts across contexts (Nowacek, 2011; Reiff \& Bawarshi, 2011; Wardle, 2009). Yet, writing studies does not have a model that defines the specific components and subcomponents of metacognition or their relationships. Nor does it have strategies for teaching these (sub)components, either individually or to promote metacognitive development that supports the transfer of writing-related knowledge across courses and contexts.

The importance of metacognition in successful learning has been described widely across disciplines including education (Dignath \& Buttner, 2008), reading comprehension (Cross \& Paris, 1988; Haller, Child \& Walberg, 1988; 
McKeown \& Beck, 2009; Thiede, Griffin, Wiley \& Redford, 2009; Williams \& Atkins, 2009), science (White, Frederiksen \& Collins, 2009), and mathematics (Jacobse \& Harskamp, 2012; Mevarech \& Kramarski, 2003; Lobato, 2003, 2012). Defining and identifying metacognitive elements, however, continues to be a difficult task (Georghiades, 2004; Scott \& Levy, 2013). As Scott and Levy observed, "Metacognition is a fuzzy concept but widely used by the research community," and prior to their study, "it [was] still unclear if there is an umbrella concept with one major factor that can be labeled metacognition or whether metacognition has clear and distinct factors upon which researchers can base their research" (2013, p. 121). Writing studies scholars like Nowacek (2011), Reiff and Bawarshi (2011), and Wardle (2009) gestured toward the importance of metacognition for transfer but have not yet considered its operation, development, complexity, and components or addressed the concept's "fuzziness." As we show below, this fuzziness has posed both conceptual and methodological problems for understanding where and how students are using metacognitive skills in writing tasks. Further, fuzziness about metacognitive components poses a challenge for teachers, who need a clear explanation of what the components are, how they relate to one another, and how they support writing transfer. Perhaps most importantly, instructors need information on how to teach metacognitive components in ways that promote transfer.

We address this problem by constructing a taxonomy that identifies the metacognitive moves that students use in college-level writing. We grounded the taxonomy in a qualitative, theoretically informed analysis of students' written reflections and interview data about writing. Using the taxonomy, we show how writing instructors can teach the key metacognitive components cumulatively, in ways that help students develop what we call constructive metacognition, a metacognitive move that demonstrates a critically reflective stance likely to support transfer of writing knowledge across contexts. While this type of metacognition is only one of several factors that appear to support students in transferring writing knowledge, we show that students who engage in constructive metacognition reflected on their texts, strategies, and sense of writerly identity across a series of writing tasks and contexts by using writing and rhetorical studies concepts. As we discuss, these reflections seem linked to the transfer of writing knowledge across contexts.

Our work extends two principles articulated in the Elon Statement on Writing Transfer (2015; Appendix A): (1) that students' meta-awareness often plays a key role in transfer and (2) that learners may engage in both routinized and transformative types of transfer when drawing on prior knowledge. The curricular and classroom practices we recommend below support two of the enabling practices advocated by the Elon Statement, as well as one of the statement's working principles. The first enabling practice involves asking students to engage in activities 
that help them develop metacognitive awareness. The second practice entails explicitly modeling transfer-focused thinking, in this case, forms of metacognitive thinking. The working principle from the Elon Statement posits that students who receive explicit rhetorical instruction have better chances of transforming rhetorical awareness into stronger rhetorical performance.

In what follows, we discuss writing studies scholarship on the role of metacognition in writing development and transfer, overview metacognition in current psychology research, and show how we drew on that research and our qualitative analysis to construct a taxonomy of metacognitive components specific to writing. Using the taxonomy, we demonstrate how writing instructors can teach individual metacognitive (sub)components in order to help students integrate the (sub)components in ways leading to constructive metacognition. While further research is needed to ascertain the role of constructive metacognition in students' writing development, both our initial findings and established theories of writing development suggest that it may do so. However, as we discuss below, it is only one factor in writing transfer, and we recommend ways to link it to other factors to optimize students' potential for transferring writing knowledge across contexts.

\section{PROMOTING WRITING TRANSFER THROUGH METACOGNITION}

Recent writing studies research has begun to consider how metacognition can promote writing knowledge transfer. Like earlier work by Flower and Hayes (1981), current studies have examined students' thinking in relation to composing (Beaufort, 2007; Reiff \& Bawarshi, 2011). While Flower and Hayes developed a cognitive model, more recent studies have extended the investigation of writers' thinking to metacognition. Cognition involves thinking to perform a task, while metacognition entails reflection on that thinking, its efficacy, and/ or its outcomes. Clearly, cognition and metacognition are closely linked, and Flower and Hayes' work addressed an important component of metacognition-monitoring — which we define below. Similarly, Beaufort's $(2007,2012)$ work has suggested the increasing emphasis on metacognition by stressing the importance of metacognition's role in situated writing performances. This emphasis on metacognition and closely related terms has expanded in the last several years.

For instance, some recent research has linked important writing studies concepts like genre knowledge to meta-awareness, which promotes critical, flexible engagement with new writing tasks. Researchers have investigated students' meta-awareness of genre as they move between writing tasks and contexts. Rounsaville, Goldberg, and Bawarshi, for example, suggested that metacognitive 
knowledge can enable students to "reorient their relationship to what they already know," and they use student survey and interview data to show that mindfully connecting the demands of new writing situations to prior genre knowledge may help students to mobilize their writing repertoires across contexts (2008, p. 108). However, these scholars focused on identifying the prior genre knowledge that students bring to first-year writing and did not explore metacognition as a construct, beyond noting its role in transfer.

Other studies have suggested the importance of metacognition in writing development and transfer, particularly in relation to reflection, but have not defined its nature, components, or role. Reiff and Bawarshi presumed that reflection prompted metacognitive development that facilitates transfer (2011, p. 315). Earlier, Nelms and Dively made similar presumptions concerning metacognition and reflection, arguing that "reflection represents an important mechanism for achieving metacognitive awareness of the potential for transferring learning across contexts" (2007, p. 216). Similarly, both Wardle (2009) and Bergmann and Zepernick (2007) argued that while students did indeed learn writing strategies deemed valuable by compositionists (such as a flexible writing process that included drafting and revision techniques), students claimed that the kinds of writing done in the first-year writing (FYW) courses that required these strategies were applicable only in other English courses (Bergmann \& Zepernick, 2007; also see Driscoll, 2011) or that the writing tasks they encountered in future courses did not demand the use of these strategies (Wardle, 2007). While Bergmann and Zepernick did not explicitly discuss students' decisions to ignore writing skills and strategies as metacognitive choices, these decisions suggest that students made such choices, whether consciously or not. Wardle stressed the need for students to develop metacognitive skills, arguing that "meta-awareness about writing, language, and rhetorical strategies in FY[W] may be the most important ability our courses can cultivate" (2007, p. 82).

While several of these projects drew on Perkins and Salomon's $(1989,1998)$ influential work on transfer and suggested that transfer relies on students' ability to "reflect on one's choices and decisions" (Nelms \& Dively, p. 218), none provided an operationalized definition of metacognition, which researchers need in order to identify and analyze metacognitive functions as students learn to write and which instructors need in order to help students cultivate specific metacognitive capacities to support writing and writing development. Writing studies scholars have not yet considered the nature and effects of the different kinds of metacognitive moves students make while writing, whether different reflective activities may prompt different metacognitive moves, or the role of such different moves in writers' development. As Nowacek argued, "The nature of these metacognitive abilities needs to be further qualified and described. To put our 
faith in unspecified metacognitive abilities is tantamount to pointing to a black box in which a general cognitive ability magically operates" (2011, p. 17). In short, the field has yet to conceptualize how metacognition operates in writing.

This lack of specificity in prior research has posed more than just conceptual limitations to understanding writers' development. Without such specificity, instructors have no way to identify students' work with particular metacognitive (sub)components, to understand how these (sub)components interact to support writing development, or to teach the (sub)components, either individually or cumulatively. For instance, while Negretti's (2012) work has shown the importance of basic writers' self-regulation in their writing development, her study did not address the relation between regulation/control and other metacognitive (sub)components. As a result, the study could not provide a framework for considering how these (sub)components interact in writing and for designing approaches to teaching the (sub)components.

Thus, while recent research has stressed the role of metacognition in writing transfer, only a few studies have examined metacognitive moves in student writing; none, to our knowledge, have identified and defined the metacognitive (sub)components and how they operate in writing. ${ }^{1}$ Yet investigating how writers use such (sub)components is crucial to promoting transfer for four key reasons: (1) Psychology scholarship on metacognition shows that metacognitive (sub) components play an important role in governing task completion and learning; (2) Our research suggests that when metacognitive moves occur during writing, they often do so in forms specifically shaped by writing knowledge; (3) We need to learn how the various (sub)components of metacognition relate to one another in supporting writing development and transfer; and (4) Understanding these (sub)components makes it possible to teach specific metacognitive moves - rather than generalized awareness of cognition-and to help students integrate such moves into the writing process, as well as into their discussions of their texts, which prior research suggests is important to their development of expertise (Anson, 2000). Our study pursues such understanding, as well as insight into how this understanding might inform writing instruction.

Therefore, we ask these questions:

- When and how do metacognitive moves occur when students reflect on and talk about writing?

- Do such metacognitive moves rely on conceptual and/or procedural knowledge about writing?

- If so, what kinds of conceptual and/or procedural knowledge are needed, and how do these forms of knowledge support metacognitive moves? 
- How might examining these metacognitive moves provide a more nuanced understanding of metacognitive (sub)components, as they function in student writing?

- Do these moves show interactions between metacognitive (sub) components, both in specific writing tasks and in writers' development across tasks? If so, how?

- Which moves, or combinations of moves, seem likely to lead to more successful transfer?

Answering these questions may open Nowacek's (2011) black box to reveal more precisely how metacognition supports both the development and transfer of writing knowledge. We address them below by presenting our findings from a mixed-methods, longitudinal study of student writing at four universities with different missions, student demographics, and locations.

\section{METHODOLOGY}

\section{DATASET}

The data from this project was sampled from a larger multi-institutional dataset collected over a two-year period through the Writing Transfer Project. The larger dataset includes work produced by 123 students at four universities as they took five different writing courses (first-year writing at George Washington University, Oakland University, and Seton Hall University; intermediate writing at Wayne State University; and upper-division writing at Oakland University) and work produced by a subset of students writing in subsequent courses. We define students' "initial course" as the writing course students first took in the study (which may not be their first writing course at college). As part of their initial courses, students were asked to write a series of reflections designed to facilitate metacognitive awareness, rhetorical knowledge, and transfer of learning. The dataset includes multiple reflections from each student, using a similar prompt at each institution $(\mathrm{N}=398)$; student papers written before, during, and after their writing courses $(\mathrm{N}=274)$; and follow-up interviews with a subset of students $(\mathrm{N}=30)$ the year after the initial writing courses. The interviews lasted 45-80 minutes, and students were asked a number of questions on writing, metacognitive awareness, genre awareness, and transfer of learning. At Seton Hall, students completed a second interview that included a think-aloud writing protocol in which students described their processes for drafting a paper for a course taken after their initial writing courses. At the remaining sites, students discussed a paper they wrote in a course after their initial writing courses. 
As part of the larger study, 274 student papers were rated by a group of trained graduate student raters from multiple disciplines. Raters used a rubric designed by the authors to evaluate the effectiveness of texts in meeting genre conventions, including the use of sources, contextualization, and responsiveness to disciplinary audience, purpose, and style.

Further, the research team identified potentially important categories related to transfer and developed these categories into 98 codes in six categories, including two important to this study: transfer-focused thinking and metacognition. Initial coding generated 14,156 code applications for 381 reflective pieces of writing and 38 interviews.

\section{SAMPLING}

Because our initial coding in the larger dataset covered a wide range of categories, it suggested the importance of metacognition in transfer but did not provide the detailed picture needed to specify metacognition's role in writing development and transfer. The patterns revealed by our initial coding suggested that we needed to develop a more detailed set of codes for examining students' representations of their metacognitive moves. We focused on two types of data in our set that we believed were most likely to include such representations. The first entailed students' responses to our final reflective prompt; students wrote this reflection after completing their final papers or portfolios. The second entailed students' follow-up interviews, which described various writing experiences a year after students' initial writing courses. These two document types represent both the kinds of data writing transfer researchers often collect (student interviews and analysis of student writing) and the kinds of data that writing teachers often encounter (reflective writing).

To begin a limited exploration of how metacognition and written performance relate, we used students' writing rubric scores to sample from our larger dataset. We found that some students' scores improved from the final paper in the initial course to the paper in the subsequent course, while others' scores declined. Therefore, we randomly selected one student from each university whose scores had increased and one student whose scores had declined. This yielded a subset of eight student interviews and eight final reflections; all three types of courses are included in the sample.

\section{Collaborative Glossary Development}

To develop codes, we drew on Smagorinsky, who suggested that coding is not a "static representation of reality" but rather a dynamic, collaborative process 
that yields "continual refinement of categories" (2008, p. 393). We believe his approach is well suited to this project because the work is in-depth and exploratory. Using it, the first three authors of this manuscript worked collaboratively throughout the coding process to develop, refine, and redefine categories. To provide a framework for our coding glossary, we discussed our readings of the metacognition literature and several example reflections and interviews not included in our small sample from the larger dataset We collaboratively coded all reflections and the first five interviews, reading each paragraph or segment individually, then discussing and coding it. Disagreements often led to code revisions, prompting us to refine or add to the codes; through this process, we developed a new category in the taxonomy-constructive metacognition-as well as markers for deep and shallow metacognition. A table of the codes we used appears in the section presenting our taxonomy.

The coding approach we used yields 100\% inter-rater reliability because coders do not move forward until there is complete agreement. After coding eight reflections and five interviews, we reached saturation, based on Creswell's criteria, "the point when you have identified the major themes and no new information can add to your list of themes, or to the detail for existing themes" (2002, p. 244). We each individually read and coded one of the last three interviews, discussing any questions with the other two group members who were present.

In addition to the collaborative coding, we examined the relationship of writing scores to metacognitive codes for the eight papers. For all eight students, we had two scores: a score from a paper written at the end of their initial writing course and a score from a paper we collected approximately one year later. Half of these students had scores that declined and half had scores that improved. We examined the patterns in metacognitive awareness (through number of codes) to identify possible relationships between metacognition and student writing performance over time. Further, we examined numbers of code co-occurrences, when two or more codes appeared in the same text segment to identify relationships between codes within the taxonomy.

\section{STUdy Limitations}

We set out to develop a taxonomy of students' depictions of the metacognitive moves they make while writing. We examined qualitatively how students described these moves but, due to the demands of qualitative analysis, we could not code a sample large enough to allow us to draw generalizable conclusions. Nonetheless, we examined our relatively small coded sample quantitatively to investigate code co-occurrences and the relationships between our codes and 
students' writing performance over time. Because our purpose in this study was to develop the taxonomy to support instruction and further research, we hope that later, larger-scale studies using it will uncover such relationships.

Further, we examined mostly retrospective data (interviews and reflections). These data provided insight into metacognitive knowledge (person, task, strategy) and some forms of regulation (evaluation) but not into all of the metacognitive (sub)components students may use while writing. Nowacek (2013) noted that retrospective data limits access to students' use of metacognitive (sub)components during the writing process, as students' memories are likely imperfect.

Retrospective data also raises questions about the reliability of self-reported data, particularly in research on metacognition. Study participants may choose not to reveal all relevant information and may not be consciously aware of all of relevant cognitive and metacognitive moves. While there has been debate over the existence of nonconscious metacognitive thinking (Efklides, 2008; Hacker, 1998), because it has thus far been impossible to track such thinking, most researchers have focused on conscious metacognitive moves (Georghiades, 2004; Harris, Alexander \& Graham, 2008). Further, students may report what they predict teachers or researchers wish to hear. Despite the limits of self-report data, $\mathrm{H}$. Rubin and I. Rubin argued that qualitative interviews are best for learning about issues that are not simple or brief, but rather require in-depth explanation (2005, pp. 2-3). Because we looked not for general claims about the utility of what students learned but instead for evidence of students' work with specific metacognitive (sub)components, such as analysis of a student's particular strengths and challenges in relation to a specific writing task, such in-depth modes of data collection were especially useful for our study.

Thus despite its limitations, we believe such data is still valuable. First, it reveals which metacognitive moves students see as relevant to the writing process. Second, Lobato (2012) argued that to understand transfer and what facilitates it, we need self-reported data to examine the roles of students' dispositional traits and perceptions of their problem-solving efforts. Third, by prompting students to talk through their texts and writing processes, producing such data may make some of their nonconscious or unarticulated metacognitive moves more visible or more conscious. Making these moves visible provides us with a basis to help teachers recognize the moves and to guide students in extending them in ways that build students' metacognitive capacities. As we discuss below, by developing prompts that ask students to evidence specific metacognitive moves, reflective assignments can help shift students away from teacher-pleasing responses into practicing activities that build their metacognitive capacities. 


\section{TAXONOMY}

\section{Overview, Sources, and Rationale}

To develop our codes, we turned to Scott and Levy's (2013) study of the components of metacognition. We did so because Scott and Levy worked with the five components of metacognition most accepted by psychology researchers (knowledge of cognition, planning, monitoring, regulation/control, and evaluation) and because they incorporated definitions of key subcomponents. ${ }^{2}$ Their statistical analyses of students' responses to survey instruments showed that these components and subcomponents work closely together and can be grouped under two overarching factors, knowledge of cognition and regulation of cognition. ${ }^{3}$ Knowledge is the first of the five components and entails knowledge about one's own thinking and about thinking more broadly. However, knowledge also includes three subcomponents: person, task, and strategy. Person involves understanding one's own thought processes and the fact that others have distinct thought processes; task consists of understanding the affordances and constraints posed by a project and its circumstances; and strategy includes knowledge of the range of approaches one might effectively use to complete a project. Planning, the second of the five components, entails identifying a problem, analyzing it, and choosing a strategy to address it. Monitoring, the third, involves evaluating one's cognition and efforts toward a project. The fourth component, regulation/control, includes the choices one makes as the result of monitoring. According to Scott and Levy, such choices may be conscious or not. The final component, evaluation, entails assessing the quality of a completed project.

We made one substantial revision to Scott and Levy's (2013) terms by drawing on Harris, Graham, and Sandmel's (2009) definition of person, which is more specific to writing and so more useful for us. Harris et al. defined person as "the knowledge the writer has about themselves [sic] as a writer, including such things as what forms of writing have been engaged in successfully or unsuccessfully in the past, what components or elements of writing they're comfortable with, and which they have not yet mastered (such as using dialogue in creative writing) and what environmental characteristics are preferable" (2009, p. 134). Using this explanation, we included understanding of genres, conventions, and rhetorical and writing process strategies in our definition of person.

Further, based on our coding, we developed a metacognitive category not mentioned in Scott and Levy's (2013) or Harris et al.'s (2009) discussions, one we have named constructive metacognition, following Yancey's (1998) work on reflection. Yancey explained that by reflecting on strategies they found helpful 
in one context, writers develop principles they can use to construct prototypical models to guide their work in subsequent contexts, thus shaping their identities as writers. For Yancey, such constructive reflection results from cumulative reflections that allow the writer to apply knowledge gained in a set of prior experiences to subsequent experiences. As she noted, constructive reflection entails reflective transfer. However, she added, it also takes one "from being able to generalize across rhetorical situations to seeing oneself so generalize, seeing oneself interpret differently from one to the next and understanding that these generalizations . . exert their own cumulative effects" (Yancey, 1998, p. 51). Because asking writers to reflect explicitly on their texts promotes such seeing, she argued, it contributes to the conscious construction of a writerly identity across composing contexts. Swartz and Perkins (1990) argued that such work helps writers move from the strategic level of metacognitive thinking to the reflective level, where they use strategies not just out of habit but by consciously considering a possible strategy's appropriateness and effectiveness for a given task. Such consideration may occur before, during, and after task completion, as "through reflection, [students] can probe and assess, revise and test, their own thinking processes" (Swartz \& Perkins, 1990, p. 53). Constructive metacognition entails reflection across writing tasks and contexts, using writing and rhetorical concepts to explain choices and evaluations and to construct a writerly identity. By illustrating each subcomponent and how these subcomponents work cumulatively to promote constructive metacognition, our taxonomy lays the foundation for teaching metacognition. More specifically, we explain below how instructors can guide students in practicing individual subcomponents in a way that cultivates constructive metacognition.

Our set of coding categories, based on our augmented version of Scott and Levy's (2013) set of metacognitive terms, enables us to specify more precisely the relations among the components and subcomponents of metacognitive knowledge. The subcomponents and their definitions follow in Table 8.1.

As we illustrate below through examples of each (sub)component, the (sub)components' specificity allows us to examine in more detail the kinds of metacognitive moves that appeared in students' written and oral reflections on their texts and writing processes. This groundwork enables us to consider questions of (a) writers' metacognitive development across tasks and contexts and (b) the socially shaped nature of metacognition. Understanding this social character leads us to emphasize the importance of teaching the metacognitive (sub)components in courses that promote other transfer factors, such as student motivation, engagement, and understanding of the connections between the material students are learning and, broadly speaking, how students will use this material in subsequent contexts. 
Table 8.1. Definitions of metacognitive subcomponents identified in this study

\begin{tabular}{ll}
\hline Metacognitive Subcomponent & Definition \\
\hline Person (Knowledge of Cognition) & $\begin{array}{l}\text { Knowledge of oneself as a writer, including one's } \\
\text { (un)successful use of genres, conventions, and rhe- } \\
\text { torical and writing process strategies } \\
\text { Understanding of affordances and constraints posed } \\
\text { by a project and its circumstances }\end{array}$ \\
Strategy (Knowledge of Cognition) & $\begin{array}{l}\text { Knowledge of the range of approaches one might } \\
\text { effectively use to complete a project }\end{array}$ \\
Planning (Regulation of Cognition) & $\begin{array}{l}\text { Identifying a problem, analyzing it, and choosing a } \\
\text { strategy to address it }\end{array}$ \\
Monitoring (Regulation of Cognition) & $\begin{array}{l}\text { Evaluating one's cognition and efforts toward a project } \\
\text { The choices one makes as the result of monitoring }\end{array}$ \\
Control (Regulation of Cognition) & $\begin{array}{l}\text { Assessing the quality of a completed project } \\
\text { Evaluation (Regulation of Cognition) } \\
\text { Constructive Metacognition }\end{array}$ \\
$\begin{array}{l}\text { Reflection across writing tasks and contexts, using } \\
\text { writing and rhetorical concepts to explain choices } \\
\text { and evaluations and to construct a writerly identity }\end{array}$ \\
\hline
\end{tabular}

\section{Key Coding Distinctions}

To illustrate the metacognitive moves students described and how these moves operate in writing, we offer examples of each (sub)component we coded. Several of the types of thinking represented by these (sub)components can take either cognitive or metacognitive form, while others are inherently metacognitive. As explained above, cognition entails thinking to complete a task, while metacognition involves reflection on that thinking and its efficacy or outcomes. Task, planning, control, and strategy can all occur either as cognitive moves or as metacognitive moves, depending on whether they are used consciously or habitually and uncritically. ${ }^{4}$ In each case, a writer may describe thinking processes, such as analyzing the affordances and constraints of a writing task, without conscious awareness that she or he is engaging in such analysis. We categorize such instances as cognition rather than as metacognition, and for each type of thinking that can occur cognitively or metacognitively, we provide examples to clarify the differences. In contrast, person, monitoring, evaluation, and constructive metacognition are all inherently metacognitive. Although Scott and Levy (2013) suggested that metacognitive thinking may happen nonconsciously, we follow Georghiades' (2004) and Swartz and Perkins' (1990) emphasis on conscious metacognition, though we do include moments when students consciously reflect later on the use of thinking processes they may originally have employed nonconsciously. 
The charts below present examples of each metacognitive component or subcomponent to illustrate its role in students' rhetorical choices and writing processes, both in completing individual writing tasks and their construction (or not) of a writerly identity across tasks. In coding, we found that some instances of metacognition included significant depth and detail, so we coded these as "deep." In contrast, other instances lacked depth and detail, so we coded them as "shallow." Most instances included a middling level of detail and therefore were coded as "middling." We include samples of all three types (deep, shallow, and middling) in the charts, and we discuss the significance of deep metacognition below. To ensure clarity, we present and gloss examples of one (sub)component at a time. We note code co-occurrences in the body of the taxonomy to alert researchers and teachers to the likelihood of co-occurrences as they work with particular (sub)components.

\section{Component ANd Subcomponent EXAMPLES}

\section{Chart 8.1. "Person" metacognitive subcomponent and examples with codes}

(Meta)cognitive Subcomponent

Person: knowledge of oneself as a writer, including one's (un)successful use of genres, conventions, and rhetorical and writing process strategies

\section{Cognitive Example}

N/A

\section{Metacognitive Examples}

(Interview) New skills [I needed to learn]? Well, I'm definitely gonna have to adjust my view of the comments I received because [the instructor] made some comments that I hadn't considered, I guess. So I'll definitely have to ... And I understand that. I understand that he's not trying to get me or anything... I'm just stubborn, I suppose. . . . Yeah, I'll have to be more open to suggestions. (Middling)

(Interview) Oh, I'm really tired. All right, I'm gonna make a flow chart. I can't think in my head. (Middling)

(Interview) I like the way I form sentences ... I think they are more complex. I don't just say, "When Gregor did this ..." I was like, "Thinking this, Gregor, in a debilitated state..." That's something I'm really proud about—having cultivated my sentence structure and my use of vocabulary. I feel like my vocabulary is really colorful. . . I I feel like that's something essential to writing. . . . Especially if you have a term, I suppose. You see that term over and over again, but you need a little variety to surround it, to make it interesting, to hook your reader. (Deep) 
As these examples show, knowing oneself as a writer includes understanding one's dispositions (e.g., toward stubbornness or openness) and physiological state and its effects (e.g., tiredness), as well as one's capacities (e.g., to use a broad vocabulary or form complex sentences). The final example shows deep metacognitive understanding of self as a writer because the student articulates the importance of the skill (to hook one's reader by using a key term in varying ways). Further, knowledge of oneself as a writer often relates closely to knowledge of strategy use, as suggested by the second and third examples. We discuss this connection in more depth below.

\section{Chart 8.2. "Task" metacognitive subcomponent and examples with codes}

\section{(Meta)cognitive Subcomponent}

Task: understanding of affordances and constraints posed by a project and its circumstances

\section{Cognitive Example}

(Interview) Well, I guess throughout the whole paper, I'm personifying these creatures. . . . So I say, "Though these bodies do not appear human, they are inhabited by psyches that exhibit human-like behaviors and drives." . . . I'm just tying it back to my original point ... Which makes it definitely an essay. (Middling)

\section{Metacognitive Example}

(Interview) Student [on why a final project was assigned]: I think it was a way for us to pick a certain type of writing - a certain type of article that we thought was easy to write because ... the six different assignments were kind of all over the place. And this allowed us to kind of write where we felt most comfortable and felt we could succeed while showing [the instructor] ... what he wanted to see. (Shallow)

\section{Cognitive Example}

(Interview) So we were given . . . a narrow list of topics about five or six, um, I don't think there was a minimum or maximum page requirement just because the instructor expected us . . . it was going to be a big paper where we're going to be doing pretty intensive analysis of the topic. (Middling)

\section{Metacognitive Example}

(Interview) Student [explaining what was difficult in writing a specific paper]: Taking myself out of it. . . I It's sometimes easier to think that if you have an inside view to something, it'll be easier to write about, [and] in some aspects it did help because I did have people I could talk to . . . But at the same time, if my audience was the [university name] population, they're looking at it differently than I will. And that was hard for me to kind of grasp. (Middling) 
In the examples of cognition about a writing task, students describe the constraints of the task but not how those constraints shaped their thinking about the task or strategies for approaching it. In contrast, while the shallow example of metacognition provides little depth, it shows the writer's analysis of the task as encouraging students to choose genres or conventions used successfully in the past. The fully metacognitive example in the second excerpt reveals the writer's examination of the task's affordances and constraints (access to interviewees able to provide important information and an audience unfamiliar with the details of the topic). It also links these task aspects to the student's understanding of a writerly self. Students often made such links, as Scott and Levy's (2013) emphasis on the connections between metacognitive components and subcomponents implies they should.

\section{Chart 8.3. "Strategy" metacognitive subcomponent and examples with codes}

\section{(Meta)cognitive Subcomponent}

Strategy: knowledge of the range of approaches one might effectively use to complete a project

\section{Cognitive Example}

(Interview) Interviewer: What skills did you bring to this paper when writing? So what did you already know how to do?

Student: Start it like ... that's what I knew ... my whole writing process like I know it works for me so, like, I applied it to this and it worked. (Shallow)

\section{Metacognitive Example}

(Interview) Student [explaining what helped her or him succeed in the course]: I think [when] I was just not getting it, I talked to [the instructor] and said, "I am not a Journalism major. I do not know what I'm doing. I need help.” And I think that was when I started to realize that asking him for help and asking him to revise my papers and [show] me successful articles and how they were different from what I was writing really helped ... I worked to change how I was writing, but he definitely helped. (Middling)

\section{Cognitive Example}

(Interview) Student [explaining where she or he learned to use scholarly sources to define a term used to analyze a primary text]: I feel like appealing to a scholarly source other than my text I learned in [FYW]. Because before, I would just ... use the text that directly apply to ... You know, like I read House of Mirth and I would only use Edith Wharton, Edith Wharton, Edith Wharton. But now, I can use other people ... [I] rely more heavily on quotes now than I did in high school. Because before, I thought, "If I'm using all these quotes, I'm not doing my own work." . . . But I've definitely learned that using quotes, or that's what I've been told anyway, using quotes helps prove your point better to show that you have more support, that you've done your research. (Deep) 


\section{Metacognitive Example}

(Interview) Student [on analyzing a Dostoevsky novel]: Like, able to pick out certain parts that tie back into what [the author is] really trying to say, like the main point. ... And once you can do that, you can . . . analyze it because you can't analyze it if you don't know what he's saying or what he's talking about. So it's not the same kind of rhetorical reading that we were doing in the essays [in FYW] . . . But it's definitely applicable in [analyzing] literature. (Middling)

The second of the two examples of cognition about strategy is deep because the student explains in depth what scholarly sources achieve in the text described, while the first is shallow because the student includes little such detail. Both examples are cognitive because the descriptions suggest that students use their strategies habitually and uncritically, without respect to their fit (or lack thereof) for particular writing tasks or contexts. The first of the two metacognitive examples entails explicit reflection on specific strategies (talking with the instructor, seeking comments to use in revising, and examining models) that led to success in particular circumstances; thus, it is metacognitive. The second includes explicit reference to when the strategy described (literary analysis) is applicable and to how it contrasts with other known strategies (rhetorical analysis) and so is also metacognitive. We found a noteworthy percentage of code co-occurrences linking strategy codes with person codes. Of the 146 person codes, 47 of them $(32.2 \%)$ co-occurred with strategy, while of the 207 strategy codes, 47 (22.7\%) co-occurred with person.

\section{Chart 8.4. "Planning" metacognitive component and example with codes}

\section{(Meta)cognitive Component}

Planning: identifying a problem, analyzing it, and choosing a strategy to address it

\section{Cognitive Example}

(Interview) Student [describing an unsuccessful text]: It was not really well organized. And we had to get three quotes from three left-handed people and three quotes from three right-handed people, and I had avoided until the end to put those in. And I was just like, "Oh I'll just have them support whatever I'm saying" and see if I kind of work the quote in. And that isn't how it works and so that was not a very successful first article [laughs]. (Middling)

\section{Metacognitive Example}

(Interview) Because when I sat down to write my proposal [to do a Freudian reading of fairy tales], [the instructor] wanted terms and I was, like, "Oh, God. I can't choose one." So then I had to go back and reformulate. And I realized that with every term, there was a different connotation . . . I wanted to pick ... the term that had the most bearing, meaning for my purpose. (Middling) 
The example of cognition about planning recounts the writer's process, but because that process did not include consideration of the potential effectiveness of the approach used or of alternate approaches, we consider it cognitive. While the student's comment "that isn't how it works" implies a move toward metacognition, that move occurred subsequently, during an interview that prompted reflection, rather than during the planning process itself. But the fact that subsequent reflection prompted this move suggests that teachers can usefully encourage students to cultivate and extend such recognitions to foster metacognitive capacity, as we discuss below. Because the example of metacognitive planning includes the writer's rationale for choosing the term used (the one most relevant to the text's purpose), we consider it metacognitive.

\section{Chart 8.5. "Monitoring" metacognitive component and example with codes}

\section{(Meta)cognitive Component}

Monitoring: evaluating one's cognition and efforts toward a project

\section{Cognitive Example}

N/A

\section{Metacognitive Example}

(Interview) This year in particular ... everyone was saying there was a huge drop in numbers [of new pledges to Greek organizations]. And I was trying to focus on that. But when I . . went back into the facts, I looked at ... five years back and saw that it was the last two years that [had] an irrational spike in the numbers and it wasn't that this year dropped. ... And I think I finally, after a lot of like fine-tuning and working with [the instructor, I] was able to portray that, as opposed to just starting out by saying the numbers dropped significantly. (Middling)

This example entails the writer's monitoring of the development of a draft in relation to key source information and a resulting decision to shift the text's focus to present the source data more effectively (and more accurately). It illustrates the close relationship between monitoring and control, particularly as the latter code was also applied to this excerpt.

\section{Chart 8.6. "Control” metacognitive component and example with codes.}

\section{(Meta)cognitive Component}

Control: the choices one makes as the result of monitoring

\section{Cognitive Example}

(Reflection) Not being redundant posed a very big problem for our group as we eventually plateaued and entered a period of writer's block. We were able to 
exit this unfortunate phase by taking several days off to rest and getting second opinions on the paper. (Middling)

\section{Metacognitive Example}

(Reflection) I then located an interviewee candidate and sent her the questions. They were never answered, so I relied more heavily on the sources I had and worked to find more sources when I realized they weren't enough. I met with my professor who ... also sent an extra source my way. (Middling)

In the example of cognition about control, the student described how her or his writing group overcame writer's block but did not clarify whether students explicitly recognized the writer's block as such and consciously chose the strategies of taking time off and getting feedback on their draft, or whether the writer retrospectively realized that these strategies had solved the problem. In contrast, the example of metacognitive control ties the description of a problem (insufficient sources) to strategies consciously chosen to address the issue (mining existing sources more heavily, seeking additional sources, and asking the instructor to recommend sources). Of the 152 control codes, 47 (30.9\%) co-occurred with monitoring codes, while 47 of 164 monitoring codes (28.6\%) appearing with control codes.

\section{Chart 8.7. "Evaluation" metacognitive component and example with codes}

\section{(Meta)cognitive Component}

Evaluation: assessing the quality of a completed project

\section{Cognitive Example}

$\mathrm{N} / \mathrm{A}$

\section{Metacognitive Example}

(Interview) In this example ... I feel I do an excellent job of providing a well-focused and well-detailed analysis of Ahlstrom et al.'s work. The first example ... displays the author's rhetorical situation, "David Ahlstrom, a professor of management at the Chinese University of Hong Kong." In this sentence, I highlight that Ahlstrom has a position of authority to be speaking on the subject. Next, I highlight on a specific example that David Ahlstrom lists as being a barrier of entry into the China market, "that many of the government officials in China still have a strong Marxist economic background. The idea that venture capital can be used to control the factors of production violates one of the basic fundamentals of Marxism." With [this quotation], my readers know that Ahlstrom's purpose is to talk about specific barriers to the venture capital industry in China. (Deep) 
We coded this example as deeply metacognitive evaluation because the writer assesses the quality of a specific aspect of the text through a detailed presentation of the textual features that illustrate the achievement of one of the text's key purposes, rhetorically analyzing an academic article. This kind of depth in some cases contributes to students' development of the capacity to move from the evaluation of a particular text to a more comprehensive understanding of the achievements of multiple texts across time and writing contexts and of how these achievements relate to the writer's strategies, as well as to her or his strengths and challenges.

\section{Constructive Metacognition}

We found a surprising number of demonstrations of this more comprehensive understanding, which we call constructive metacognition. Students who displayed it reflected on their texts, strategies, and sense of writerly identity across a series of writing tasks and contexts, and they typically articulated these reflections through concepts from writing and rhetorical studies. We suggest that this form of explicit metacognitive work, which uses rhetorical terms to frame an understanding of multiple writing tasks and contexts and a writerly identity may particularly support transfer. While metacognition is only one factor in promoting transfer, we believe that its efficacy is augmented when teachers link practice in working with metacognitive subcomponents to other transfer factors. Given that constructive metacognition emerges from students' integration of other metacognitive (sub)components, we understand its development as a cumulative process.

\section{Chart 8.8. "Constructive metacognition" metacognitive component and example with codes}

\section{(Meta)cognitive Component}

Constructive Metacognition: reflection across writing tasks and contexts, using writing and rhetorical concepts to explain choices and evaluations and to construct a writerly identity.

\section{Cognitive Example}

N/A

\section{Metacognitive Examples}

(Reflection) Before my first semester of college English, I had never given much, if any, thought to answering a "so-what" question in my essays. I knew that [I needed] a topic to provide an argument for and subconsciously knew 
that the topic should be important enough to catch the reader's interest, but I never realized the overall significance of the so-what question until [FYW]. In the beginning, I had difficulty providing reasons and discussions for why a person should be interested in my topic of choice.... Nevertheless, by examining my own curiosities within a given subject and finding gaps in between already known information, I became better at forming so-what questions. When I initially wrote my third paper, "Writing in Psychology: How Format Helps to Obtain Maximum Understanding," I knew that I wanted to have my paper concentrate on how the APA format benefitted a psychologist's writings (1). However, I understood that most people would not care about how the format helped a psychologist to write. So after further surveying my own interest ... I discovered that I was invested in the format psychologists used because I understood that it should be beneficial in helping to [achieve] goals. I knew this so-what question would [garner] more attention because a psychologist's goal is to find solutions for problems, and just as people would want to know if a surgeon failed his MCATs, they would want to know if a flaw in a psychologist's writing could prohibit their goal from being accomplished. Although I am not perfect at coming up with so-what questions ... I have developed and used the devices needed to produce a so-what question. (Deep)

(Reflection) In the past, when I . . f faced . . . a new writing situation, I would typically try to acquire samples of texts similar to that which I was expected to produce, and then perform a rudimentary rhetorical analysis on them. If I was still unsure how to proceed, I would try to find someone familiar with the writing situation willing to divulge as much information as possible about it, and possibly even produce a quick sample for me. I have often used this technique for college writing, and it was especially helpful during my previous profession (military communications). Of course, most of the work was cognitive, with very little writing beyond the production of the required text. However, the heuristic developed during this course - performing a rhetorical analysis, interviewing an expert, and conducting an ethnographic observation, then examining the data for characteristics of writing expertise-provides me with a far more useful tool for approaching new writing situations than my previous informal methods. Indeed, my strategy for undertaking new writing situations has changed considerably since the beginning of this course, when I thought that "using basic writing skills and critical analysis, one should be able to approach any new discourse [community] confidently." If each new writing situation does in fact require me to build on my existing knowledge of writing, I am certain that the progress I made toward [using reflection to improve writing strategies] has equipped me with a much more organized, simple, and practical approach for success in any new writing situation. (Deep)

As these examples of constructive metacognition suggest, this category unites most of the other metacognitive components and subcomponents. We coded 35 
instances of constructive metacognition. Of those, 10 (28.6\%) co-occurred with strategy codes and seven (20\%) with person codes. While other co-occurrences are lower, they do appear: control and monitoring, four (11\%); evaluation, three (8.5\%); and task/future task, two (5.7\%). In these examples, both writers depict their conscious analyses of tasks, use of thinking strategies during tasks, monitoring of these strategies and of task progress, and conscious control of their strategies based on monitoring and evaluation. Further, they describe consciously considering the cumulative implications of such analyses, the resulting shifts in their writerly identities, and the potential for knowledge transfer to future writing contexts. While the first student may still occasionally struggle to demonstrate the significance of a thesis, she or he has recognized the need to do so and developed strategies for pursuing the task in various writing situations. The second student shifted from using informal strategies tacitly to using more elaborated strategies consciously and from seeing all writing situations as similar to recognizing that writing tasks change with contexts. Both examples show Yancey's (1998) constructive reflection because the students shaped writing identities by reflecting on various composing experiences. But they also reveal constructive metacognition because they discuss thinking strategies in terms of writing and rhetorical concepts to produce adaptable principles for approaching new writing situations. They show two features of constructive metacognition: the integration of metacognitive components and their articulation with writing and rhetorical concepts to shape a writerly identity.

Further, reflection seems to promote constructive metacognition. Five of the eight students whose reflections we coded displayed instances of constructive metacognition (two of those five students' writing scores declined over time and three improved). These students were relatively evenly distributed across institutions. Two came from one institution, two from a second, and one from a third. Only one participating institution did not have students who showed instances of constructive metacognition, and this lack may result from the small number of students whose data we coded for this portion of our study. The integrative nature of constructive metacognition and its clear connections to the factors of transfer indicated by prior scholarship—such as genre awareness, understanding versus rote memorization of procedures, monitoring of one's learning experience, and abstraction of principles_-suggest its potential importance for understanding how successful transfer of writing-related knowledge and skills unfolds when it occurs (National Research Council, 2000; Reiff \& Bawarshi, 2011; Rounsaville et al., 2008). The prevalence of this metacognitive move in our small sample suggests that it can be encouraged through curricula and pedagogies that use reflective assignments and other strategies that prompt students to practice using metacognitive (sub)components. 
Learning how metacognitive representations connect to writing performance is crucial, and while our analysis is limited due to our study's primarily qualitative nature, some interesting trends emerge. We coded 33 instances of evaluation in reflections from the four students whose scores increased from the final paper in the initial course to the paper in the subsequent course (improving writers), while we coded only 17 instances in reflections from students whose scores decreased (declining writers). Similarly, we found 15 instances of planning among improving writers but only eight among declining writers. Improving writers had 13 deep codes, while declining writers had only five. Conversely, improving writers focused less on task, at 23 instances, than did declining writers, at 35. Interestingly, both groups had higher numbers of person codes than of any other code except strategy, 64 for improving writers and 54 for declining writers. Both groups gave the same level of attention to monitoring ( 28 codes) and to strategy (75). These numbers may suggest that metacognitive (sub)components like evaluation and planning play a particularly important role in transfer, while others like monitoring and strategy may contribute to transfer more effectively when linked to other codes, such as control and person. Improving and declining writers displayed nearly identical instances of constructive metacognition (six versus seven). Given the findings of prior research on the role of metacognition in transfer and the fact that constructive metacognition integrates other metacognitive (sub)components, we suspect that these proportions may indicate that declining writers used several metacognitive (sub)components but had not effectively integrated key components like evaluation and planning. Research on a larger dataset is needed to investigate the potential role of constructive metacognition in transfer and the relations among the metacognitive (sub)components. Nonetheless, our findings suggest both important pairings (person and strategy, monitoring and control) and key components (evaluation and planning), as well as the role of these pairings and components in writers' development of constructive metacognition.

Our examples suggest that teachers might most effectively promote constructive metacognition by helping students move toward specificity, depth, and abstraction in their reflections. More specifically, by guiding students to reflect on their cognitive processes, teachers may help students to explicitly recognize cognitive strategies they had previously used tacitly and to make conscious choices about task analysis, planning, and the selection, monitoring, and control of strategies. Similarly, by prompting students to reflect on the implications of such efforts and on their uses of reflection across writing tasks and contexts, teachers may help students to develop an explicit writerly identity based in the use of adaptable strategies tailored to specific contexts and rhetorical situations. In doing so, teachers might foster transfer by pro- 
moting the consciously reflective metacognition Swartz and Perkins (1990) advocated.

\section{A Potential Barrier to Developing Constructive Metacognition}

One theme we encountered during coding reveals potential roadblocks in students' development of constructive metacognition. As prior research (Larkin, 2009) has suggested, affect may play an important role in encouraging or discouraging students' use of metacognitive (sub)components. We found a small handful of examples in which negative affect appeared to impede metacognition. In one, a student discussed at length the desire to use writing to explore a topic, rather than to make an argument, and a resulting succession of poor or failing grades on argument papers. Despite repeated feedback from instructors on the issue, the student said, "I never know that [the lack of an argument] is a problem ... until someone tells me it is. .. . The one thing that happens in academic writing that either I don't agree with or it's hard for me to, like, wrap my head around is that writing always has to argue something." This student seems unable to reflect usefully on individual writing experiences and the connections across such experiences due to an antipathy toward a crucial requirement of most academic genres.

In a second case, a student who made many extensive metacognitive moves in the final FYW reflection, including constructive metacognition, showed minimal metacognitive awareness in an interview conducted after she or he had taken a subsequent writing course. The interview responses revealed that the student did not grasp the cumulative nature of the two courses and that he or she actively rejected a writerly identity. (The student denied having a writerly identity in response to a question about what type of writerly identity fit best.) These responses showed that the student felt deeply demoralized after the second course. The role of affect in this process was suggested by comments such as, "Last semester tore me apart; my [confidence was] shot down" and "I just felt like I kept failing," in context of a claim that revision did not seem to address the problems, based on the student's reading of instructor comments on revised drafts. As this example implies, metacognitive awareness alone does not guarantee transfer. Larkin's (2009) study of social metacognition in young writers found that writing pairs with a competitive orientation had higher levels of negative affect and lower levels of metacognition, while pairs with a collaborative orientation had a calmer affect and higher levels of metacognition. Both Larkin's findings and ours suggest that instruction in metacognition may best support transfer when integrated into curricula and pedagogies that promote other transfer factors, particularly affective factors such as motivation and self-efficacy (Latawiec, 2016). 


\section{CULTIVATING CONSTRUCTIVE METACOGNITION: IMPLICATIONS FOR TEACHERS, WRITING PROGRAM ADMINISTRATORS, AND RESEARCHERS}

Our taxonomy reveals how specific metacognitive components and subcomponents operate and intersect in writing. The intersections among metacognitive components and their integration with writing and rhetorical concepts led us to propose the concept of constructive metacognition. Because our analysis suggests that it occurs relatively often when students respond to reflective prompts designed to elicit descriptions of how they used metacognitive (sub)components and rhetorical knowledge, this analysis suggests that writing instructors can design curricula and pedagogies that promote constructive metacognition. By opening Nowacek's (2011) black box of metacognition, our taxonomy provides a basis for teaching metacognitive (sub)components cumulatively, to cultivate constructive metacognition. Further, it provides tools for designing professional development and assessment approaches pitched to help instructors devise curricula and pedagogies that support students' metacognitive development and that integrate such efforts into instruction that promotes other transfer factors as well. We illustrate below how the taxonomy can be used to further such endeavors and briefly note its relevance for future research that could provide additional insights into how to teach metacognitive (sub)components in ways that foster students' writing development.

\section{IMPLICATIONS FOR TEACHERS}

With a deeper understanding of the metacognitive (sub)components students use as they learn to write and reflect on their writing experiences, we can develop pedagogies that encourage metacognitive development. As noted above, constructive metacognition integrates metacognitive (sub)components with each other and with writing knowledge and is linked to transfer factors identified by prior scholarship. Thus, it may promote transfer. Using our taxonomy, we propose three potential implications for fostering it by cultivating metacognitive development.

First, to structure metacognitive practice into curricula, instructors might model and elicit the metacognitive moves described in our taxonomy and design prompts that ask students to undertake these moves - for example, by showing students how instructors routinely examine their own drafts to ensure that the points of an argument support a working thesis (monitoring) and revising to better fit points to thesis (control), as well as by developing prompts that ask students to discuss their metacognitive knowledge of person, task, and strategy; 
or prompts that ask them to reflect on moments of difficulty producing texts (monitoring) and how they overcame these difficulties (control). These prompts might include both reflective writing and the use of brief think-aloud protocols combined with screen capture technology to help students articulate the moves they are making — and why_ as they write (see Blythe, this volume). Students should engage in this practice both as they compose individual texts and as they consider their writing development across a semester by examining their work on a series of texts. Examining examples from the taxonomy should help instructors design such prompts, and integrating them into writing curricula may promote students' development of metacognitive skills. Using the taxonomy, we've developed and are piloting a module that engages students in such practice by asking students to enact and represent specific metacognitive activities linked to each (sub)component. For instance, to introduce students to monitoring, the module asks them to read a short text; identify, summarize, apply, and/ or respond to key concepts in that text; and to recognize the reading strategies they're using, analyze the efficacy of those strategies in helping them to draft the assigned text, and consider which of those strategies are serving their goals and which could be improved to better enable them to fulfill the writing assignment.

Second, metacognitive moves are linked to each other, and practicing them appears to contribute cumulatively to the development of constructive metacognition. For example, an increasing understanding of person, that is, of one's strengths and challenges as they unfold across writing tasks, seems to help students develop more sophisticated strategies and more effective monitoring and control (see the constructive metacognition examples and discussion above). Thus, instructors might usefully ask students to begin with individual metacognitive moves and then to link these moves to one another and to an evolving understanding of their writerly identities as students draft and evaluate their texts. Our metacognition module promotes this work by prompting students to practice identifying and assessing their strengths and challenges in particular aspects of writing at the beginning of the term; to assess growth in these strength and challenge areas after practicing the use of several metacognitive (sub)components; and finally to consider the implications for their progress as writers after the use of all metacognitive (sub)components. We believe that building such practice cumulatively into writing curricula may promote transfer by encouraging constructive metacognition, and we argue that practicing activities that build metacognitive competence can intersect productively with other transfer factors, such as efforts to promote positive dispositions toward writing self-efficacy and to integrate transfer cues into writing curricula.

Third, our findings suggest that metacognitive moves in writing appear to rely on knowledge of writing processes and concepts. Thus, we should link in- 
struction in metacognitive moves to the teaching of key writing studies concepts, particularly genre, rhetorical situation, and the use of the writing process. Recent course designs, such as Wardle and Down's 2011 writing-about-writing approach (as cited in Beaufort, 2012), Beaufort's (2007) course outline in College Writing and Beyond, and the curriculum outlined in Yancey, Robertson, and Taczak's (2014) Writing Across Contexts: Transfer, Composition, and Sites of Writing, have made similar connections between learning to write, the mastery of writing studies concepts, and metacognitive development to promote writing transfer. For Wardle and Downs, accomplishing these interconnected objectives requires students to do the following:

Broaden their conceptions of what writing is and how it is done, think explicitly about the affordances and constraints for the writing they face, see themselves as writers, understand the contributive and conversational nature of both reading and writing, and understand writing rhetorically. (as cited in Beaufort, 2012, "Second Consideration," para. 4)

Fostering students' understanding of writing studies concepts as a language for critically examining their writing practices can increase metacognitive awareness and flexibility, particularly in new writing contexts. Instructors might fruitfully link such efforts to other means of promoting transfer. For example, by encouraging students to investigate where and how they'll be asked to write in their intended majors and/or professions, instructors can encourage transfer in two additional ways. The first entails fostering engagement and motivation because, as Bergmann and Zepernick (2007) show, many students are focused on disciplinary courses and professional preparation. The second involves helping students understand how the concepts and skills they're developing in general education writing courses are preparing them to succeed in future contexts, a form of cueing that promotes transfer (National Research Council, 2000). Because our taxonomy offers a more detailed view of how metacognitive components operate in writing, it can both help teachers guide students in developing metacognitive competence in writing and serve as a springboard for linking such instruction to other efforts to support transfer.

\section{Implications for Writing Program Administrators}

Writing Program Administrators (WPAs) can help instructors to develop curricula and pedagogies to foster metacognition by drawing on our taxonomy in professional development and assessment programs. In designing professional development approaches, WPAs can use the taxonomy to help instructors learn 
to recognize metacognitive subcomponents and to draft reflective and other assignments that ask students to practice activities associated with subcomponents like analyzing writing tasks in relation to the student's prior knowledge in order to identify knowledge and skills the student must increase to complete the assignment successfully. Such efforts should educate instructors about how metacognitive (sub)components relate to each other and support writing development. For example, our metacognition module guides students through practicing (sub)components so that they build on one another, moving from knowledge of person to knowledge of task and strategies to knowledge of monitoring and control. Further, WPAs should help instructors to link work with metacognitive (sub)components to other pedagogical approaches that promote transfer, including efforts to prompt motivation and engagement.

Finally, WPAs should use the taxonomy to develop assessment methods for learning which metacognitive (sub)components particular curricula and pedagogies help students to master, if any, and how effectively such curricula and pedagogies promote cumulative development across (sub)components. Our metacognitive module illustrates reflective assignments intended to elicit practice using particular (sub)components in a way that builds toward constructive metacognition and incorporates assessments of students' developing metacognitive capacities.

\section{IMPLICATIONS FOR RESEARCHERS}

To help teachers to foreground and build more effectively on students' existing metacognitive capacities, further research should investigate more fully what metacognitive moves students are already making. We suggest this focus in part because we believe that students engaged in metacognitive thinking far more often than was represented in their reflective writing and interview data. For example, in the case of monitoring, we saw a difference between representations of monitoring and actual monitoring. We saw the outcome of monitoring behavior, where a student exhibited a behavioral change but did not describe the process that led to that change. ${ }^{5}$ As a result, we know some monitoring happened but was not represented in students' descriptions. This lack reveals a limitation of asking students to reflect after the fact, either through a writing process reflection or through an interview.

However, a more fruitful approach for both future research and instruction in metacognitive moves tailored to writing emerged through our study. At one site, a researcher did extended interviews that included a think-aloud protocol in which students discussed a current writing assignment. We included two of these protocols in our sample, and in coding them, we found a wider range 
of metacognitive moves—especially planning, monitoring, and control—than we saw in other interviews and reflections. The need to capture data on metacognition during the process of task completion is emphasized by Georghiades (2004):

In order to measure "knowing about knowing" "more accurately" it has been suggested (Ericsson \& Simon, 1980; Garner \& Alexander, 1989) that researchers should use multiple methods that do not share the same source of error. Garner and Alexander proposed three ways of finding out what children know about their cognitions: (a) asking them, (b) having them think aloud while performing a task, and (c) asking them to teach a younger child a good solution for a problem. (1989, p. 374)

Similarly, we suggest that asking students questions as they write (through think-aloud protocols) or asking them to record their writing processes can help us understand students' use of metacognitive components, much as Nowacek (2013) argued in saying that researchers should investigate students' composing processes by studying writing center tutoring sessions. The metacognition module we've developed uses this approach.

Finally, to better understand students' existing metacognitive moves, additional research on code co-occurrence is also needed. We noted co-occurrence in our taxonomy, and learning which metacognitive subcomponents appear to be linked even without instruction could support the design of pedagogies likely to promote metacognition.

\section{CONCLUSION}

By showing how metacognitive components operate in writing, our taxonomy clarifies metacognition's role in writing development and provides an important tool for helping students to cultivate metacognitive capacities that support writing development. Our findings on constructive metacognition reinforce Scott and Levy's (2013) stress on the relationships among metacognitive components. They suggest that metacognitive capacities develop cumulatively and support the growth of a conscious writerly identity, potentially promoting writing knowledge transfer. By developing curricula and pedagogies that engage students in practicing activities associated with each (sub)component, instructors can shift students away from the teacher-pleasing often associated with reflective assignments and into concrete discussions of specific metacognitive moves. By sequencing such practice to help students extend their work with (sub)components like person 
and task, instructors may facilitate students' mastery of (sub)components like monitoring and control. By incorporating prompts asking for evidence-based accounts of changes in students' capacities to use particular (sub)components and the impact of such changes on students' writing performance, instructors can guide students toward developing constructive metacognition. Finally, by situating such efforts in curricula that promote other transfer factors, like motivation, engagement, and writing self-efficacy, instructors can embed instruction in metacognition into a holistic effort to encourage writing transfer.

\section{NOTES}

1. We understand metacognitive moves and metacognitive (sub)components as related, but distinct, terms. As we discuss below, metacognitive (sub)components name specific metacognitive processes. Representations of these processes appear as metacognitive moves in students' reflective writing and interview responses.

2. While Scott and Levy (2013) did not address all of the terms psychology researchers have used to discuss metacognition, their set included those most used by prior researchers. Although the terms declarative, procedural, and conditional knowledge described by Schraw (1998) were not explicitly listed, Scott and Levy's categories of knowledge and evaluation implicitly involved declarative and conditional knowledge, while their categories of planning, monitoring, regulation/control, and evaluation implicitly included procedural and conditional knowledge.

3. Scott and Levy's (2013) study showed that these five components can be measured through an instrument that gauges two factors, knowledge and regulation/control, and it acknowledged the importance of all components.

4. For the sake of brevity, we refer to Scott and Levy's (2013) regulation/control as "control" throughout the rest of our text.

5. Note: We coded these moves as "control" even when we could not see the monitoring associated with those changes.

\section{REFERENCES}

Akyol, Z. \& Garrison, D. R. (2011). Assessing metacognition in an online community of inquiry. Internet and Higher Education, 14(3), 183-190.

Anson, C. M. (2000). Talking about writing: A classroom-based study of students' reflections on their drafts. In J. B. Smith \& K. B. Yancey (Eds.), Self-assessment and development in writing: A collaborative inquiry (pp. 59-74). Cresskill, NJ: Hampton Press.

Beaufort, A. (2007). College writing and beyond: A new framework for university writing instruction. Logan, UT: Utah State University Press.

Beaufort, A. (2012). College writing and beyond: Five years later. Composition Forum, 26. Retrieved from http://compositionforum.com/issue/26/college-writing-beyond.php. 
Bergmann, L. S. \& Zepernick, J. (2007). Disciplinarity and transfer: Students' perceptions of learning to write. WPA: Writing Program Administration, 31(1-2), 124-149.

Creswell, J. W. (2002). Research design: Qualitative, quantitative, and mixed methods approaches (2nd ed.). Thousand Oaks, CA: Sage.

Cross, D. R. \& Paris, S. G. (1988). Developmental and instructional analyses of children's metacognition and reading comprehension. Journal of Educational Psychology, $80(2), 131-142$.

Council of Writing Program Administrators, National Council of Teachers of English \& National Writing Project. (2011). Framework for success in postsecondary writing. Retrieved from http://wpacouncil.org/files/framework-for-success-postsecondary -writing.pdf.

Dignath, C. \& Buttner, G. (2008). Components of fostering self-regulated learning among students. A meta-analysis on intervention studies at primary and secondary school level. Metacognition and Learning, 3, 231-264.

Driscoll, D. L. (2011). Connected, disconnected, or uncertain: Student attitudes about future writing contexts and perceptions of transfer from first-year writing to the disciplines. Across the Disciplines, 8(2). Retrieved from http://wac.colostate.edu/atd /articles/driscoll2011/index.cfm.

Efklides, A. (2008). Metacognition: Defining its facets and levels of functioning in relation to self-regulation and co-regulation. European Psychologist, 13(4), 277-287. doi: 10.1027/1016-9040.13.4.277.

Elon Statement on Writing Transfer. (2015). Retrieved from http://www.centerfor engagedlearning.org/elon-statement-on-writing-transfer/.

Ericsson, K. \& Simon, H. A. (1980). Verbal reports as data. Psychological Review, 87, 215-251.

Flower, L. \& Hayes, J. R. (1981). A cognitive process theory of writing. College Composition and Communication, 32(4), 365-387.

Garner, R. \& Alexander, P. A. (1989). Metacognition: Answered and unanswered questions. Educational Psychologist, 24(2), 143-158.

Georghiades, P. (2004). From the general to the situated: Three decades of metacognition. International Journal of Science Education, 26(3), 365-383.

Garrison, D. R. \& Akyol, Z. (2013). Toward the development of a metacognition construct for communities of inquiry. The Internet and Higher Education, 17, 84-89.

Hacker, D. J. (1998). Definitions and empirical foundations. In D. J. Hacker, J. Dunlosky \& A. C. Graesser (Eds.), Metacognition in educational theory and practice (pp. 1-23). Mahwah, NJ: Erlbaum.

Haller, E. P., Child, D. A. \& Walberg, H. J. (1988). Can comprehension be taught? A quantitative synthesis of metacognitive studies. Educational Researcher, 17(9), 5-8.

Harris, K., Graham, S. \& Sandmel, K. (2009). Metacognition and children's writing. In D. J. Hacker, J. Dunlosky \& A. C. Graesser (Eds.), Handbook of metacognition in education (pp. 131-153). New York: Routledge.

Harris, K. R., Alexander, P. \& Graham, S. (2008). Michael Pressley's contributions to the history and future of strategy research. Educational Psychology, 43, 86-96. 
Jacobse, A. E. \& Harskamp, E. G. (2012). Toward efficient measurement of metacognition in mathematical problem solving. Metacognition Learning, 7, 133-149.

Larkin, S. (2009). Socially mediated metacognition and learning to write. Thinking Skills and Creativity, 4, 149-159.

Latawiec, A. M. (2016). Self-directed learning and the development of self-efficacy and motivation in basic writing. (Unpublished doctoral dissertation). Wayne State University, Detroit, MI.

Lobato, J. (2003). How design experiments can inform a rethinking of transfer and vice versa. Educational Researcher, 32(1), 17-20.

Lobato, J. (2012). The actor-oriented transfer perspective and its contributions to educational research and practice. Educational Psychologist, 47(3), 232-247.

McKeown, M. G. \& Beck, I. L. (2009). The role of metacognition in understanding and supporting reading comprehension. In D. J. Hacker, J. Dunlosky \& A. C. Graesser (Eds.), Handbook of metacognition in education (pp. 7-25). New York: Routledge.

Mevarech, Z. R. \& Kramarski, B. (2003). The effects of metacognitive training versus worked-out examples on students' mathematical reasoning. British Journal of Educational Psychology, 73, 449-471.

National Research Council. (2000). How people learn: Brain, mind, experience, and school. Washington, DC: National Academy Press.

Negretti, R. (2012). Metacognition in student academic writing: A longitudinal study of metacognitive awareness and its relation to task perception, self-regulation, and evaluation performance. Written Communication, 29(2), 142-179.

Nelms, G. \& Dively, R. L. (2007). Perceived roadblocks to transferring knowledge from first-year composition to writing intensive major courses: A pilot study. WPA: Writing Program Administration, 31(1-2), 214-240.

Nowacek, R. (2011). Agents of integration: Understanding transfer as a rhetorical act. Carbondale, IL: Southern Illinois University Press.

Nowacek, R. (2013, March). Transfer as bricolage: Assembling genre knowledge across contexts. Paper presented at the meeting of Conference on College Composition and Communication, Las Vegas, NV.

Perkins, D. N. \& Salomon, G. (1989). Are cognitive skills context-bound? Educational Researcher, 18(1), 16-25.

Perkins, D. N. \& Salomon, G. (1998). Teaching for transfer. Educational Leadership, 46(1), 22-32.

Reiff, M. J. \& Bawarshi, A. (2011). Tracing discursive resources: How students use prior genre knowledge to negotiate new writing contexts in first-year composition. Written Communication, 28(3), 312-337.

Rounsaville, A., Goldberg, R. \& Bawarshi, A. (2008). From incomes to outcomes: FYW students' prior genre knowledge, meta-cognition, and the question of transfer. WPA: Writing Program Administration, 32(1-2), 97-112.

Rubin, H. \& Rubin, I. (2005). Qualitative interviewing: The art of hearing data (2nd ed.). Thousand Oaks, CA: Sage.

Schraw, G. (1998). Promoting general metacognitive awareness. Instructional Science, 26, 113-125. 
Scott, B. M. \& Levy, M. G. (2013). Metacognition: Examining the components of a fuzzy concept. Educational Research, 2(2), 120-131.

Smagorinsky, P. (2008). The method section as conceptual epicenter in constructing social science research reports. Written Communication, 25(3), 389-411. doi: 10.1177/0741088308317815.

Swartz, R. \& Perkins, D. (1990). Teaching thinking: Issues \& approaches. Pacific Grove, CA: Critical Thinking Press \& Software.

Taczak, K. (2011). Connecting the dots: Does reflection foster transfer? (Unpublished doctoral dissertation). Florida State University, Tallahassee, FL.

Thiede, K. W., Griffin, T. D., Wiley, J. \& Redford, J. S. (2009). Metacognitive monitoring during and after reading. In D. J. Hacker, J. Dunlosky \& A. C. Graesser (Eds.), Handbook of metacognition in education (pp. 131-153). New York: Routledge.

Wardle, E. (2007). Understanding "transfer" from FYC: Preliminary results of a longitudinal study. WPA: Writing Program Administration, 31(1-2), 65-85.

Wardle, E. (2009). "Mutt genres" and the goal of FYC: Can we help students write the genres of the university? College Composition and Communication, 60(4), 765-789.

White, B., Frederiksen, J. \& Collins, A. (2009). The interplay of scientific inquiry and metacognition. In D. J. Hacker, J. Dunlosky \& A. C. Graesser (Eds.), Handbook of metacognition in education (pp. 175-205). New York: Routledge.

Williams, J. P \& Atkins, J. G. (2009). The role of metacognition in the teaching of reading comprehension to primary students. In D. J. Hacker, J. Dunlosky \& A. C. Graesser (Eds.), Handbook of metacognition in education (pp. 26-44). New York: Routledge.

Yancey, K. B. (1998). Reflection in the writing classroom. Logan, UT: Utah State University Press.

Yancey, K. B., Robertson, L. \& Taczak, K. (2014). Writing across contexts: Transfer, composition, and sites of writing. Logan, UT: Utah State University Press. 
CHAPTER 9

STUDENTS' PERCEPTIONS OF

THE TRANSFER OF RHETORICAL

KNOWLEDGE BETWEEN DIGITAL

SELF-SPONSORED WRITING

AND ACADEMIC WRITING: THE

IMPORTANCE OF AUTHENTIC

CONTEXTS AND REFLECTION

\section{Paula Rosinski}

We know that students engage in more self-sponsored kinds of digital writing - such as texting, emailing, and writing Facebook status updates or twitter posts-than ever before (Grabill et al., 2010; Lenhart, 2012; Lenhart, Arafeh, Smith \& Macgill, 2008; Madden, Lenhart, Duggan, Cortesi \& Gasser, 2013; Purcell, Buchanan \& Friedrich, 2013; Stanford Study of Writing, n.d.; Yancey, 2009). With the increase in this kind of student writing, there has also come an increase in speculation about whether or not digital self-sponsored writing contributes to the decline of students' academic writing abilities (Finley, 2014; McWhorter, 2013). Potentially, many people—such as parents, teachers, students, and employers-have a stake in determining whether any kind of transfer occurs between the self-sponsored digital writing and academic writing of students. While the more common knee-jerk reaction seems to be assuming that self-sponsored digital writing negatively affects more formal kinds of academic or even professional writing, it is possible that the reverse occurs as well, that the self-sponsored digital writing that students engage in so frequently might have a positive effect, or could have a positive effect, on their academic writing. The Elon Statement on Writing Transfer recognizes this possibility in its call for additional research into the in-development working principle that "the transfer of rhetorical knowledge and strategies between self-sponsored and academic writing can be encouraged by designing academic writing opportunities with authentic audiences and purposes and by asking students to engage in metacognition" (2015, p. 6; Appendix A). 
While there is a rich body of research exploring the complex interaction between different discursive practices of students, much of this research is not about digital self-sponsored writing specifically (Roozen, 2008, 2009a, 2009b) or deliberately interested in self-sponsored writing (Herrington \& Curtis, 2000; McCarthy, 1987; Sternglass, 1997). Many of the Pew Research Internet Projects have provided valuable insight into the use of digital tools by teenagers and high schoolers, as well as their attitudes - and those of their parents' and teachers' - toward these tools. The studies have not, however, specifically studied whether or not any kind of writing or rhetorical knowledge transfers between self-sponsored digital writing and academic writing. For example, Purcell, Buchanan, and Friedrich's "The Impact of Digital Tools on Student Writing and How Writing is Taught in Schools" concludes that digital technologies help students improve their "personal expression and creativity, broadening the audience for their written material, and encouraging teens to write more" (2013, p. 1 ) in new formats, and also warns about the danger of the "creep' of informal style into formal writing assignments" (2013, p. 1), but it does not make claims about the kinds of rhetorical knowledge students might transfer between the two different kinds of writing.

There also exists a fair amount of personal anecdote surrounding this topic. For example, the lore includes conversations about banning laptops and cell phones from writing classrooms because the writing that occurs with these technologies is assumed to be disruptive or destructive. Popular media accounts often focus on how newer ways of writing, or social media forms of communication, are destroying students' abilities to write complete sentences (Hansen, 2013; Maples, 2009; Singleton-Rickman, 2009). These kinds of discussions assume that transfer (although they do not use this term) occurs- with a negative effect-between students' self-sponsored digital and academic writing. Further, they play into claims made regularly over the years about the dramatic demise of students' writing abilities.

Scholars like Yancey $(1998,2009)$ and Lunsford (n.d.) have argued that we need more research into the actual digital writing activities of students in order to better understand the kinds of writing knowledge they acquire on their own, so that we can design updated pedagogies that actually take into account the range of student writing experiences. Lunsford says:

If we look beyond the hand-wringing about young people and literacy today, beyond the view that paints them as either brain-damaged by technology or as cogs in the latest race to the top, we will see that the changes brought about by the digital revolution are just that: changes. These changes alter 
the very grounds of literacy as the definition, nature, and scope of writing are all shifting away from the consumption of discourse to its production across a wide range of genre and media . . . away from a single static standard of correctness to a situated understanding of audience and context and purpose for writing. Luckily, young people are changing as well, moving swiftly to join in this expanded culture of writing (n.d., p. 3)

The emphasis on a shift from singular correctness to "situated understanding of audience and context and purpose for writing" is especially significant when considering that students' digital conversations constantly shift across media as well as audience, context, and purpose. Lunsford concludes that "what students need in facing these challenges is not derision or dismissal but solid and informed instruction. And that's where the real problem may lie- not with student semi-literacy but with that of their teachers" (Lunsford, n.d., p. 3). I extend this even further and argue that any such "solid and informed instruction" must be informed by evidence of whether students transfer rhetorical ideas and strategies between their digital self-sponsored writing and their academic writing; otherwise, any writing instruction is in danger of being obsolete and failing to address the kinds of knowledge students arrive in our classrooms already having developed as a result of their very active digital writing lives.

As a way to collect data-based evidence that could speak to the kinds of concerns raised by technology-alarmists, as well as the scholars like Yancey and Lunsford calling for more research, this study asks the following questions:

1. Do students transfer rhetorical strategies (audience analysis; kairotic understanding; genre and delivery choices) between digital self-sponsored and academic writing?

2. Does asking students to engage in reflection about the rhetorical strategies used in both kinds of writing increase their ability to transfer such knowledge?

This study uses the term self-sponsored writing in line with the way scholars such as Yancey $(1998,2009)$ and Roozen $(2008,2009$ a, 2009b) have used the term, to mean writing that students choose to do (and are not required to do) and that students are not officially taught to write in academic or educational settings. This definition of self-sponsored is not limited to writing that students do only for themselves; rather, it includes writing they do for other people and real audiences. In all cases, students do this writing because they choose to do it, not because they have been assigned in a school or professional context to do 
it. Often, students engage in a kind of self-directed apprenticeship as they become more skilled in writing in these self-sponsored ways (Yancey, 2009). While self-sponsored writing refers to both digital writing, such as text messaging and Twitter posts, and paper-based writing, such as poetry written in notebooks and reminders written on sticky notes, this study focuses on the digital, and especially social media types, of self-sponsored writing.

\section{WHAT WE KNOW ABOUT STUDENTS' SELF- SPONSORED WRITING LIVES}

\section{The Variety of Students' Writing Lives and Self-Sponsored Writing}

The writing lives of students - their entire writing lives, not just their academic writing lives-deserve further attention. Yancey's (2009) and Mueller's (2009) work have found that while students are writing more self-sponsored and digital writing than ever before, the nature of how this writing is produced has changed and traditional writing pedagogies may not apply; academia as a whole and writing studies in particular have not adequately studied or responded to these changes. Yancey focuses on the need to study the entire writing lives of students, especially the new writing processes that students develop on their own outside of school, as a way to reinvent writing pedagogy in classrooms before it becomes entirely out of date and out of step with the rich writerly knowledge students bring to school as a result of their self-sponsored writing apprenticeships. Mueller emphasizes that the self-sponsored digital writing of students creates a kind of digital underlife (a concept adapted for composition and rhetoric by Brooke, 1987, from the sociologist Goffman, 1961, 1963)_which refers to those digital activities that students engage in outside of the classroom as a way to assert their identities and that are criticized for diverting student attention away from teacher-assigned tasks. He asserts that these digital activities are often a rich part of students' writing lives, even though he resists the idea that this kind of writing should be integrated into the classroom, lest its power be undermined.

Roozen's (2009a, 2009b) longitudinal and case-based research, which examines different kinds of self-sponsored student writing such as poetry and stand-up comedy, has found that there is significant interplay between the extracurricular and academic literate lives of students (2008, 2009a, 2009b). He says that "our sense of ourselves as literate persons is forged in the interplay of multiple encounters with literacy, private as well as public, and how authoring a literate life means engaging in the ongoing work of reconciling the conflicts and synergies among them" (Roozen, 2009b, p. 541). While Roozen's distinction 
between private and public literate activities does not perfectly parallel self-sponsored and academic writing, it does point out that students are part of multiple literate activity systems that are in conflict and require reconciliation to achieve an identity as a literate person.

Researchers conducting collaborative studies across multiple secondary institutions have repeatedly found that students are writing more self-sponsored writing, including digital forms, than ever before, with a greater variety of media and with greater flexibility across media than ever before (Grabill et al., 2010; Moore et al., 2016; Purcell et al., 2013; Stanford Study of Writing, n.d.). What all of these scholars have concluded, either directly or indirectly, is that writing studies lags behind in understanding writing processes and rhetorical strategies that students develop, before they even arrive at high school or college, through their self-sponsored digital writing. At the heart of the matter is this: We have little understanding, if any, about how students' self-sponsored digital writing and academic writing affect each other.

\section{Lore Versus Research on Digital Self-Sponsored Writing}

There are many online examples of lore warning us about how digital selfsponsored writing damages the academic writing of students, and the discussions on text messaging and social media are representative of these claims. One online news forum posted an article about how texting may hurt students' ability to read and write in "proper" ways (Maples, 2009), and a multimedia editor at The Week argues that "the reliance on text speak and compressed language necessary for Twitter seems to be hard to break even in the face of, say, a passing grade" (Hansen, 2013). However, Drouin and Davis' (2009) research demonstrates that between students who use text speak (short-hand abbreviations of words) and those who do not in their text messaging, there were no significant differences between the standardized literacy scores of these two groups. It is interesting to note, though, that more than half of the 80 participants believed that text speak was indeed hindering their ability to write in academic English, even though they also reported that they would not use text speak when communicating with professors via email. This suggests that students themselves also believe in the negative lore about digital self-sponsored writing.

\section{WRITING TRANSFER}

This study seeks to examine, in part, the non-academic or self-sponsored writing activity of students. As such, it is interested in determining what kinds, if any, of boundary-crossings occur (Moore, 2012). In general, writing transfer research 
has found that students do not expect writing abilities or skills to transfer from course to course or from courses to professional context (Bergman \& Zepernick, 2007; Driscoll, 2011), which implies students would also not expect writing abilities or skills to transfer from digital self-sponsored writing, typically written outside of academic contexts, to academic writing.

\section{Near, Mid, and Far Transfer \& Transfer by Affordances}

The scholarship on transfer makes a distinction between near, mid, and far transfer, with each category representing an increasingly far "stretch" or unfamiliar context in which to transfer the skills or knowledge in question. Near transfer is the transfer of knowledge or skills between very similar contexts, while far transfer is the transfer of knowledge or skills between contexts that seem very different from one another (Perkins \& Salomon, 1992). Similarly, the research on transfer affordances focuses on the extent to which a person learns something in a particular situation and the extent to which the transfer of skills or knowledge is facilitated when the person is in a situation with similar affordances (Perkins $\&$ Salomon, 1992). What is important in this model is that the person must be able to recognize the similarity in situations, or the affordances available, so that she or he may facilitate the transfer. This research suggests the important role context plays in the transfer of knowledge and skills; both similarity of context and the ability of the person to recognize similarities is a factor in whether or not, or to what extent, transfer occurs.

\section{ACtivity Theory AND ConTeXT}

While academic writing has long been recognized as a valid activity worthy of study, activity theory gives us a way to understand the different kinds of self-sponsored digital writing as significant, complex communicative moments as well. According to Kain and Wardle, "For those of us interested in rhetorical theory, the most helpful aspect of activity theory is the way it helps us see more fully all the aspects of a situation and community that influence how people use the tools of language and genre" (n. d., p. 1). According to activity theory, students move from activity system to activity system, each with its own set of expectations and ways to communicate, each with its own objective or purpose, and each with its own set of tools (Russell, 1997). Kain and Wardle also say that "activity theory provides us with very specific aspects of context to look at as we consider the various factors that influence and change the tool of writing," and this study takes seriously the self-sponsored digital writing of students as an activity system which "change(s) the tool of writing" (n.d., p. 1). 
In her review of transfer theories, Moore (2012) notes that writing-related transfer studies include studies of academic and workplace contexts, focusing on the knowledge that is needed to be successful in each context. She also notes, however, that the field of writing studies has yet to determine how knowledge from these different contexts is valued: "Once these (perhaps, conflicting) priorities are addressed, scholars still face the question of how knowledge transfers-if it even does" ("Questions About," para. 5). This study seeks to extend writing-related transfer research into the realm of self-sponsored writing contexts, to value the kinds of rhetorical knowledge that students develop in these realms, and to consider whether this knowledge is transferred into academic contexts, as well.

\section{METHODS}

Although surveys of student writing experiences and interviews are methods commonly used in writing transfer studies (Moore, 2012) a common problem among transfer studies is determining how exactly one knows that transfer occurred-and this study sidesteps this complication by not attempting to determine whether or not the transfer of rhetorical knowledge actually occurred between the self-sponsored and academic writing of students. Rather, these methods were selected as a way to get a general picture, a very broad snapshot, of student perceptions - what students themselves thought was happening-to determine whether or not they make any connections between their writing choices and strategies when writing self-sponsored and academic texts. Given the scholarship that suggests students' self-sponsored writing lives deserve further study and likely affect the store of writerly knowledge they build over time and outside of the classroom, studies that focus on student perceptions of their non-academic writing lives are an appropriate place to begin.

For these reasons, to gain a general "lay of the land" of students' perceptions of the transfer of rhetorical knowledge between digital self-sponsored writing and academic writing, I used a combination of surveys and case study interviews in which students referenced self-sponsored and academic writing samples they brought with them. Although smaller in sample size, this study builds on several larger-scale studies that sought to create a broad map of understanding of student writing behaviors and/or strategies (Grabill et al., 2010; Lenhart et al., 2008; Madden et al., 2013; Moore et al., 2016; Purcell et al., 2013; Stanford Study of Writing, n.d.). Similarly, the case study interview component of this methodology reflects other transfer research methodology (see, for instance, Gorzelsky, Driscoll, Paszek, Jones, and Hayes, this volume), as well as studies that observed participant reflections on their writing (Beyer, Gillmore \& Fisher, 2007; Moore, 2012; Yancey, 1998). 


\section{Recruitment and Population}

Undergraduate participants were recruited through emails sent to students in several first-year writing and English senior seminar classes via class instructors who were willing to forward my email invitation to their students. The goal was to recruit students at both the beginning and the end of their college careers; no effort was made to control the student study population by gender, race, or major. The email briefly explained that the study would require them to complete a paper survey about their demographics and writing behaviors, participate in an individual interview, and bring two pieces of their own writing to discuss during the interview (one self-sponsored and one academic piece of writing). The email also informed students that the entire process would take about one hour, that participants who completed the process would receive a $\$ 15$ gift certificate, and that they were invited to email me to set up individual times to complete the survey and conduct the interview.

Ten students from across all four years of study responded to the email inquiry and completed the interview and survey process; although only first-year writing and senior-seminar classes were targeted, first-year students with sophomore status and junior-year students taking their senior seminar early replied and participated in the study. The number of first-year/sophomore and junior/senior students was even at five participants in each category. The gender breakdownone male and nine females-generally reflects the overall demographic of Elon students. Additional information on each participant can be found in Table 9.1.

\section{Survey and Case Study Interviews}

Participants first completed a paper survey that asked demographic questions about their age, year in school, gender, and racial identification, as well as questions about what kinds of writing they do most often. This survey asked some similar questions as previous studies (e.g., Grabill et al., 2010), as a way to get a general sense of whether or not the participant population had similar writing habits as participants in these other studies, which did turn out to be the case.

The following interview questions were designed to invite participants to reflect on the rhetorical decisions or strategies they used while composing these different texts in different contexts and for different audiences:

- Who is the audience for the piece of writing?

- In what ways do you take your audience into account when you are writing?

- What is the purpose of this writing? 
- How often do you do this kind of writing?

- How long have you been writing this genre?

- How do you know if your writing for this genre is effective?

- How much do you enjoy this writing (1-5 scale)?

- Does the composing technology you use to create this genre impact your writing?

During the individual interviews, I asked the participants the same set of questions twice, first for their self-sponsored writing and then a second time for their academic writing. While I was interested in participant responses to these questions, I also wanted to get them talking and reflecting out loud about their rhetorical writing choices.

I then asked participants to reflect on and compare and contrast their self-sponsored and academic writing. The questions were:

- Are there any similarities/differences in regard to

- How/when/why you start writing?

- Your writing process?

- Where you write? How long you write? When you stop?

- How you think about audience or appeal to your audience?

- How you use evidence?

- How you use humor?

- How you select words?

- Which would you prefer to write, writing outside of school or academic writing? Why?

- Which do you care more about? Why?

- Are there elements of one kind of writing you wish were in the other?

- Do you see any connections between these two kinds of writing in your lives?

As with the first set of questions, while I was interested in how participants responded to these questions, I also asked them as a way to get the students talking about and reflecting on their rhetorical writing decisions. This second set of questions elicited many fascinating responses which, for the most part, are not included in the current study because they deal with content too distinct from this article's focus. However, participant responses to two of the questions (Are there any similarities/differences between your digital self-sponsored and academic writing in regard to how you think about audience or appeal to your audience? How you select words?) were coded and included in the results of this study because they generated answers that were pertinent to this study's focus on rhetorical writing choices. 
Table 9.1. Participant demographics and texts

\begin{tabular}{|c|c|c|c|c|c|c|}
\hline $\begin{array}{l}\text { Partic- } \\
\text { ipant }\end{array}$ & Gender & $\begin{array}{l}\text { Year in } \\
\text { School }\end{array}$ & Age & $\begin{array}{l}\text { Race/ } \\
\text { Ethnicity }\end{array}$ & $\begin{array}{l}\text { Digital } \\
\text { Self-Sponsored } \\
\text { Writing Brought } \\
\text { to Interview }\end{array}$ & $\begin{array}{l}\text { Academic Writing } \\
\text { Brought to Interview }\end{array}$ \\
\hline 1 & Female & First-year & 18 & White & Blog & Literary analysis paper \\
\hline \multirow[t]{2}{*}{2} & Female & Junior & 20 & White & Facebook posts & Analysis paper \\
\hline & & & & $\begin{array}{l}\text { Black/ } \\
\text { African- } \\
\text { American }\end{array}$ & & \\
\hline 3 & Female & Senior & 22 & White & Text messages & Travel writing \\
\hline 4 & Female & $\begin{array}{l}\text { Sopho- } \\
\text { more }\end{array}$ & 19 & White & Text messages & Philosophy paper \\
\hline 5 & Female & $\begin{array}{l}\text { Sopho- } \\
\text { more }\end{array}$ & 19 & White & Email & $\begin{array}{l}\text { Classroom } \\
\text { observation }\end{array}$ \\
\hline 6 & Male & $\begin{array}{l}\text { Sopho- } \\
\text { more }\end{array}$ & 19 & White & Text messages & Evaluative argument \\
\hline 7 & Female & First-year & 18 & White & Facebook posts & Literary analysis paper \\
\hline 8 & Female & Junior & 20 & White & Blog & Analysis paper \\
\hline 9 & Female & Senior & 21 & White & Text messages & Literary analysis paper \\
\hline 10 & Female & Senior & 22 & White & Text messages & Analysis paper \\
\hline
\end{tabular}

\section{Qualitative and Quantitative Data Analysis}

I used generative coding for the interview data; the survey data was used to report on demographic information only. I first read through two of the 10 interviews to identify common themes in the student responses. At this point, I identified that much of the data referred to rhetorical features of audience awareness, purposes for writing, and ways of determining writing effectiveness. I then re-read and coded the first two interviews again, coding instances of strong and weak audience awareness, purposes for writing, and ways of determining writing effectiveness. During this second pass through the first two interviews, I also generated secondary codes that added further detail to the primary codes; so, for example, strong audience awareness could be further identified as revising visual design for a particular audience's needs (code "visual design") or adjusting content based on multiple audiences (code "multiple audiences"). Each primary code of strong or weak audience awareness, purposes for writing, and ways of determining writing effectiveness also had an "other" code for comments that 
Table 9.2. Primary codes

\begin{tabular}{|c|c|c|c|c|c|c|}
\hline & \multicolumn{2}{|c|}{ Audience Awareness } & \multicolumn{2}{|c|}{$\begin{array}{c}\text { Understanding of } \\
\text { Effectiveness }\end{array}$} & \multicolumn{2}{|c|}{$\begin{array}{c}\text { Understanding of } \\
\text { Purpose }\end{array}$} \\
\hline & Strong & Weak & Strong & Weak & Strong & Weak \\
\hline \multicolumn{7}{|l|}{ Academic Writing } \\
\hline \multicolumn{7}{|l|}{ Self-Sponsored } \\
\hline Digital Writing & & & & & & \\
\hline
\end{tabular}

were not repeated. Any given excerpt could be given more than one secondary code; for example, an excerpt coded as "self-sponsored digital writing: strong audience awareness" could be given multiple secondary codes such as selecting appropriate "language" and paying attention to "visual design" given a particular audience. After initial coding, each interview was reviewed to increase consistency. Using Dedoose software, I coded the interviews with the following primary categories, as represented in Table 9.2.

\section{RESULTS AND DISCUSSION}

\section{Rhetorical Audience Awareness}

Participants showed a broad range of rhetorical audience awareness when discussing the decisions they made when composing their digital self-sponsored pieces of writing, as shown in Figure 9.1. The most common decisions participants mentioned were how they selected details and ideas to include and exclude based on audience needs (32 instances) and how they made certain decisions because they were writing for real people and not simply the default and generic audience of an instructor (36 instances). One student gave a response that was voiced by several others as well when she explained that "I think a lot about commenting on my grandma's pictures. My grandma and her friends think about the purpose of [Facebook] very differently than me. I know her friends will see the comments!"

Participants showed an even more sophisticated awareness of audience complexity when discussing the need to modulate their content further if multiple audiences would be reading their writing (19 instances). For example, one participant said that "I'm aware that I am not only a friend, but a daughter, a big sister to different people." The use of humor ( 2 instances), how context affected their writing (3 instances), visual design choices (6 instances), their choice of medium (9 instances), and their choice of language (13 instances) were mentioned less frequently but still show the wide range of issues participants adjusted according to their audiences. 


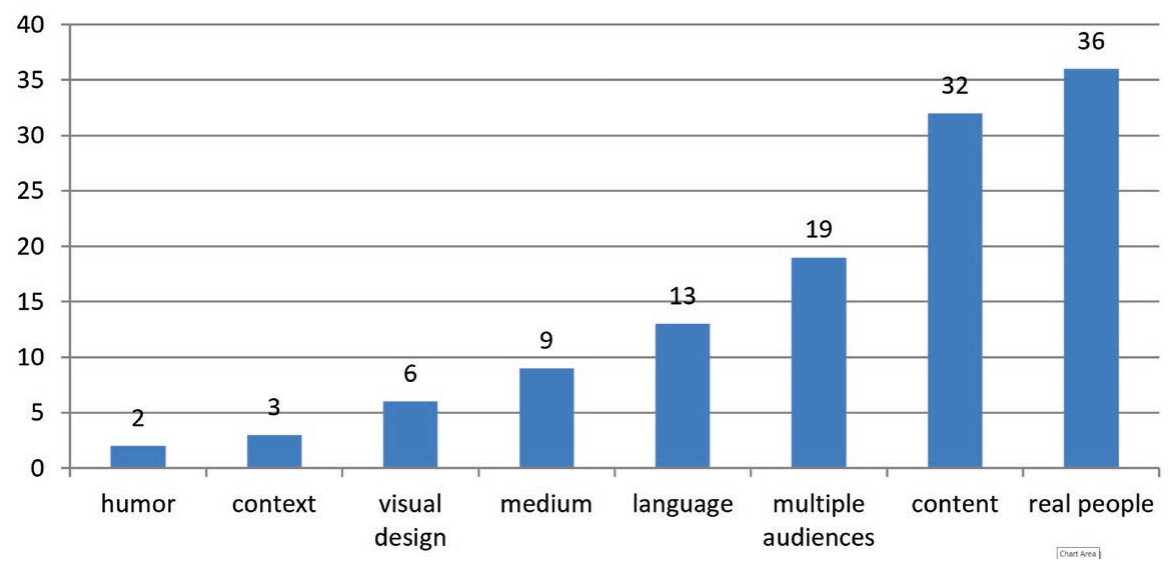

Figure 9.1. Rhetorical audience awareness in digital self-sponsored writing: 120 instances.

While attention to humor and context totaled only five instances together, they were particularly interesting because of the level of complexity. One student explained that she decides whether and when to use humor/sarcasm in a text depending on the personality of the person she is speaking with and the content of their conversation: "I guess I usually know if a person's receptive to it. Because I have certain friends who are very sarcastic and certain ones who don't deal with it well. I guess, who I'm speaking to matters. And then, if we're having a serious conversation, I'm not going to like jump into sarcasm halfway through. So the tone of the conversation so far, and where we're going with that." Another student showed careful attention to the broader context in her texts, noting that it is important to not inadvertently offend someone with a rude text. She therefore takes a more polite and personal approach with someone she knows less well:

If they're not friendly when they're texting I'm like "Wait, what's wrong? Are they mad at me?" . . I I mean, if people are short in their text messages, sometimes there can be that, you know, insinuation that something's wrong. So I'm always like "Hi, how are you? Is there any way that you could blah blah blah blah blah?" . . . that's how I am as a person but also I just think it's more effective in speaking to someone. It's more polite. Texting is so ... it can be done so thoughtlessly, I try to keep like a very personal touch when I'm texting somebody for a specific reason, but then again if it's somebody who I'm 
always communicating with ... like my boyfriend or my best friends from home, then it's more like, light-hearted.

Participants produced fewer instances of audience awareness when talking about their academic writing, in terms of both the number and variety of references they made to this consideration (see Figure 9.2). They mentioned how they took their audience into account when making decisions about grammar and spelling (1 instance), achieving a goal (1 instance), responding to audience feedback ( 2 instances), and determining how to help a real person or group of people when working on a client project ( 7 instances). In a pattern that also occurs in regard to writing purpose, it is telling that the highest number of responses was in regard to writing for a real audience. Students were particularly interested in discussing how they made different decisions about content or style based on the needs or expectations of real audiences, as shown in this example of a student talking about content she wrote for a travel writing website:

I took into consideration that most people probably didn't read that book [she was basing an entry on].... [the movie] wasn't in line really with the book . . . so I had to keep that in mind too. So what people assumed it was about wasn't necessarily what she wrote it about. So I had to ... explain what she wrote about while also . . . balancing my own experiences. I didn't want to talk too much about myself or too much about the book, but I wanted to balance comparison but also expression of . . . what she wrote about versus what I wrote about.

Collectively these rich excerpts, which show students struggling and explaining writing choices they made for real audiences with different needs and expectations, suggest that students gain more experience making rhetorical writing decisions based on audience awareness when they are actually writing for real audiences.

In regard to their academic writing, students more often talked about decisions they made, based on their audience, in comparatively unrhetorical ways (see Figure 9.2). For example, they mentioned "giving my professor what he or she wanted" (2 instances), repeating what their professor had said word-for-word ( 2 instances), writing to make their professor happy (7 instances), or a few other unrelated comments about superficial audience needs ( 3 instances). Comments such as "I tried to do everything that she asked for on the assignment sheet" are not examples of students making rhetorical writing decisions. I categorized "giving my professor what he wanted" and repeating what their professor had so say word-for-word as evidence of less effective rhetorical awareness because such 


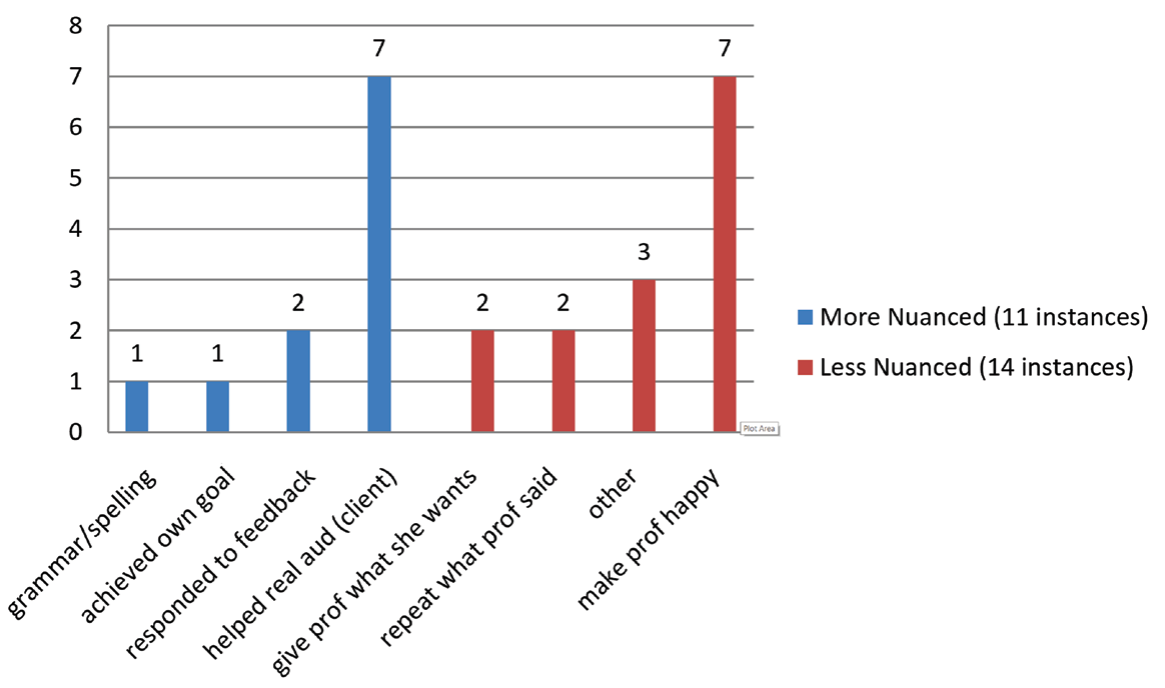

Figure 9.2. Rhetorical understanding of audience awareness in academic writing.

comments show that the goal of these decisions was to get a good grade, and wider considerations such as persuading their audience to believe something or moving them toward action were not part of the discussion.

The kinds of comments that were coded as superficial audience needs include "I knew it was going to get graded, so I had to double-check to ensure that my grammar and spelling were right, and that all of my sentences end correctly" and repeating a story the professor told in class so that he or she might be more receptive to the student's writing. While attention to correct grammar and audience interests does show audience awareness and attention to ethos, I coded them as being less rhetorically effective because these choices were made with the goal of getting a good grade or getting the professor to like the student. Again, one might argue that these are rhetorical choices, but they are not the kinds of attention to audience needs on which teachers typically focus.

When students discussed their digital self-sponsored writing, they made significantly more references to writing for different audiences, as well as for multiple audiences; they discussed selecting the appropriate medium, content, and words; and they showed kairotic understanding when they discussed the importance of being aware of the timing of their writing. On the contrary, when students discussed their academic writing, they made far fewer references to making decisions based on their audience; and while they did take rhetorically impactful issues into consideration such as word choice or responding to audi- 


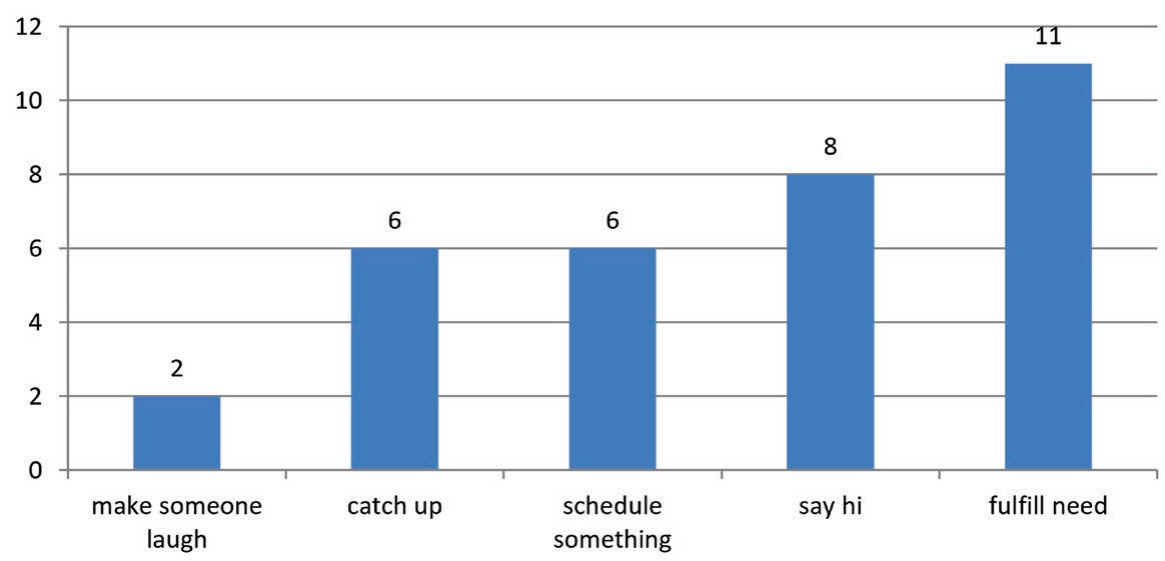

Figure 9.3. Rhetorical understanding of purpose in digital self-sponsored writing: 33 instances.

ence feedback, they were very cynical about not having to take their audience into account because they were writing for their professors for a grade, as exemplified in this comment: "He likes for us to use his layout from class then add in, use his own sayings. . . . He liked it. I got a good grade." The exception to this cynicism was when students were doing client projects and writing for real audiences; in these cases, students noted that they took their audiences' needs into account because their writing was going to have an effect on real people.

\section{Rhetorical Understanding of Purpose}

During their interviews, participants generated a total of 33 instances of discussing different purposes for writing digital self-sponsored texts (see Figure 9.3). Participants' reasons for writing self-sponsored texts ranged from very social/phatic purposes such as "to make someone laugh" (2 instances), "to catch up" (6 instances), and "to say hi" (8 instances), to more goal-focused purposes such as "to schedule something" (6 instances) and "to fulfill a need" (11 instances). This last and most common purpose, "to fulfill a need," is exemplified by one participant's comment that she texts because "I need something, a ride, an answer; [I] want to get something done."

During their interviews, participants generated a total of 15 rhetorically informed instances of discussing different purposes for writing academic texts (see Figure 9.4). They said that their reasons for writing academic texts included "to develop thoughts" (1 instance), "to reflect" (1 response), "to prove you 


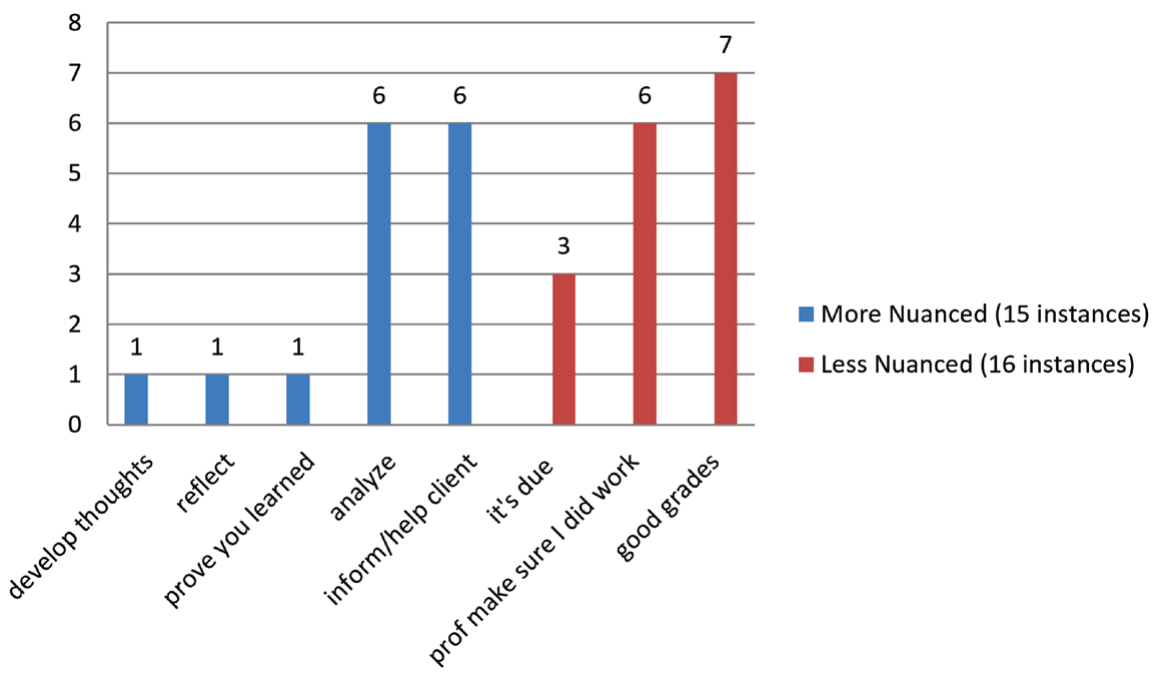

Figure 9.4. Rhetorical understanding of purpose in academic writing.

learned" ( 1 response), "to analyze" (6 responses), and "to inform/help client" (6 responses). Each of these purposes for writing academic texts are commonly taught in writing classes, and the last purpose, "to inform/help client," is a common purpose in the case of client-based projects.

Interestingly, this is the question that produced the most responses for academic texts; in other words, the 15 responses that showed rhetorical understanding of purpose represent the highest number of responses that participants gave in regard to any question about academic texts. In addition, one of the reasons for writing - "to inform /help clients"-is in the context of writing for a real audience. This suggests that students understand that the stakes are higher when writing for real people with real informational needs, which in turn suggests that if we want students to experience and analyze writing purposes in rhetorically complex ways, then we need to create real writing contexts in our classrooms, with real audiences.

Participants produced an almost equal number of less rhetorically nuanced instances (16) for why they write academic texts (see Figure 9.4). Three students explained that they write an academic text because "it's due," six said because their professor wanted to "make sure I did the work," and seven said because they wanted to get "good grades." When asked to discuss the purpose of the particular piece of academic writing they brought in, seven students simply said some version of "for the grade. [If I] didn't turn it in, then I wouldn't get a grade" and "to get a good grade. It was asked of me in the class." 


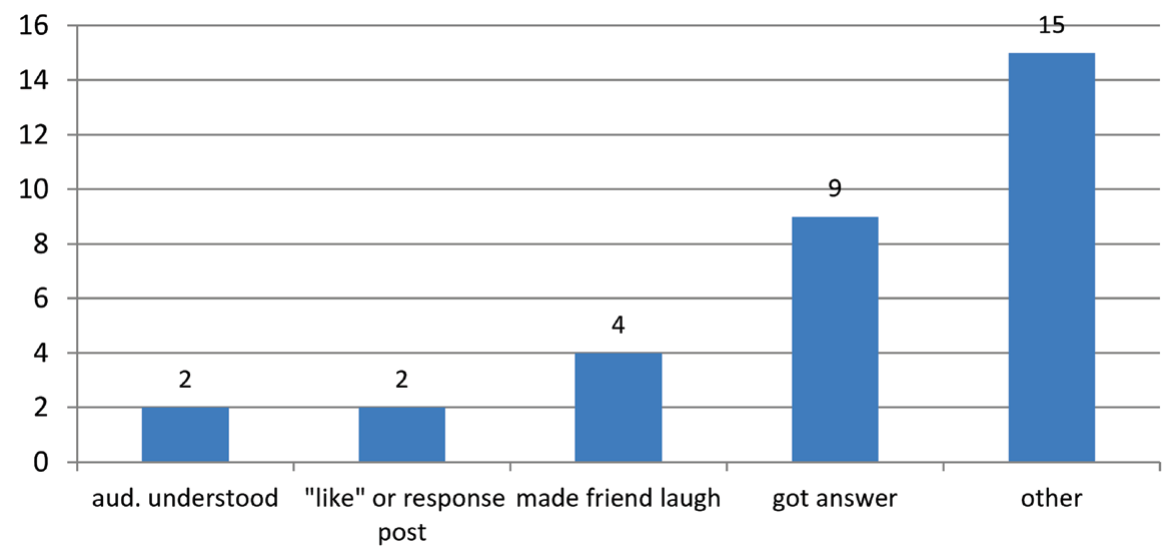

Figure 9.5. Rhetorical understanding of effectiveness in digital self-sponsored writing: 32 instances.

Categorizing these responses as less rhetorically nuanced is problematic because on the one hand, they each do show some attention to the context and audience in question, insofar as completing a project by its due date and pleasing an audience with knowledge-gained shows attention to context and audience. On the other hand, such purposes for writing are less rhetorically complex and are inherently different than the kinds of nuanced rhetorical choices students discussed making for their self-sponsored digital writing, and they are not the kinds of purposes writing teachers typically strive to teach their students about.

\section{Rhetorical Understanding of EfFective Writing}

Participants showed a wide range of rhetorical ways to understand when their digital self-sponsored writing was effective (see Figure 9.5). Students explained that they knew this kind of writing was effective if their audience understood (2 instances), if they received a "like" or a response to a social media post ( 2 instances), if they made a friend laugh ( 4 instances), or if they got the answer they needed ( 9 instances), in addition to a variety of other singular but still rhetorical responses (15 responses). For example, students said they knew their self-sponsored writing was effective "if I get a lot of 'likes' on FB, I know it was good writing" or "if I get a response. If I get the answer I needed, I know I wrote effectively." One student succinctly said that he knows his Facebook post is effective when he has "made someone laugh," while a second student was attuned to how the effectiveness of a Facebook post could transfer from an online 


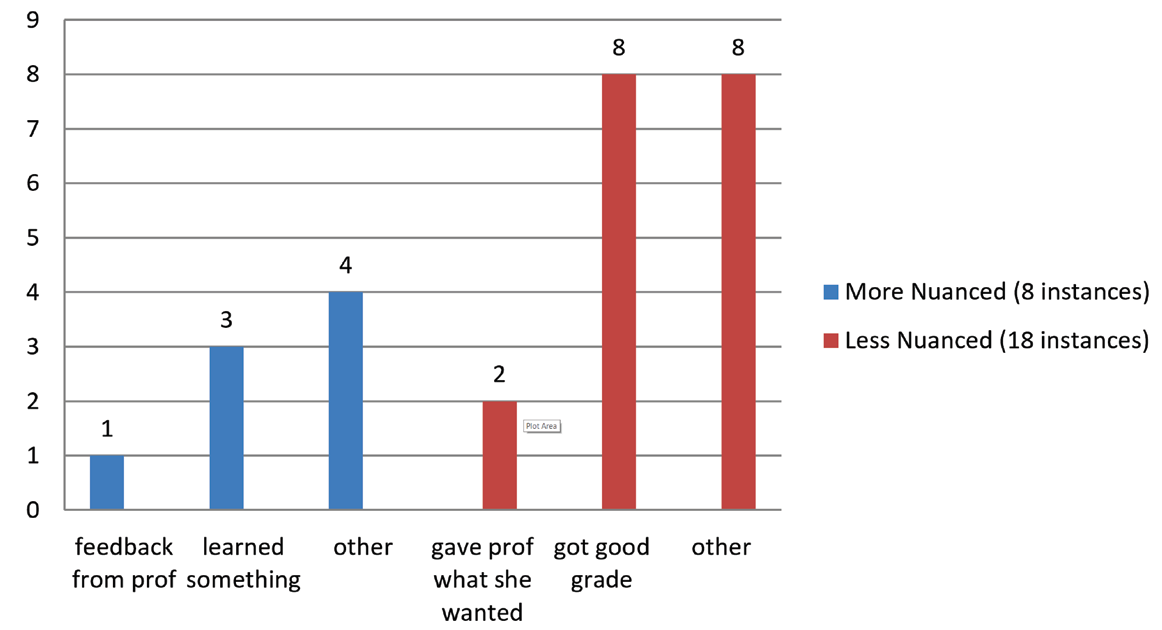

Figure 9.6. Rhetorical understanding of effectiveness in academic writing.

to a face-to-face context: "I guess since it's [Facebook] usually used for humor, it's, someone will laugh or have another funny response. Or maybe they'll bring it up later. Sometimes that happens, when you actually see the friend in person, they'll bring up, like, something you posted on their wall."

Participants had far fewer rhetorical ways of explaining when their academic writing was effective (see Figure 9.6). Responses included that they knew their writing was effective if their professor told them it was effective (1 instance), if they learned something ( 3 instances), or if a student has managed to "[use] the right terminology" or "bring in ... a certain critic or theorist" it will have made her writing more effective ( 1 of the 4 "other" coded instances). This last example reflects an understanding on the student's part that using the language and theories of a particular discourse community can make writing stronger.

Participants produced even more instances of less nuanced rhetorical understanding of effectiveness of their academic texts, with a total of 18 instances (see Figure 9.6). Participant responses included giving the professor the content they believed he or she wanted ( 2 instances) and getting a good grade ( 8 instances). While the response that a piece of writing is effective if it gets a good grade is not completely without rhetorical awareness - in this context, good writing equals a high grade-for the purposes of this study, such a response lacks a deeper consideration of or understanding for what an audience might find persuasive. The even more blunt comment that "I was desperate to get an A, so I gave him [the teacher] his opinions" drives home the point that the student was focusing mostly on his teacher's expectations as a way to earn a high grade. 
Table 9.3. Summary of participant responses

\begin{tabular}{lll}
\hline & Self-Sponsored Digital Writing & Academic Writing \\
\hline $\begin{array}{l}\text { Rhetorical Audience } \\
\text { Awareness }\end{array}$ & $\begin{array}{l}120 \text { instances (use of humor, attention } \\
\text { to context or visual design, etc.) }\end{array}$ & $\begin{array}{l}11 \text { instances (grammar/ } \\
\text { spelling, responded to } \\
\text { professor feedback, etc.) }\end{array}$ \\
$\begin{array}{l}\text { Rhetorical Understand- } \\
\text { ing of Effective Writing }\end{array}$ & $\begin{array}{l}32 \text { instances (audience understood, got } \\
\text { necessary answer, etc.) }\end{array}$ & $\begin{array}{l}8 \text { instances (got } \\
\text { good grade, learned } \\
\text { something) }\end{array}$ \\
$\begin{array}{l}\text { Rhetorical Understand- } \\
\text { ing of Purpose }\end{array}$ & $\begin{array}{l}33 \text { instances (made someone laugh, } \\
\text { fulfilled need, etc.) }\end{array}$ & $\begin{array}{l}15 \text { instances (developed } \\
\text { thoughts, helped client) }\end{array}$ \\
\hline
\end{tabular}

Table 9.3 summarizes the total number of responses for each type of writing in each rhetorical category (audience awareness, effective writing, and purpose). Very broadly, the number of responses indicates that participants were more interested in talking about, and had more things they wanted to share about, their digital self-sponsored writing than their academic writing. This may have something to do with students not considering their self-sponsored digital writing to be actual writing. Several students were reluctant and surprised when they heard I was asking serious questions about this kind of writing. One student explained this when he said that "when I text, I don't like ... it's not like I'm writing. Writing, for me, it's like writing something down on a piece of paper or I'm typing. I don't think of when I text, I don't think of it as I'm writing. Which is, like, I know it is, but that's not something that I really think about." Lenhart et al.'s study reached a similar conclusion when they said that "even though teens are heavily embedded in a tech-rich world, they do not believe that communication over the internet or text messaging is writing" (2008, para. 6).

Another factor that may be at play here is students' preference that their writing do something, or, as Lunsford (n.d.) says in "Our Semi-Literate Youth? Not so Fast," they want their writing to have agency—and self-sponsored writing is more likely to achieve this. Perhaps students are more motivated to talk about their writing when they think it actually gets something done in the world. This study's results about the effectiveness of writing supports this idea, since one way students said their self-sponsored digital writing was effective was if it helped them "get something done."

\section{CONCLUSION}

Although the sample size was small, several clear trends emerged from the participant responses: 
- Participants did not initially transfer rhetorical knowledge or writing strategies between their self-sponsored and academic writing, confirming similar findings of previous studies (Lunsford, n.d.; Lenhart et al., 2008).

- Participants showed more rhetorical sensitivity (who to write, when, in what medium, how) in their self-sponsored writing than in their academic writing.

- Participants showed less rhetorical sensitivity in their academic writing, except in the case of client projects (a kind of project that asks students to write for real, often non-academic, audiences who have real needs that can be addressed through writing).

- Participants showed a keen awareness that self-sponsored digital writing is not valued by academia/wider public and that they should not value it either.

While participants did not automatically transfer rhetorical knowledge between their digital self-sponsored and academic writing, the potential for such transfer seems to exist, especially if students write for authentic purposes (as occurred with self-sponsored writing and in client projects). Arguing that client projects provide students with rich rhetorical situations in which to act and make decisions about their writing is not new. These results suggest that we cannot expect students to engage in sophisticated rhetorical decision-making when writing contexts are not authentic. Participants repeatedly referred to the fact that they were writing for an audience of "their professors" when writing academic texts, and therefore did not engage questions about audience, purpose, or effectiveness in complex or rhetorically rich ways. As the Elon Statement posits, potential for transfer also exists when students are encouraged to engage in metacognition (as occurred in the interviews). Learning through reflection is not a new idea. What I am proposing that is slightly different is that through reflection, students may learn to see that they are already writers through their digital self-sponsored writing, and that they have a storehouse of knowledge from this kind of writing that they often neglect to draw upon in academic writing contexts.

When participants were asked during the interview process to reflect on and compare and contrast their self-sponsored and academic writing, many of them commented that they had never considered the two types of writing in relation to one another and that they thought faculty would respond disparagingly to references to their digital self-sponsored writing. Every participant showed some level of surprise, and then chagrin, that they had just talked about their digital self-sponsored writing in some rhetorically-sophisticated ways, using terms and 
criteria for making decisions which they had never considered using, or been asked to use, in their academic writing. It was at these moments that participants showed frustration with what they perceived to be academic snobbery-participants believed that far from openly referencing how or why they made writerly decisions in their self-sponsored writing while in academic contexts, they had to hide this part of their writing lives in the classroom. Some participants even expressed disbelief that I really wanted to hear about their self-sponsored digital writing, and several commented that the kinds of academic writing they were asked to do simply did not allow for any rhetorical decision-making at all. So while the potential for transfer from digital self-sponsored writing exists, participants do not believe their faculty members value this kind of writing and so they are careful to keep these writing experiences to themselves; in these cases, students aren't encouraged to reflect on and potentially transfer writing knowledge from one kind of writing to the other.

The results of this research suggest that, to encourage the potential transfer of rhetorical strategies between students' digital self-sponsored and academic writing, instructors could ask students to:

- Examine their rhetorical knowledge/strategies in non-academic writing domains;

- Consider the rhetorical knowledge/strategies they use in their own self-sponsored digital writing; and

- Reflect on these strategies, examine their value and effectiveness, and consider applying them in academic writing.

These suggestions are meant to invite students to bring the entirety of their writing lives and their writing experiences into the classroom for discussion and reflection; they encourage students to value, and imply that faculty also value, the writing that they do in internships, on-the-job, for themselves, and for their friends and family.

The kinds of activities faculty could design based on these suggestions could be short, informal and low-stakes; what is important is that these activities invite students to reflect on and engage in metacognition about the writerly decisions they make in their digital self-sponsored writing, thereby increasing the likelihood that they would transfer this knowledge to their academic writing as well. For example, students could be asked to use their cell phones to copy down 2-3 different text conversations, and then asked to reflect, in writing, on the rhetorical situation and the decisions they made when responding (the interview questions used in this study could be used for this purpose). After sharing their reflections in small groups, students could then be asked to discuss whether they had used in their academic writing any of the rhetorical choices or writing 
strategies they had just mentioned in reference to their self-sponsored digital writing. Besides reminding students that they likely do a fair amount of writing in their day-to-day lives, this activity may encourage students to recognize that they likely consider rhetorical factors frequently in their self-sponsored writing, and that such factors should be considered in academic writing too. A second activity that could be used alone or in conjunction with the one just described is to ask students to alter one of the rhetorical features of a text message conversation (such as changing the audience from a friend to a grandmother, or the occasion from a celebration to a study session); in this activity students could reflect on whether or not their word, style, or content choices were appropriate for a specific audience or context.

As mentioned above, participants showed more rhetorical sensitivity to audiences in their digital self-sponsored writing, while paying hardly any attention to audience or context concerns in their academic writing. Reflection that shows participants how they attended to audience and context concerns in their self-sponsored writing might very well shock them into realizing that they too sometimes fail, like this study's participants, to engage in these rhetorical practices in their academic writing. I am not suggesting that faculty should assign students to write Facebook posts or force students to text each other for classwork; instead, short, low-stakes reflective activities like these are meant to invite students to bring rhetorical expertise they have honed while engaging in digital self-sponsored writing into their academic writing. Self-sponsored digital writing is not ruining students' academic writing ability; in fact, it might inform their rhetorical decision-making in productive ways. These are also considerations we might take into account when participating in discussions with colleagues or when making decisions about classroom policies banning cell phones or laptops in class, because such decisions send the message to students that the self-sponsored writing they do with these devices, and the rhetorical knowledge they've developed, is not valued in academia.

Given the small sample size of this study, future studies could benefit from more participants and from multiple and different kinds of institutions. Additional considerations for future studies include following participants longitudinally to determine whether active reflection between strategies used in digital self-sponsored and academic writing makes a difference; conducting faculty interviews as a way to complicate the data; and using students as co-researchers so that participants may be less self-conscious in their interview discussions.

The fact that participants were willing to and interested in talking about their digital self-sponsored writing at greater length suggests that we may be missing opportunities, as Yancey $(1998,2009)$ and Mueller (2009) have suggested, to tap into students' knowledge about writing that is formed outside of academic 
settings, as well as students' potential identification of themselves as writers. Encouraging students to identify themselves as writers, with abilities to assess a writing context, audience, and purpose and respond accordingly, is a valuable part to becoming an effective writer. In addition to being a way to learn about what students bring to college already knowing about writing, and in addition to rethinking emerging writing processes and adjusting pedagogies accordingly, discussing students' self-sponsored digital writing is a way to access their identities as real writers.

Further, since participants engaged in savvier, more complex rhetorical decision-making when writing their digital self-sponsored texts, we may be neglecting to take advantage of opportunities to alter classroom pedagogies in ways that could greatly enhance the transfer of rhetorical knowledge and strategies between the digital self-sponsored and academic writing of students. For example, this research suggests that students would likely view the transfer of rhetorical strategies between digital self-sponsored writing and academic writing as a kind of far transfer; however, it is possible that by inviting classroom discussions about digital self-sponsored writing-by encouraging students to reflect on rhetorical decisions they make in their digital self-sponsored writing - students might come to view this part of their writing lives as a kind of rhetorically rich context in which they make writerly decisions, thereby changing it into a kind of near transfer context. Therefore, there is value in asking students to reflect on this part of their writing lives, the academically unsanctioned part, as they build their frameworks of rhetorical strategies for writing and construct their writerly identities.

\section{REFERENCES}

Bergmann, L. S. \& Zepernick, J. (2007). Disciplinarity and transfer: Students' perceptions of learning to write. WPA: Writing Program Administration, 31(2), 124-149.

Beyer, C. H., Gillmore, G. M. \& Fisher, A. T. (2007). Inside the undergraduate experience: The University of Washington's study of undergraduate learning. Bolton, MA: Anker.

Brooke, R. (1987). Underlife and writing instruction. College Composition and Communication, 38(2), 141-152.

Driscoll, D. L. (2011). Connected, disconnected, or uncertain: Student attitudes about future writing contexts and perceptions of transfer from first-year writing to the disciplines. Across the Disciplines, 8(2). Retrieved from http://wac.colostate.edu/atd /articles/driscoll2011/index.cfm.

Drouin, M. \& Davis, C. (2009). R u texting? Is the use of text speak hurting your literacy? Journal of Literacy Research, 41, 46-67.

Elon Statement on Writing Transfer. (2015). Retrieved from http://www.centerfor engagedlearning.org/elon-statement-on-writing-transfer/. 
Finley, T. (2014, July 26). Troy Hicks: A conversation about digital writing [Web log post]. Retrieved from http://www.edutopia.org/blog/troy-hicks-conversation-digital -writing-todd-finley.

Goffman, E. (1961). Asylums: Essays on the social situation of mental patients and other inmates. New York: Anchor.

Goffman, E. (1963). Stigma: Notes on the management of spoiled identity. Englewood Cliffs, NJ: Prentice-Hall.

Grabill, J., Hart-Davidson, W., Pigg, S., McLeod, M., Curran, P., Moore, J. L., Rosinski, P., Peeples, T., Rumsey, S., Courant-Rife, M., Tasaka, R., Lackey, D. \& Brunk-Chavez, B. (2010). Revisualizing composition: Mapping the writing lives of first-year college students. Writing in Digital Environments Research Center [Whitepaper]. Retrieved from http://www2.matrix.msu.edu/portfolio-item/revisualizing -composition-mapping-the-writing-lives-of-first-year-writing-students/.

Hansen, L. (2013). 6 things social media is ruining. The Week. Retrieved from http:// theweek.com/article/index/245370/6-things-social-media-is-ruining.

Herrington, A. J. \& Curtis, M. (2000). Persons in process: Four stories of writing and personal development in college. Urbana, IL: National Council of Teachers of English.

Kain, D. \& Wardle, E. (n.d.). Activity theory: An introduction for the writing classroom. Retrieved from http://www.academia.edu/493321/Activity_Theory_An _Introduction_for_the_Writing_Classroom.

Lenhart, A. (2012). Teens, smartphones \& texting. Retrieved from http://www.pew internet.org/Reports/2012/Teens-and-smartphones.aspx?src=prc-headline.

Lenhart, A., Arafeh, S., Smith, A. \& Macgill, A. (2008). Writing, technology and teens. Retrieved from http://pewinternet.org/Reports/2008/Writing-Technology -and-Teens.aspx.

Lunsford, A. (n.d.). Our semi-literate youth? Not so fast. Retrieved from https://ssw .stanford.edu/sites/default/files/OPED_Our_Semi-Literate_Youth.pdf.

Madden, M., Lenhart, A., Duggan, M., Cortesi, S. \& Gasser, U. (2013). Teens \& technology 2013. Pew Research Internet Project. Retrieved from http://www.pew internet.org/2013/03/13/teens-and-technology-2013/.

Maples, R. (2009, March 17). Texting effects on teenagers' grammar. KHQA News. Retrieved from http://khqa.com/news/local/texting-effects-on-teenagers-grammar.

McCarthy, L. P. (1987). A stranger in strange lands: A college student writing across the curriculum. Research in Teaching English, 21(3), 233-265.

McWhorter, J. (2013, April 25). Is texting killing the English language? Time. Retrieved from http://ideas.time.com/2013/04/25/is-texting-killing-the-english -language/.

Moore, J. L. (2012). Mapping the questions: The state of writing-related transfer research. Composition Forum, 26. Retrieved from http://compositionforum.com /issue/26/map-questions-transfer-research.php.

Moore, J. L., Rosinski, P. R., Peeples, T., Pigg, S., Rife, M. C., Brunk-Chavez, B., Lackey, D., Rumsey, S. K., Tasaka, R., Curran, P. \& Grabill, J. T. (2016). Revisualizing composition: How first-year writers use composing technologies. Computers and Composition, 39, 1-13. 
Mueller, D. N. (2009). Digital underlife in the networked classroom. Computers and Composition, 26, 240-250.

Perkins, D. N. \& Salomon, G. (1992). The science and art of transfer. In A. L. Costa, J. A. Bellanca \& R. Fogarty (Eds.), If minds matter: A foreword to the future (Vol. 1) (pp. 201-210). Palatine, IL: IRI/Skylight.

Purcell, K., Buchanan, J. \& Friedrich, L. (2013). The impact of digital tools on student writing and how writing is taught in schools. Pew Research Internet Project. Retrieved from http://www.pewinternet.org/2013/07/16/the-impact.

Roozen, K. (2008). Journalism, poetry, stand-up comedy, and academic literacy: Mapping the interplay of curricular and extracurricular literate activities. Journal of Basic Writing, 27(2), 5-34.

Roozen, K. (2009a). "Fanfic-ing graduate school:" A case study exploring the interplay of vernacular literacies and disciplinary engagement. Research in the Teaching of English, 44(2), 136-169.

Roozen, K. (2009b). From journals to journalism: Tracing trajectories of literate development. College Composition and Communication, 60(3), 541-572.

Russell, D. (1997). Rethinking genre in school and society: An activity theory analysis. Written Communication, 14(4), 504-554.

Singleton-Rickman, L. (2009, July 15). Does texting hurt writing skills? The Times Daily. Retrieved from http://www.timesdaily.com/archives/does-texting-hurt -writing-skills/article_81445a80-781d-5f82-b7ac-00f951cf10bc.html.

Stanford Study of Writing. (n.d.). Stanford University. Retrieved from http://ssw.stan ford.edu/index.php.

Sternglass, M. A. (1997). Time to know them: A longitudinal study of writing and learning at the college level. Hillsdale, NJ: Lawrence Erlbaum.

Yancey, K. B. (1998). Reflection in the writing classroom. Logan, UT: Utah State University Press.

Yancey, K. B. (2009). Writing in the 21st century: A report from the national council of teachers of English. Urbana: IL, National Council of Teachers of English. 



\section{CHAPTER 10}

\section{LIMINAL SPACE AS A GENERATIVE SITE OF STRUGGLE: WRITING TRANSFER AND L2 STUDENTS}

\section{Gita DasBender}

The question of whether writing knowledge garnered in one learning situation can be successfully carried into new situations continues to be a vexing one; yet sustained inquiries into the efficacy of transfer practices, such as those recently conducted by participants in Elon University's Research Seminar on Critical Transitions, reveal that "transfer does occur, contrary to suggestions reflected in prior research" (Elon Statement on Writing Transfer, 2015). This is hopeful news for the future of transfer studies. And as the larger conversation on writing transfer continues to shape undergraduate education, such positive predictions in transfer scholarship can have a healthy impact on writing transfer research of multilingual students, particularly second language (L2) learners, and of contributing to the field's growing understanding of how-and under what conditions - writing transfer happens for L2 learners. Indeed, the case studies of L2 learners presented in this chapter not only reflect some of the working principles articulated in the Elon Statement but also demonstrate how useful these principles may be in informing emergent L2 transfer studies. There is sufficient evidence in the findings of this study that L2 students' socio-cultural background, the prior writing knowledge they carry from L1 settings, and the extent of their metacognitive awareness of linguistic and rhetorical differences in writing can not only foster or disrupt writing transfer, but also play a critical role in their development as multilingual writers in a US educational context.

The essential belief that the goal of education is the transfer of learning from one setting to another still undergirds our view of education and general knowledge acquisition. Bransford and Schwartz point out that because of this entrenched belief,

most educators want learning activities to have positive effects that extend beyond the exact conditions of initial learning. They are hopeful that students will show evidence of transfer in a variety of situations: from one problem to another within 
a course, from one course to another, from one school year to the next, and from their years in school to their years in the workplace. (1999, p. 61)

Common sense dictates that the structured learning which occurs within formal, institutionalized settings can hardly be considered valuable if what is learned is not retained, reformulated, and reused in other, new settings. Perkins and Salomon (1994) make it clear that educational goals cannot be met without transfer of learning. At the same time, they also emphasize that there is ample evidence to support the fact that not all learning experiences necessarily lead to transfer. The authors sound a cautionary note when they remind us that "transfer . . cannot be taken for granted" (1994, p. 3). Likewise, more recent studies on writing transfer based on L1 composition not only tend to reinforce the view that transfer is not necessarily inevitable, but as Moore (2012) points out, also "suggest that transfer is limited and students do not expect their writing in FYC, or even in classes in their majors, to transfer to other coursework or to professional contexts." In her examination of the pertinent questions and state of writing-related transfer research, Moore reviews the contexts within which transfer is studied in the United States and concludes that these contexts are limited to certain geographical areas, indicating that transfer research needs to be more wide-spread.

With the rapid growth and influx of students with diverse language histories and literacy backgrounds and whose learning experiences may not follow the more predictable trajectories of US educated native and non-native English speakers, established views of transfer, whether promising or problematic, need to be re-examined to provide a deeper sense of how transfer functions for multilingual learners in a writing class. To understand the challenges confronted by international students in first year composition classes, this article focuses on two case studies that emerged from data collected for a research study conducted in a six-credit writing course designed for multilingual students taught in the writing program of a mid-sized private university in northeastern United States.

\section{L2 WRITING TRANSFER}

The complexities involved in studying, understanding, and drawing firm conclusions about transfer issues of L2 writers are readily seen in studies conducted in the past decade or so. In her comparative review of studies on how first language (L1) and L2 writers learn about genres, Tardy notes that both groups "writing and reading in both their first and second languages often face difficulty transferring knowledge developed in one domain to another" (2006, p. 95). 
While Tardy would like to see genre-based instructional approaches where students learn methods of genre analysis that would serve as tools in future writing settings, she also finds no evidence in the empirical research she investigates that such tools would have a positive impact on later learning (2006, p. 97). She calls for "a stronger research base in the influences of instruction (of various types) on learners' subsequent generic practices" (2006, p. 97). In their exploratory study of the effects of intensive writing training in L1 for Japanese high school students, Kobayashi and Rinnert (2008) find that such intensive instruction in L1 appears to have a positive effect on text construction in both L1 and L2. However, despite student gains in metacognitive awareness and improved writing choices, the authors are uncertain about the precise causes of such improvement and call for further study in that area. In their observations they indicate that because of several factors, including a small sample size and subjects' lack of experience in university writing, the findings, which show "relatively strong evidence for transferability of writing competence across languages," (2008, p. 20) cannot be generalized beyond the context of the specific study.

Other research on L2 writing transfer such as James' (2008) study of the impact of perceptions of task similarity or difference on L2 learning transfer indicates that successful transfer of outcomes from a writing course depends not so much on objective views of task similarity or difference as on self-determined student perceptions. James' finding that "perceived task similarity had a positive impact on the scores on the writing task" (2008, p. 94) has important implications as it points to the likelihood that writing transfer for L2 learners is greater if students perceive similarities in writing-based activities across a variety of courses that employ writing tasks. And yet in a 2009 study in which James follows up on the effect of perceived task similarity on writing transfer, data reveals that students who were asked to look for task similarities did not demonstrate any more evidence of learning transfer than those who were not asked to look for task similarities. This finding, among others, leads James to conclude that while transfer of learning outcomes from an ESL writing course to a substantially different writing task did occur for certain students, many students were constrained by their perception of task dissimilarity. The study's focus on identifying task similarity before the task was completed was not sufficient to overcome students' views that the writing task was inherently different and as a result did little to promote writing transfer (James, 2009, p. 79).

In examining scholarship that considers transfer issues in relation to the intersections of genre acquisition, language, and writing, Bawarshi and Reiff's claim that "genres situate and distribute cognition [and] frame social identities" (2010, p. 95) is particularly meaningful for L2 students who bring different learner identities and academic habits and practices to the classroom and require 
teachers to be more attentive to how prior experiences shape writing produced in new contexts (Hyland, 2007). As Johns (2011) considers the role and value of Genre-based Writing Instruction (GBWI), she discusses approaches to genre pedagogy that promote high road transfer. Drawing upon comments made by professionals in L2 contexts she notes that while it is indeed valuable to focus initially on textual structures (especially when working with beginner or novice writers), writing instruction must then "move towards an integration of theories and practices that value analysis of context, complex writing processes, and intertextuality" (Johns, 2011, p. 64). The implication of Johns' claim is that for successful writing transfer to occur, L2 writing students need not only to understand the temporal and shifting nature of texts but also be willing to use knowledge from prior settings as they begin to recognize the situated nature of all writing tasks and are therefore able to meet their demands in future settings.

While Johns succeeds in laying out the enormous potential of GBWI, she ends with the concern that "there has not been sufficient concern about, or research on L2 novice students, and the GBWI that is appropriate for them" (2011, p. 66), pointing to the larger need for studies that demonstrate a positive relationship between writing transfer and Genre-based Writing Instruction. Gentil (2011) sounds a similar note in his study of the potential benefits of a biliteracy approach to genre research as he examines how multilingual writers develop genre expertise across languages. He emphasizes the importance of learning and transferring common underlying proficiencies (CUPs) from an L1 or "stronger language" to L2 in order to develop genre competence, but he also warns that such learning does not guarantee that "transfer of genre expertise across languages will necessarily occur or be successful" (2011, p. 20).

In an attempt to theorize L2 writing transfer, DePalma and Ringer (2011) propose "adaptive transfer" as a useful construct that might help account for the ways L2 writers not only reuse, but reshape, and reconstitute prior writing knowledge in new learning contexts. They define adaptive transfer as "the conscious or intuitive process of applying or reshaping learned writing knowledge in new and potentially unfamiliar writing situations" (2011, p. 135). In promoting adaptive transfer as a critical, dynamic model of writing, the authors emphasize how such a model "views individuals as the locus of transfer" (2011, p. 142) since it values the agency of L2 writers as they not only use learned writing knowledge but transform such knowledge based on the demands of the new rhetorical contexts. L2 writers thus become "potential contributors" rather than "passive recipients of the knowledge and conventions of a discourse of power" (DePalma \& Ringer, 2011, p. 142). As much as adaptive transfer appears to be promising as a multidimensional, multidisciplinary framework for studying writing transfer, Grujicuc-Alatriste (2013) questions several aspects 
of the framework, particularly how the breadth of its scope affects applicability across various writing situations; how its relationship to writing and language socialization remains largely unexplored; and whether "reshaping" of writing knowledge is just another form of genre instantiation (Swales, 1990) that cannot be simplified and thus requires further examination. A concern about the lack of practical methodological and pedagogical tools for the implementing adaptive transfer is also noted.

The L2 transfer research studies referenced here display awareness of concerns about small size, context, and generalizability of findings; there are a variety of limitations on transfer, and often claims about evidence of transfer are followed by caveats about constraints. Even theoretical frameworks that are useful for understanding transfer, such as the one proposed by DePalma and Ringer, reveal limitations in terms of application. If we are to agree that all learning is situational and occurs within highly specific contexts, and that the learning of writing is a situated activity (Lave \& Wenger, 1991), then it becomes a bit clearer as to why scholars attempting to understand writing transfer processes tend to express ambivalence about and point to the limitations of positive findings of transfer. It is not that transfer is an illusory or slippery concept, something that is impossible to achieve, but that to recognize instances of transfer in particular research contexts is also to recognize the attendant limitations of such contexts. It is important, then, to reflect upon why it is that definitive claims about transfer are often conditional, especially for L2 learners. Perhaps it is because such a view relies upon the understanding that any claim about successful transfer is highly situational, context- dependent, and therefore unsuited to broader generalizations about transfer.

\section{Threshold Concepts, Troublesome Knowledge, and Liminality}

To approach and to seek to understand writing transfer as a binary, as something that either occurs or does not, is to subscribe to a reductive and ultimately unproductive view of transfer. What might be a more fruitful approach is to understand what happens when transfer is attempted, both from an instructional and learning perspective. Meyer and Land's recent theoretical approach to learning processes introduces the basic notion that learners negotiate disciplinary knowledge in the form of specific, foundational ideas known as "threshold concepts" that are "'conceptual gateways' or 'portals' that lead to a previously inaccessible, and perhaps 'troublesome,' way of understanding something” (2005, p. 373). Threshold concepts are constitutive of a dramatic turning-point, a crucial transformative moment in the understanding of complex discipline-specific ideas and ways of thinking which are essential for progress and continuity of learning. They 
represent not only a conscious, active, and conceptual way of understanding disciplinary knowledge but also the process that learners undergo on their way to gaining such knowledge (see also Adler-Kassner, Clark, Robertson, Taczak \& Yancey, this volume). Such a transformative view of learning as represented in the notion of threshold concepts has particular relevance for L2 students for whom developing a writerly identity in relation to the English language may represent the crossing of cultural, rhetorical, and linguistic thresholds.

While boundary-crossing itself is a landmark of learning, research in threshold concepts also focuses on the attendant notion of what David Perkins (1999) calls "troublesome knowledge," knowledge that is "alien," difficult to comprehend, and often intellectually at odds with what is already known. Recognizing the challenges inherent in the social construction of knowledge, Perkins points out that "different kinds of knowledge-inert, ritual, conceptually difficult, and foreign - are likely to prove troublesome for learners in different ways" (1999, p. 8 ), and as learners navigate and grapple with these difficulties, they occupy and pass through a state of "liminality" - "a suspended state in which understanding approximates to a kind of mimicry or lack of authenticity" (Meyer \& Land, 2003, p. 10). In short, threshold concept theorists contend that learners often not only have trouble reconciling new knowledge with previously held beliefs and ideas as they struggle to grasp foundational concepts within a discipline but also that this struggle happens during the "liminal" stage - a period of disorientation essential to a growing awareness of learning-that leads to disciplinary identity formation and participation. As they pass through or occupy the liminal space, the transformation in the learner's identity that occurs as a result of a shift in language and thinking (Land, Rattray \& Vivian, 2014, p. 2) is particularly relevant for language learners who are just beginning to engage with new linguistic forms and genres of writing.

As such, in negotiating the new and unfamiliar terrain of college writing courses, multilingual students-who generally come from very diverse cultural, linguistic, and educational backgrounds-inevitably encounter difficulties that affect their learning experience in such settings. Whether they are visa-bearing international students for whom English is a foreign or second language, or US-educated English language learners (often known as generation 1.5 students), college writing courses are challenging spaces where language proficiency and literacy experiences are foregrounded and become an explicit part of the classroom experience. Here L2 students encounter tasks that not only demand general fluency and command of the English language but also a basic knowledge of rhetorical strategies and writing conventions with which they may not be fully familiar. As a result, the setting, the context, the tasks, and the overall goals of the writing course may all appear to be distinct from those encountered in other learning 
environments. Further, given the wide range of contextual factors such as institutional setting, placement policies, curricular goals, course materials, and pedagogical approaches, L2 writers' particular experiences in an L2 writing course are bound to vary but they would nevertheless be expected to work toward achieving specific writing goals and outcomes as determined by a first year writing program. For many L2 students who have little or no background in text-based critical, analytical writing, adjusting to the academic expectations of a writing course-even one that is designed with non-native speakers in mind-may appear conceptually troublesome and may thrust them into a liminal space where they struggle with new and unfamiliar writing skills and knowledge.

\section{L2 Students and Writing Difficulty}

To understand how international students navigate the challenges of a first year writing course, I conducted a research study in a six-credit linked course designed for multilingual students that I taught in the first year writing program of a mid-sized private university in the northeastern part of the United States. The course, designed for underprepared L2 students, links a first year writing course with a reading and writing lab so that students have additional time in class to work on their writing skills. With Institutional Review Board (IRB) approval, in the fall semester of 2012 I collected data in the form of one brief literacy history narrative and responses to three focused reflective writing prompts. The literacy history narrative was assigned early in the semester and required students to reflect upon their English language experiences, specifically related to reading and writing, and to their sense of self as users of English. This is an assignment that is normally included in the linked course syllabus because it provides crucial information about my students' prior language and writing experiences and how they describe the identity or persona they adopt - whether consciously or unconsciously-when they write in English. The task conforms to the imperative articulated in one of the transfer principles of the Elon Statement on Writing Transfer that "Prior knowledge is a complex construct that can benefit or hinder writing transfer. Yet understanding and exploring that complexity is central to investigating transfer" (2015, p. 4) as it allows both the students to develop an awareness of this "prior knowledge" and instructors to determine its benefits and limitations for future instruction.

Participants in the study also responded to three focused reflective writing prompts, each written after the completion of formal essay assignments that were required for the course. In these responses participants reflected upon the difficulties they faced as they completed the formal essay assignments, discussed the particular strategies they employed to overcome these difficulties, and described 
their perceptions about what they were learning about writing and becoming a writer. Instructors may recognize elements of these reflective prompts in what is often taught as "meta-writing" where students submit a short reflective passage on their essay writing experience-particularly the process - at the end of an essay assignment. The prompts used in my study are a more elaborate version as they not only include questions that guide the students through the metawriting process but also require detailed responses for each question. While they were particularly useful for the research study, the prompts are regularly integrated into the L2 course syllabus. The prompts also actively enact two principles from the Elon Statement on Writing Transfer. The first principle addresses the value of meta-awareness for transfer and states that "Students' meta-awareness often plays a key role in transfer, and reflective writing promotes preparation for transfer and transfer-focused thinking" (Elon Statement on Writing Transfer, 2015 , p. 5) The second principle is particularly relevant to metacognition of multilingual students as it emphasizes that "The importance of meta-cognition of available identities, situational awareness, audience awareness, etc., become even more critical in writing transfer between languages because of the need to negotiate language-based differences and to develop awareness about the ways language operates in written communication across languages" (Elon Statement on Writing Transfer, 2015, p. 5).

The study allowed me to pose questions related to writing difficulties that I hoped would reveal students' perceptions of the writing processes they participated in within the context of a college level writing course. A total of 10 subjects, all visa-bearing international student who were native Chinese speakers, had completed the program's online directed self-placement survey and placed themselves into the linked Core English 1201 (3 credits) and Reading and Writing Workshop 0180 (3 non-counting credits) for L2 writers. The reflective writing prompts were integrated into the syllabus to encourage the practice of metacognitive activities and help build students' ability to reflect upon their learning experience in the course.

In order to select two subjects whose reflective responses I would examine closely for the purposes of this article, I had to look carefully at the data I had collected that term. All students who participated in the study were able to write reflectively but many produced responses that were short, repetitive, and lacking in detailed descriptions of the difficulties they encountered as L2 writers. These students, who comprised the majority in the course, had less than a year's training in English, were in the early stages of English language acquisition, and had no prior experience in composing critical, analytical essays in English. While they did progress during the semester and were gradually able to generate several pages of competent writing for each of the three formal written assign- 
ments, because of linguistic constraints they struggled to describe the complex experiences and processes in the reflective writing prompts. I considered these students to be in a pre-liminal stage of their development as English language learners and worthy of a separate investigative study as a sub-set of L2 writers who are in the earliest stages of language learning but are nevertheless enrolled in credit-bearing college writing courses. Ultimately, I selected two of the most competent writers in the class-Shiyu and Ming (both pseudonyms)—as subjects for this article because they possessed sufficient language skills to produce reflective writing that was both meaningful and that responded thoroughly to the prompts given as part of the research project. They also serve as models of typical but slightly advanced and highly motivated international L2 learners who are better prepared, both rhetorically and linguistically, for the demands of college writing courses.

The literacy history narrative, assigned during the first week of classes, was an in-class writing task designed to elicit general information about students' English background and specific details about their writing experiences. Because these details provide a crucial backdrop for their writing performance in the course, students were informed that the narratives would be used during the semester to guide me in individual instruction and feedback on writing assignments. Also, since we are required to use Blackboard ${ }^{\circledR}$, a web-based course management system, students had access to all the formal and informal writing assignments posted on Blackboard's Discussion Board, including the literacy history narrative and the reflective writing prompts.

\section{Literacy History Narrative Prompt}

Please write a carefully organized essay about your experiences with writing in English. Respond to the questions below as you compose your essay.

1. What types of formal or informal writing are you most used to or familiar with? For how long have you been doing this kind of writing?

2. What does academic writing mean to you? What kinds of writing do you associate with it?

3. Have you ever written about non-fiction texts? If yes, please describe the kinds of writing you have done.

4. What kinds of writing do you find most difficult? Why? Please include any other information about your experiences as a multilingual user of English such as your English language background, the age (or grade) you started learning English, how much experience you have with reading and writing in English, and how you would describe your identity as a reader, writer, thinker, and speaker in English. 
The reflective writing prompts were designed as a set of questions and also administered in the form of in-class writing three times during the term. The first prompt was assigned after students completed the first formal writing assignment (Essay 1), an analytical essay for which students had to analyze and develop their own idea in response to one self-selected text from three assigned readings. The second prompt was completed after Essay 2, an image analysis essay that also required integration of ideas from two assigned readings; and the third prompt was completed after the research assignment (Essay 3 ), the third and final writing assignment that required students to come to an understanding of a historical or political issue by examining at least three textual sources that represented the issue from different, possibly conflicting perspectives.

\section{Reflective Writing Prompt 1}

- What did you struggle with the most as you wrote Essay 1? Describe each problem in detail.

- Address each of the problems you stated above and explain the strategies you used to overcome each of these difficulties.

- How have your perceptions about academic writing changed since the start of the semester?

- What are you learning and realizing about writing and being a writer?

\section{Reflective Writing Prompt 2}

- What did you struggle with the most as you wrote Essay 2?

- Address each of the problems you stated above and explain the strategies you used to overcome each of these difficulties.

- How have your perceptions about academic writing changed since you wrote Essay 2?

- What are you learning and realizing about writing and being a writer?

\section{Reflective Writing Prompt 3}

- What was the most difficult aspect of writing this essay?

- What are your strengths now as a writer and what do you still need to work on and improve?

- What have you learned in this course about writing and being a writer? Consider how your thinking about issues such as reading, revision, self-review, audience, and developing ideas has changed since you've started writing in this class. How you have changed as a writer since the beginning of the semester? 


\section{“The Most Tangled Part . . .”-The Case of Shiyu}

A cheerful, bespectacled 18-year old in a petite frame, Shiyu is an Accounting major who grew up in Shenzhen, China, and came to the United States in the spring of 2012 to study toward an undergraduate degree in Business Management. In her literacy history narrative she writes that she started learning English from the age of 6 at grammar school where she only learnt "basic alphabets and some simple greeting sentences." In middle school she began reading "articles" and writing short essays, and it was not until her freshman year at high school that she had "experiences with writing longer essays related to certain topics." The type of English writing she is most familiar with, she notes, is the formal "MLA pattern paper" which she learned to write when she worked on a research paper on Shakespeare's marriage in a non-credit bearing ESL Advanced Writing course during her first semester at the university. She also wrote a "book critique essay" in a Microeconomics class she took the following summer. Interestingly, while she claims she is familiar with this type of "formal" writing, she makes it clear that she did not engage in any formal academic writing before arriving in the US. She states, "E-mails, texts, letters are playing a significant role in my daily life. I have been engaged in these informal writings since I started short writing essays." She believes that even though she has been learning English for over a decade, "The most challenging writing to me is academic writing. It is mostly due to the language barrier." She then explains that she believes academic writing is "formal writing based on various of researches, surveys, and other kinds of ways to express academics' feelings and idea toward the world" and that "usually, research papers are associated with it." In the short time that she has spent in an academic setting in the US, she has not only learned to associate academic writing with research papers but also feels that her language skills are inadequate for this type of writing as she lacks the requisite "vocabulary, grammar, as well as slangs." Here it seems as if Shiyu associates the word "slang" either with idiomatic English or general fluency, neither of which she sees herself possessing. She concludes with a realistic appraisal of what lies ahead in the writing course noting how she will face "a ton of difficulties while learning a new language, such as English.”

In the first reflective writing prompt, Shiyu identifies two aspects of writing with which she struggles the most while attempting textual analysis in Essay 1. The first is difficulty with the analysis itself. Shiyu believes that she wasn't able to analyze the text in "the proper way" as she had "many good quotes but only dropped the direct long quotes without paraphrasing or giving contexts" and "didn't explain some of the author's ideas from the quotes." As she grapples with the multi-layered task of examining the text while also responsibly integrating 
source material into her writing, she works on revising the draft by returning to "every quote presented in my essay so as to find the relationships among them." She notes that the most important strategy she used was "to narrow down all the long, repeated quotes and use my own words to explain them." The second area of difficulty, Shiyu writes, is "critical thinking and explore my own ideas" because she was "simply restating part of the author's main ideas but not connecting the ideas with my own experiences." She associates critical thinking with her "experiences" and perhaps with a personal approach to the text which is separate from the "author's ideas."

Textual analysis, which not only involves discussion of the ideas of the text but also integration of the material (in the form of quotations and paraphrase), is new to Shiyu both conceptually and as a practical skill. Yet, its obviously visual component makes it a manageable difficulty and she demonstrates a growing understanding of how to engage with the quotations she has selected for her essay. The difficulty with critical thinking, a far more abstract and sophisticated act, is harder for Shiyu to express and to overcome. Yet she writes about the "significance" of critical thinking in this way: "Sublimation [sic] the ideas you learnt from the text is a key step to improve our writing." By using the word "sublimation,"-a synonym for modification — Shiyu seems to be saying that critical thinking may have something to do with working toward transformed ideas and not repetition. This becomes clear when she notes that her "insights about academic writing have changed. Academic writing is not only about the summarizing the academic texts, like a book review; but also a stage to give yourself an opportunity to show how you benefit from them and what is your own thinking of different values." The metaphor of writing as a "stage" which hints at the performative aspects of composing fits neatly into Shiyu's growing belief that she needs to demonstrate her own agency as a writer in her essays. She wraps up her reflective essay by stating that "Perhaps the big difference between writing and being a writer is that everyone can write randomly without thinking; while as a writer, we need to demonstrate our critical thinking ideas in a logical way. This transformation depends on how hard we try to think." Shiyu seems to be coming to grips with issues of writerly identity not commonly seen among novice L2 writers. To her, the moment of transformation-when one crosses a threshold and becomes an academic "writer"-occurs as one engages intensely with the text as a critical thinker. In the development of this identity is also the conscious recognition, and hence transformed understanding, of writing and thinking as complementary and constitutive acts. For novice L2 learners, focused critical reading holds promise as a threshold concept especially if L2 learners have little or no experience reading lengthy, complex texts and hence find troublesome the intellectual processes necessary for critical engagement with such readings. 
In her second reflective writing assignment Shiyu explains that "the most tangled part" of writing the second essay (which required her to analyze an advertisement through the theoretical lens of two published texts), was to "seek the main problematic idea in the printed ad that I used then to connect with the two articles." The dual-and complex — task of analyzing the image and developing linkages with the ideas of the articles that discuss complex approaches to interpreting images was clearly quite complicated for Shiyu. But she notes that she "still accomplished the task by overcoming these difficulties." After receiving instructor feedback she "pick[ed] the correct ideas from the advertising ... listed all the ideas that can be revealed in the commercial and remain the primary ideas by crossing out the secondary ones." Relying on a strategy she learned while writing Essay 1, she reviews the two readings once again "to select the important quotes which would be a great evidence to support my views." In this response Shiyu emphasizes that "by practicing writing" in the course, she has a "clearer notion of academic writing after completing Essay 2." What she has really learned to do well in the second assignment is "the development on combining ideas with different quotations." One of the working principles in the Elon University Statement on Writing Transfer states that "Any social context provides affordances and constraints that impact use of prior knowledge, skills, strategies, and dispositions, and writing transfer successes and challenges cannot be understood outside of learners' social-cultural spaces." In Shiyu's case, her Chinese educational background and prior writing experiences, which she notes had not sufficiently prepared her for the type of analytical writing required in first year writing courses in the US, appears not to have any significant impact on her current writing. The vast differences between L1 and L2 writing (Silva, 1993), between Chinese school writing and those practiced in US academic settings (Sullivan, Zhang \& Zheng, 2012) in particular, may have acted as constraints and prevented Shiyu from re-engaging any prior writing knowledge and adapting such knowledge for new rhetorical purposes. Predictably, and in a sign of positive near transfer, it is the new learning she encounters in the writing course, specifically academic discourse and analytical writing, that acts as an affordance; she relies on newly-learned strategies from the first writing assignment for the more complex analytical work of the second writing assignment. She explains that her developing sense of a "good writer"-perhaps an implied "English" writer-is related not only to "critical analysis, but also is concerning the ideas (either new ideas or critical ones) and how to find proofs from outside," skills she had not been taught in the Chinese setting. Shiyu notes a growing awareness of the importance of process - another approach to writing that is new to her-claiming that "revision and self-review are the most beneficial step to rethink essays." 
At the end of the semester, looking back at her learning experience in this linked course for L2 writers, Shiyu discusses the difficulties she faced as she wrote the research assignment where students were expected to produce at least six pages of writing. The assignment required students to examine a historical event (or issue) of their choice by searching for and evaluating competing narratives that not only allowed them to see the event from multiple perspectives but also gave them the opportunity to develop a more nuanced understanding of their topic. As she explains, "The main purpose of writing this paper is to identify the China and Taiwan issue and give different perspectives on this topic in order to find the best solution." Reflecting back on class discussions on how awareness of audience is critical to both developing and executing the research project, Shiyu starts out by noting that as she developed the assignment, she was very aware of the "potential reader" of her essay and "what they would learn from it." She notes that the notion of addressing an audience that might actually be affected by the writing was "new knowledge that I would never think of before writing my essay." As she notes in her literacy narrative, although Shiyu was familiar with basic genre types (such as emails, texts, and letters) that require a keen sense of a readership, she had no prior formal instruction in audience awareness, either in L1 or L2. Once she realizes the importance of audience, she pays close attention to the effect of her ideas, and especially her own political views, on a future reader. The purpose of her essay, she claims, is to give her audience "an overall view of understanding the relation between China and Taiwan and provide with my own bias that either unification or independence is not practical on the current situation so maintaining the status quo would be the best option to resolve this issue for the time being."

Given that she had taken on a rather complex topic, Shiyu admits that she encountered "diverse difficulties" in writing the essay. For instance, she claims that she struggled with "narrowing down the topic and coming up with proper questions." She also had trouble "finding the right sources" since "there are thousands of books, articles, journals, and news relative to the topic but selecting quotes and analyzing them can be a challenge." Commenting on her struggle with the process of synthesizing source material while also developing a point of view, she notes the complexities inherent in the intellectual work required "to collect one side of sources as an evidence to support one perspective, and then connect all the sources with its analysis to develop a standpoint." The difficulties here are both procedural and conceptual, and like any novice writer, Shiyu finds it hard to separate the two. While she mentions the importance of "editing the information in a clear and brief way" she associates editing with effective use of sources as she tends to use "more quotes than the explanation or understanding towards that quote." She finds this heavy reliance on source 
materials to be problematic as "it is easier to be convinced by other people's idea and replace ourselves." She is highly aware of the difficulty she has juggling with sources, but in her articulation of the idea that excessive use of source material has the potential to displace the writerly self, there is an indication of her growing understanding of a key concept in writing-effective use and integration of evidence. She concludes with a remarkably insightful comment on the effect of excessive dependence on sources: "there will be no individual thinking and ideas but only interpretations and those kinds of writing cannot be regarded as academic writing." Implicit in the final sentence is Shiyu's transformed view of academic writing where she recognizes the centrality of the writerly self in formal discourse, the one that is not only present in the text as a thinking self but who also responsibly pulls together and reconciles other competing voices.

While Shiyu doesn't provide details about the particular strategies she employs to address these issues, she emphasizes that she eventually overcame those difficulties "by trying hundreds of ways, such as send an email to the author of a book which is my first source, or interview my friend who is a Taiwanese to understand the second perception better." She finds the subject of the research essay to be so compelling that she reads an entire book on China-Taiwan relations and takes the initiative to write an email to the author inquiring further into the conclusions he draws in the book. Besides reflecting her control and agency as a writer, the decision also indicates her commitment to the pursuit of knowledge, and she sums that up by saying: "for my research essay, I find it really interesting that I can't stop writing."

Reflecting on her overall growth as a writer over the course of the semester, Shiyu compares her experience in an Advanced ESL writing course with what she has learned in the first year writing class. She notes that the non-credit bearing ESL writing course she had taken during the first semester was "not very useful" because though she wrote a paper on the "marriage of Shakespeare" and learned how to "do research using primary and secondary sources," she "did not get much information neither on how to better use quotes to support my idea nor how to do deeper analysis." In the college writing course she learned to "summarize the essay in a brief and proper way, deeply analyze and support with proper quotes, better develop connections between two texts, and use both in-text citation and work cited in a proficient way." She concludes by saying that it was only after she started studying at the university that she "began writing more in English like a real writer (my emphasis) who can express his/her idea of life, people, and what is happening around them in a skillful manner." She notes that at the end of the course she finds that she is "more confident and passionate in writing in English," a testament to her attention to the power of language and its singular place in her growth as a writer. 
Several important points emerge in Shiyu's case that shed light on L2 transfer issues, particularly for novice L2 writers. There is no indication in her self-report that her prior English writing experiences - both in China and in an ESL course in the US - have any significant bearing, positive or negative, on the writing she does for the college writing course. The differences in types of discourse, that is, between informal writing such as emails, texts, letters and the more formal analytic college writing, seems to have naturally eliminated the possibility of any re-engagement of prior knowledge. If there was any occurrence of "adaptive transfer," (DePalma \& Ringer, 2011) any reliance on and application of prior writing knowledge, Shiyu makes no mention of it perhaps because the reflective writing prompts did not require participants to focus explicitly on whetherand to what extent - they were drawing upon previously learned genres to complete their writing assignments. However, there is some evidence of near transfer as Shiyu notes in her reflective writing that she successfully applies analytical skills learned in Essay 1 to the more complex writing requirements of Essay 2 demonstrating transfer of skills between similar contexts. The degree to which her heightened sense of audience, her developing identity as a "real writer," and her newly acquired writing knowledge will be re-activated in new writing situations will depend upon Shiyu's metacognitive strength in recalling prior knowledge and ability to reflect upon the demands of the situation when faced with dissimilar tasks, and upon genre-based, transfer-focused writing instruction (Johns, 2011). Furthermore, questions of far (or high road) transfer of L2 learners may be better addressed by longitudinal studies of L2 writing.

\section{“The Understanding Has Been Changed”-The Case of Ming}

Ming is a tall, quietly dignified twenty-year old from Beijing who is an undeclared Business major studying toward a degree in Business Management. $\mathrm{He}$ arrived in the US in the spring of 2012 and enrolled in three ESL courses before taking College English for L2 writers in the fall of 2012. He writes that he started learning English in grammar school and was introduced to non-fiction writing in middle school when his "Chinese teacher gave us an article in newspaper and then she told us to write our opinions about the air pollution." $\mathrm{He}$ explains, "This is my first non-fiction text that I've done and my point of view is that people shouldn't make money by destroying the environment because the Earth is the only place that people can live on. If human damaged the only living place, we would be homeless." In high school Ming was introduced to the research paper and was "taught to structure and how to write academic essay based on non-fiction readings." He states that he considers himself "as a reader and part of thinker in English because I cannot express myself properly sometimes." 
He attributes his lack of proficiency to a lackadaisical attitude toward learning and shares that he was a "naughty boy" in school who "didn't want rules to block me and prefer to finish the things in one step because it's quicker." Noting the trouble he has had organizing his writing Ming states that it is "hard for me to write response to an article or a point of view. The ideas just come out my mind and I don't know how to arrange the structure of the essay and divide ideas into different parts." Showing an awareness of his tendency to repeat himself and his inability to develop ideas he states "what's more, I may separate the same idea into different paragraphs."

In the first reflective essay Ming writes about the difficulties he confronts in Essay 1 and how he "struggled to do the thesis and connect the next paragraph fluently." He has a "thesis" in the first paragraph "but the paragraph after the introduction is about the article. It took me a lot of time to solve this problem." He has trouble transitioning from general ideas that he calls his "thesis" to textual analysis and in his words, "Transferring sentences didn't seem perfect." To solve this problem he "tried to find the connections between the thesis and essay." He then notes a second problem "which about how to do textual analysis and add my opinions" and to address this he "started the textual analysis first and added my personal opinion and express like agree or against the ideas that author came up and why I agree or disagree." From Ming's standpoint, "textual analysis" cannot include his "opinion" and so he tackles these as related but separate tasks.

Ming's biggest problem, he notes, has to do with "building the structure." He worries that, as a result of his inability to clearly organize his thoughts, "Different ideas may be put in the same paragraph and the ideas are not organized logically." At the same time, he is concerned that this lack of proper organization has another effect: "the ideas of the essay don't go deeper, but like the electrocardiogram. The ideas which should be put together are separated into different parts and some of the ideas come up suddenly. The whole essay doesn't seem like a whole without logic and transition sentences." Here Ming expresses what he perceived to be the most troublesome aspect of writing in English, his ability to fluidly and logically organize his thoughts while also maintaining a depth and integrity of ideas that "go deeper and deeper rather than move horizontal which means adding materials." A good writer is one who knows how to "organize the article well and each paragraph connects perfectly. The different ideas won't come out suddenly the ideas should be prepared before they come up." As he concludes his first reflective essay, he focuses on a developing writing skill. He states "In this semester, I feel free to write because I learn how to use quotations. When I use the quotes, I should add them in sentences and add some context. Do the contexts before giving the quotations and explain the importance of the 
quotation and how I connect my ideas and the quotations. And my essays are more substantial than before."

In his second reflective essay, Ming reiterates the same struggles and successes he noted earlier, emphasizing the difficulty with organization and his growing ability to integrate source material into his writing. He writes that although he spent "much time" on the second formal writing assignment, he still had trouble balancing the different parts of his essay. He notes, "Organizing the structure is the biggest problem that I have now. I use too many pages to explain Berger's essay without connect the advertisement that I choose. It's like I use Berger's essay to explain Berger's ideas." As he contemplates on revision strategies he notes, "I need to use Berger's ideas to explain the problems which hide in the publicity. Analyze image first, find the details in the essay and then use Berger's ideas to explain the problems in the advertisement. Use his ideas like reference. Don't let his ideas take over the essay." Ming realizes that Berger's ideas are central to his analysis of the advertisement but he "did spend much time on analyzing Berger's ideas, which is the reason why my essay has less voice from myself." He arrives at a new understanding, it seems, of the importance of authorial voice in a piece of writing, and reminds himself that "Berger's idea is the supporter" and that as a writer, Ming should not "let him to take over the essay." He ends the reflective piece by emphasizing that he has learned "how to use the sources and analyze the references in the article" and that "using quotation is the way to make the essay strong." He also values the importance of close reading so that he can "understand the deep ideas of the articles."

For the last formal writing assignment of the course, the research essay, Ming chose "to interpret the Diaoyu Islands issue. The territory conflicts between China and Japan. And figure out the reasons why both China and Japan want to take these islands and why America was involved in this issue." In his third reflective essay he explains that he selected this topic so that he could find out "what will America get during this issue?" and enlighten his audience who he believes are "the people who argue about the complicated historical issue and those don't get the deeper meaning—-game playing among America, China and Japan." He states, "I hope that my audiences could learn something from essay, which is to watch a same thing through different angle rather than make decision in haste." Working with a topic that is both politically sensitive and complicated, Ming invariably comes up against the same trouble spot he has been struggling with from the beginning of the term-how to organize his ideas and create a satisfactory structure for his essay. He writes, that "the most difficult aspect of writing the research paper is organizing the structure of the essay. I need to write with history order because it makes easier for readers to understand the historical documents that both China and Japan provide. The methodic 
[sic] structure helps the readers to reach author's goal of writing gradually." But while he is concerned about pulling the source materials together, Ming also displays an awareness of the effect that a chronological ordering and discussion of the source material will have on his audience. He writes that a "well-organized structure give people clear sense of the ideas ... Otherwise, the ideas may not go deeper and the whole essay is like adding material. For instance, if there are historical documents in the essay, the history details will be written in history order. If the history details weren't placed in history order, readers might feel confused about the progressing of the events." What is clear here is that as Ming reflects upon what seems to be troublesome-thoughtful analysis of textual material and organization of ideas — he simultaneously considers writing strategies that will help him overcome it.

Ming also highlights another recurring writing trouble-spot-improving "connections between ideas" so that "the ideas go deeper naturally." He notes that he still struggles to do this well because he writes "a little bit more paragraphs on the same idea and paraphrase other authors' ideas sometimes. I may focus more on my own ideas rather than others' idea." Summing this up in pithy note-to-self statements, he writes, "Don't let the quotation take over the whole. Use the quotations like reference." He elaborates on the usefulness of this newly-found skill: "Using the quotations properly is the first thing that I learn in this course. In high school, the quotations in my essay don't connect the ideas fluently. What I know is to use the quotations to support the ideas. However, I don't know anything about how to use the quotations, which is the reason why the quotations appear suddenly. Now, I know how to make quotations link glibly." In a commentary on what he believes he has learned in the course he focuses on the importance of reading and critical thinking skills. He writes, "This course teaches me to think critically and many writing skills, such as, connecting the ideas and quotations, organizing the essay structure and transition sentences, making the ideas go deeper. Before taking this class, I may only mention the surface meaning of the article rather than deep meaning. For instance, I even don't know there are hidden ideas which may transform people in the ads. I can think critically after taking this course. The understanding has been changed. Writing is not all about personal opinions, it includes critical thinking and developing ideas."

While Ming does have some prior experience with academic writing, he repeatedly writes about his struggle with in-depth analysis and logical development and organization of ideas but he doesn't discuss whether he draws upon any prior writing knowledge, both in L1 and L2, as he approaches college writing assignments. Sullivan, Zhang, and Zheng explain that a genre of lyrical prose called sanwen - a stylized and expressive form of writing commonly used in 
Chinese writing instruction - is characteristically understood to mean "scattered writing" since often "there is no restriction on topic or structure" (2012, p. 310). It is possible that as a novice English writer Ming instinctively falls back upon familiar discursive strategies used in Chinese lyrical prose to compose analytical essays, as a result of which his writing moves "horizontally" instead of going "deeper and deeper." The differences between a Chinese prose style based on expressive writing and the conventional text-based, critical and analytical writing valued in first year writing courses may not only account for the difficulties Ming faces but also reflect troublesome knowledge that possibly interferes with writing required in the new setting. In hindsight it is clear that a greater focus on culture-specific rhetorical knowledge, both in the literacy narrative as well as the reflective writing assignments, might have allowed Ming to be more aware of the differences in discourse patterns between Chinese prose and western prose styles and provided more flexibility in the writing process.

\section{DISCUSSION}

Although like many international students who come with a strong English literacy background Shiyu and Ming are relatively fluent in English, they are also novice writers who find themselves adapting to a new and unfamiliar learning environment - the college English writing course. In this struggle to adapt, they find themselves in a liminal state where confusion and disequilibrium reigns. In large part, their status as novice L2 writers whose cultural background and prior writing experiences may not have sufficiently prepared them for the kinds of writing expected in first year writing contribute to this disorientation. But the context of the disorientation - the influence of different rhetorical traditions upon the different types of writing instruction experienced in China and in the US (Sullivan, Zhang \& Zheng, 2012, p. 323)—if purposefully integrated into L2 writing instruction can help diminish the confusion students experience when faced with new writing tasks. When consciously invoked, conversations about differences in rhetorical traditions can help bring these differences to light, allow L2 students to make appropriate writerly choices, and effectively situate them in the new writing context.

While Ming and Shiyu do find themselves caught between rhetorical traditions, as they develop as writers they are able to productively negotiate writerly difficulties and demonstrate their ability to proceed along the liminal spectrum. They directly address the difficulties they face, and in their reiteration of positive outcomes and emphasis on strategies used to overcome these difficulties, there is also a sense of accomplishment and growth that outweighs the struggle they face as L2 writers. If they entered the course at a pre-liminal stage in terms of 
understanding what it means to compose in English, given the evidence of their deepened perspectives on writing and becoming writers, at the end of the term they seem to be poised at the intersection of the liminal and post-liminal spheres in their writing development. Undoubtedly, their reflective writing responses allow us to get an intimate glimpse into this process; it is in the articulation of the difficulties and attempts to overcome them that Shiyu and Ming show the most promise. In their engagement with the meta-writing tasks about their writing difficulties there is evidence of a two-fold process: of looking backward at what was new and troublesome and of looking forward at a deeper awareness of writing processes and at strategies for resolving them. Thus in the reflective writing we see them as learners occupying a liminal space where they struggle to make sense of new writing knowledge as they identify trouble spots and stumbling blocks, but which also opens up a generative space that is expansive, dynamic, and potentially productive.

Nevertheless, while teacher-initiated metacognitive tasks can encourage introspection and evaluation of their growth as writers, without external structures that create possibilities for reflection it is questionable whether L2 (and even L1) students would be motivated enough to seek out opportunities that would help build meta-awareness — and meta-knowledge - of their troublesome journey in first year writing courses. Novice L2 writers, in particular, need to be guided through the various stages of liminality in they continue on this journey, and in Shiyu and Ming's reflective responses we see evidence of the slow but steady progress L2 writers are capable of making. With continued support and creation of opportunities for acts of metacognition, they will continue to develop as writers in general education courses and in courses in the major and across the disciplines. To achieve this, there needs to be continuity from one course to another in the form of curricular structures and instructional materials that allow for expression of L 2 writing knowledge development through metacognitive tasks. One way of implementing this would be to administer focused writing prompts at the beginning of the semester when students reflect upon skills, abilities, and prior writing knowledge they bring to the course. This would serve a dual purpose; it would not only provide instructors with critical information about L2 students' self-perception as related to writing abilities but also allow students to recall how prior writing situations and experiences have shaped their development as writers. Bereiter's observation that "the potential for transfer is not usually thought of as residing in the learner but rather in whatever has been learned" (1995, p. 21) is a critique of the traditional-and largely pessimist-view of transfer that fails to take into account the critical role of learner dispositions, the ability of the learner "to seek out and to create situations similar to those in which reflective discourse was experienced initially" (1995, p. 31). 
Seen through the lens of this dispositional approach to transfer, metacognitive language- both situationally created and self-generated-has the potential to serve as a tool and as a vehicle for expressions of growth in writing knowledge. One can only hope, as does Bereiter, that such growth "reappears" (1995, p. 33) in other learning contexts.

Small learning achievements often represent big steps for L2 learners, and reflection on these milestones in writing knowledge development may also have an impact on the perceived self-efficacy-defined by Bandura as "self-referent judgments arrived at through cognitive processing of diverse sources of efficacy information" (1986, p. 362) — of L2 writers and help build confidence in their ability to take on the challenges inherent in new writing situations. By the end of the first year writing course, Shiyu says she "can't stop writing" and Ming notes that he can now "think critically," statements reflective of both pride and high achievement. If in future learning contexts they are provided with tasks that explicitly address and continue to build their understanding of areas they identify as trouble spots, such as textual analysis, critical reading and thinking, organization of ideas, integration of sources, sense of audience, writerly identity in English, and the genre of academic writing (across disciplinary contexts), they may be able to sustain and deepen their transformed view of writing when they encounter new writing situations and come closer to mastering what could potentially be understood as threshold concepts for L2 writers.

Currently there is ongoing effort in the field of composition studies to identify and investigate concepts that have "threshold" features and that carry disciplinary value (see Adler Kassner et al., this volume, and Adler-Kassner \& Wardle, 2015). In their brief overview of literature anchored in foundational concepts related to writing, Adler-Kassner, Majewski, and Koshnik (2012) propose that this literature-mainly on genre studies and situated learning theory-points to evidence that there are "several interrelated threshold concepts such as genre, purpose, audience, and situated practice that are consistently invoked in the literature on and teaching of writing." As writing scholars continue to work toward establishing what constitutes significant thresholds in the teaching and practice of writing, it is useful to remember that "ways of thinking and practising" also constitutes a crucial threshold function" (Meyer \& Land, 2003, p. 9) and enable students to arrive at a transformed understanding of writing and what it means to be a writer. Thus, metacognitive activities that are intentionally built into course design and understood to represent a "form of engagement" within a larger "framework of engagement" (Meyer \& Land, 2005, p. 57) not only give L2 students an opportunity to see themselves as participants in a community of practice but also establish authentic possibilities for "ways of thinking and practising" - that is, mindful recall of writing-related concepts and subsequent 
text production based on the understanding of these concepts-when they encounter writing-based tasks in new learning contexts.

As growing writers, the difficulties that L2 students face are linguistic, rhetorical, stylistic, and genre-bound, and often reflect a double bind as they struggle to find language that adequately represents the ideas they want to express. In particular, the struggle involved in the conceptual work required of L2 writers as they try to articulate their writing problems is often connected with their ability to find language that adequately expresses these concerns. But this troublesome articulation has the potential to lead to greater understanding once the thought is written and the idea established in words. As Meyer and Land point out, "Language itself, as used within any academic discipline, can be another source of conceptual troublesomeness" (2003, p. 11). For language learners, writing problems are deeply intertwined with language problems since "language is the content" (Reimann, 2002, as cited in Meyer \& Land, 2003). Given this view of the troublesome nature of language, it would be important to keep in mind the ideological implications of establishing threshold concepts in L2 writing as practiced in North America, for a transformed view of writing - a sociocultural act - may appear to promote a "privileged and dominant view and therefore a contestable way of understanding something" (Meyer \& Land, p. 3). From a contrastive rhetoric perspective, contrastive rhetoric being the examination of differences and similarities in English writing, both ESL and EFL, across language, cultures, and contexts (Connor, 2002), writing is a social activity both embedded in and the result of specific cultural norms and conventions. However, as Connor explains, since "the teaching of norms invokes the dangers of perpetuating established power hierarchies" (2002, p. 505), critics of contrastive rhetoric have noted the ideological problems that arise from teaching L2 learners the western conventions of writing that cater to native English speakers' expectations. Given the differences in genre, purpose, goals, norms, and expectations of writing across cultures, L2 writing instructors may well be aware of their pedagogical goals and learning outcomes for the particular population they are teaching. But regardless of the larger intentions and political implications of curricular goals and outcomes, a stronger focus on metacognitive tasks about writing development can help L2 writers articulate their struggles and successes and build their capacity for self-reflection.

Significant variations across institutions in L2 curricular goals, instructional materials, writing tasks, instructor preparation, student ability, and the unpredictable nature and outcomes of the process of learning itself, calls for L2 writing transfer to be understood from a situated learning perspective- through the lens of what may be called a situated approach to transfer-as a process that entails troublesome negotiation of writing knowledge in particular learning 
contexts, and not as an inevitable learning outcome that is generalizable across all contexts and learning situations. Further, connected to this situational view of transfer, it would be useful for instructors to evaluate their own understanding of the threshold concept "variation in student learning" (Meyer, 2012. p. 9) which involves knowledge of "differentiated mechanisms of production of learning outcomes" (author's emphasis) (p. 9). As Meyer explains, the way that students engage with the content and context of disciplinary knowledge varies from individual to individual, and yet instructors struggle to grasp this very fundamental pedagogical concept. This concept takes on a greater significance when we consider the variety and differences in the literacy history, personal background, and prior writing experiences of L2 students and serves to remind us how crucial it is that all writing instructors attend to the differences not only between L1 and L2 learners but among L2 as well.

As Meyer has remarked, "Provoking and managing (author's emphasis) a state of liminality is in itself a useful pedagogic strategy" (2012, p. 12). With the increasing presence in college courses of multilingual writers who bring with them a range of abilities and experiences, there is a need for studies that look more closely at accounts of learning in the liminal space where the struggles and triumphs - the signs and evidence of learning as a recursive as well as progressive activity-is most evident. This will open up the possibility of imagining liminal spaces inhabited by L2 students as not merely sites of struggle, characterized solely by disorientation or confusion, but as generative spaces where troublesome knowledge coexists with emergent understandings and one that should be valued as a productive phase of L2 writing transfer.

\section{REFERENCES}

Adler-Kassner, L., Majewski, J. \& Koshnick, D. (2012). The value of troublesome knowledge: Transfer and threshold concepts in writing and history. In Composition Forum, 26. Retrieved from http://compositionforum.com/issue/26/troublesome -knowledge-threshold.php.

Adler-Kassner, L. \& Wardle, E. (Eds.). (2015). Naming what we know: Threshold concepts in writing studies. Logan, UT: Utah State University Press.

Bandura, A. (1986). The explanatory and predictive scope of self-efficacy theory. The Journal of Social and Clinical Psychology, 4(3), 359-373.

Bawarshi, A. \& Reiff, M. J. (2010). Genre: An introduction to history, theory, research, and pedagogy. Fort Collins, CO: The WAC Clearinghouse/Parlor Press. Available at http://wac.colostate.edu/books/bawarshi_reiff/.

Bereiter, C. (1995). A dispositional view of transfer. In A. McKeough, J. Lupart \& A. Marini (Eds.), Teaching for transfer: Fostering generalization in learning (pp. 21-34). Hillsdale, NJ: Lawrence Erlbaum. 
Bransford, J. D. \& Schwartz, D. L. (1999). Rethinking transfer: A simple proposal with multiple implications. Review of Research in Education, 24, 61-100.

Connor, U. (2002). New directions in contrastive rhetoric. TESOL Quarterly, 36(4), 493-510.

DePalma, M. \& Ringer, J. M. (2011). Toward a theory of adaptive transfer: Expanding disciplinary discussions of "transfer" in second language writing and composition studies. Journal of Second Language Writing, 20, 134-147.

Elon Statement on Writing Transfer. (2015). Retrieved from http://www.centerfor engagedlearning.org/elon-statement-on-writing-transfer/.

Gentil, G. (2011). A biliteracy agenda for genre research. Journal of Second Language Writing, 20, 6-23.

Grujicuc-Alatriste, L. (2013). A response to DePalma and Ringer's article "Toward a theory of adaptive transfer: Expanding disciplinary discussions of 'transfer' in second-language writing and composition studies." Journal of Second Language Writing, 22, 460-464.

Hyland, K. (2007). Genre pedagogy. Journal of Second Language Writing, 16, 148-164. James, M. A. (2008). The influence of perceptions of task similarity/difference on learning transfer in second language writing. Written Communication, 25, 76-103.

James, M. A. (2009). "Far" transfer of learning outcomes from an ESL writing course: Can the gap be bridged? Journal of Second Language Writing, 18, 69-84.

Johns, A. M. (2011). The future of genre in second language writing: Fundamental, but contested, instructional design. Journal of Second Language Writing, 20, 56-68.

Kobayashi, H. \& Rinnert, C. (2008). Task response and text construction across L1 and L2 writing. Journal of Second Language Writing, 17, 7-29.

Land, R., Cousin, G., Meyer, J. H. \& Davies, P. (2005). Threshold concepts and troublesome knowledge (3): Implications for course design and evaluation. In C. Rust (Ed.), Improving student learning-equality and diversity (pp. 53-64). Oxford, UK: Oxford Centre for Staff and Learning Development.

Land, R., Rattray, J. \& Vivian, P. (2014). Learning in the liminal space: a semiotic approach to threshold concepts. Higher Education, 67(2), 199-217.

Lave, J. \& Wenger, E. (1991). Situated learning: Legitimate peripheral participation. Cambridge, UK: Cambridge University Press.

Meyer, J. H. F. (2012). "Variation in student learning" as a threshold concept. The Journal of Faculty Development, 26(3), 8-13.

Meyer, J. H. F. \& Land, R. (2003). Threshold concepts and troublesome knowledge 1 -linkages to ways of thinking and practising. In C. Rust (Ed.), Improving student learning - ten years on (pp. 1-16). Oxford, UK: Oxford Centre for Staff and Learning Development.

Meyer, J. H. F. \& Land, R. (2005). Threshold concepts and troublesome knowledge (2): Epistemological considerations and a conceptual framework for teaching and learning. Higher Education, 49, 373-388.

Meyer, J. H. F. \& Land, R. (2006). Threshold concepts and troublesome knowledge: An introduction. In J. H. F. Meyer \& R. Land (Eds.), Overcoming barriers to student understanding (pp. 3-18). London: Routledge. 
Moore, J. L. (2012). Mapping the questions: The state of writing-related transfer research. Composition Forum, 26. Retrieved from http://compositionforum.com /issue/26/map-questions-transfer-research.php.

Perkins, D. N. (1999). The many faces of constructivism. Educational Leadership, 57(3), 6-11.

Perkins, D. N. (2006). Constructivism and troublesome knowledge. In J. H. F. Meyer \& R. Land (Eds.), Overcoming barriers to student understanding (pp. 33-47). London: Routledge.

Perkins, D. N. \& Salomon, G. (1994). Transfer of learning. In T. Husen \& T. N. Postlethwaite (Eds.), The international encyclopedia of education (Vol. 11) (2nd ed.) (pp. 6452-6457). Oxford, UK: Pergamon.

Silva, T. (1993). Toward an understanding of the distinct nature of L2 writing: The ESL research and its implications. TESOL Quarterly, 27(4), 657-677.

Sullivan, P., Zhang, Y. \& Zheng, F. (2012). College writing in China and America: A modest and humble conversation, with writing samples. College Composition and Communication, 64(2), 306-331.

Swales, J. (1990). Genre analysis: English in academic and research settings. Cambridge, UK: Cambridge University Press.

Tardy, C. M. (2006). Researching first and second language genre learning: A comparative review and a look ahead. Journal of Second Language Writing, 15, 79-101. 


\title{
CHAPTER 11
}

\section{NEGOTIATING MULTIPLE \\ IDENTITIES IN SECOND- OR \\ FOREIGN-LANGUAGE WRITING \\ IN HIGHER EDUCATION}

\author{
Stacey M. Cozart, Tine Wirenfeldt Jensen, \\ Gitte Wichmann-Hansen, Ketevan Kupatadze, \\ and Scott Chien-Hsiung Chiu ${ }^{1}$
}

As educational researchers and second/foreign language instructors, we maintain that the second language (L2) writing context elicits the negotiation of difference and develops an awareness of language as a carrier of individual and collective cultural identities. In line with the Elon Statement on Writing Transfer (2015), we also firmly believe that teachers and others supporting L2 writers can take a number of steps to help students better navigate the challenging and complex process of transferring their writing knowledge and skills in their first language (L1) to the L2. As the Elon Statement notes, writing development is strongly linked to meta-cognition of available identities, as well as to situational and audience awareness. This chapter is intended to explore further the concept of developing student awareness of available identities in the process of learning a second language and, particularly, L2 writing. We argue that identity, situational, and audience awareness are "even more critical in writing transfer between languages because of the need to negotiate language-based differences and to develop awareness about the ways language operates in written communication in each language" (Elon Statement on Writing Transfer, 2015, pp. 4-5). In this context, the aim of this chapter is to enrich our common understanding of how students experience the transition from L1 to L2 writing in higher education settings. We do this by presenting and discussing the core findings from a multi-institutional project that comprises three separate studies of L2 writing conducted by the authors. The three studies represent three different linguistic, cultural, institutional, and pedagogical contexts. This particular cross-cultural and cross-disciplinary framework allows new perspectives to emerge, especially regarding the crucial role that identity plays in student approaches to L2 writing and issues of writing transfer. Based on these studies, we also claim that L2 
writing is a critical transition that involves the negotiation of multiple identities in order to be successful. Finally, we conclude that since L2 writing is inevitably shaped by students' self-perceptions and attitudes, more research should be conducted to study these aspects of second and foreign language writing and, consequently, more effort should be made to develop pedagogies to address self-perceptions and attitudes that deter students from developing as successful L2 writers. We close the chapter by summing up our common findings, showing how the L2 writing context can help provide new reflective frameworks for supporting students' writing abilities both in the L1 and the L2.

The processes and elements of the tasks involved in writing in L1 and L2 are far from identical. Based on the conceptualizations of transfer on the basis of the individual (Bereiter, 1995) and context (Greeno, Smith \& Moore, 1993), we view L2 writing development as inextricably linked to students' perceptions of and attitudes toward writing in the L2. They inevitably engage in the changing contexts between the language uses of L1 and L2 and apply their acquired knowledge and principles to new writing situations. Recent writing transfer research has indicated that students' individual dispositionssuch as value, self-efficacy, attribution, and self-regulation-play crucial roles in successful writing transfer beyond knowledge and skills (Driscoll \& Wells, 2012). While we share this notion that students' individual dispositions are vital to their successful development as L2 writers, we think that students' self-perceptions and their socially and culturally constructed attitudes toward L2 acquisition also play an important role in their ability to transfer knowledge when writing in L2. This may be particularly true for adult students who have received previous training in L1 writing and have already formed distinct identities as academic and professional L1 writers, or those who have different experiences with their L2 writing in different contexts. Thus, drawing in particular on the works of Kramsch (1993, 2010), Byram (2010), and Wenger (1998), we focus on the social and cultural dimensions of language learning and identity negotiation.

To further examine the theoretical constructs of transfer and better understand writing transfer across different L2 writing contexts, we examine the role of student attitudes and perceptions in their development as writers. We explore the possibilities and problems of writing transfer from L1 to L2, as well as the effects that second/foreign language writing has on writers' identities, guided by the following shared questions:

(1) How and to what degree do students perceive their identities as L1 and L2 writers as similar or different from each other? What language learner identities are available to the students in each of our contexts? What role do students' individual and collective identities play in L2 writing? 
(2) What do the students find most challenging about writing in the L2? How do their L1 writing experiences inform their L2 writing strategies? How do rhetorical and discursive strategies of L1 writing affect students' learning of L2 writing, and should this effect be viewed as an opportunity or as a problem when teaching second/foreign language writing?

(3) Based on our findings, how can we best support students writing in the $\mathrm{L} 2$, in transferring their academic writing skills from one language into another, or from one context to another?

Our multi-institutional research on teaching and learning L2 writing is predicated on the idea that cross-contextual, cross-cultural, and cross-disciplinary research into second/foreign language writing is essential for a clearer and broader picture to emerge on how writing transfer occurs from one language into another. In the following sections, we present the main findings of our three studies, which are based on quantitative and qualitative data collected in separate institutions, including data from surveys and semi-structured interviews with students. Although the purpose of our research was shared, each of us designed survey and interview questions as was deemed appropriate for his or her institutional context. Each research project was perceived and developed within a very particular institutional and cultural context, and this contextually sensitive approach allowed us to identify common threads in the process of writing transfer from L1 to L2. The first research project focuses on how Danish doctoral students experience and handle the processes and expectations associated with academic writing in L2 English and how they are addressed as a theme in supervision. The second research project addresses the need for designing a more successful approach to teaching advanced-level writing in a US Spanish-language classroom to make the transfer from L1 to L2 more effective, and at the same time to develop students' awareness about the (im)possibilities of directly and seamlessly transferring meaning from one language into another because of the differences in the worldviews that are apparent through language use. The third research project investigates Chinese international students' transitions to writing courses in a US university and how challenges from different, and sometimes conflicting, ways of communicating, living, and learning can account for the students' English writing development.

\section{BECOMING AN INTERNATIONAL ACADEMIC: THE CASE OF DANISH DOCTORAL STUDENTS WRITING IN ENGLISH}

\section{Background ANd Aim of STUdy}

This project explores the challenges and self-perceptions of Danish students faced with transferring their academic writing skills from Danish to English 
at the doctoral level at the Graduate School of Arts at Aarhus University in Denmark. In general, Danish doctoral students have such excellent oral skills in English that some are perceived as being bilingual, a circumstance that shapes both their own and their surroundings' relatively high expectations of their abilities as academic writers of English. This type of L2 writing context, in which the students have strong interpersonal communicative skills in English but are generally only beginning to develop their English academic writing skills, has been underexplored.

We initiated this project in 2011 because we noticed several tendencies that needed more systematic attention. As in other Scandinavian and European countries, an increasing number of doctoral students in Denmark are now completing their dissertations in English in response to the growing internationalization of higher education. In addition, an increasing number of doctoral students in the humanities and social sciences are now following the lead of students in the hard sciences by writing article-based dissertations rather than monographs as the primary dissertation format (Sabharwal, 2013). Overall, this puts pressure on students whose native language is a minority language to publish in English. However, at many European universities, this development has not been accompanied by a corresponding increased focus on students' writing skills. Particularly in Denmark, where students are generally assumed to have sufficiently advanced English skills to perform well in English-language academic contexts, a lack of systematic institutional support of students' academic writing skills has been quite prevalent. But do Danish doctoral students really have sufficient skills not only to write clearly and coherently in English and to relatively quickly master the required academic genres such as the research article, abstract, and literature review, but also to use English as a tool for producing knowledge? We became interested in starting to address this question by exploring how Danish doctoral students perceive their own writing skills and writing needs and whether they receive sufficient support in assessing and developing their writing skills from the institution, including their supervisors.

We also noticed a lack of systematic attention to $\mathrm{L} 2$ writing in the literature on doctoral students' writing processes. Until recently, research into writing in higher education has mainly focused on undergraduate students and, to a lesser extent, on postgraduate students (Fergie, Beeke, McKenna \& Creme, 2011). As Badley (2009) has suggested, the limited focus on Ph.D. writing in research and curricula is due to the assumption that students at the Ph.D. level do not need to address writing development explicitly. They are simply expected to have the necessary skills to produce publishable academic texts by the time they reach this level. However, recent research on doctoral students' writing processes suggests 
that they need much more guidance from their supervisors, peers, and the academic environment than is usually expected and provided (Kamler, 2008; Lee \& Boud, 2003; McGrail, Rickard \& Jones, 2006).

\section{Method: Online Survey and Written Reflections}

The study draws on both quantitative and qualitative data in the form of two different surveys. The quantitative data are based on an online anonymous survey that we conducted in the spring of 2012 among all Ph.D. students enrolled at the Graduate School of Arts at Aarhus University in Denmark, which included 274 students. The survey encompassed 35 closed-ended questions and six open questions. The questions addressed the students' experiences of academic writing in both Danish and English: genres, extent of experience, feedback received, strategies and tools, the dissertation language and motivation for their choice, supervisory support, and their self-assessment of their writing skills. The response rate was $54 \%(=149)$. Data were analyzed using descriptive statistics.

The qualitative data includes pre-course surveys in the form of written reflections collected before three academic writing courses called Introduction to Academic Writing in English for Ph.D. students, offered at the same graduate school in 2011-2012. The course was not mandatory, so we may assume that the majority of the students enrolled were interested in improving their English skills. Prior to the course, the students were asked to respond to reflection questions about their academic writing processes and experiences in both English and Danish, as well as their style, voice, and identity in both languages. They were also asked to complete the sentence "Writing in English is like ..." "Writing in Danish is like..." (see Table 11.1). This question was included to elicit explicit metaphors from the research participants in order to enrich our understanding of their conceptualizations of writing in both languages. ${ }^{2}$ Schmitt (2005) points out the limitations of eliciting explicit metaphors ${ }^{3}$ in qualitative research when this approach stands alone, but the overall design of our study, as well as our approach to the analytical process, heeds the importance of what Schmitt calls the "thoroughness of the comparison with non-metaphorical finds" (2005, p. 381). The written reflections of the 20 students who permitted us to use their responses in our research project were analyzed thematically using grounded theory methods (Charmaz, 2006).

\section{FINDINGS}

Our online survey offered some valuable insights into the respondents' experiences of academic writing in English: More than half of the respondents (57\%) 


\section{Table 11.1. Pre-course survey questions}

How would you describe and evaluate your experience with writing in your native language? Consider:

- How you typically organize your writing process

- When and where you write

- What helps you most when writing

- What you like/dislike about writing

How would you characterize your style of writing in your native language? Consider your style, voice, and identity as a writer.

How would you describe and evaluate your experience with writing in English? Consider whether your experience is the same as or different from your experience with writing in your native language, and, if there are differences, how and why.

How would you characterize your style of writing in English? Consider your style, voice, and identity as a writer.

What problems do you experience when you write in English, and how do you solve them? Consider also what type of support you need to become better at writing in English.

Choose a phrase, expression, or metaphor that best captures your experience with writing in Danish. "Writing in Danish is like..."

Choose a phrase, expression, or metaphor that best captures your experience with writing in English. "Writing in English is like..."

stated that they were writing - or planning to write-their doctoral dissertations in English, and 67\% of these rated their writing skills as very good or good. However, $30 \%$ of the students writing in English only had very limited experience writing academic texts in English when they began their Ph.D. studies (14\% had no prior experience, and 16\% had only written between 1 and 10 pages in English in total). Furthermore, 54\% of the students stated that their supervisors had not read anything they had written in English before the choice of language was made. Likewise, 25\% had neither discussed the choice of language with their supervisors nor had their supervisors read anything they had written in English before making their decision. In addition, $66 \%$ of the students writing in English stated they have never attended a course in academic English, and $42 \%$ stated that they had concerns about writing their dissertations in English.

\section{Themes from the Written Reflections}

Our analysis of the written reflections resonates with the findings from the survey. The students' written reflections reveal that the majority of students considered writing in English to be more demanding than writing in Danish. Their 
most frequent concerns were about linguistic challenges in English, in particular insufficient vocabulary knowledge. In addition, though half the students described their writing processes in Danish and English as very similar, the emotions and attitudes they expressed regarding their experiences in Danish and English are generally quite different. Many of the students expressed feelings of insecurity, alienation, and a lack of autonomy in respect to their style of writing, voice, and identity in English-feelings they generally did not associate with academic writing in Danish. For example, one student commented, "Maybe I have a slight tendency to incorporate the tone, wording and terminology of the theoretical texts I read in English, while in Danish I can better recognize my own voice."

The metaphors elicited by 14 doctoral students who attended the introductory academic writing courses reveal similar negative feelings in connection with writing in English. For one student, the difficulty and insecurity experienced in connection with writing in English was like "biking on a pedestrian street"; for another, like "driving without a GPS"; and for yet another, like "a handicap." We also see that several of the metaphors indicate embodied or personal identity-related activities such as "a bad hair day," "not wearing glasses," and "walking in high heels." Furthermore, the metaphors reveal that some students viewed writing in academic English as an unnatural activity involving imitation rather than authenticity and creativity, such as "making an Italian pizza" (as a Dane), "cooking from a recipe without daring to add new spices," and "imitating those who are proficient at writing in English."

The majority of the students' metaphor pairs for writing in Danish and English, respectively, further underline the students' difficulties transitioning from Danish to English, in particular their sense of alienation, inadequacy, and lack of creativity in connection with writing in English (see Table 11.2). For instance, one student pointed to the challenge of clarifying and producing knowledge in English: "Writing in Danish is like thinking," whereas "writing in English is like imitating," while another contrasted the naturalness of writing in Danish, which is equated with "breathing," with the effort involved in writing in English, which is likened to "digging up potatoes." A few students did appear confident (student 6: "Putting my thoughts in writing in English"; 11: "You get better and better"; and 13: "There is the desire to train"), but overall, the picture is of restricted abilities rather than new or alternative possibilities.

\section{Discussion}

Although we had known that the students received little systematic institutional writing support, the survey findings still came as a surprise to us. Considering 
Table 11.2. Danish doctoral students' metaphors for writing in Danish and English, respectively.

\begin{tabular}{|c|c|c|}
\hline & "Writing in Danish is like..." & "Writing in English is like ..." \\
\hline 1 & $\begin{array}{l}\text { zigzagging left and right, but constantly } \\
\text { moving forward at a rather fast pace. }\end{array}$ & $\begin{array}{l}\text { being somewhat more uncertain whether it is } \\
\text { actually moving forward. }\end{array}$ \\
\hline 2 & Thinking. & Imitating. \\
\hline 3 & $\begin{array}{l}\text { Building with Lego blocks with my } \\
\text { two-year-old son-there are many } \\
\text { possible combinations, ways of creat- } \\
\text { ing connections; many blocks to move } \\
\text { around-and you never know what will } \\
\text { emerge in the end. }\end{array}$ & $\begin{array}{l}\text { Playing with a Brio train set (with the same } \\
\text { son)—-there is still room for deciding how } \\
\text { the track should go, on a general level, but it } \\
\text { seems more "one-track," with fewer possibil- } \\
\text { ities for variation. It goes in one direction: } \\
\text { towards content, and there is less opportunity } \\
\text { to play with the language-if the train leaves } \\
\text { the track, it gets out of control. }\end{array}$ \\
\hline 4 & Breathing. & Digging up potatoes. \\
\hline 5 & $\begin{array}{l}\text { Driving on a freeway while my supervi- } \\
\text { sor occasionally tells me to switch to the } \\
\text { academic lane. }\end{array}$ & $\begin{array}{l}\text { Driving on a freeway with holes in the } \\
\text { asphalt. }\end{array}$ \\
\hline 6 & Putting my thoughts in writing. & Putting my thoughts in writing in English. \\
\hline 7 & Shaping clay. & $\begin{array}{l}\text { Knitting a sweater without knowing whether } \\
\text { there is enough yarn. }\end{array}$ \\
\hline 8 & $\begin{array}{l}\text { Playing a grand piano based on } 30 \text { years' } \\
\text { experience. }\end{array}$ & $\begin{array}{l}\text { Beating on a little tin xylophone without any } \\
\text { guidance. In the dark. }\end{array}$ \\
\hline 9 & $\begin{array}{l}\text { Painting a very detailed picture while } \\
\text { focusing on both the individual figures } \\
\text { and the overall design I want to create. }\end{array}$ & $\begin{array}{l}\text { Trying to make the same picture, but now } \\
\text { based on the collage method and clippings } \\
\text { from old newspapers. The trick now is to get } \\
\text { the various text pictures and picture frag- } \\
\text { ments to appear as though they are connected } \\
\text { and do not come from different articles or } \\
\text { newspapers. }\end{array}$ \\
\hline 10 & Cutting with a laser scalpel. & $\begin{array}{l}\text { Hammering with a very big and rather heavy } \\
\text { sledge hammer. }\end{array}$ \\
\hline 11 & $\begin{array}{l}\text { Biking. Once you have figured out how } \\
\text { to do it, it goes really well—even though } \\
\text { it can be hard at times. }\end{array}$ & $\begin{array}{l}\text { Playing acrobat; you have to practice and } \\
\text { train all the time, so that you get better and } \\
\text { better with each task. }\end{array}$ \\
\hline 12 & Blowing soap bubbles. & Blowing soap bubbles that I can't see. \\
\hline 13 & $\begin{array}{l}\text { Is always a pleasure-rich with oppor- } \\
\text { tunities for humor, implications, and } \\
\text { wonderful turns of phrase. There is a } \\
\text { fundamental sense of security that makes } \\
\text { it possible to play with the language. }\end{array}$ & $\begin{array}{l}\text { Is not quite as fun since a sense of linguistic } \\
\text { insecurity is always present, but at the same } \\
\text { time there is the desire to train the ability to } \\
\text { write freely and fluently. }\end{array}$ \\
\hline 14 & Writing to someone familiar. & Writing to a more distant reader. \\
\hline
\end{tabular}


that more than half of the students surveyed stated that the were writing (or planning to write) their dissertation in English, that one-third of the students facing the demanding task of writing their dissertation in English rated their writing skills as less than good, and that $42 \%$ stated that they had concerns about writing their dissertation in English, we cannot but wonder whether the students made the best choice for themselves, and whether they received the support they needed. We also found it remarkable that $30 \%$ of the students writing in English had such limited experience writing academic texts in English (10 pages or less). This reveals a structural problem: How could it be assumed that they were able to write a dissertation in English when so many were so poorly prepared for the task through their prior education? Finally, we were surprised to discover that the supervisors were not necessarily involved in the students' language choice, or that if they were, it did not necessarily mean that they had read any of the students' written work in English (as was the case for more than half of the students). This finding is particularly striking since reading students' drafts and providing feedback on them is an integral part of the Danish doctoral supervision process. The findings show that the students were met with extremely high, if not unrealistic, expectations on the part of the institution: They were expected to be able to choose the language of their dissertation on their own, and, as part of that process, to accurately assess their own English writing skills. And if they did choose to write in English, they were expected to be able to do so with little or no systematic support.

The study suggests the important role of identity in the students' development of their academic writing abilities in English, a finding consistent with current writing transfer research, as summarized by the Elon Statement on Writing Transfer. The written reflections revealed that many students viewed academic writing in English as limiting or restricting their identities as writers, as seen through their overall sense of inadequacy and lack of creativity, rather than allowing them to explore and expand their writerly identities through the linguistic and rhetorical possibilities available to them in Danish. In addition, our overall study indicates that the identity of "(advanced) language learner" was not available to these Danish graduate students within the structural framework of their doctoral programs. No institutional framework has existed to aid the students in assuming such an identity if appropriate- for example, in the form of mandatory academic writing courses either before or during their doctoral studies, formal or informal assessments of students' writing skills in English, or frameworks for discussing students' writing issues or concerns about writing in English with supervisors. Moreover, no institutional space has been made available in which students and supervisors may discuss these quite complex issues, and if the students want to do so, they must carve out this space individually. On the contrary, the increasing demand 
to write the dissertation in English and publish internationally in English as soon as possible communicates to these students that they should be capable of constructing and communicating knowledge in English at the highest academic level with little or no support. We suggest that these issues could have a negative effect on their perceptions of themselves as nascent members of their academic communities, particularly considering the central role of writing in the creation and sharing of knowledge in the humanities.

Consequently, it is our view that the doctoral students' writing skills and processes and the challenges that many of them face should not be regarded as an individual or personal problem but rather as a structural issue and an institutional concern that is closely linked to students' writing development in school settings. At this point, we think that significant improvements could be achieved by increasing the students' rhetorical and metacognitive awareness as well as their ability to "remix and repurpose" their L1 and undergraduate knowledge about writing and writing processes (Elon Statement on Writing Transfer, 2015). This process can be supported both by writing courses and, equally as important, by strengthening the supervisor's role in the writing process. For instance, the institution could provide better support at earlier stages by encouraging students to practice continuous self-monitored writing (Buckingham, 2008): to write early and regularly and to evaluate their own writing skills and processes, such as by using an individualized portfolio approach to writing, and to ensure that the portfolio becomes part of the supervision meetings (Hirvela, 1997). We also recommend more explicit communication about writing requirements and expectations as part of supervision programs, the creation of opportunities for the students to make well-informed, conscious decisions about the language of their dissertation, and the training of supervisors in order to develop their competencies in talking about these themes in a legitimate manner.

However, the supervisors are not the only or most important resources for doctoral students. The traditional dyadic apprenticeship model has been challenged in recent research in higher education and replaced with a sociocultural approach. In line with this development, we recommend integrating students into wider discourse communities of practice (Boud \& Lee, 2005; Wenger, 1998) and creating space for the students to reflect on and discuss writing issues as well as to negotiate multiple identities as L2 writers among peers. This is an approach which also serves to counteract the individualized nature of the problems associated with writing in English as young academics. Students' integration into discourse communities could be encouraged through the provision of workshops on learning from peer reviewers' feedback, as well as through institutionally supported frameworks for peer feedback (Fergie et al., 2011; Parker, 
2009), including writing groups (Stracke, 2010) with input from senior scholarly writers, and other forms of doctoral student collaboration. Besides being in line with the recommendations of current research demonstrating the importance of feedback for learning in higher education (e.g., Hattie \& Timperley, 2007; Nicol et al., 2013), such pedagogical practices involving self- and peer assessment and feedback should promote writing transfer by further enhancing students' meta-cognition, rhetorical and in particular audience awareness (see the Elon Statement on Writing Transfer, 2015).

\section{DEVELOPING INTERCULTURAL LITERACY THROUGH L2 WRITING: THE CASE OF AMERICAN UNDERGRADUATE STUDENTS WRITING IN SPANISH}

\section{Background and Aim of The STUdy}

Most recent studies in foreign-language education have called for the infusion of our curricula (particularly in higher education) with not only communicative language teaching but also content-based education that would be geared toward the development of students' L2 literacy and intercultural competence (Byram, 2010; Kramsch, 1993, 2010; Scarino, 2010). Such pedagogy would combine teaching of the target culture with teaching of language as a carrier of cultural identity as two sides of the same coin. Several important studies have been published in recent years that outline the traditional emphasis of L2 education on action versus reflection, that is, the communicative approach to language teaching as opposed to the literacy-based approach. These studies argue that L2 pedagogy should be grounded on the dialectic relationship between the instruction of target language and target cultural identity through language. Here, as Kramsch writes,

The experience of the foreign always implies a reconsideration of the familiar. ... In part because of the rationality of its grammar and the logic of its vocabulary, language has been taught and learned mostly as a tool for rational thinking, for the expression and communication of factual truths and information, and for the description of a stable and commonly agreed-upon reality. It has not been taught as a symbolic system that constructs the very reality it refers to. (2010, p. 5)

Kramsch (1993) points out that the false dichotomy between language teaching and the teaching of culture has been part of the profession, and she argues for the need to educate cross-cultural individuals, those who will encounter 
a third space through the negotiations of differences when learning language as a carrier of cultural identity. Byram (2010) highlights the need to focus language education on bildung, the (trans)formation of the individual as a social actor and active citizen. Scarino (2010) also argues for such an approach, although her argument is that literacy-based and content-oriented language education is transformative for students' individual identities.

These arguments, which seem all too obvious to L2 educators, might sound more like a theory to those outside our field, particularly to students who often view writing in a second language as a simple process. By simple, I mean a process that requires transfer of information from one language into another, in which each word and form in one language has an exact corresponding word and form in another. Students often think that with a set of grammatical rules and vocabulary lists, they can unequivocally and seamlessly transfer meaning from L1 to L2. How many of us have been perplexed by students' word-byword translations of idiomatic phrases and native sentence structures? Students are often surprised that a certain phrase is non-transferable from one language into another, and more importantly, when corrected they realize for the very first time the culturally situated nature of the L1 phrase they just used. All this points to students' lack of understanding of language as a carrier of cultural identity and, as a result, leads to their unwillingness to engage with a pedagogy that is reflective and that elicits a successful transfer through the realization that culture is very much part of every language. The question is: Can the reflective learning of language and subsequent correct transfer happen in the classroom? What would have to happen for this pedagogy to be wanted by students and, therefore, successful?

If we truly believe in the power of language to reflect and transform one's identity, as well as to construct the very reality it describes, we must adopt the literacy-based pedagogy that supports the development of L2 writing based on the development of both linguistic accuracy and cultural competency. But for educators to be successful, we should also make sure that students fully understand the purpose and value of such pedagogy before (or while) it is implemented. Foreign-language instructors who work on developing students' L2 writing often find that the task of convincing students of the value of a content and literacy-based approach to language acquisition is complicated and goes against students' initial and/or previously adopted attitudes towards foreign-language learning and their very pragmatic reasons for learning the language.

In keeping with the questions that guide the three projects regarding the crucial role of students' perceptions of and attitudes toward writing in L2 for successful writing transfer, this particular study shows the gap between students' and educators' understandings of what it means to become a good L2 writer, 
and it ventures to determine the reasons for such a gap. It starts out with the following shared questions that guide this multi-institutional research project: (a) Are students aware of their identities as L1 writers? (b) How do students develop beliefs and attitudes toward L2 writing, and what effect do these beliefs and attitudes have on their learning of L2 writing? And (c) do they think that L2 writing could affect their identities?

\section{Method: Pre- And Post-Course Surveys}

This research focuses on 60 students enrolled in advanced-level Spanish writing course at a private, liberal arts institution (Elon University) in the US, with a relatively homogeneous student population. Students who regularly register for this course are those who intend to minor or major in Spanish. Many times, they are first-year students who have taken several years of Spanish in high school. They are motivated and confident in their learning abilities. Although categorized as a composition and grammar course, the course was developed based on particular cultural content (the relations between the United States and the Hispanic world) that would be appealing to students and would provoke reflection about not only target but also native cultural contexts. The primary goals were to develop students' intercultural competence, deepening their knowledge of self and other. In terms of writing development, the content and structure of the course prompts situations where students have to negotiate the differences between native and target cultural identities.

At the beginning of the semester, students were asked to complete a survey about their perceptions of, and attitudes toward, writing in both their native (i.e., English) and second (i.e., Spanish) languages (see Table 11.3). Throughout the course, students also engaged in writing and editing tasks ranging from short response papers to lengthy argumentative essays and creative writing assignments. Once the majority of the writing assignments were completed, the students were asked to complete a post-course survey (Table 11.4). The major purpose of asking students to complete the pre- and post-course surveys was to inquire into the ways students perceived and articulated their identities as L1 and L2 writers, to see whether the difference (if any) in students' perception of L1 and L2 writing was purely formal (i.e., lack of vocabulary and/or grammatical knowledge in L2) or cognitive, and to see whether there were any changes in their perceptions of ways to develop L2 writing abilities after they had a semester of intensive L2 writing by way of a content-based, reflective instruction that placed learning about culture at the center of the course.

In order to enrich the understanding of students' perceptions of writing both in L1 and L2, students were asked to think of a metaphor to express their feel- 


\section{Table 11.3. Pre-course survey}

\section{Based on my recent major writing assignments, I have the following experiences (check all that apply):}

Perceptions of Writing in English (or your native language):

I avoid writing

I have no fear of my writing being evaluated

I look forward to writing

Taking a composition course is a frightening experience

Expressing ideas through writing seems to be very difficult

I feel confident in my ability to express my ideas in writing

Discussing my writing with others is enjoyable and beneficial

\section{Perceptions of Writing in Spanish (L2):}

I think writing in Spanish does not faithfully express my thoughts

I sound childish in my Spanish writing

I don't think Spanish speakers can truly understand my writing

I am always translating my ideas from my L1 to L2

I can be more creative in L2 writing

Writing in my native language and Spanish is pretty much the same to me

I love writing in Spanish

I am very concerned with my language choice and grammar in my writing

I feel frustrated that my writing is not like a native speaker's writing

My goal of learning Spanish writing is to write authentic sentences without foreign "accent"

\section{Table 11.4. Post-course survey}

I. What helped you most with improving your written skills in Spanish?

II. What helped you most with grammar?

III. What TWO things helped you most with learning vocabulary and correct phrasing?

IV. What aspect of the course helped YOU the least?

V. Do you have any other suggestions about what might be useful?

ings when writing in their native as well as their target language, similar to the Danish case. Some examples of students' responses are represented in Table 11.5.

\section{FINDINGS}

According to the results of the pre-course survey, students have a good understanding of what type of writing is expected of them in a US academic en- 


\section{Table 11.5. Metaphors for writing in English and Spanish}

\begin{tabular}{lll}
\hline & "Writing in English is like ..." & "Writing in Spanish is like ..." \\
\hline $\mathbf{1}$ & Riding a bike. & Diving into a cold swimming pool. \\
$\mathbf{2}$ & Wearing comfy shoes. & Wearing shoes on the wrong feet. \\
$\mathbf{3}$ & Sunbathing at the beach. & Getting wisdom tooth removed. \\
$\mathbf{4}$ & Solving a puzzle and having fun doing it. & Trying to solve the puzzle with missing parts. \\
$\mathbf{5}$ & Running, hard but necessary. & Trying to run fast in sand/running in flip-flops. \\
$\mathbf{6}$ & Driving an automatic car. & Driving a stick shift. \\
7 & Dancing across the paper. & Dancing on the razor blades. \\
\hline
\end{tabular}

vironment. They have relatively high linguistic (syntactic and grammatical) proficiency in L1 and think of themselves as good writers (i.e., they do not perceive themselves as apprehensive writers in L1). What's more, students are very comfortable within their cultural contexts. Most of them have already taken L1 composition courses and have succeeded in them. Table 11.5 shows students' perceptions of L1 and L2 writing expressed in metaphors. It was clear from their survey answers, as well as their metaphors, that students overwhelmingly viewed their identities as L1 and L2 writers as static. They considered language to be a skill and focused on the need for improving the technique of writing, that is, syntax, grammar, and lexicon. Even in their metaphors that could describe their identities as L1 or L2 learners, the emphasis was on their ability to convey the meaning, to communicate with ease-viewing language as a skill that needed to be mastered. L2, as opposed to L1, was physically more demanding, although the images they used were somewhat similar. If L1 was driving an automatic car, L2 was driving a stick shift; if L1 was walking, L2 was running, etc.

In the initial survey, when students were asked to rate course-related work according to their importance, the vast majority of students rated grammar and vocabulary practice as the most important component for developing L2 writing skills. Most students noted that their goal for the course was to achieve "error-free grammar and mechanics." They ranked learning about the target culture, as well as reading and analyzing texts, last or second-to-last for their value in becoming better writers. In the survey given at the end of the course, students' comments showed that editing their writing, which involved the improvement of content, structure, and form, was one of the most helpful parts of the course. But their comments also suggested that editing their writing for grammatical accuracy and having the course structure based on grammatical concepts rather than cultural content would have been more useful. Students were once again 
asked to rank the value of learning new vocabulary, learning grammar, reading and analyzing texts, learning about culture, and writing and editing when trying to become a better L2 writer. Fifteen percent of the students (as opposed to 0\% initially) ranked learning about culture and reading and analyzing texts as the top most helpful tools.

\section{Discussion}

From students' responses and reactions, it is evident that the implementation of the content-based reflective pedagogy adopted for L2 writing development is challenging. The learners of a second language do not necessarily view the process as one that requires the creation of or the negotiation with a different identity, which caused their lack of understanding of the importance of the right kind of transfer. As proposed in the Elon Statement on Writing Transfer, successful development of students' writing abilities is closely tied to their awareness of language as a bearer of different cultural identities. Unfortunately, students do not perceive language learning to be in a dialectic relationship with developing cultural competence and, for the most part, do not view L2 writing as an opportunity to enrich their identities. Most second language learners view it as a tool to communicate, devoid of any content that can only be expressed in the given language. Their assumptions are that (a) whatever identity they have already assumed as L1 writers will seamlessly transfer from one written language into another, and (b) although often packaged together, learning the target language is irrelevant to learning the target culture.

This is why, in agreement with the Elon Statement on Writing Transfer, we strongly believe in the need for teachers and others supporting L2 writers to make consistent and explicit efforts towards developing not only students' linguistic and grammatical accuracy skills when teaching L2 writing, but also their awareness of the language learning process as one that involves the formation and even a change of identity. Without students' awareness of language as a bearer and the creator of not only linguistic but also cultural and rhetorical differences, transfer of knowledge from one language into another leads to miscommunication(s), awkward phrasing, and failed attempts to reach the desired audience. Furthermore, without students' awareness of language as a carrier of cultural difference and their intentional engagement with this difference, the process of L2 writing development seems extraordinarily frustrating for both instructors and students due to the differences in their understandings of the value of the particular method of instruction that is based on developing learners' cultural competence and understanding of what it means to learn a language. 


\section{UNLEARNING AND RE-LEARNING ESL WRITERLY IDENTITIES: THE CASE OF CHINESE STUDENTS WRITING IN ENGLISH}

\section{Background And Aim of the Study}

The third study we report on was undertaken at Michigan State University (MSU). Since 2006, MSU has admitted more and more international undergraduate students, with the number rising from 1,333 to 4,519 between 2006 and 2013 (Michigan State University, 2014). Among the 130 countries sending students to MSU, China is ranked number one and is the major source of the increasing international undergraduate student population on MSU's campus. The number of Chinese undergraduate students increased from 92 to 3,458 between 2006 and 2013, making them the majority international student population at MSU. They were most visible in the required first-year writing courses, especially the courses at the basic and developmental level for less appropriately prepared students - preparation for college writing (PCW) courses. The PCW courses were a prerequisite course for most international students for the regular Tier 1 writing courses at MSU. During the time of this research project, the PCW courses were based on the same curriculum that engaged students in writing and reflection through invention, arrangement, and revision activities across different inquiry situations. Students would develop knowledge and awareness of how contextual factors and the rhetorical situations affect their inquiries of knowledge and their engagement in reading, writing, and researching.

The PCW courses were intended for either domestic or international students who needed to take a slower pace at transitioning from high school to college and adapting to writing requirements and literacy practices in US higher education. However, with the influx of Chinese students to the MSU campus, Chinese students with varying degrees of English proficiency dominated the PCW courses. The makeup of the student body in the PCW courses constituted a unique ecological environment and a community of literacy practices, which made noticeable and critical the question of how Chinese students' preparation is related to college writing at MSU and how the students' previous experiences with writing in Chinese and English affect their transitional processes and their perceptions of their own writerly identities.

This study primarily focuses on how the transfer of prior knowledge affects individuals' engagement with writing tasks in new writing contexts and how the students engage with the ecological system and their writerly identities across contexts. We ask (1) how students identify themselves with L2 writing and what role students' individual and collective identities play in L2 writing; (2) how 
their L1 writing experiences inform their L2 writing strategies and how L1 strategies transfer to the L2 context; and (3) what we can learn from the case of these Chinese students to inform new perspectives on supporting L2 writing development and transfer.

In search for answers to and insights into our shared research questions through the qualitative data, this study of Chinese undergraduate students touches upon multilayered issues of language learning, curricular structures, literacy and identity, and the role of L1 in cross-language communication in the case of Chinese undergraduate students.

\section{Method: Surveys AND Follow-Up INTERVIEWS}

The participants recruited from first-year writing courses varied significantly in their English proficiencies and previous writing experiences. Some came from high schools in China, some completed non-credit ESL courses at the English Language Center at MSU, and some had graduated from high schools in the US or international high schools in China. This study reports on three focus groups and three individual cases in PCW and Tier 1 writing courses between spring 2012 and spring 2013. The participants were enrolled in the PCW courses when they started participating in this study.

Data collected from the participants included general survey questions regarding students' perceptions of the difference between their previous classes and current writing classes, their reports on writing processes, reflection essays on their writing development, and their writing assignments. The survey questions, presented in Tables 11.6 and 11.7, were conducted in class, and the researcher followed up with the focus groups and individuals in open-ended interviews at the mid-term and the end of the semester to allow the participants to elaborate on their responses to the surveys. The interviews were conducted in the students' first language, Mandarin Chinese, and the researcher also collected their notes, pre-writing activities, and group discussions in both English and Chinese.

\section{FiNDINGS}

When the Chinese students were adapting to the new learning contexts and attempting to transfer their writing skills, they were situated in a new environment and confronting an unfamiliar community of literacy practices. Mapping the new context onto their existing knowledge in writing and prior experiences with English academic writing turned out to be a source of struggles. They struggled with the rhetorical differences between L1 and L2, the linguistic uncertainty of 


\section{Table 11.6. Questions for mid-term reflection}

Writing class. Previous writing class vs. current writing class. Any noticeable changes?

How was your first month of the WRA (PCW) class?

What changes do you notice in the writing classes? How is it different from your experience with your previous writing class (high school, other institutes, etc.)?

Do you like the class? Do you have questions about this class?

What do you think about the classmates?

What do you think about college writing so far? Do you think this is a required class that you just need to get out of the way?

\section{Writing process.}

How long did it take for you to complete this paper? How many drafts did you do? How many hours did it take?

What kind of difficulty or questions did you have in mind when you were composing this paper? How did you cope with those problems, if there were any?

Whom did you talk to? What resources did you use? What tools or strategies did you use?

Where (what places) did you write your papers?

What change did you see in your writing process, compared to your writing experience before?

\section{Writers.}

What are your goals in this class?

Are you making progress to reach your goals in this class?

Did you feel nervous about Paper \#1? Why? Why not?

Did you have a goal in completing this paper (e.g., did you target an A paper)?

Did you feel you were changing as a writer?

L2 writing, the unfamiliar literacy practices in the first-year writing courses, and their perceptions of English writing and their established identities.

\section{L1 Rhetoric in the New Rhetorical Context}

First and foremost, Chinese students struggled with their language control over their L2 writing in English whenever they wanted to impart something sophisticated or original. They searched for language beyond their comfort level and resorted to translation from L1 linguistically and rhetorically; in other words, they cognitively struggled with the sense of uncertainty in the L2 language choices and linguistic forms that might end up being confusing or simply sounding awkward to the readers. This happened in particular when a student was writing about a 


\section{Table 11.7. Questions for final reflection}

\section{Writing class. Previous writing class vs. current writing class. Any noticeable changes?}

How was your learning experience with the WRA (PCW) class?

What changes do you notice in the writing classes? How is it different from your experience with your previous writing class (high school, other institutes, etc.)?

How do you like the class? What's your favorite part of the class? What is the part of the class you don't like?

What do you think about the classmates? Are they helpful to your learning?

What do you think about college writing so far? (How) Do you think this required class is relevant and helpful to your college career?

What are your suggestions on making this class a better collaborative learning space?

\section{Writing process.}

What is the most challenging part of the process to you?

How are you able to find the time, space, motivation, or support for your writing?

How do readers' responses (including the instructor's) help you with your writing process and the product?

How do the rhetorical concepts of MAPS, SWAP, RAIDS facilitate your writing process?

What are the challenges or problems with the assignments? How are you able to understand and meet all the requirements?

Whom did you talk to? What resources did you use? What tools or strategies did you use?

How does your home language or native language play a role in your writing process? Do you work with other writers who share your home/native language?

How does your social network (friends) play a role in your writing process? Do you seek support from the people you hang out with? What kind of support from them that benefits your writing process?

Where (what places) did you write your papers?

What change did you see in your writing process, compared to your writing experience before?

\section{Writers.}

What does writing in college mean to you now?

Do you feel good about accomplishing the goal of becoming a better writer through this course?

Do you feel you are changing as a (better) writer? How and why?

How do you feel about your competency in joining in the written conversation in the academic community?

How confident are you in your written communication with the audience in college?

How you feel about college writing outside PCW? Are you confident or nervous about it? Why or why not?

What's your goal of improving your writing skills?

What do you think the most important factors are in your writing development? 
significant concept in Chinese culture that should not be compromised by simplified language. For example, in describing the foot-binding culture in the Qing Dynasty, one student, Lao (pseudonym), wrote, "When I know why women need to foot-binding, I think that most important thing is women play the part of humble person." ${ }^{\prime \prime}$

Researcher: When you say that is the most important part, what do you mean?

Lao: What I want to say is, for now, the culture has changed. Women should not practice foot-binding and women in China have got some rights and respect in society. Maybe instead of humble, the word should be vulnerable. That was the reason.

The student was culturally literate on the topic and had a clear argument to make; however, her control of language was not on par with her thoughts in writing.

In another example, Lao wrote, "But after 19 century, the Qing dynasty was destroyed. China got some western method about women which was very different between China and other countries."

Researcher: What do you mean by method? Like ideas and stuff like that?

Lao: Yeah ...

Lao: I want the person who reads my paper to know exactly what foot-binding is, because a person who is not Chinese may not be able to understand what foot-binding really means to Chinese culture and the society in Qing Dynasty.

The student felt compelled to explain the cultural significance of the foot-binding phenomenon in Qing Dynasty to her readers. She was concerned that the significance and complexity of the cultural issue might be lost in a simple word like "idea" and decided to try the unusual word "method" for the readers to consider it from a different perspective. In fact, the student's language choice reveals her sense of audience and her purpose to communicate with the audience.

In Chinese rhetoric, like Western rhetoric, the author-audience relationship affects how writing is composed, though significantly in different ways. This difference is illustrated by a piece written by another student, Moyu (pseudonym), who started his lived literacy paper with a lengthy narrative on how he suffered in his new life in the US and how he experienced rapid changes in every aspect of life. At the end of the paragraph, he finally introduced his topic of his piano playing, a musical literacy he had developed in China and brought with him to 
the US. When asked in Chinese why he would not start off by introducing a scene from his musical development and quickly get to the point about piano playing for the readers, he looked confused and replied, "Wouldn't that be bai le?"(白了, "bai le": explicit). In Chinese, skilled writers avoid a straightforward introduction that deprives the readers of the joy of reading between the lines and contemplating the subtlety of the author's texts. The student purposefully engaged the readers by writing in an indirect and roundabout fashion, which demonstrated a fundamental awareness of the audience in his first language, Chinese. Thus, in his attempt to communicate respectfully with his readers, the student applied a Chinese rhetorical pattern in his English writing.

Another example came up in the same paper when the student made an abrupt shift in topic from one paragraph to the next and started an unrelated scene of the story. He explained, “This is called tsa shu” (插敘, "tsa shu”: a writing strategy involving narration interspersed with flashbacks). Again, the student drew upon the familiar Chinese rhetorical pattern in hopes of engaging the readers in his narration. As the above examples demonstrate, the influence of L1 in L2 writing is noticeable in the students' linguistic choices and rhetorical decisions.

\section{L1 Perspective on the New Rhetorical Context}

The linguistic and cultural barriers also resulted in students struggling with rhetorical knowledge-in other words, cultural and conventional knowledge of how to communicate with different types of audiences effectively. When introduced to different audiences, they did not share the assumptions of Western audiences. Understanding the rhetorical context created in an assignment sheet is like piecing together a rhetorical puzzle. The data show that in attempting to complete the writing assignment based on the FYW curriculum, students struggled with writing in the second language, understanding terms, and meeting the requirements. Below is an excerpt from the students' group discussion (with pseudonyms) when they tried to reach a shared understanding of the assignment and the requirements.

Excerpt 1 (researcher's translation from Chinese):

Chi-ni: We used Wikipedia to look up the term "critical thinking" and translated into our own language. In Chinese, it means pi pan xin de (批判性的: criticizing); you have to know how to ask questions of others and yourself.

Sherry: I think "critical reflection" asks for deeper level of self-reflection on why I would do this. Did I want to just earn the credit or for other motivation.

Bi: Then, to be critical on what?

Sherry/Chi-ni: Your story, your experience. 
Chi-ni: What you did this semester, the activities, the assignment you did, and your-

Qi: How to criticize those...

Shirley/ Chi-ni: Not to criticize, to self-reflect-

Bi: To reflect on myself what I did wrong?

Sherry: How you did it.

Chi-ni: It doesn't have to be what you did badly. It can be . . .

Qi: Why do you reflect on something good?

Sherry: You can talk about why you did well? What was your motivation? Why ...

Chi-ni: Being critical doesn't mean being negative. You don't have to be critical only on the things you do badly. Being critical does not mean self-reflecting either. Don't judge it good or bad. Just think first. Make good things as experience; make bad things as education. There are always two sides of a story. That's the point of being critical.

Bi: [nodding]

In this conversation, the student $\mathrm{Bi}$ was not sure about the meaning of the term critical thinking stated in the assignment sheet. The other two students, Chi-ni and Sherry, figured out its meaning by looking it up on Wikipedia in Chinese. When they explained it to Bi in Chinese, the literal translation of "critical" caused Qi to misunderstand it. Finally, Bi was able to understand the meaning through her classmates' elaboration of the concept rather than from the literal word-to-word translation. This example shows that even the terms and language used in college-level writing assignments might pose problems of understanding for these Chinese students, and Chinese students' L1 perspectives on the new rhetorical context could affect their navigation into the college academic discourse. Once again, we see that Chinese students learning the new academic discourse by translating Chinese knowledge into the academic English context encounter cross-cultural barriers.

\section{Writerly Perceptions and Identities}

The students' experiences with previous English writing classes and their perceptions of writing and themselves as writers have carried over to their new writing courses and affected how they engage with the FYW curriculum. Most of the Chinese students have very limited English writing experiences. In China, their English writing classes, like other classes, are designed to prepare students for tests on their knowledge of grammatical rules and vocabulary. Preparing 
for standardized writing tests like the Test of English as a Foreign Language (TOEFL) or SAT writing tests is viewed as the purpose of improving students' writing skills. Significantly, when describing their experiences with previous English writing in the surveys, they frequently used the words "dull," "terrible," "scary," "nervous," "frustrated," "boring," "hard," and "difficult." The students understood writing skills were essential, and they all believed that improving vocabulary and grammar was fundamental to improving their writing in English. At the same time, they had mixed feelings about the label "ESL students" and all the stereotypes and assumptions about their competence and developmental processes associated with the fact that they spoke English as a second language. As their ultimate writing goal, they wished to be able to write "like a native speaker of English" and write "like an American adult"-thus, "no more baby sentences." In particular, they wished to conceal their Chinese traits in writing, which they called Chinglish. Revealing their Chinese identities in English writing would give a negative impression of their English skills.

\section{Becoming Better Writers}

The Chinese students were conscientious about improving their English writing proficiency and mindful of the limitations of being ESL writers, which they were constantly reminded of in various writing classes, both in China and in the US. One student commented, "I want to learn some skills about how to write a beautiful article and avoid common mistakes since I am limited in vocabulary and poor at structure." The students nevertheless knew about the significance of writing, and the definitions of good writing learned from previous writing experience remained influential on them. Writing "logical" and "beautiful" texts was a common desirable quality for good writing. One student explained, "I was in high school in China, so teachers always taught us to expand the prose gracefully by using rhetoric." She expressed her goal of learning writing: "I hope my writing would be logical and fascinating." The students wanted to learn English rhetoric to write logical and emotionally appealing texts, which were most valued in their understanding of writing.

The students' writerly perceptions of what they could do and what they hoped to do with writing were interwoven into their development in the new contexts of US college writing classes. One student reflected on her experience with writing: "To be honest, I do not like writing in English, but I love writing in Chinese. Writing is one of the best ways to reduce my stress. However, the fear of English grammar hinders me to love English writing." They had mixed feelings about how they were taught about writing and what writing meant to them as they continued to develop their writing skills and identities for different purposes. 


\section{DisCUSSION}

Similar to the Danish doctoral students in the first case presented in this chapter, the Chinese students were more concerned with linguistic accuracy and language problems in their English writing; however, they did not know exactly what language issues are entailed in academic writing, which involves complicated rhetorical decision-making in connection with language choices. They intended to write to impress the reader or the rater of their papers with their texts, rather than to communicate effectively with their readers. Unlike the students of L2 Spanish in the second case, whose Spanish writing tasks were more detached from everyday life and did not result in high-stake consequences, the Chinese students' English writing processes involved engagement with the reallife communication situations and survival, which made their transition from previous linguistic and rhetorical traditions and transfer of knowledge critical and significant. When transitioning from previous writing classes and academic literacy practices, Chinese international students were linking their knowledge and strategies to the new contexts of college literacy practices in the US. They brought with them their own literacies, their ways of communicating, their identities, and their individual dispositions to engage with the transition and transformation in their first year of college. Writing for tests and all the familiar struggles with English writing appeared to be haunting them in the process of their transition and development.

When the students were introduced to new writing tasks and different rhetorical contexts, language problems and L1 interference were the constant concerns rather than the process and transcending different writing contexts. While students might be expected to change their conceptions of writing in college, getting rid of the Chinglish impression seemed to be the common ultimate goal of the Chinese students, however unrealistic and unethical it might be. In reality, though, they relied on their L1 to engage in the learning process of college writing, and their learned knowledge from previous writing classes carried over into the new discourse context. When the Chinese students were encouraged to write not for tests but to engage in authentic communication with the audience in their papers, they would draw upon their Chinese rhetorical strategies to engage the audience and communicate their ideas. The clash between their own perspectives and the new expectations constitutes a contact zone (Pratt, 1991) between two linguistic and rhetorical traditions (L1/L2), where the transformation of writers and construction of knowledge occurs.

Students' dispositions play a significant role in their writing transfer (Driscoll \& Wells, 2012), and how students perceive the learning context is linked to how their dispositions may affect their successful transfer in college writing courses. 
Different identities implied and imposed by different writing courses affected how students felt motivated, how they engaged in the class, how they set their goals, and how they evaluated their own engagement and performances. The developmental sequence of writing courses affects how the student writers perceive themselves as developmental writers. However, writing development is never a linear process. It is multi-directional participation and negotiation that constructs an individual writer within the local contexts and the local discourse community. In addition, the students' perceptions of who they are as students in college writing courses are complicated by the ecological system they share with intimate Chinese networks.

For the Chinese undergraduate students in US higher education, developing as L2 writers of English over different writing courses and writing contexts involves a constant contest among identities they embody in and outside the classroom, on and off campus. The occurrence of writing transfer is manifested in the writing process, where students unlearn and relearn to identify the rhetorical requirements and identify with their new roles as college writers. As proposed in the Elon Statement on Writing Transfer (2015), successful writing transfer occurs only when students can transform or repurpose their prior knowledge and understanding when confronting a new and challenging writing task. When keeping the process and opportunity for writing transfer in perspective, as writing teachers, we can help students overcome the writing struggles, benefit from the necessary trouble in unfamiliar rhetorical contexts, and come away with new applicable knowledge.

\section{Pedagogical Implications}

How do we mitigate the "necessary trouble" that the Chinese international students had to go through in order to settle into their environment and develop confidence in their writerly identities and ultimately benefit from US higher education?

Writing classes are too familiar for the students to expect anything new, novel, or exciting. Students have preconceptions about their writing and themselves as ESL writers that stand in the way of their learning. This existing knowledge and these misconceptions may inevitably apply to writing instructors, as well. In order to meet the students where they are in their developmental process, learning targets, materials, and expectations should be relevant to students where they are in their writing classes. It is essential for writing instructors to acknowledge students' strategies and take advantage of what they bring with them to the classroom to address their instructional needs. Instructors might consider the following aspects of learning when they work with Chinese international students: 
- Acknowledge that Chinese students' multilingual and multi-identities can add to the complicated layers of the transitional process and the transfer of writing skills.

- Acknowledge that students' instructional needs both inside and outside the writing classroom contribute to their successful adaptation to the learning environment.

- Acknowledge students' linguistic problems and writing struggles across different contexts.

- Engage and change the students conceptually through different contexts and the changing relationship between themselves and the audience.

- Engage and change students' perceptions of writing for testing and of themselves as learners of standard academic English.

- Engage and change students' understandings of their writerly identities as writing strategies.

- Acknowledge that students' developmental processes are complicated, networked engagements with literacy activities inside and outside the classroom.

\section{SUPPORTING TRANSFER IN L2 WRITING: STRATEGIES FOR THE FUTURE}

\section{COMMON FINDINGS}

We have examined students' experiences and perceptions of L2 writing in three different contexts where students engage with L2 writing for various purposes and navigate through multiple identities in their writing and communication. The Danish case illustrates some of the effects of assumptions made about L2 writing transfer at the highest educational level, as seen in the lack of a systematic institutional framework for supporting L2 academic writing in English. The case of US American undergraduate students writing in Spanish invites us to reflect on our pedagogical strategies and find ways to bridge the gap that exists between students' and educators' understandings of what it means and what it takes to become a good L2 writer. Finally, the case of Chinese students writing in English reveals the need to address the cultural and political premises of the types of writing we require from students in US academia.

Our common findings tell us that although students perceive writing as a reflection of their identities, they do not necessarily and always think of L2 writing as an opportunity to experiment with and create new identities. This 
is frequently due to the fact that students do not perceive foreign language as a meaning-making mechanism, but rather as a translation tool. That is to say, meaning is created in L1, while L2 is only used to communicate (translate). Students are often concerned with being handicapped when writing in L2 and want to have better knowledge of the grammar, vocabulary, rhetorical strategies, and cultural conventions of the given language in order to sound more authentic. Hence, they perceive L2 writing in terms of limitations and restrictions rather than experimentation and opportunities. However, the inextricable link between $\mathrm{L} 1$ and L2 in the $\mathrm{L} 2$ writing process is manifested in our data across the contexts.

Our research showed that the immediate goals of the US students of Spanish when writing in L2 were the correct use of form and correct transfer of information. Similar to the US students, the Danish students viewed language proficiency as key to successful academic writing but were, on the contrary, acutely aware of how their language and rhetorical skills affected their voices and identities as budding scholars. And, perhaps due to their exposure to and integration into the target cultural and curricular setting, the Chinese students developed an awareness of language as a carrier of cultural identity and started exploring their voices, combining and enriching their L1 identities with the L2.

Finally, we found that successful L2 writing development is closely tied to students' self-perceptions and their socially and culturally constructed attitudes towards L2 writing. This is particularly true when it comes to adult students who in some way have already had successful academic experiences and/or see themselves as accomplished L1 writers. Thus, consistent with the Elon Statement on Writing Transfer, which proposes that "prior knowledge is a complex construct that can benefit or hinder writing transfer. Yet understanding and exploring that complexity is central to investigating transfer" (2015, p. 4), we argue that it can be difficult and at times counterproductive to teach L2 writing without addressing students' prior knowledge about L2 writing, the potential gap between students' and educators' perceptions of successful L2 writing development pedagogy, and the value of such pedagogy.

\section{Future Directions}

Our studies clearly show the need for increased and improved institutional and societal support for the development of L2 writing abilities. L2 writing instruction and pedagogies are informed by scholarship in relevant disciplines but developed and practiced in local contexts. To support students' continuous development of L2 writing competence and identities, we think that it is important for researchers and teachers across the borders to have an open and in-depth 
conversation about how we teach L2 writing and what pedagogical resources we use to foster the development of L2 writers. It is also important to examine our own cultural biases when we teach L2 writing.

Based on our findings, we argue that L2 educators need to adopt a much more purposeful approach to address students' lack of awareness of language as a creator of identity, and to advocate actively for reflective pedagogy that views language study, particularly the study of L2 writing, as an activity that expands and enriches one's identity. The realization that language is a carrier and a creator of identity and culture is one of the threshold moments in the development of L2 writing. In other words, this is the moment when learners become aware of the culturally situated nature of language and, as a result, develop heightened awareness of culturally determined linguistic structures not only in the target language but also in their native ones-when they encounter the third space discussed by Kramsch (1993) and when knowledge transfer encounters roadblocks that need to be overcome. The moment when learners develop awareness of these roadblocks and start searching for ways to overcome them is the turning point in the development of L2 writing. Once this awareness happens, transfer can be a positive practice because learners are better able to identify the problematic features of transfer from L1 to L2. They can see places where transfer can happen seamlessly and others where "unlearning" needs to take place in order to give way to the differences in worldviews and perspectives that are manifested through language.

A more consistent pedagogy needs to be adopted throughout all levels of L2 writing development that would explicitly connect language acquisition with the enrichment of students' identities. Our studies indicate that taking into account the connection between language and identity is as critical for writing development as it is complex. While some students are unprepared to think of L2 writing as an opportunity to explore new identities, others view their L1 writerly identities as authentic and their L2 identities as inauthentic. Students' notions of authentic linguistic identity are inseparable from their comfort levels as speakers and writers. For some students, L2 writing is a tool that helps them adopt or rehearse another's established identity rather than expand or reshape their own identities; hence they dwell on imitation instead of creation in their L2 literacy development. In the end, both groups fail to see L2 writing as an enriching experience, focusing mainly on their limitations and lack of linguistic "authenticity." Our studies also indicate that the creation of a new identity (a third space) comes very late in the process of foreign language learning and the development of L2 writing. Although this is and should be the ultimate goal, educators should take into consideration the limitations that students have in the process and lead them very intentionally and carefully 
toward the understanding of language learning as an opportunity to expand and enrich their identities.

To conclude, we suggest that L2 writing instructors adopt a pedagogy that not only develops students' linguistic proficiency and cultural competency but also communicates to the students the purpose and value of their pedagogical approach. Otherwise, the gap between their perceptions of the learning goals and our teaching practices will make it very hard to achieve the desired goals. Our work points to the benefits of researching writerly identities in a cross-cultural perspective through cross-cultural collaboration as a means to make visible culturally embedded understandings of and approaches to writing that we tend to take for granted in the local context. To borrow Kramsch's (1993) term, we view this kind of collaboration as a way to carve out a third space for carrying out writing transfer research.

\section{NOTES}

1. The authors are listed in the order of the separate institutions appearing in the chapter. Each author contributed equally to this work.

2. For the first two courses, we asked the students to answer the reflection questions and to complete the sentence "Writing in English is like ..." In order to get a better sense of student attitudes toward writing in their first language and the relation between the two, we decided to ask the students enrolled in the third course to complete the sentence "Writing in Danish is like ..." in addition to answering the reflection questions. A total of seven students completed the sentence about writing in Danish. We have since gathered seven more metaphors from students who attended a similar course offered in the spring of 2013.

3. Conceptual metaphors are understood here as words/phrases that in the given context transcend their literal meaning and transfer the literal meaning (from a source area) to an often more abstract target area (see Lakoff \& Johnson, 1980, and Schmitt, 2005, among others).

4. All the quotes and excerpts from the students' writing that are presented here are transcribed as they wrote them, without corrections.

\section{REFERENCES}

Badley, G. (2009). Academic writing as shaping and re-shaping. Teaching in Higher Education, 14(2), 209-219.

Bereiter, C. (1995). A dispositional view of transfer. In A. McKeough, J. L. Lupart \& A. Marini (Eds.), Teaching for transfer: Fostering generalization in learning (pp. 21-34). Hillsdale, NJ: Erlbaum.

Boud, D. \& Lee, A. (2005). "Peer learning" as pedagogic discourse for research educa- 
tion. Studies in Higher Education, 30(5), 501-516.

Buckingham, L. (2008). Development of English academic writing competence by Turkish scholars. International Journal of Doctoral Studies, 3, 1-18.

Byram, M. (2010). Linguistic and cultural education for Bildung and citizenship. The Modern Language Journal, 94(2), 317-331.

Charmaz, K. (2006) Constructing grounded theory. A practical guide through qualitative analysis. London: Sage.

Driscoll, D. \& Wells, J. (2012). Beyond knowledge and skills: Writing transfer and the role of student dispositions. Composition Forum, 26. Retrieved from http://compo sitionforum.com/issue/26/beyond-knowledge-skills.php.

Elon Statement on Writing Transfer. (2015). Retrieved from http://www.centerforen gagedlearning.org/elon-statement-on-writing-transfer/.

Fergie, G., Beeke, S., McKenna, C. \& Creme, P. (2011). "It's a lonely walk”: Supporting postgraduate researchers through writing. International Journal of Teaching and Learning in Higher Education, 23(2), 236-245.

Greeno, J. G., Smith, D. R. \& Moore, J. L. (1993). Transfer of situated learning. In D. K. Detterman \& R. J. Sternberg (Eds.), Transfer on trial: Intelligence, cognition, and instruction (pp. 99-167). Norwood, NJ: Ablex.

Hattie, J. \& Timperley, H. (2007). The power of feedback. Review of Educational Research, 77(1), 81-112.

Hirvela, A. (1997). "Disciplinary portfolios" and EAP writing instruction. English for Specific Purposes, 16(2), 83-100.

Kamler, B. (2008). Rethinking doctoral publication practices: Writing from and beyond the thesis. Studies in Higher Education, 33(3), 283-294. doi: 10.1080/030750 70802049236.

Kramsch, C. (1993). Context and culture in language teaching. Oxford, UK: Oxford University Press.

Kramsch, C. (2010). The multilingual subject. Oxford, UK: Oxford University Press.

Lakoff, G. \& Johnson, J. (1980). Metaphors we live by. Chicago: University of Chicago.

Lee, A. \& Boud, D. (2003). Writing groups, change and academic identity: Research development as local practice. Studies in Higher Education 28(2), 187-200.

McGrail, M. R., Rickard, C. M. \& Jones, R. (2006). Publish or perish: A systematic review of interventions to increase academic publication rates. Higher Education Research \& Development, 25(1), 19-35. doi: 10.1080/07294360500453053.

Michigan State University. (2014). 2013 report. Statistical Report. Retrieved from http://oiss.isp.msu.edu/about/statistics.htm.

Nicol, D., Thomson, A. \& Breslin, C.. 2013. Rethinking feedback practices in higher education: A peer review perspective. Assessment \& Evaluation in Higher Education, 39(1), 102-122.

Parker, R. (2009). A learning community approach to doctoral education in the social sciences. Teaching in Higher Education, 14(1), 43-54.

Pratt, M. L. (1991). Arts of the contact zone. Profession, 91, 33-40.

Sabharwal, M. (2013). Comparing research productivity across disciplines and career 
Cozart et al.

stages. Journal of Comparative Policy Analysis: Research and Practice, 15(2), 141-163.

Scarino, A. (2010). Assessing intercultural capability in learning languages: A renewed understanding of language, culture, learning, and the nature of assessment. The Modern Language Journal, 94(2), 315-336.

Schmitt, R. (2005). Systematic metaphor analysis as a method of qualitative research. The Qualitative Report, 10(2), 358-394.

Stracke, E. (2010). Undertaking the journey together: Peer learning for a successful and enjoyable $\mathrm{PhD}$ experience. Journal of University Teaching \& Learning Practice, $7(1), 1-10$.

Wenger, E. (1998). Communities of practice: Learning, meaning, and identity. Cambridge, UK: Cambridge University Press. 


\section{AFTERWORD}

\section{Chris M. Anson and Jessie L. Moore}

As the contributions to this volume have shown, deploying knowledge and abilities across complex communities of practice that exhibit the ongoing development of communicative practices and the evolution of both context-specific and shared genres represents significant challenge for writers at all levels but particularly for students. Although most undergraduate students won't find themselves assigned to write highly specialized kinds of discourse in their coursework, the varied constructions of even common academic genres such as "term papers" or "analyses" mirror the contradictions, complexities, and idiosyncrasies of many types of writing found beyond academia. Regardless of preparation, all students face the difficulty of applying what they've learned about writing in one context to a new and less familiar one. As Ambrose and colleagues conclude,

Most research has found that (a) transfer occurs neither often nor automatically, and (b) the more dissimilar the learning and transfer contexts, the less likely successful transfer will occur. In other words, much as we would like them to, students often do not successfully apply relevant skills or knowledge in novel contexts. (2010, p. 108)

Plentiful anecdotal evidence for these conclusions can be found in what firstyear college students say they learned in high school about good writing—or how they interpreted their teachers' advice. And just as high school-to-college transitions can be confounded by mislearned strategies, misapprehended expectations, mistaken assumptions, and new contexts and genres, so college-to-workplace transitions can suffer from the learning that happens in that liminal domain of writing, "conditional rhetorical space" (Anson \& Dannels, 2004). The activities in such spaces don't always help students to apply what they've learned about writing in their majors to the work they're asked to do when newly employed after graduation, as Stuart Blythe (this volume) and others have documented. To make matters worse, the generic labels given even to common forms of writing (such as the "afterword") mask widely disparate underlying contextual uses of those forms, which are indeterminate and socially constructed (Miller, 1984). The question at the heart of writing transition, and to which the contributors to this volume have committed the research facilitated by the Elon transfer project, is whether anything we do can help writers, especially novice student writers, to 
move effectively across and into different communities of practice. To echo Donahue (this volume), what teaching practices facilitate transfer, how, and why? The answers to these questions must lie both in the individual's capacities and in the nature of the community in which that individual is trying to write (including the varied functions and nature of its genres).

The history of writing research and the study of literacy more generally is a chronicle of the place of transfer and transition in our thinking about writing development. Pre-1960s formalism so fully neglected agency in writing that transfer was of little or no interest (see Nystrand, Greene \& Wiemelt, 1993) and is mentioned infrequently. The constructivism that led to early research on writing processes still saw the writer as a self-contained entity, adapting rhetorical and composing knowledge to all tasks. Although theories of invention touched on the process of transferring thoughts into texts (see Rohman and Wlecke's 1965 distinction between specific and nonspecific transfer), everything focused on what was in the writer's head. This "autonomous" view of writing eventually gave way to a social-practices orientation that sees learning as highly contextual and based on human actions, relationships, and participation in joint activities (Gee, 1996; Hull \& Schultz, 2001; Street, 1993). As Brandt puts it, literacy is "not the narrow ability to deal with texts but the broader ability to deal with other people as a writer or reader" (1990, p. 14) This view soon generated interest in questions of diversity and the kinds of prior experiences and knowledge students were bringing into new writing contexts.

The implications of these literacy orientations become clearer when we instantiate them in scenes of people learning how to write new kinds of texts in new settings. Imagine that students in an upper-level undergraduate course in art history are assigned to write an object condition report based on artifacts found in the storage area of a campus museum-an actual assignment that we have encountered at more than one university. Most people who are not art historians will plead ignorance of this genre. Without sustained study, even the typical first-year composition instructor would find guiding students to write an object condition report as challenging as teaching a unit on the genetic mutation of $P$. aeruginosa. Lacking prior experience and the discourse schemas it creates, students faced with an assignment to choose an artifact in the museum and write an object condition report on it would - like almost all of us - floun.der, at least at first. What would we do?

In an autonomous orientation, the "ability" to write the report is located in the learner, without regard to context. The better the learner, the more facile the transfer. In this view, successful previous instruction guarantees successful transfer; when transfer fails, the prior instruction—and instructors—are blamed for not training the student to be a good, versatile writer. For this reason, transfer is 
not supported but expected, and its facility becomes a measure of performance and a way to rank and sort students based on what they bring in and/or can do. Because there is little sensitivity to prior (or future) contexts, there is little articulation among different contexts: courses exist as self-contained microcosms of knowledge. Good learners figure out what's necessary to do well wherever they go, intuiting idiosyncratic expectations of teachers or twisted versions of wellknown genres like the "term paper." On the whole it's up to students to piece everything together. The operative phrase here is that transfer happens. From this perspective, there's no interest in what students do or need to do to write the assigned paper. Pedagogy comes by way of trial and error; learning takes place after the fact and is based on what can be intuited from the judgment of the instructor - an expert in the genre of object condition reports-and whatever written comments convey it. (Such practices remind us that while it's possible to trace the history of scholarly trends in writing studies, earlier stages are not simply the dusty archives of bygone eras; daily they still are enacted by teachers who inherit and then pass on deeply-rooted traditions.)

A social-practices orientation acknowledges that discourse exists within contexts and that success is determined in part by those who inhabit it. Our focus shifts away from the individual's generic abilities and skills and toward how writing is situated within and defined by social and institutional contexts. Learners must "read" or "figure out" how to write effectively when the domain of knowledge, genres, ways of creating and mediating information, and sedimented processes and practices for communication may be unfamiliar. However, based on new investigations of transition and transfer, including studies in this collection, we might propose two versions of the social-practices orientation, in parallel to Brent's (2011) summary of scholars' orientations toward transfer as either "glass half empty" or "glass half full." In the learner-centered social practices orientation ("glass half full"), it's possible to equip writers with various forms of awareness or metacognitive strategies so they can efficiently analyze a new context and figure out how it works. Educationally, it becomes important to prepare the learner for what's to follow-to provide common language and concepts and to show how to integrate prior and new knowledge for writing (see Adler-Kassner \& Wardle, 2015, and Yancey, Robertson \& Taczak, 2014). The more self-aware the writer, the better prepared she'll be to face the demands of unfamiliar genres in new communities of practice. Instruction provides heightened awareness of other contexts but doesn't articulate with them; they may represent alien worlds, but students are supposed to parachute into them with enough intellectual gear to adapt quickly. The operative phrase here is transfer happens through awareness and metacognition.

As several chapters in this collection demonstrate (Adler-Kassner, Clark, Robertson, Taczak \& Yancey; Gorzelsky, Driscoll, Paszek, Jones \& Hayes; 
Wardle \& Mercer Clement), adaptation to new contexts for writing may be sped up or facilitated by making explicit the rhetorical and situational needs required to perform effectively. A student prepared in this way might recognize that the genre of the object condition report requires detailed description based on close observation. She would then "remix" what she knows (Yancey et al., 2014), deploying skills developed in an experiential assignment in first-year composition or a lab report from a general-education course in chemistry. The student might also ask questions about the genre, such as its structure and purpose, and find examples of object condition reports to study such features as their style, use of specific terms or concepts, and implied audiences. The assumption is that many contexts won't provide much support for figuring all this out; support comes from what students have learned previously in courses that provide explicit instruction in the processes of transfer.

In a context-centered social-practices orientation ("glass half empty"), learning is seen as highly situated - depending at least as much on the characteristics and inhabitants of the context and its discourse as on what the writer brings into it. As Russell puts it, writers

do not "learn to write, period." Nor do they improve their writing in a general way outside of all activity systems and then apply an autonomous skill to them. Rather, one acquires the genres (typified semiotic means) used by some activity field, as one interacts with people involved in the activity field and the material objects and signs those people use (including those marks on a surface that we call writing). (1995, p. 57; see also Wardle, 2009)

For this reason, transition is never easy and often starts with weak approximations of successful performance or with outright failure (Anson, 2016; Anson \& Forsberg, 1990; Lave \& Wenger, 1991; Smart, 2000). The focus is on intentionally bringing learners into the context with the understanding that they already carry prior knowledge and experience with them but need to learn anew-sometimes entirely. There's little question that something comes in, but it may be of little use or even of detrimental influence depending on how rigidly the writer deploys prior learned practices to meet new demands. Teachers in the new settings build on prior contexts, but they realize that students need to reconstruct existing knowledge or acquire entirely new knowledge (of genre, composing practices, tools, and the like) within a new activity system. Sometimes teachers even assume that students should discard prior knowledge gained outside the classroom, downplaying the potential rhetorical awareness that, as Paula Rosinski (this collection) reminds us, students routinely exhibit in their 
daily, non-academic writing. The operative word is enculturation. As Russell has put it, "One cannot learn to write (or think, or reason, or solve problems) apart from the activities of some historically-situated human community(ies)" (1993, p. 186). Instructors in each new course, therefore, intentionally provide mentoring and guidance-one of the major goals of faculty-development and curricular consultation in every writing-across-the-curriculum or writing-inthe-disciplines program. "In this view," Russell continues,

growth in writing means that students would move toward acquiring the genres, the habits of discourse, the voices of social groups involved in organized activities while students more and more fully participate in (either directly or vicariously) the activities of those groups and eventually contribute to and transform them - not before they participate in them. (1997, p. 186)

Ideally, teachers and administrators collaborate to align their different courses and curricula so that students' learning can be appropriately scaffolded. But this is quite rare.

From a context-centered social-practices perspective, learning is a "process of understanding through participation with others in ongoing activity" (Jawitz, 2007, p. 186). For students struggling to write an object condition report, instructors would acquaint them with the genre and explore the prior knowledge and experience they bring to it (or lack thereof). The instructor demonstrates how the text works and why it's important in art history, describes the multiple, complex audiences for the reports, and explains how the reports are used in the preservation, curation, display, storage, and transportation of art objects or historical artifacts such as a Civil War frock coat. Should the report mention areas in need of repair? Should it include an accession form or deed of gift, a catalog sheet and card, an incoming condition report, or a donor questionnaire? While helping students to understand how object condition reports can vary across different museums, auction houses, and private collections, the instructor might also constrain or define the assignment in ways that answer these questions.

Finally, the processes of transition and transfer must also acknowledge the role of the writer's ethos and authority within the social context of discourse. Those with the most power and prestige can violate certain norms of discourse with impunity (sometimes even setting in motion changes to the genre within its community). While the newly-hired underling in a corporation tries almost desperately to "follow the rules" when writing memos to various members of the hierarchy (Brown \& Herndl, 1986), the CEO may not care. While the freshly minted assistant professor cites a hundred scholars in an article submitted to a 
journal-partly to show that he really knows his stuff-the world-renowned scholar doesn't feel compelled to cite anyone at all; her work is what others cite. While novice writers express near-desperation about knowing "what the teacher wants" in a paper in a general-education course, seniors and graduate students may find themselves asking permission to push the boundaries of a genre or create something unusual. The willingness to shape a genre to meet local or discursive needs, redefining its borders and restructuring its rhetorical activity, usually comes with experience and the freedom borne of authority, as several of the chapters in this volume suggest.

Thanks to the scholars in this collection, we are now learning much more about the relationships between writers' knowledge and the complex characteristics of communities of practice. But there is still much to discover, including especially how writers and their prior knowledge-their dispositions, their adaptation of writing practices employed successfully in other contexts, their additional languages, their comfort with writing technologies, and other social inter- and intrapersonal dimensions - shape these communities and students' transitions and transfer of knowledge within them and to them. In addition, most studies of transfer have focused on developing writers-students enrolled in high school and college courses. Such a focus is clearly of great importance as scholars and teachers try to understand more fully what knowledge and abilities students carry from one course or discipline to another. But the challenges of transfer are not only about what's "in the writer." Highly skilled writers who find themselves needing to write in unfamiliar contexts also experience severe difficulties — even total failure initially — in spite of all their prior experience and practice (see Anson, 2016; Anson \& Forsberg, 1990; Smart, 2000). In fact, years of writing in the same contexts and genres may solidify or sediment mature writers' practices to the point that they experience challenges perhaps different in kind but not in degree to the challenges faced by struggling novice writers in educational settings. This work suggests that transfer as a phenomenon is as much about what's "outside" the writer — in the writing context—as what's inside, and that we should be more fully investigating the relationship between the two.

In addition to a door wide open to research on the transfer of communication abilities, the field of writing studies also faces an opportunity-we might say a necessity - to foster an understanding of transition among a broader range of publics, including policymakers, parents, school boards, and educators who spend little time reading or thinking about the nature of writing and its development. Prevailing mythologies of writing still see it as a skill to be learned once and deployed well thereafter. From this perspective, shock about students' poor abilities and the blame of their previous teachers is understandable if misguided. But unlike some concepts in the field, it's not difficult to shift these concep- 
tions through an understanding of transfer. Everyone who has ever struggled to write in different settings knows what it means. But few have carefully and critically considered what it means for educational practice, especially in the realm of testing. Among those broader publics are teachers of disciplinary content-in the schools, those who do not teach the language arts; in colleges and universities, those who daily walk into their physics, musicology, plant genetics, civil engineering, or psychology courses — who don't see themselves as being charged with or trained for the support of students' writing development. It sometimes takes radical steps to demonstrate to faculty the difficulty of moving across contexts, as Sheila Tobias did through a series of cross-enrollment experiences among experts who were asked to study subjects outside the realm of their training (Tobias, 1986, 1988; Tobias \& Abel, 1988; Tobias \& Hake, 1988). So used to their familiar contexts and disciplines, the faculty in these experiments were jarred out of their disciplinary complacency when they realized that they were struggling to learn and even failing. Fascinating and at times amusing, such experiments are, of course, impractical as a way to reach broader publics about the importance of transfer as a phenomenon that ought to play a central role in rethinking educational practice. But reach them we must if we can expect more principled educational programs, curricula, and pedagogies.

We might start by sharing claims in the Elon Statement: It is possible to teach for transfer of writing knowledge. To do so, we must construct writing curricula that focus on the study of and practice with writing's threshold concepts that enable students to analyze- and respond to-expectations for writing within and across specific contexts. We must engage students in asking questions about writing situations and developing strategies for examining unfamiliar writing contexts. And we must have leeway in education policies to build curricular spaces for explicitly modeling transfer-focused thinking. Of course, successful transfer also requires new contexts that are receptive to transfer; students need the tools to adapt to new contexts, and those new contexts must include people (teachers, employers, etc.) who acknowledge the challenges of transfer and are ready to support new learners (students, employees, etc.) in making the transition.

As this collection demonstrates, the field of writing studies has by no means started closing the door on the research on transfer and transition. If anything, it has cracked it open wider, revealing that there is a lot more light beyond that hasn't yet flooded into our thinking about how writers move across different communities and struggle to produce the discourse found there. With that ongoing research, we will be better prepared to do the important work of translation-of moving out of our academic communities and finding ways to deploy our communication abilities to reach many other people who have a stake in educational policy and practice. 


\section{REFERENCES}

Adler-Kassner, L. \& Wardle, E. (Eds.). (2015) Naming what we know: Threshold concepts in writing studies. Logan, UT: Utah State University Press.

Ambrose, S. A., Bridges, M. W., DiPietro, M., Lovett, M. C. \& Norman, M. K. (2010). How learning works: Seven research-based principles for smart teaching. San Francisco: Wiley.

Anson, C. M. (2016). The Pop Warner chronicles: A case study in contextual adaptation and the transfer of writing ability. College Composition and Communication, 67(4), 518-549.

Anson, C. M. \& Dannels, D. (2004). Writing and speaking in conditional rhetorical space. In E. Nagelhout \& C. Rutz (Eds.), Classroom space(s) and writing instruction (pp. 55-70). Cresskill, NJ: Hampton Press.

Anson, C. M. \& Forsberg, L. L. (1990). Moving beyond the academic community: Transitional stages in professional writing. Written Communication, 7, 200-231.

Barton, D. (1994). Literacy -An introduction to the ecology of written language. Oxford, UK: Blackwell.

Barton, D. \& Hamilton, M. (1998). Local literacies. London: Routledge.

Barton, D., Hamilton, M. \& Ivanic, R. (2000). Situated literacies: Theorising reading and writing in context. New York: Routledge.

Brandt, D. (1990). Literacy as involvement: The acts of readers, writers, and texts. Carbondale, IL: Southern Illinois University Press.

Brent, D. (2011). Transfer, transformation, and rhetorical knowledge: Insights from transfer theory. Journal of Business and Technical Communication, 25(4), 396-420.

Brown, Robert L. \& Herndl, C. (1986). An ethnographic study of corporate writing: Job status as reflected in written text. In B. Couture (Ed.), Functional approaches to writing: Research perspectives (pp. 11-28). New York: Ablex.

Jawitz, J. (2007). New academics negotiating communities of practice: Learning to swim with the big fish. Teaching in Higher Education, 12, 185-197.

Lave, J. \& Wenger, E. (1991). Situated learning: Legitimate peripheral participation. New York: Cambridge University Press.

Miller, C. R. (1984). “Genre as social action.” Quarterly Journal of Speech, 70, $151-167$.

Nystrand, M., Greene, S. \& Wiemelt, J. (1993). Where did composition studies come from? An intellectual history. Written Communication, 10, 267-333.

Roman, D. G. \& Wlecke, A. O. (1964). Pre-writing: The construction and application of models for concept formation writing. East Lansing, MI: Michigan State University Press.

Russell, D. A. (1995). Activity theory and its implications for writing instruction. In J. Petraglia (Ed.), Reconceiving writing, rethinking writing instruction (pp. 51-78). Mahwah, NJ: Lawrence Erlbaum.

Russell, D. R. (1993). Vygotsky, Dewey, and externalism: Beyond the student/discipline dichotomy. Journal of Advanced Composition, 13(1), 173-197. 
Smart, G. (2000). Reinventing expertise: Experienced writers in the workplace encounter a new genre. In P. Dias \& A. Paré (Eds.), Transitions: Writing in academic and workplace settings (pp. 223-252). Cresskill, NJ: Hampton.

Street, B. V. (Ed.) (1993). Cross-cultural approaches to literacy. Cambridge, UK: Cambridge University Press.

Street, B. V. (2001). Introduction. In B. V. Street (Ed.), Literacy and development: Ethnographic perspectives (pp. 1-19). London: Routledge.

Tobias, S. (1986). Peer perspectives on the teaching of science. Change: The Magazine of Higher Learning, 18(2), 36-41. doi: 10.1080/00091383.1986.9937055.

Tobias, S. (1988). Peer perspectives on physics. The Physics Teacher, 26(2), 77-80.

Tobias, S. \& Abel, L. (1988). Peer perspectives on the teaching of poetry. American Council of Learned Societies Newsletter, l(4).

Tobias, S. \& Hake, R. R. (1988). Professors as physics students: What can they teach us? American Journal of Physics, 56(9), 786-794.

Wardle, E. (2009). "Mutt genres" and the goal of FYC: Can we help students write the genres of the university? College Composition and Communication, 60(4), 765-789.

Yancey, K. B., Robertson, L. \& Taczak, L. (2014). Writing across contexts: Transfer, composition, and sites of writing. Boulder, CO: Utah State University Press. 



\section{CONTRIBUTORS}

Linda Adler-Kassner is Associate Dean of Undergraduate Education and Professor of Writing Studies at University of California Santa Barbara. At UCSB and elsewhere, she works with faculty and students on issues around identification of threshold concepts and the roles that those concepts play in learning and teaching. Her most recent book, co-edited with Elizabeth Wardle, is Naming What We Know: Threshold Concepts of Writing Studies. She is currently Associate Chair of the Conference on College Composition and Communication and is a Past President of the Council of Writing Program Administrators.

Chris Anson is Distinguished University Professor and Director of the Campus Writing and Speaking Program at North Carolina State University, where he teaches graduate and undergraduate courses in language, composition, and literacy and works with faculty across the disciplines to enhance writing and speaking instruction. He has published fifteen books and over 120 articles and book chapters relating to writing and has spoken widely across the U.S. and in 28 other countries. He is Past Chair of the Conference on College Composition and Communication and Past President of the Council of Writing Program Administrators. His full c.v. is at www.ansonica.net

Stuart Blythe is Associate Professor in the Department of Writing, Rhetoric, and American Cultures at Michigan State University. His research interests include writing pedagogy and administration as well as public discourse relating to science and technology. From 2011-2013, he was a participant in the Elon University Research Seminar on Critical Transitions: Writing and the Question of Transfer.

Scott C. Chiu is Director of the Writing Center and Assistant Professor of English at California Lutheran University. He leads the planning and implementation of the Writing Center programs, which emphasize multiliteracy practices, community outreach, and research on writing center pedagogies. $\mathrm{He}$ teaches basic writing, writing center theory and practice, and introduction to TESOL. His current research focuses on L1/L2 writing transfer, translingual approaches, writing center studies, and community literacies.

Irene Clark is Professor of English, Director of Composition, and Director of the Master's option in Rhetoric and Composition at California State University, Northridge. Her publications include articles in The Journal of Basic Writing, Teaching English in the Two Year College, College Composition and Communication, Writing Program Administration, Composition Forum, the WAC Journal, and the Writing Center Journal. Her most recent books are a second edition of 
College Arguments: Understanding the Genres (2016), a second edition of Concepts in Composition: Theory and Practice in the Teaching of Writing (2012), Writing the Successful Thesis and Dissertation: Entering the Conversation (2007), and Writing in the Center: Teaching in a Writing Center Setting 4th Edition (2009). She is currently working on a new book concerned with the relationship between genre and transfer.

Nicolette Clement graduated from the University of Central Florida in August 2015 with a Bachelor of Science in Nursing. She is currently a registered nurse on a women's medical-surgical unit in Jacksonville, Florida.

Stacey M. Cozart is a senior educational consultant at the Centre for Teaching Development and Digital Media at Aarhus University in Denmark. Her work centers on teaching, learning, writing, and language in the international university, and she teaches primarily professional development courses and workshops on these issues. She has been involved in several national and European research and educational development projects, currently as a member of the management committee for the EU funded COST network WeRELaTE, aimed at enhancing support for research, writing, teaching, and learning in higher education.

Gita DasBender is the coordinator of second language writing and senior faculty associate at Seton Hall University where she also serves as director of prestigious fellowships for the Provost's office. Her research interests include writing transfer of multilingual students, threshold concepts in writing, writing center pedagogy for multilingual learners, international writing research, critical literacy in global contexts, and teacher education. She is the author of Language: A Reader for Writers (OUP, 2013) and was awarded a Fulbright Specialist grant to Vietnam in 2013.

Christiane Donahue has been a writing program administrator in one form or another since 1992 in the United States. At the same time, she has pursued scholarship, including her PhD in Linguistics, in France. Her work with French research laboratory THEODILE-Cirel at l'Université de Lille and her participation in multiple European research projects, networks, conferences and collaborations informs her understanding of writing instruction, research, and program development in European and US contexts. She is Director of the Institute for Writing and Rhetoric at Dartmouth, Hanover, NH, USA, where she teaches writing and focuses on research about writing, translingualism, cross-cultural comparisons, and research methods.

Dana Lynn Driscoll is Associate Professor of English at Indiana University of Pennsylvania, where she teaches in the Composition and TESOL doctoral program. Her scholarly interests include writing centers, writing transfer, RAD research methodologies, writing across the curriculum, and writing assessment. 
Her work has appeared in journals such as Writing Program Administration, Assessing Writing, Computers and Composition, Composition Forum, Writing Center Journal, and Teaching and Learning Inquiry. Her co-authored article won the International Writing Center Association's 2012 Outstanding Article of the Year Award. She also serves on the Executive Board of CCCC.

Dana Ferris is Professor in the University Writing Program at the University of California, Davis, where she is associate director for second language writing. Her research examines the literacy needs of multilingual writers and readers and focuses especially on response to student writing. She is editor-in-chief of the Journal of Response to Writing.

Gwen Gorzelsky is Executive Director of The Institute for Learning and Teaching (TILT) and Associate Professor of English at Colorado State University. She has published articles in College Composition and Communication, College English, Reflections, JAC, JAEPL, and other venues, as well as The Language of Experience: Literate Practices and Social Change (University of Pittsburgh Press, 2005). Her research interests include writing instruction, learning transfer, metacognition, and literacy learning, particularly uses of literacy for personal and social change.

Carol Hayes is Assistant Professor of Writing at The George Washington University, where she teaches in the University Writing Program and has served in several administrative positions. She currently directs the GW Writing Center. Her research within writing studies focuses on writing transfer, public writing, and writing centers.

Hogan Hayes is Assistant Professor of Rhetoric and Composition in the English Department at California State University, Sacramento. His research focuses on the transfer of writing skills into WID settings, the features and expectations associated with academic writing prior to a student's development of discipline-specific writing conventions, and large-scale writing assessment using electronic portfolios.

Ed Jones directs the basic writing program and coordinates assessment in the English Department at Seton Hall University. His areas of scholarly interest are knowledge transfer, the effect of race and class on self-beliefs and writing achievement, and issues related to administering a writing program. Since 1999, he has been involved with and helped lead the New Jersey Writing Alliance, an organization that builds bridges between college and secondary composition educators.

Ketevan Kupatadze is a senior lecturer of Spanish. Her recent research examines the flipped classroom pedagogy and discussion-based, collaborative approaches to teaching a foreign language. She has led the planning and implementation of a new Spanish curriculum at Elon University's Department of World Languages 
and Cultures, which focuses on the development of students' intercultural competence and critical thinking abilities, in combination with the advancement of their linguistic competence. She has also co-led the department's efforts to integrate meaningful writing assignments throughout the language curriculum as part of the University's Writing Excellence Initiative.

Regina McManigell Grijalva is Associate Professor of English and director of composition at Oklahoma City University, a small liberal arts college where she is involved with general education and assessment, including at the level of programs, departments, and schools or colleges. With her colleague, Amrita Sen, she directs the Global and Transnational Migrations Digital Archives Project. Much of her research focuses on pedagogy, learning, and assessment in higher education and the ways they interact with class, race, ethnicity, and/or gender.

Jessie L. Moore is Associate Drector of the Center for Engaged Learning and Associate Professor of English: Professional Writing \& Rhetoric at Elon University. She leads planning, implementation, and assessment of the Center's research seminars, which support multi-institutional inquiry on high-impact pedagogies and other focused engaged learning topics. Her recent research examines transfer of writing knowledge and practices, multi-institutional research and collaborative inquiry, writing residencies for faculty writers, the writing lives of university students, and high-impact pedagogies. She currently serves as the elected Secretary of CCCC. Her full CV is at jessiemoore.net.

Joe Paszek is a PhD candidate in Rhetoric and Composition at Wayne State University in Detroit, Michigan, and the Writing Center Coordinator at the University of Detroit Mercy. His research focuses on students' processes of disciplinary enculturation and their development of writing skills and practices in mid-level writing classrooms, portions of which have been presented at CCC, WPA, and NCTE. His upcoming project focuses on students' development of theories of writing through the use of disciplinary metaphor. Joe has been a member of the Writing Transfer Project since 2012.

Donna Qualley is Professor of English at Western Washington University where she teaches courses in writing studies, literacy studies, and pedagogy. She is the author of the barely alive, but still breathing Turns of Thought: Teaching Writing as Reflexive Inquiry (1997), co-editor of the now deceased Pedagogy in the Age of Politics: Writing and Reading (in) the Academy (1994), and other essays on reading, writing, and writing program administration. In June 2015, Donna hung up her hat as the Director of Composition at Western Washington University after wearing it for most of the previous two decades.

Liane Robertson is Associate Professor of English at William Paterson University of New Jersey, where she directs the Writing Across the Curriculum program. Her current research explores writing transfer across multi-institutional 
contexts, especially the role of particular content in advanced writing courses and its impact on students' ability to transfer knowledge and practice into a range of writing situations. Her recent work is featured in Writing Across Contexts: Transfer, Composition, and Sites of Writing and Naming What We Know: Threshold Concepts of Writing Studies.

Paula Rosinski is Professor of Professional Writing \& Rhetoric and Writing Across the University Director at Elon University. She leads her university's Quality Enhancement Plan on Writing Excellence, which seeks to enhance the teaching and learning of academic, professional, and co-curricular writing for students, faculty, and staff. Her recent research focuses on the transfer of rhetorical knowledge and writing strategies between self-sponsored and academic texts, reframing rhetorical theories and writing practices in multimodal environments, the technologically-mediated writing lives of students, faculty and student Writing Center Fellows, and multi-institutional RAD research.

Kara Taczak is Teaching Assistant Professor at the University of Denver. Her research centers on the transfer of knowledge and practices: her current project, The Transfer of Transfer Project, examines the efficacy of the Teaching for Transfer curriculum in multiple courses across multiple institutional sites. This research is the second phase of research reported on in her co-authored book, Writing Across Contexts, which was awarded the 2015 CCCC Research Impact award. Taczak's other publications have appeared in Composition Forum, Teaching English in a Two-Year College, and Across the Disciplines.

Elizabeth Wardle is Professor and Director of the Roger and Joyce Howe Center for Writing Excellence at Miami University $(\mathrm{OH})$. She was Chair of the Department of Writing and Rhetoric at the University of Central Florida (UCF), and Director of Writing Programs at UCF and University of Dayton. These experiences fed her interest in how students learn and repurpose what they know in new settings. With Doug Downs, she is the co-author of Writing about Writing. With Linda Adler-Kassner, she is co-editor of Naming What We Know: Threshold Concepts of Writing Studies, winner of the CWPA Outstanding Contribution to the Discipline Award.

Carl Whithaus is Professor of Writing and Rhetoric and Director of the University Writing Program (UWP) at the University of California, Davis. His research areas include writing in the disciplines and professions (particularly in the sciences and engineering), writing assessment, and the impact of information technologies on literacy practices. His books include Multimodal Literacies and Emerging Genres (University of Pittsburgh Press, 2013), Writing Across Distances and Disciplines: Research and Pedagogy in Distributed Learning (Routledge, 2008) and Teaching and Evaluating Writing in the Age of Computers and HighStakes Testing (Erlbaum, 2005). 
Gitte Wichmann-Hansen is Research Director and Associate Professor at the Centre for Teaching and Learning at Aarhus University in Denmark. She is responsible for the competence development of all supervisors at her faculty, and she holds a wide range of supervision courses for faculty members across different levels and disciplines at Aarhus University as well as other Danish and Nordic Universities. Her main research area is Ph.D. supervision. She is involved in several major research projects about Ph.D. students' writing processes, feelings of self-efficacy as well as satisfaction with supervision and integration into the research environment.

Tine Wirenfeldt Jensen is an external lecturer at the University of Southern Denmark and an educational consultant specializing in academic writing. Her $\mathrm{Ph} . \mathrm{D}$. focused on the Master's thesis, and she has designed and taught courses focusing on academic writing and supervision aimed at students, Ph.D. students, and university teachers. As the former leader of Academic Skills Development Team at the Faculty of Arts at Aarhus University, she has developed several resources aimed at supporting academic writing such as the Study Metro web resource and a peer feedback board game.

Kathleen Blake Yancey, Kellogg W. Hunt Professor of English and Distinguished Research Professor at Florida State University, has served in several elected leadership positions, including as Chair of CCCC and President of NCTE and CWPA. Immediate Past Editor of College Composition and Communication, she is the lead PI for the "Transfer of Transfer" research project focused on the Teaching for Transfer (TFT) writing curriculum. Author/co-author of more than 100 articles/chapters and of 13 books_including Writing across Contexts: Transfer, Composition, and Sites of Writing, and A Rhetoric of Reflection (August 2016) — she has received several awards, among them the Purdue Distinguished Woman Scholar Award and the FSU Graduate Mentor Award. 


\section{APPENDIX A: THE \\ ELON STATEMENT ON \\ WRITING TRANSFER}

Developed by 45 writing researchers participating in the 2011-2013 Elon University Research Seminar (ERS) on Critical Transitions: Writing and the Question of Transfer, this statement summarizes and synthesizes the seminar's metalevel discussions about writing and transfer, not as an end-point, but in an effort to provide a framework for continued inquiry and theory-building. As part of the seminar, ERS facilitated international, multi-institutional research about writing transfer and fostered discussions about recognizing, identifying enabling practices for, and developing working principles about writing transfer.

This statement was first distributed at the 2013 Critical Transitions: Writing and the Question of Transfer Conference at Elon University and online at http://www.centerforengagedlearning.org/elon-statement-on-writing-transfer/.

\section{TERMS}

For many scholars "transfer" accurately describes the phenomenon of using prior knowledge in a routinized way and functions as an umbrella term, connecting Writing Studies research to other multi-disciplinary inquiries about transfer of learning. Yet many consider "transfer" inadequate for describing the phenomenon of using prior knowledge in new ways that entail change, transformation, repurposing, and expansive learning. As a result of continued inquiry into these dimensions, scholars have embraced a number of terms that highlight varied theoretical and research-informed connections to discuss this intersection of prior knowledge and movement sometimes referred to simply as transfer. But to advance disciplinary understanding of "writing transfer" (used as a collective, umbrella term throughout this statement), scholars need to qualify the word "transfer," unless we mean transfer in a routinized sense, and reach some consensus about how related, descriptive terms are used in this line of inquiry.

Towards that end, the following list and graphic include terms used in writing transfer research and definitions of those terms from the transfer and writing transfer literature. This list is not exhaustive. Continuing work in writing transfer should explicitly reconcile new terms - and new usage of existing termswith the scholarship's existing vocabulary: 


\section{Transfer}

"Transfer refers to how previous learning influences current and future learning, and how past or current learning is applied or adapted to similar or novel situations. Transfer, then, isn't so much an instructional and learning technique as a way of thinking, perceiving, and processing information" (Haskell, 2001, p. 23). Haskell further offers a taxonomy for transfer, with six levels of transfer (i.e., nonspecific, application, context, near, far, and displacement or creative) and fourteen interrelated kinds of transfer (i.e., content-to-content, procedural-to-procedural, declarative-to-procedural, procedural-to-declarative, strategic, conditional, theoretical, general or nonspecific, literal, vertical, lateral, reverse, proportional, and relational). This taxonomy borrows from other definitions, including David Perkins and Gavriel Salomon's concepts of near transfer and far transfer:

- "Near transfer occurs when knowledge or skill is used in situations very like the initial context of learning" (Perkins \& Salomon, 1992, p. 202).

- "Far transfer occurs when people make connections to contexts that intuitively seem vastly different from the context of learning" (Perkins \& Salomon, 1992, p. 202).

\section{High Road and Low Road Transfer}

Perkins and Salomon $(1988,1992)$ also distinguish between high road and low road transfer. In low road transfer, similarities between a new context and prior situations trigger extensively practiced (near automaticity) skills. In contrast, high road transfer requires mindful abstraction of principles to apply them in new situations.

\section{Generalization and Consequential Transitions}

King Beach (2003) examines generalization as knowledge propagation, suggesting that generalization is informed by social organization and acknowledges change by both the individual and the organization. "Transition . . . is the concept we use to understand how knowledge is generalized, or propagated, across social space and time. A transition is consequential when it is consciously reflected on, struggled with, and shifts the individual's sense of self or social position. Thus, consequential transitions link identity with knowledge propagation" (Beach, 2003, p. 42).

\section{Boundary-Crossing}

Terttu Tuomi-Gröhn and Yrjö Engeström write that boundary-crossing "involves encountering difference, entering into territory in which we are unfa- 
miliar and, to some significant extent therefore, unqualified. In the face of such obstacles, boundary-crossing seems to require significant cognitive retooling" (2003, p. 4). Boundary-crossers employ "boundary objects," tools that develop at the intersections of communities/activity systems to facilitate interaction between and across systems.

\section{REMIX AND REPURPOSE}

Kathleen Blake Yancey suggests that "remix — the combining of ideas, narratives, sources-is a classical means of invention... . Remixing, both a practice and a set of material practices, is connected to the creation of new texts" (2009, p. 5-6). In studies of writing and transfer, remix and repurpose often are used to describe writers' process of conscious reflection on prior knowledge and adaptation of it for new contexts and purposes.

\section{INTEGRATION}

Successful integration refers to "an act of transfer that assumes some degree of metacognitive awareness and a positive outcome for the student" representative of high road transfer, dialogized consciousness, and expansive learning (Nowacek, 2011, pp. 33-34). Rebecca Nowacek cautions that students also can experience frustrated integration, though, when despite "meta-aware seeing," students' outcomes are unsuccessful.

\section{LEARNING AND TRANSFER THEORIES}

In addition to drawing from writing studies theories, writing transfer inquiry integrates a range of broader learning and transfer theories (e.g., affinity spaces, affordances, genre theory, information literacy studies, zone of proximal development, etc.) by a variety of scholars (e.g., Bourdieu, Engeström, Gee, Vygotsky, Wenger, etc.). The following theories and concepts have been especially prevalent in ERS studies as frameworks for studying and describing the complex dynamics of writing transfer:

\section{Biofcological Models and Dispositions}

Like cultural-historical activity theory, the Bioecological Model of Human Development developed by Urie Bronfenbrenner and colleagues attends to the context of learner development (see, for instance, Bronfenbrenner \& Morris, 2006). Their work extends the focus on the individual in the system to consider the 
impact of the individual's interactions with his/her context over time. Applied to transfer studies, the bioecological model suggests that learner's dispositions can impact willingness to engage with transfer and can have generative or disruptive impacts on the learner's context.

\section{Communities of Practice}

Etienne Wenger and others suggest that communities of practice are collectives of individuals and groups sharing values, goals, and interests (see, for instance, Wenger, McDermott \& Snyder, 2002). Communities include both novices and experts. Part of the dialogic process of moving from novice to expert involves learning how to learn within communities. As we think about learning transfer, then, we should look for the enabling practices that help students develop those learning-how-to-learn strategies that apply across contexts or communities.

\section{Cultural-Historical Activity Theory (CHAT)}

As the Center for Research on Activity, Development, and Learning explains, cultural-historical activity theory builds from the concept that "A human individual never reacts directly (or merely with inborn reflects) to environment. The relationship between human agent and objects of environment is mediated by cultural means, tools and signs." Students routinely move among activity systems (including curricular, co-curricular, and extra-curricular contexts), and language functions as one of their mediating tools, but they must learn how to adapt their use of the tool to each activity system. Meanwhile, students also change the contexts as they interact with, resist, and renegotiate each activity system.

\section{Threshold CONCEPTS}

Jan (Erik) Meyer and Ray Land (2006), building on David Perkins' notion of troublesome knowledge, challenge educators to identify concepts central to epistemological participation in disciplines and interdisciplines, "transformed way[s] of understanding" that function as a "portal, opening up a new and previously inaccessible way of thinking about something" (2006, p. 3). Once educators identify threshold concepts that are central to meaning making in their fields, as the contributors to Naming What We Know have done for writing studies, they can prioritize teaching these concepts, in turn increasing the likelihood that students will carry an understanding of these core concepts into future coursework and contexts.

Figure A.1 illustrates how these learning and transfer theories examine intersections among knowledge, learners, and contexts. 


\section{What does the concept/idea emphasize?}

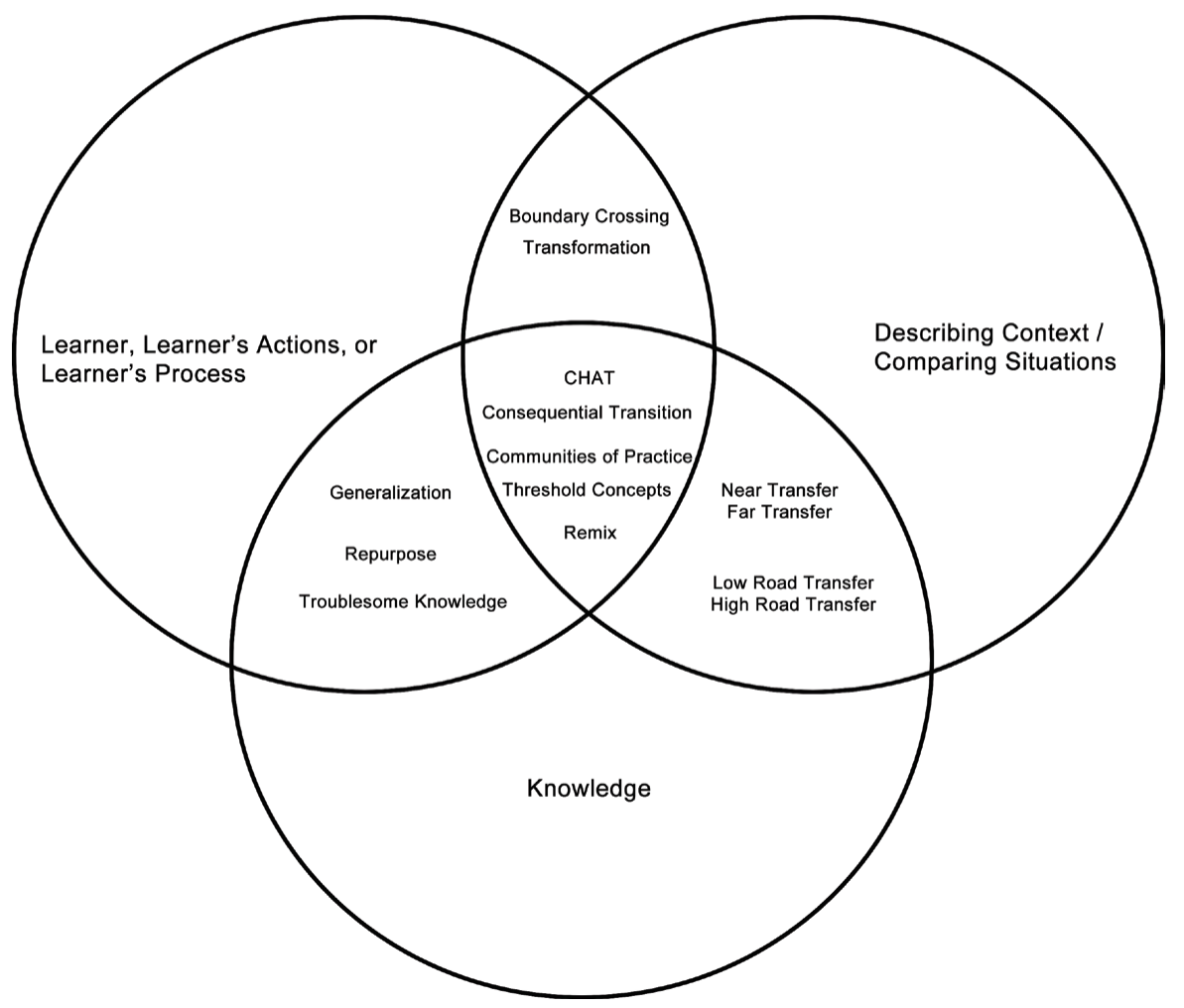

Figure A.1. What the learning and transfer theories emphasize.

\section{WORKING PRINCIPLES ABOUT WRITING TRANSFER}

Drawing on their own research and that of others, ERS participants have identified a number of principles in which they have high confidence- that is, principles that emerge out of empirical studies focusing on writing transfer. These principles extend from the idea that transfer does occur, contrary to suggestions reflected in some prior research. Writers consistently draw on prior knowledge in order to navigate within and among various contexts for writing and learning. Sometimes the rhetorical challenge requires bringing what we know to conscious attention in order to think about similarities and differences between what we know and have done and what we must do now. Sometimes we must reflect, repurpose, and generalize what we bring to bear. Sometimes we must do even more than repurpose and must engage in consequential transitions (Beach, 
2003; see above). And usually, even while we are bringing existing knowledge and experience to bear on the new situation, we must learn anew as part of the process of understanding, adaptation, and enculturation.

Nevertheless, while we know that writing transfer both occurs and is necessary for successful writing, prior research highlights the challenges of teaching to facilitate transfer. Students typically do not expect to be able to apply what they are learning in traditional first-year writing courses to other contexts (e.g., Bergmann \& Zepernick, 2007; Driscoll, 2011), and when they do try to transfer new skills and knowledge from one academic setting to another, they often encounter roadblocks (e.g., Nelms \& Dively, 2007; Nowacek, 2011). Furthermore, some curricular designs unintentionally impede transfer (e.g., Wardle, 2009).

As teachers, then, we must consider what sorts of rhetorical challenges students encounter in our classes and contexts beyond and how to best help students navigate those challenges. Research suggests that there are things that teachers can do to afford learning in these moments of challenge. In other words, it is possible to "teach for transfer" (as Perkins and Salomon put it), and the discipline is learning more about what writing transfer entails:

- Writing transfer is the phenomenon in which new and unfamiliar writing tasks are approached through the application, remixing, or integration of previous knowledge, skills, strategies, and dispositions.

- Any social context provides affordances and constraints that impact use of prior knowledge, skills, strategies, and dispositions, and writing transfer successes and challenges cannot be understood outside of learners' social-cultural spaces.

- Prior knowledge is a complex construct that can benefit or hinder writing transfer. Yet understanding and exploring that complexity is central to investigating transfer.

- Individual dispositions and individual identity play key roles in transfer.

- Individuals may engage in both routinized and transformative (adaptive, integrated, repurposed, expansive) forms of transfer when they draw on or utilize prior knowledge and learning, whether crossing concurrent contexts or sequential contexts.

- Successful writing transfer occurs when a writer can transform rhetorical knowledge and rhetorical awareness into performance. Students facing a new and difficult rhetorical task draw on previous knowledge and strategies, and when they do that, they must transform or repurpose that prior knowledge, if only slightly. 
- Students' meta-awareness often plays a key role in transfer, and reflective writing promotes preparation for transfer and transfer-focused thinking.

- The importance of meta-cognition of available identities, situational awareness, audience awareness, etc., become even more critical in writing transfer between languages because of the need to negotiate language-based differences and to develop awareness about the ways language operates in written communication in each language.

\section{ENABLING PRACTICES}

Practices that promote writing transfer include:

- Constructing writing curricula and classes that focus on study of and practice with concepts that enable students to analyze expectations for writing and learning within specific contexts. These include rhetorically-based concepts (such as genre, purpose, and audience);

- Asking students to engage in activities that foster the development of metacognitive awareness, including asking good questions about writing situations and developing heuristics for analyzing unfamiliar writing situations; and

- Explicitly modeling transfer-focused thinking and the application of metacognitive awareness as a conscious and explicit part of a process of learning.

ERS participants have investigated both "Teaching for Transfer" and "Writing about Writing" curricula in multi-institutional studies. Because these types of curricular approaches forefront rhetorical knowledge, terms, and concepts that students will need to apply in future contexts, they equip students with tools and strategies for successful boundary crossing. These approaches typically also build in reiterative opportunities for developing metacognitive awareness. Although these curricula often are implemented in first-year writing contexts, courses university-wide can include reflection activities about both generalizable and discipline-specific writing strategies.

\section{RECOGNIZING AND STUDYING TRANSFER: SITES AND METHODS}

Cross-institutional, cross-disciplinary, and cross-cultural collaboration enriches the discussion about writing transfer and allows new perspectives to become 
visible. Even if multi-institutional research is not feasible for a specific writing transfer study, scholars should pursue both new and replication studies in varied contexts and routinely revisit how new inquiries intersect with prior and concurrent studies.

Both in case studies of individuals or contexts and in larger data samples, writing transfer studies use a variety of qualitative and quantitative methods to identify evidence of and measure transfer, including surveys, focus groups, interviews, classroom observations, text analysis, discourse analysis, composing-aloud and think-aloud protocols, group discussion logs, and analysis of students' course work and faculty comments. While students often are the primary participants in transfer studies, researchers also interact with and collect data from teachers and community partners, and new studies are beginning to investigate transfer in experienced writers (e.g., Anson, in press; see also Smart, 2000). Most transfer studies are short-term (one or two terms), but additional longitudinal studies and studies that examine both writers' academic and non-academic activity systems could extend the field's understanding of writing transfer.

ERS studies and other contemporary work in writing transfer reiterate the value of using mixed methods across multiple contexts to achieve a "scalable" understanding of writing transfer-enabling teacher-scholars both to focus in detail on specific communities of practice and activity systems and to "zoom out" to examine working principles of writing transfer that apply across multiple contexts. For this reason, both short-term and longitudinal studies will enrich disciplinary understandings of transfer, particularly as scholars examine learners' development as writers, not merely their transitions from one context to another. Adding student voices as participants, or even as co-inquirers, facilitates this more holistic examination of learners' development, boundary-crossing, remixing, and integration.

\section{WORKING PRINCIPLES IN DEVELOPMENT}

In addition to the high-confidence working principles discussed above, ERS participants identified a number of working principles that remain in development. ERS participants have moderate to high confidence in these in-development principles, but they merit further research.

- With explicit rhetorical education, students are more likely to transform rhetorical awareness into performance.

- Helping students develop strategies and tools to think about how writing functions in communities can potentially prepare them to draw effectively on prior knowledge when they encounter writing in 
new settings, whether writing for a major, writing in a workplace, or writing for extracurricular activities.

- Some dispositions seem to better afford engaged rhetorical problemsolving. We are only starting to explore what such dispositions might be, so pedagogy that promotes transfer needs to be attentive to dispositions research.

- Some physical and digital space designs afford learning and transfer better than others.

- The transfer of rhetorical knowledge and strategies between selfsponsored and academic writing can be encouraged by designing academic writing opportunities with authentic audiences and purposes and by asking students to engage in meta-cognition.

\section{NEXT STEPS AND IMPLICATIONS}

Clearly these principles — when paired with supporting research and evidencehave implications for first-year writing programs, writing across the curriculum programs, writing majors, general education curricula, and higher education more broadly. Updates to the ERS projects and any subsequent revisions to this statement will be posted at http://www.centerforengagedlearning.org/elon -statement-on-writing-transfer/.

\section{BIBLIOGRAPHY AND RECOMMENDED READINGS Writing STUdies ScholarshiP}

Adler-Kassner, L., Majewski, J. \& Koshnick, D. (2012). The value of troublesome knowledge: Transfer and threshold concepts in writing and history. Composition Forum, 26. Retrieved from http://compositionforum.com/issue/26/troublesome -knowledge-threshold.php.

Adler-Kassner, L. \& Wardle, E. (2015). Naming what we know: Threshold concepts in writing studies. Logan, UT: Utah State University Press.

Anson, C. M. (in press). The Pop Warner chronicles: A case study in contextual adaptation and the transfer of writing ability. College Composition and Communication.

Anson, C. M. \& Forsberg, L. (1990). Moving beyond the academic community: Transitional stages in professional writing. Written Communication, 7(2), 200-231.

Bacon, N. (1999). The trouble with transfer: Lessons from a study of community service writing. Michigan Journal of Community Service Learning, 6, 53-62.

Beaufort, A. (2007). College writing and beyond: A new framework for university writing instruction. Logan, UT: Utah State University Press.

Bergmann, L. S. \& Zepernick, J. (2007). Disciplinarity and transfer: Students' percep- 
tions of learning to write. WPA: Writing Program Administration, 31(1-2), 124-149.

Clark, I. L. \& Hernandez, A. (2011). Genre awareness, academic argument, and transferability. The WAC Journal, 22. Retrieved from http://wac.colostate.edu/journal /vol22/clark.pdf.

Donahue, C. (2012). Transfer, portability, generalization: (How) does composition expertise "carry"? In K. Ritter \& P. Matsuda (Eds.), Defining composition studies: Research, scholarship, and inquiry for the twenty-first century (pp. 145-166). Logan, UT: Utah State University Press.

Downs, D. \& Wardle, E. (2007). Teaching about writing, righting misconceptions: (Re)envisioning "first-year composition" as introduction to writing studies. College Composition and Communication, 58(4), 552-584.

Driscoll, D. L. (2011). Connected, disconnected, or uncertain: Student attitudes about future writing contexts and perceptions of transfer from first year writing to the disciplines. Across the Disciplines, 8(2). Retrieved from http://wac.colostate.edu/atd /articles/driscoll2011/index.cfm.

Driscoll, D. L. \& Wells, J. H. M. (2012). Beyond knowledge and skills: Writing transfer and the role of student dispositions in and beyond the writing classroom. Composition Forum, 26. Retrieved from http://compositionforum.com/issue/26 /beyond-knowledge-skills.php.

McCarthy, L. P. (1987). A stranger in strange lands: A college student writing across the curriculum. Research in the Teaching of English, 21(3), 233-265.

Moore, J. L. (2012). Mapping the questions: The state of writing-related transfer research. Composition Forum, 26. Retrieved from http://compositionforum.com /issue/26/map-questions-transfer-research.php.

Nelms, G. \& Dively, R. L. (2007). Perceived roadblocks to transferring knowledge from first-year composition to writing-intensive major courses: A pilot study. WPA: Writing Program Administration, 31(1-2), 214-240.

Nowacek, R. (2011). Agents of integration: Understanding transfer as a rhetorical act. Carbondale, IL: Southern Illinois University Press.

Reiff, M. J. \& Bawarshi, A. (2011). Tracing discursive resources: How students use prior genre knowledge to negotiate new writing contexts in first-year composition. Written Communication, 28(3), 312 -337.

Robertson, L., Taczak, K \& Yancey, K. B. (2012). A theory of prior knowledge and its role in college composers' transfer of knowledge and practice. Composition Forum, 26. Retrieved from http://compositionforum.com/issue/26/prior-knowledge -transfer.php.

Rounsaville, A. (2012). Selecting genres for transfer: The role of uptake in students' antecedent genre knowledge. Composition Forum, 26. Retrieved from http://compo sitionforum.com/issue/26/selecting-genres-uptake.php.

Russell, D. (1997). Rethinking genre in school and society: An activity theory analysis. Written Communication, 14(4), 504-554.

Smart, G. (2000). Reinventing expertise: Experienced writers in the workplace encounter a new genre. In P. Dias \& A. Paré (Eds.), Transitions: Writing in academic 
and workplace settings (pp. 223-252). Cresskill, NJ: Hampton.

Sternglass, M. S. (1997). Time to know them: A longitudinal study of writing and learning at the college level. Mahwah, NJ: Lawrence Erlbaum.

Wardle, E. (2007). Understanding "transfer" from FYC: Preliminary results from a longitudinal study." WPA: Writing Program Administration, 31(1-2), 65-85.

Wardle, E. (2009). "Mutt genres" and the goal of FYC: Can we help students write the genres of the university? College Composition and Communication, 60(4), 765-789.

Wardle, E. (2012). Creative repurposing for expansive learning: Considering "problem-exploring" and "answer-getting" dispositions in individuals and fields. Composition Forum, 26. Retrieved from http://compositionforum.com/issue/26/creative -repurposing.php.

Yancey, K. B. (2009). Re-designing graduate education in composition and rhetoric: The use of remix as concept, material, and method. Computers and Composition, 26(1), 4-12.

Yancey, K. B., Robertson, L. \& Taczak, K. (2014). Writing across contexts: Transfer, composition, and sites of writing. Logan, UT: Utah State University Press.

\section{Learning and Transfer Theory Scholarship}

Beach, K. (2003). Consequential transitions: A developmental view of knowledge propagation through social organizations. In T. Tuomi-Gröhn \& Y. Engeström (Eds.), Between school and work: New perspectives on transfer and boundary-crossing (pp. 39-61). Bingley, UK: Emerald Group Publishing, 2003.

Bronfenbrenner, U. \& Morris, P. A. (2006). The bioecological model of human development. In R. M. Lerner \& W. Damon (Eds.), Handbook of child psychology, Vol. 1 (pp. 793-898). New York: Wiley.

Haskell, R. (2011). Transfer of learning: Cognition, instruction, and reasoning. San Diego, CA: Academic.

Meyer, J. H. F. \& Land, R. (2006). Introduction. In J. H. F. Meyer \& R. Land (Eds.), Overcoming barriers to student understanding: Threshold concepts and troublesome knowledge (pp. 3-18). London: Routledge.

Meyer, J. H. F., Land, R. \& Baillie, C. (Eds.). (2010). Threshold concepts and transformation learning. Rotterdam, NL: Sense.

National Research Council. (2000). How people learn: Brain, mind, experience, and school (Expanded ed.). Washington, D.C.: National Academy Press.

Perkins, D. N. \& Salomon, G. (1988). Teaching for transfer. Educational Leadership, 46(1), 22-32.

Perkins, D. N. \& Salomon, G. (1989). Are cognitive skills context-bound? Educational Researcher, 18(1), 16-25.

Perkins, D. N. \& Salomon, G. (1992). The science and art of transfer. In A. L. Costa, J. Bellanca \& R. Forgarty (Eds.), If minds matter: A forward to the future (Vol. 1) (pp. 201-209). Palatine, IL: Skylight Publishing.

Tuomi-Gröhn, T. \& Engeström, Y. (2003) Conceptualizing transfer: From standard 
Appendix A

notions to developmental perspectives. In T. Tuomi-Gröhn \& Y. Engeström (Eds.), Between school and work: New perspectives on transfer and boundary-crossing (pp. 19-38). Bingley, UK: Emerald Group Publishing.

Wenger, E., McDermott, R. \& Snyder, W. M. (2002). Cultivating communities of practice: A guide to managing knowledge. Boston: Harvard Business School Press. 


\title{
APPENDIX B: THE VIDEO JOURNALS ASSIGNMENT
}

\author{
WRA 493: Internship in Professional Writing \\ Dr. Stuart Blythe, Associate Professor \\ Writing, Rhetoric \& American Cultures \\ Spring 2012
}

With the video journals assignment, I ask you to create six videos that capture moments of your work as a professional writing intern. Most of the journals should be two- to three-minute pieces that capture you "in action." As is explained in the Prompts/Assignments section below, you are required to create some videos that address certain topics, and you are free to create other videos on topics of your own choosing.

\section{RATIONALE}

The primary purpose of the video journals is to help you document and reflect on your work as an intern. As is discussed in the video titled "A Rationale for the Video Journals in 493" (see the course website), one way you learn is to examine artifacts. By making video journals, you are creating artifacts that should be worth examining. You also have an opportunity to document your work in a dynamic way, to give others a vivid sense of you as a writer. You can create for others (potential employers, fellow students) a rich picture of your experience, the way you think through problems, and the way you use digital tools. You should also gain some experience creating messages using multiple media (i.e., video, audio, images, text).

\section{PROMPTS/ASSIGNMENTS}

Two of the six journals should be on one of the required topics below. The other four journals can be on any topic that seems worthwhile to you. You may also choose to repeat topics a couple times.

Required: Document your work on a particular writing task. Possible tasks include such activities as writing an introduction or conclusion, searching for credible information, deciding how to organize information, and managing multiple documents. As you record, talk aloud. Consider showing us things that help you complete some of these sentences: 
1. The task I'm going to focus on is ...

2. This task is part of a project for ...

3. My primary audience for this project is ...

4. I think my audience will want to know about ...

5. This task at work differs from (or is similar to) tasks at school in these ways ...

\section{Required:}

Either: Document and reflect on a classroom-workplace disconnect by completing sentences like these:

1. In ... class, I learned ...

2. But at work, it's different because ...

3. Here's how I've resolved that disconnect ...

Or: Document and reflect on a classroom-workplace connection by completing these sentences:

1. In ... class, I learned ... .

2. This really helped me at work because...

3. Here's how I've used what I learned at school applies to work ...

Optional: Create a portfolio piece. Create a video that documents your work in a way suitable for your senior/professional portfolio. This should be something that showcases some aspect your work for potential employers. Note: Because you might want to make a more "polished" video for your portfolio, consider using something like Camtasia or iMovie or Moviemaker. Camtasia is available in the computer lab in Bessey (Room 317).

Optional: Document your reaction to feedback from your supervisor. Show us things that help you complete sentences like these:

1. I recently submitted ...

2. Here's what my supervisor said ...

3. I was surprised by this feedback because ... OR I expected this feedback because...

4. As a result of this feedback, I'm going to ... because ...

Optional: Document your efforts at collaborating with others. If you have to work with others at some point during your internship, you might use your weekly video journal to document some aspect of how you've collaborated with others. You could complete sentences like these:

1. The project I am collaborating on is ...

2. The purpose of the project is ..., and the audience is ... 
3. I'm working with ..., and here's what each of them is supposed to do...

4. I'm expected to contribute to this project by ...

5. My biggest concern regarding this collaboration is ..., and here's how I plan to address this concern ...

Of course, other ideas are possible. 



\section{APPENDIX C: OCU ENGLISH \\ DEPARTMENT COMPOSITION \\ OUTCOMES STATEMENT}

\section{Oklahoma City University English Department Composition Program Outcomes}

The English Department works toward the following goals and objectives in all composition courses-ENGL 1113, 1113I, 1113H, 1213, 1213I, 1213H. In both Composition I and II (ENGL 1113 and 1213), we have five primary goals:

Students should develop and improve their abilities in the following five goals:

1. Rhetorical Knowledge

2. Critical Thinking, Reading, and Writing

3. Processes

4. Knowledge of Conventions

5. Composing in Electronic Environments

International and honors courses address the same objectives as the traditional, domestic courses. Though the goals are the same, they are emphasized developmentally, meaning composing strategies practiced in Composition I will provide the foundation for composing done in Composition II. In sum then, Composition I and II, together, emphasize the reading of academic, literary, and/or professional texts as well as writing/composing in them.

\section{RHETORICAL KNOWLEDGE}

By the end of first year composition, students should:

- Focus on a clear and specific purpose

- Respond to the needs of different audiences

- Respond appropriately to different kinds of rhetorical situations

- Use conventions of format and structure appropriate to the rhetorical situation

- Adopt appropriate voice, tone, and level of formality to the situation or task

- Understand how genres shape reading and writing 
- Write in several genres and/or forms such as narratives, reflections, summaries, arguments, syntheses, critiques, objective reports, essays, and/or essay-exams

- Understand academic writing as specific and situated discourse

\section{Critical Thinking, Reading, and Writing}

By the end of first year composition, students should:

- Use writing and reading for inquiry, learning, thinking, and communicating

- Engage in thinking that requires movement from general to specific (deduction) and from the specific to the general (induction)

- Use problem-solving heuristics and then transfer those heuristics to other situations

- Develop basic research skills

- Understand a writing assignment as a series of tasks, including finding, evaluating, analyzing, and synthesizing appropriate primary and secondary sources

- Critique foundational assumptions and bring controversial assumptions to light

- Read as a writer with an eye to borrowing strategies, techniques, and forms from other writers

- Interpret literary texts, such as non-fiction, short stories, poems, songs, and/or films with a specific focus or theoretical frame

- Integrate their own ideas with those of others

- Develop ideas using concrete details and specific examples to support ideas, illustrate points, and make writing interesting, compelling, and persuasive

- Understand the relationships among language, knowledge, and power

- Learn that composition is, among other things, a path to knowledge, self-discovery and communicating with others

- In international sections, increase English vocabulary conventions

- Learn to identify implied points or consequences of ideas

\section{Processes}

By the end of first year composition, students should:

- Use invention techniques such as talking to peers, free writing, questioning, clustering, journaling, and conducting research 
- Be aware that it takes several drafts to complete a successful text and learn to improve successive drafts, using rubrics, revision checklists or other specified criteria

- Develop flexible strategies for generating, revising, editing, and proof-reading

- Understand writing as an open process that permits writers to use later invention and re-thinking to revise their work

- Understand the collaborative and social aspects of writing processes, that writing is not simply the product of learning but is part of the process of constructing meaning and knowledge

- Understand the values and challenges of collaboration and develop skill in working collaboratively within the academic community

- Learn to critique their own and others' works, present their own works to others, and learn to guide revision discussion so that they can gain from other readers and thereby improve their own texts

- Learn to balance the advantages of relying on others with the responsibility of doing their part

- Evaluate their own writing with some detachment, taking a step away from their own writing to read it critically

- Use a variety of technologies, media and/or genres to address a range of audiences

- Learn time management skills

Faculty in all programs and departments can build on this preparation by helping students learn:

- To build final results in stages

- To review work-in-progress in collaborative peer groups for purposes other than editing

- To save extensive editing for later parts of the writing process

- To apply the technologies commonly used to research and communicate within their fields

\section{Knowledge of Conventions}

By the end of first year composition, students should:

- Express thoughts clearly in effectively organized sentences and paragraphs

- Write with language that is specific, concrete, and honest, free of clichés, prefabricated language, and wasted words 
- Learn to use common formats for different kinds of compositions, such as reports, reviews, memoranda, proposals, letters, brochures, etc.

- Develop strategies for effective introductions and conclusions

- Develop knowledge of genre conventions ranging from structure and paragraphing to tone and mechanics

- Write logically with clear organization between ideas and paragraphs

- Practice appropriate means of documenting their work using professional format/style

- Understand the rationale for documentation in researched writing and how to recognize and avoid plagiarism

- Improve editing skills, becoming more adept in identifying and correcting errors in standard English grammar, mechanics, punctuation, and spelling

\section{Composing in Electronic Environments}

As has become clear over the last 20 years, writing in the twenty-first century involves using digital technologies for several purposes, from drafting to peer reviewing to editing. Therefore, although the kinds of composition processes and texts expected from students vary across programs and institutions, there are nonetheless common expectations.

By the end of first-year composition, students should:

- Use electronic technologies for drafting, reviewing, revising, editing, or sharing compositions

- Collect, locate, evaluate, organize, and use research material from electronic sources, including scholarly library databases, other official databases (e.g., federal government databases), and informal electronic networks and internet sources

- Understand and employ the differences in the rhetorical strategies and in the possibilities or options available for both print and electronic composing processes and texts

- Learn to disseminate compositions in both print and electronic forms in their fields 


\section{GLOSSARY}

Activity systems are groups of people (e.g., communities of practice) who share a common object of attention, or problem space, and motive over time. Cultural-historic activity theory posits that the human interactions within activity systems are tool-mediated, shaped by shared community rules, and fluid. Membership changes as people join the community or leave to pursue other motives. Individuals may contribute to and move among multiple activity systems - university classrooms, workplaces, family units, disciplinary communities, and so forth-necessitating boundary crossing and negotiation of sometimes conflicting motives. See Chapter 5 (McManigell Grijalva) and Chapter 6 (Wardle \& Mercer Clement).

Assemblage involves grafting new knowledge onto prior knowledge without fully integrating the new knowledge. The new knowledge becomes an "add-on," and the prior knowledge remains unchanged. See Chapter 3 (Qualley).

Backward transfer refers to new knowledge/learning influencing prior knowledge. It may occur more often when the new knowledge builds on a foundation of prior knowledge that is still developing. See Chapter 3 (Qualley).

Backward-reaching transfer entails examining prior knowledge for ideas or concepts that will help a learner understand or make sense of new knowledge. It represents a break in forward momentum, as the exigence for backward-reaching transfer is an encounter with a problem, compelling the learner to pause, reverse direction, and consult previous knowledge or experience before looking again to its application in the new context. See Chapter 3 (Qualley).

Boundary-crossing entails using "boundary objects," tools that develop at the intersections of discrete contexts or activity systems to facilitate interaction between and across these systems. Because boundary-crossing involves grappling with differences among systems and entering unfamiliar community spaces, boundary-crossing is cognitively intensive. See Terttu Tuomi-Gröhn and Yrjö Engeström (2003), and this collection's introduction (Moore \& Anson), Chapter 3 (Qualley), and Chapter 4 (Donahue).

Bridging activities facilitate high-road transfer.

Communities of practice theory offers writing studies scholars a way to examine the shared values, goals, and interests within communities (see, for instance, Wenger, McDermott \& Snyder, 2002). As novices work to advance their expertise within a community of practice, they learn from others in the community — and part of that identity development involves learning how to learn within the community. Community membership is fluid, though, so new members with different levels of expertise may enter the community while members looking 
for new challenges or seeking to meet different goals may move out. See Chapter 1 (Adler-Kassner, Clark, Robertson, Taczak \& Yancey) for a discussion connecting Communities of Practice and Threshold Concepts.

Consequential transitions may be lateral (unidirectional from a preparatory activity to a related, developmentally advanced activity), collateral (multi-directional between concurrent activities), encompassing (within social activities that are undergoing change), or meditational (mediating developmental progress in simulations of future activities). Beach explains transition as "the concept we use to understand how knowledge is generalized, or propagated, across social space and time. A transition is consequential when it is consciously reflected on, struggled with, and shifts the individual's sense of self or social position. Thus consequential transitions link identity with knowledge propagation" (2003, p. 42). See Chapter 3 (Qualley) and Chapter 6 (Wardle \& Clement Mercer).

Far transfer refers to carrying knowledge across different contexts that have little, if any, overlap (e.g., applying chess strategies to a political campaign).

Forward-reaching transfer is a form of high-road transfer in which a learner looks forward to a new context and anticipates how prior knowledge and practice might be relevant to solving a problem or developing knowledge in the future context. See Chapter 3 (Qualley).

Generalization is the application of prior knowledge to a new situation or context. As knowledge propagation, generalization is informed by social organization and acknowledges change by both the individual and the organization. See Chapter 4 (Donahue).

Genre awareness is metacognitive understanding of genre and the roles genres play within communities of practice. A rhetorical view of genre examines genres not solely based on their forms or characteristics, but also in relation to their rhetorically situated functions (with attention to audience, purpose, and rhetorical context). See Chapter 1 (Adler-Kassner et al.).

High-road transfer requires the learner's mindful abstraction to identify relevant prior knowledge and apply it in the new context.

Hugging activities facilitate low-road transfer.

Integration, alternately considered a form of high-road transfer or the opposite end of a continuum with transfer, entails (re)combining new and prior knowledge in ways that shape or change both. New knowledge is not merely spliced onto prior knowledge; the two intermingle, forming a new, cohesive knowledge base. As a result, Nowacek (2011) identifies successful integration as a metacognitive activity.

Low-road transfer occurs when something is practiced in a variety of contexts until it becomes second nature and is automatically triggered when a new context calls for use of the knowledge, skill, or strategy. 
Metacognition, in essence, is thinking about thinking. While cognition involves thinking to perform a task, metacognition entails reflection on that thinking, its efficacy, and/or its outcomes. See Chapter 8 ( Gorzelsky, Driscoll, Paszek, Jones \& Hayes).

Metacognitive awareness reflects conscious monitoring and use of metacognitive strategies.

Near transfer refers to carrying prior knowledge or skill across similar contexts (e.g., driving a truck after driving a car).

Prior Knowledge includes prior dispositions, attitudes, and understandings. Bransford et al. note in How People Learn that all "new learning involves transfer based on previous learning" (2000, p. 53). Prior knowledge may be a good fit for new learning, it may be at odds with new learning, or it may prompt dissonance between prior and current learning contexts. See Chapter 1 (Adler-Kassner et al.).

Remix entails taking elements from both prior knowledge and new knowledge and integrating them to create new understanding or practice. See Robertson et al. (2012).

Repurpose refers to using prior knowledge across different contexts, perhaps with new and varied goals for or applications of that knowledge.

Retrospective understanding "directs our attention to the transition process itself and illuminates the roles that dispositions, motivations, and meta-awareness play in transformative forms of transfer and in the development and expansion of expertise" (Chapter 3, Qualley).

Systematic reflection (or Reflection) "prompts writers to recall, reframe, and relocate their writing knowledge and practices" (Chapter 1, Adler-Kassner et al.).

Teaching for transfer refers to curricular designs with the explicit goal of fostering transfer. Course activities and assignments strive not only to teach content, but also to teach strategies for and facilitate practice in examining how the course knowledge and practices might apply to concurrent and future contexts.

Threshold Concepts are central to epistemological participation in disciplines. Jan (Erik) Meyer and Ray Land, building on David Perkins' notion of troublesome knowledge, challenge educators to identify concepts that function as a "portal, opening up a new and previously inaccessible way of thinking about something" (2006, p. 3). Threshold concepts are transformative, troublesome, and irreversible; they may challenge a learner's prior knowledge, but once a learner grasps a threshold concept, the concept changes the learner's understanding of the discipline in ways that are likely irreversible. Threshold concepts are discursive. They also may be bounded by situational or disciplinary cues, and they may be integrative, enabling a learner to bring together previously disparate 
knowledge. Finally, threshold concepts involve liminality; learners may hover in a threshold zone before fully grasping the concept and moving beyond the "conceptual gateway" (Meyer \& Land, 2006a, 2006b). Once educators identify threshold concepts that are central to meaning making in their fields, they can prioritize teaching these concepts, in turn increasing the likelihood that students will carry an understanding of these core concepts into future coursework and contexts. See Chapter 1 (Adler-Kassner et al.) for a discussion connecting Communities of Practice and Threshold Concepts.

Transfer refers to the ability to repurpose or transform prior knowledge for a new context. In some contexts, transfer may involve using prior knowledge in a routinized way, while in other contexts, successful transfer may require mindful abstraction of prior knowledge, perhaps remixed or integrated with new knowledge. For many scholars, transfer functions as an umbrella term, encompassing an array of theories about the phenomenon.

Translation refers to transforming prior knowledge for new contexts. Drawing from linguistics, social anthropology, political science, sociology, and ethnomethodology, translation emphasizes the social nature of knowledge construction and transformation. Much like linguistic translation must be cognizant of the cultural constructions of language, knowledge translation is attentive to new contextual cues. See Chapter 4 (Donahue).

Troublesome knowledge is knowledge that requires a paradigmatic shift in previous thinking. While that shift—or troublesomeness—may be problematic and disruptive, it also can be generative, prompting new ways of thinking or new reconciliations of prior and new knowledge. See Chapter 1 (Adler Kassner et al.) and Chapter 3 (Qualley). See Chapter 4 (Donahue) for a distinction between troublesome knowledge and troubling knowledge.

Writing transfer refers to a writer's ability to repurpose or transform prior knowledge about writing for a new audience, purpose, and context. In writing studies, it often functions as an umbrella term, connecting the field's transfer studies to other transfer research in learning studies, educational psychology, and related fields. 



\section{CRITICAL TRANSITIONS}

In Critical Transitions: Writing and the Question of Transfer, Chris Anson and Jessie Moore offer an important new collection about prior learning and transfer theories that asks what writing knowledge should transfer, how we might recognize that transfer, and what the significance is-from a global perspective- of understanding knowledge transformation related to writing. The contributors examine strategies for supporting writers' transfer at key critical transitions, including transitions from high-school to college, from first-year writing to writing in the major and in the disciplines, between self-sponsored and academic writing, and between languages. The collection concludes with an epilogue offering next steps in studying and designing for writing transfer.

Chris Anson is Distinguished University Professor and Director of the Campus Writing and Speaking Program at North Carolina State University. He has published fifteen books and more than 120 articles and book chapters relating to writing and has spoken widely across the U.S. and in twenty-eight other countries.

Jessie L. Moore is Associate Drector of the Center for Engaged Learning and Associate Professor of English: Professional Writing \& Rhetoric at Elon University. Her recent research examines transfer of writing knowledge and practices, multi-institutional research and collaborative inquiry, writing residencies for faculty writers, the writing lives of university students, and high-impact pedagogies.

Perspectives on Writing

Series Editors: Susan H. McLeod and Rich Rice

The WAC Clearinghouse

Fort Collins, Colorado 80523

wac.colostate.edu

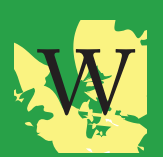

University Press of Colorado

Boulder, Colorado 80303

upcolorado.com

ISBN 978-1-64215-079-7 